
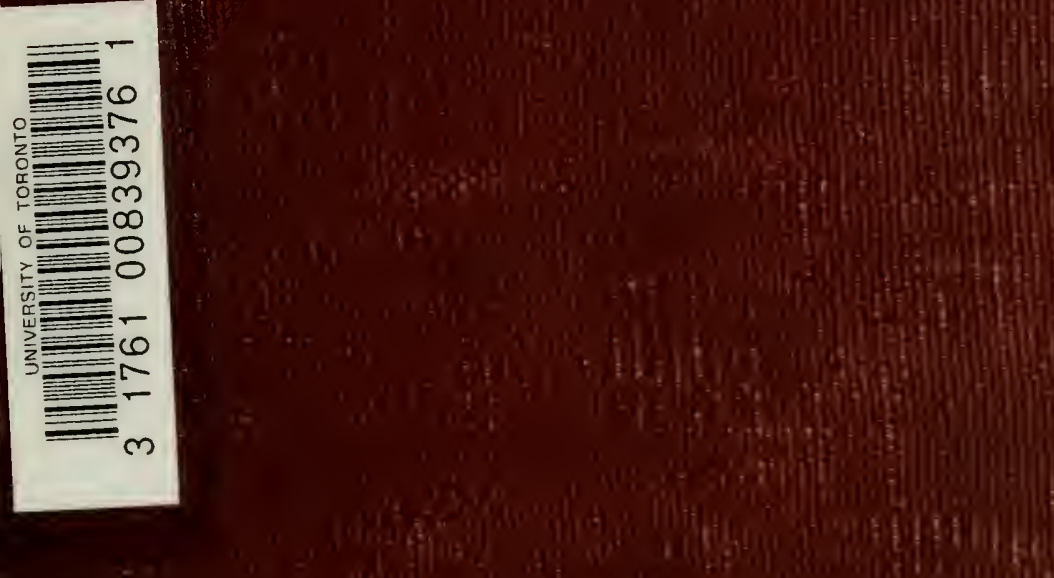

Uinvof

Toneverro

LIBRARY 

Digitized by the Internet Archive in 2008 with funding from Microsoft Corporation 




\section{HEREDITY AND SEX}

BY

THOMAS HUNT MORGAN, Ph.D

PROFESSOR OF EXPERIMENTAL ZUÖLUGX

I. COLIMHIA UNIVERSITY

SECOND (REVISED) EDITION

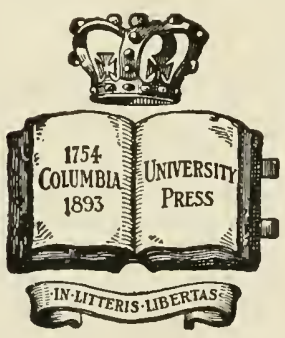

X̛ew 19ark

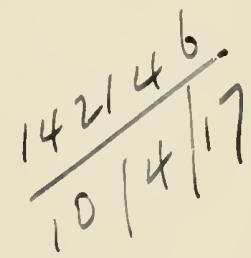

COLUMBIA UNIVERSITY PRESS

1914

All rights reserved 


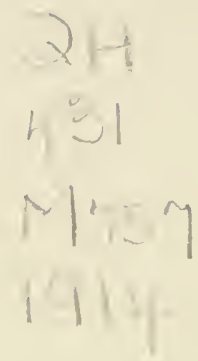

Copreight, 1913,

BY COLUMHIA UNIVERSTTY PRESS.

Set up and electrotyped. Published November, I9r3.

Normood 㹦ress

I. S. ('ushing Co. - Berwick of smith (A).

Norwood, Mass., U.S.A. 


\section{I}

\section{INTRODUCTION}

Two lines of research have developed with surprising rapidity in recent years. Their development has been independent, but at many stages in their progress they have looked to each other for help. The study of the cell has furnished some fundamental facts connected with problems of heredity. The modem study of heredity has proven itself to be an instrument even more subtle in the analysis of the materials of the germ-cells than actual observations on the germcells themselves.

In the following chapters it has been my aim to point out, wherever possible, the bearing of cytological studies on heredity, and of the study of heredity on the analysis of the germinal materials.

The time has come, I think, when a failure to recognize the close bond between these two modern lines of advance can no longer be interpreted as a wise or cautious skepticism. It seems to me to indicate rather a failure to appreciate what is being done at present, and what has been accomplished. It may not be desirable to accept everything that is new, but it is certainly undesirable to reject what is new because of its newness, or because one has failed to keep in touch with the times. A hypercritical spirit in science does not always mean greater profundity, nor is our attitude toward science more correct because we are unduly 
skeptical toward every advance. Our usefulness will, in the long run, be proven by whether or not we have heen discriminating and sympathetic in our attitude towatrl the inportant discoveries of our time. While crery une will jrobably admit such generalities, some of If- maty call those who accept less than ourselves consurvatives; others of us who accept more will be called rash or intemperate. To maintain the right balance is thr' hardest task we have to meet. In attempting to bring tugether, and to interpret, work that is still in the making I cannot hope to have always made the right rherice, but I may hope at least for some indulgence from those who realize the difficulties, and who think with me that it may be worth while to make the attempt to point out to those who are not specialists what specialists are thinking about and doing.

What I most fear is that in thus attempting to formulate some of the difficult problems of present-day inc(rest to zoölogists I may appear to make at times uncualified statements in a dogmatic spirit. I beg to rmind the rearler and possible critic that the writer lowds all (onclusions in science relative, and subject to change, for change in science does not mean so much that what has gome before was wrong as the discovery of a better strategie position than the one last held. 


\section{1}

\section{TABLE OF CONTENTS}

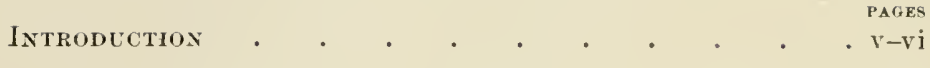

\section{CHAP'TER I \\ THE EVOLETION OF SEX}

1. Reprodection, a Distinctive Feature of Living Things . . . . . . . . 1-1

2. The "Meanixa" of Sextal Rephodection • . . 4-15

3. The Body axd the Gemplepasi . . . . 15-19

4. The Farly Isolation of the Germ-cella . . 20-2:)

5. The APPeARANCE OF THE ACCEssory Organis of REPRODUCTION . . . . . . . 2:3-26

6. The Shcondali ShXull Characters . . . 26-31

7. The Sexual listincts . . . . . 31-34

\section{CHAP'TER II}

THE MECHANISM OF SEX-DETERMINATION

1. The Maturation of the Fig and the Spera . 35-40

2. The Crtological Evidexce . . . . . 40-54

a. Protenor . . . . . . . . 41-4t

b. Lygreus . . . . . . . . $44-46$

c. Oncopeltus . . . . . . . . $46-18$

d. Ascaris . . . . . . . . 49-52

e. Aphids and Phylloxerans . . . . . 52-54

3. The Experinextal Evinface . . . . . 5. . 5.2

a. The Experiments on Sea-urchins' Eggs . 50-6i3

b. The Evidence from Sex-linked Inheritance . $63-72$ 


\section{CHAPTER III}

TIL MENIMELIAN PRINCIPLES OF HEREDITY ANI) TIIEIR BEARING ON SEX

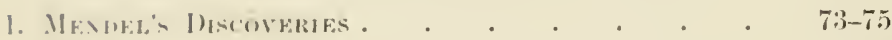

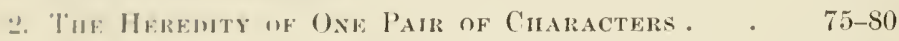

3. The If

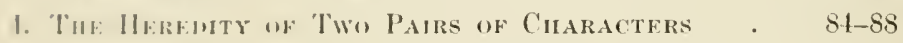

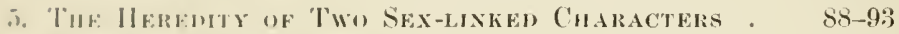

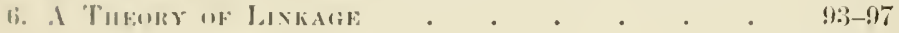

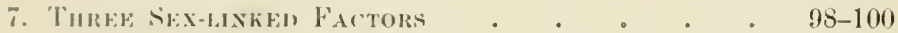

\section{CIIAT'TER IV}

SECONDARY SEXUAL CHARACTERS AND THEIR REIATION TO DARIVIN'S THEORY OF SEXITAL SELECTION

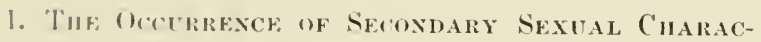

thrs ix the ANMAl Kingdon . . . . 101-112

2. Cörтинан . . . . . . . . 112-120

3. Virint axw Secondary Sexual Characters . 120-121

1. Coxtintol's Variation as a Basis for SElection 1.21-125

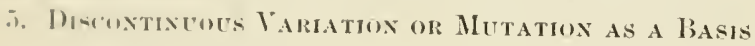
HOR SELETTIN . . . . . . . 125-131

\section{CHALTER V}

THE: FFFECTS OF (ASTHATION ANH) OF TRANSP'ANTATION (ON THE SECONDAPY SEXUAL ('H.IRAC'TERS

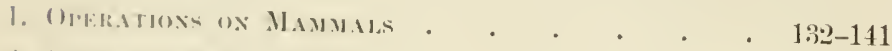

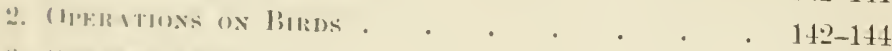

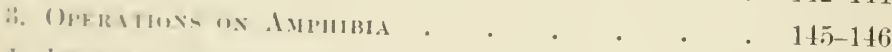

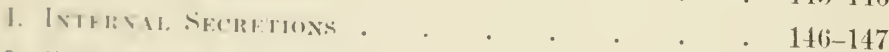

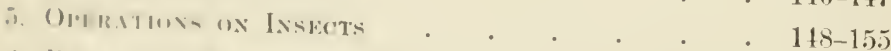

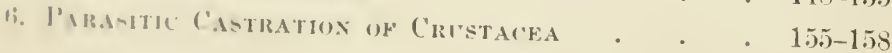




\section{CHAPTER VI}

\section{GYNANDROMORPHISM, HERMAPHRODITISM, PARTHENOGENESIS, AND SEX}
1. Grinandronorpinsis
PAGE
2. HeRMAPIRODITISM .
$161-167$
3. Parthenogenesis .
$167-17$.
4. Artifichal Partienogenesis

\section{CHAP'TER VII}

\section{FERTILITY}

1. INBREEDING * • . . . . . • . 194-199

2. Crosis-BREEDING . . . . . . . . 200-207

3. Sextal Reproduction in Paramechit . . . 207-211

4. Theories of Fertility . . . . . . 211-219

\section{CHAPTER VIII}

SPECIAL CASES OF SEX-INIIERITANCE

1. Sex in BeEs. . . . . . . . 202021

2. A SEX-LINKED LethaL FACTOR . . . . . ․ㅡ1-202?

3. Non-disunetion of the Shi-chromosomes a - 2.23-294

4. The Vaxinhag Males of the Nematodes • . 221-2.2.

5. Sex-ratios in HrobiJ) Biris and in ('rosinen

RACES IN MAN . . . . . . . 2.25-2.27

6. Sex-ratios in Frogs . . . . . . 2-28-2029

7. SEx-RATios ix MaN . . . . . . . 2:9-232

8. The Abandoned View that Extelinal Conmtions

DETERMINE SEX . . . . . . . 282-2806

9. SEx-DETERMINATJON IN MAN . . . . . 2:36-24!

BIBLIOGRHAPHY 。 • . . . , . . 251-278

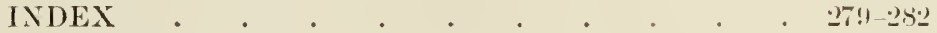





\title{
HEREDITY AND SEX
}

\author{
CHAPTER I \\ The Evolution of Sex
}

Animals and plants living to-day reproduce themselves in a great variety of ways. With a modicum of ingenuity we can arrange the different ways in series beginning with the simplest and ending with the more complex. In a word, we can construct systems of evolution, and we like to think that these systems reveal to us something about the evolutionary process that has taken place.

There can be no doubt that our minds are greatly impressed by the construction of a graded series of stages comnecting the simpler with the complex. It is true that such a series shows us how the simple forms might conceivably pass by almost insensible (or at least by overlapping) stages to the most complicated forms. This evidence reassures us that a process of evolution could have taken place in the imagined order. But our satisfaction is superficial if we imagine that such a survey gives much insight either into the causal processes that have produced the successive stages, or into the interpretation of these stages after they have been produced.

Such a series in the present case would culminate in a process of sexual reproduction with males and 
fomales as the actors in the drama. But if we are atked what advantage, if any, has resulted from the process of scxual reproduction, carried out on the two-sex scheme, we must confess to some un(ertainty.

The most important fact that we know about living matter is its inordinate power of increasing itself. If all the fifteen million eggs laid by the conger eel were to grow up, and in turn reproduce, in ten years the sea would be a wriggling mass of fish.

. singlo infusorian, produced in seven days 935 descendints. One species, stylonichia, produced in $6 \frac{1}{2}$ days a mass of protoplasm weighing one kilogram. It the end of 30 days, at the same rate, the number of kilogramss would be 1 followed by 44 zeros, or a mass of protoplasin a million times larger than the volume of the sum.

Another minute organism, hydatina, produces about 30 eggrs. It the end of a year ( 65 generations), if all the offspring survived, they would form a sphere whose linit: would extend beyond the confines of the known universe.

The omnipresent English sparrow would produce in 2() year's, if none died except from old age, so many descriclants that there would be one sparrow for every sfuare inch of the State of Illinois. Even slowbreeding man has doubled his numbers in 25 years. It the simne rate there would in 1000 years not he standing room on the surface of the earth for his offspring.

I have not gone into these calculations and will 
not vouch for them all, but whether they are entirely correct or only partially so, they give a rough idea at least of the stupendous power of growth.

There are three checks to this process: First, the food supply is insufficient - you starve; second, animals eat each other - you feed ; third, substances are produced by the activity of the body itself that interfere with its powers of growth - you poison yourself. The laws of food supply and the appetites of enemies are as inexorable as fate. Life may be defined as a constant attempt to find the one and avoid the other. But we are concerned here with the third point, the methods that have been devised of escape from the limitations of the body itself. This is found in reproduction. The simplest possible device is to divide. This makes dispersal possible with an increased chance of finding food, and of escaping annihilation, and at the same time by reducing the mass permits of a more ready escape of the by-products of the living machine.

Reproduction by simple division is a well-known process in many of the lower animals and plants; it is almost universal in one-celled forms, and not unknown even in many-celled organisms. Amoeba and paramœcium are the stock cases for unicellular animals; many plants reproduce by buds, tubers, stolons, or shoots; hydroids and sea-anemones both divide and bud; many planarians, and some worms, divide transversely to produce two new individuals. But these methods of reproduction are limited to simple structures where concentration and division of labor amongst the organs has not been carried to an extreme. In consequence, what each part lacks after the division can be 
quickly made good, for delay, if prolonged, would increase the chances of death.

But there is another method of division that is almost universal and is utilized by high and by low forms alike: individual cells, as eggs, are set free from the rest of the borly. since they represent so small a part of the body, an immense number of them may be produced on the chance that a few will escape the dangers of the long road leading to maturity. Sometimes the eggs are protected by jelly, or by shells, or by being transparent. or by being hidden in the ground or under stomes, or eren in the body of the parent. Under these circumstances the animal ventures to produce eggs with a large amount of food stored up for the young embryo.

so far reaching were the benefits of reproduction by eggs that it has been followed by almost every species in the animal and plant kingdom. It is adhered to even in those cases where the animals follow other grosser methods of separation at the same time. IVe find, however, a strange limitation has been put upon the process of reproduction by eggs. Before the rger begins its development it must be fertilized. Cells from two individuals must come together to produce a new one.

The meaning of this process has baffled biologists ever since the changes that take place during fertiliyation were first discovered; in fact, long before the actual processes that take place were in the least understool. There is a rather extensive and antiquated litcrature dealing with the part of the male and of the fomale in the process of procreation. It would take us too far to attempt to deal with these questions 
in their historical aspects, but some of their most modern aspects may well arrest our attention.

In the simplest cases, as shown by some of the onecelled organisms, two individuals fuse into a single one (Fig. 1); in other related organisms the two individuals that fuse may be unequal in size. Sometimes we speak of these as male and female, but it is questionable whether we should apply to these unicellular types the same names that we use for the

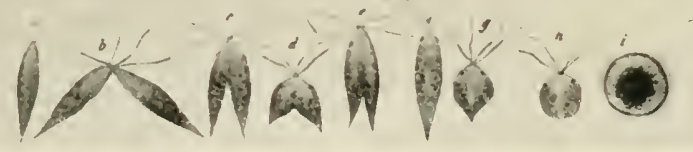

FIG. 1. - Union of two individuals (Stephanosphara pluczalis) to form a single individual. (After Döflein.)

many-celled forms where the word sex applies to the soma or body, and not to the germ cells.

One of the best known cases of conjugation is that of paramœcium. Under certain conditions two individuals unite and partially fuse together. An interchange of certain bodies, the micronuclei, then takes place, as shown in Fig. 2, and in diagram, Fig. 3. The two conjugating paramocia next separate, and each begins a new cycle of divisions. Here each individual may be said to have fertilized the other. The process recalls what takes place in hermaphroditic animals of higher groups in the sense that sperm from one individual fertilizes eggs of the other.

We owe to Maupas the inauguration of an epochmaking series of studies based on phenomena like this in paramœeium. 

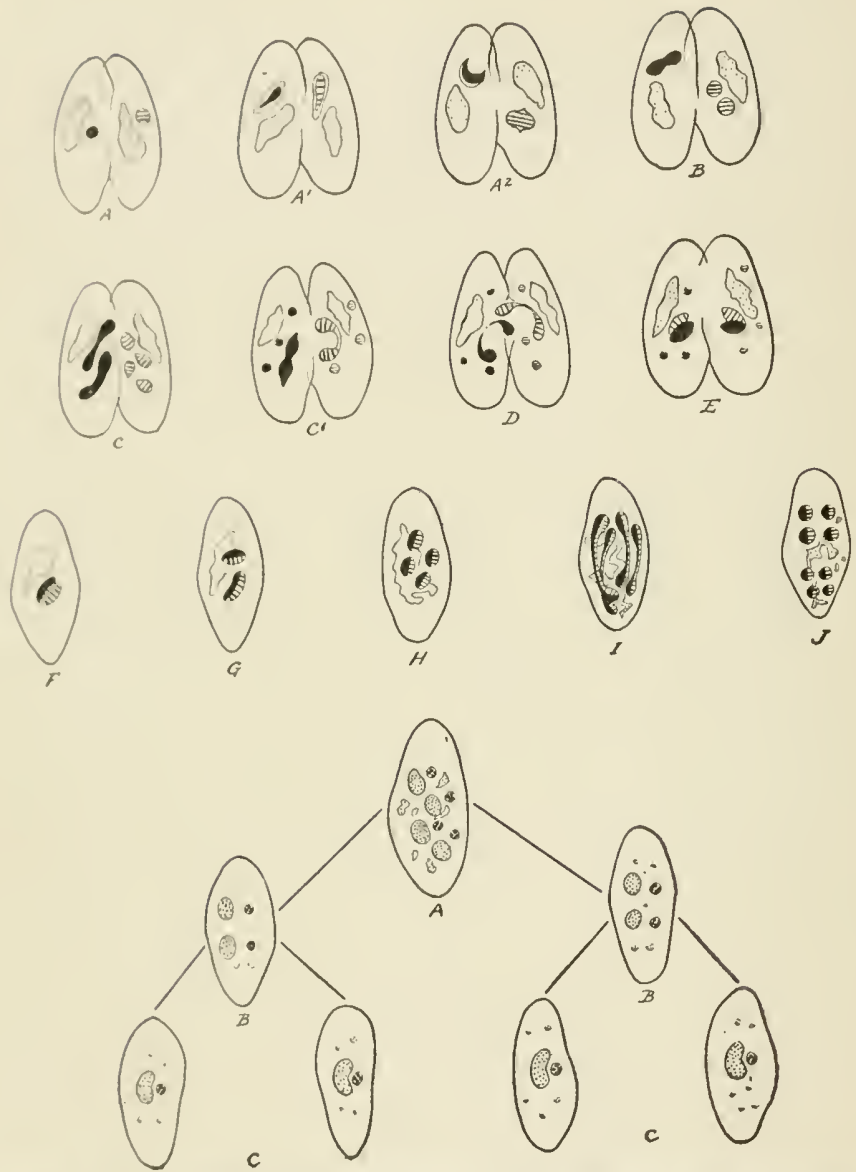

Fit. 2. - ('onjugation in Paramoceium. The micronucleus in one individual is represented in black, in the other by eross-lines. The macronurlents in both is stippled. $A-C$, division of micronucleus into 2 and I nuclei; (1)-I), elongation of conjugation muclei, which interchange and recumbine in $E ; F-J$, (onscrutive stage in one ex-conjugant to show three divisims of new mierouucleus to produce eight mieronuelei $(J)$. In lower lunt of diagram the first two divisions of the ex-eonjugant $(J)$ with eight micronumei are shown, lsy means of which a redistribution of the eight miermurelui takis place. see also Fig. 100. 


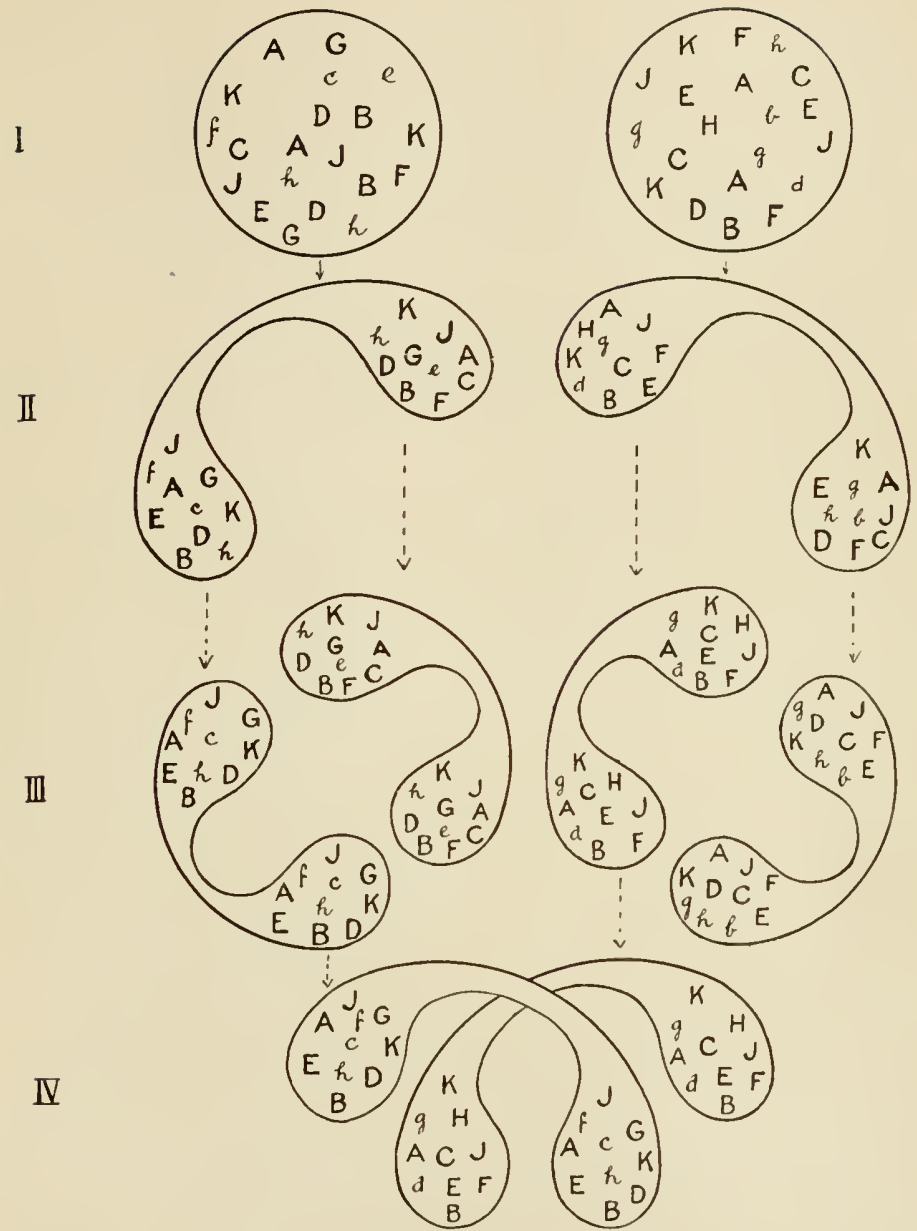

Fig. 3. - The nu lei of two individuals of parancecium in I (homozygous in certain factors, and heterozygous in other factors), are represented as dividing twice (in II and III); the first division, II, is represented as reducing, i.e. segregation occurs; the second division, III, is represented as equational, i.e. no reduction but division of factors, as in the next or conjugation division, IV, also. 
Maupas found by following from generation to generation the division of some of these protozoa that the division rate slowly deelines and finally eomes to an end. He found that if a debilitated individual conjugates with a wild individual, the death of the race is prevented, but Maupas did not elaim that through conjugation the division rate was restored. On the contrary he found it is lower for a time.

He also discovered that conjugation between two related individuals of these weakened strains produced no beneficial results.

Bütschli had earlier (1876) suggested that conjugation means rejuvenation or renewal of youth, and Maupas' results have sometimes been cited as supporting this riew. Later work has thrown many doubts on this interpretation and has raised a number of new issues.

In the first place, the question arose whether the decline that Maupas observed in the rate of division may not have been due to the uniform conditions under which his cultures were maintained, or to an insufficiency in some ingredient of these cultures rather than to lack of conjugation. Probably this is true, for Calkins has shown that by putting a declining race into a different medium the original division rate may be restored. Woodruff has used as culture media a great variety of food stuffs and has succeeded in keeping his lines without loss of vigor through 3000 generations. Maupas records a decline in other related protozoa at the end of a few hundred generations.

Biitschli's idea that by the temporary union (with interchange of micronuclei) of two weak individuals two vigorous individuals could be produced seems 
mysterious; unless it can be made more explicit, it does not seem in accord with our physico-chemical conceptions. Jennings, who has more recently studied in greater detail the process of division and conjugation in paramoecium, has found evidence on which to base a more explicit statement as to the meaning of rejuvenescence through conjugation.

Jennings' work is safeguarded at every turn by careful controls, and owing in large part to these controls his results make the interpretations more certain. $\mathrm{He}$ found in a vigorous race, that conjugated at rather definite intervals, that after conjugation the division rate was not greater than it had been before, but on the contrary was slower - a fact known, as he points out, to Maupas and to Hertwig. Conjugation does not rejuvenate in this sense.

Jennings states that, since his race was at the beginning vigorous, the objection might be raised that the conditions were not entirely fulfilled, for his predecessors had concluded that it is a weakened race that was saved from annihilation by the process. In order to meet this objection he took some individuals from his stock and reared them in a small amount of culture fluid on a slide. After a time they became weakened and their rate of division was retarded. He then allowed them to conjugate, and reared the conjugants. Most of these were not benefited in the least by the process, and soon died. A few improved and began to multiply, but even then not so fast as paramœcia in the control cultures that had been prevented from conjugating. Still others gave intermediate rates of division. 
He concludes that conjugation is not in itself beneficial to all conjugants, but that the essence of the pro('sis is that a recombination of the hereditary traits occurs as shown in the diagram, Fig. 3 and 4 . Some

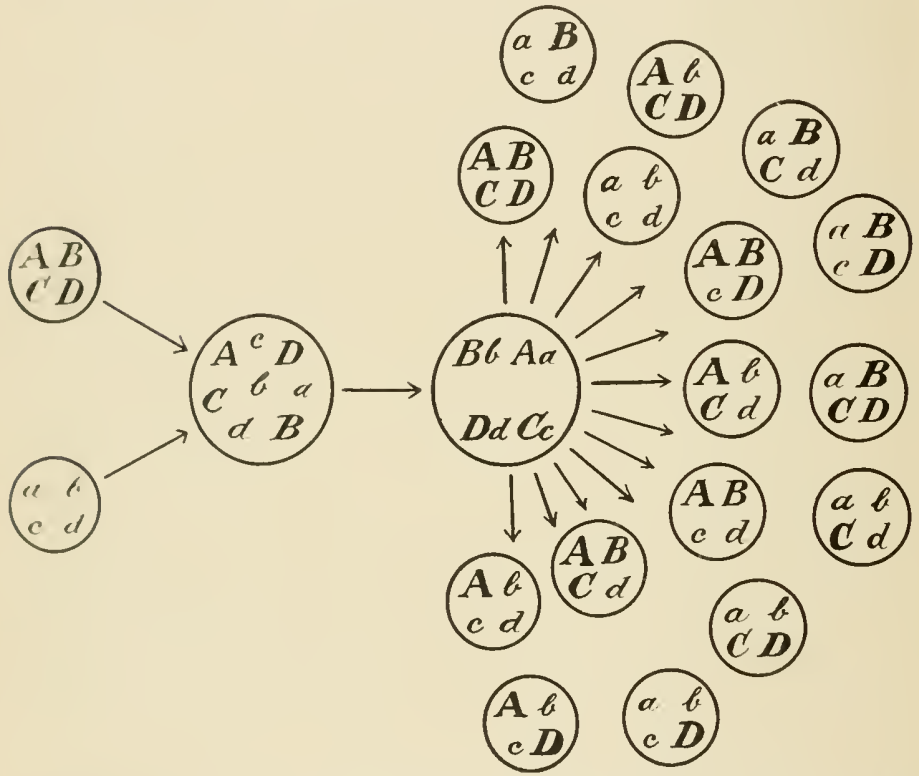

Fir. 4.- Illustrating conjugation between two stocks, with pairs of facturs $A, B, C, D$, and $a, b, c, d$; and union of pairs into $A a, B b, C c, D d$. Ifter these separate, their possible recombinations are shown in the $\mathbf{1 6}$ snaller circles. (After Wilson.)

of these new combinations are beneficial for special conditions - others not. The offspring of those conjugants that have made favorable combinations will soon crowd out the descendants of other conjugants that have made mediocre or injurious combinations. Ilence, in a mass culture containing at all times large 
numbers of individuals, the maximum division rate is kept up, because, at any one time, the majority of the individuals come from the combinations favorable to that special environment.

There are certain points in this argument that call for further consideration. In a mass culture the $f a$ vorable combinations for that culture will soon be made, if conjugation is taking place. At least this is true if such combinations are homogeneous (homozygous, in technical language). Under such circumstances the race will become a pure strain, and further conjugation could do nothing for it even if it were transferred to a medium unsuited to it.

In the ordinary division of a cell every single determiner divides and each of the new cells receives half of each determiner. Hence in the case of paramœcium all the descendants of a given paramœcium that are produced by division must be exactly alike. But in preparation for conjugation a different process may be supposed to take place, as in higher animals, among the determiners. The determiners unite in pairs and then, by division, separate from each other, Fig. 4. In consequence the number of determiners is reduced to half. Each group of determiners will be different from the parent group, provided the two determiners that united were not identical. If after this has occurred conjugation takes place, the process not only restores the total number of determiners in each conjugant, but gives new groups that differ from both of the original groups.

The maintenance of the equilibrium between an 
organism and its environment must be a very delicate matter. One combination may be best suited to one enviromment, and another combination to another. Conjugation brings about in a population a vast number of combinations, some of which may be suited to the time and place where they occur. These survive and produce the next generation.

Jennings' experiments show, if I understand him correctly, that the race he used was not homogeneous in its hereditary elements; for when two individuals conjugated, new combinations of the elements were formed. It seems probable, therefore, that the chemical equilibrium of paramœecium is maintained by the presence of not too much of some, or too little of other, hereditary materials. In a word, its favorable combinations are mixed or heterozygous.

The meaning of conjugation, and by implication, the meaning of fertilization in higher forms is from this point of view as follows : - In many forms the race, as a whole, is best maintained by adapting itself to a widely varied environment. A heterozygous or hybrid constitution makes this possible, and is more likely to perpetuate itself in the long run than a homozygous race that is from the nature of the case suited to a more limited range of external conditions.

What bearing has this conclusion on the problem of the evolution of sex and of sexual reproduction?

This is a question that is certain to be asked. I am not sure that it is wise to try to answer it at present, in the first place because of the uncertainty about the conclusions themselves, and in the next place, because, personally, I think it very unfair and often very unfor- 
tunate to measure the importance of every result by its relation to the theory of evolution. But with this understanding I may venture upon a few suggestions.

If a variation should arise in a hermaphroditic species (already reproducing sexually) that made crossfertilization more likely than self-fertilization, and if, as a rule, the hybrid condition (howerer this may be explained) is more vigorous in the sense that it leaves more offspring, such a variation would survive, other things being equal.

But the establishment of the contrivance in the species by means of which it is more likely to crossfertilize, might in another sense act as a drawback. Should weak individuals appear, they, too, may be perpetuated, for on crossing, their weakness is concealed and their offspring are vigorous owing to their hybrid condition. The race will be the loser in so far as recessive or weak combinations will continue to appear, as they do in many small communities that have some deficiency in their race; but it is a question whether the vigor that comes from mixing may not more than compensate for the loss due to the continual appearance of weakened individuals.

This argument applies to a supposed advantage within the species. But recombination of what already exists will not lead to the development of anything that is essentially new. Evolution, however, is concerned with the appearance and maintenance of new characters. Admitting that sexual reproduction proved an advantage to species, and especially so when combined with a better chance of cross-fertilization, the machinery would be at hand by means of which any 
new character that appeared would be grafted, so to speak, on to the body of the species in which it appeared. Once introduced it would be brought into combination with all the possible combinations, or races, already existing within the species. Some of the hybrid combinations thus formed might be very vigorous and would survive. This reasoning, while hypothetical, and, perhaps not convincing, points at least to a way in which new rarietics may become incorporated into the body of a species and assist in the process of evolution.

It might be argued against this view that the same end would be gained, if a new advantageous variation arose in a species that propagated by non-sexual methods or in a species that propagated by self-fertilization. The offspring of such individuals would transmit their new character more directly to the offspring. Evolution may, of course, at times have come about in this way, and it is known that in many plants selffertilization is largely or exclusively followed. But in a species in which cross-fertilization was the established means of propagation, the new character would be brought into relation with all the other variations that are found in the component races and increase thereby its chances of farorable combinations. We have in recent years come to see that a new heritable character is not lost by crossing, or even weakened by "blenrling," as was formerly supposed to be the case; hence no loss to the character itself will result in the union with other strains, or races, within the species.

If then we cannot explain the origin of sexual reproduction by means of the theory of evolution, we 
can at least see how the process once begun might be utilized in the building up of new combinations; and to-day evolution has come to mean not so much a study of the origination of new characters as the method by which new characters become-established after they have appeared.

\section{THE BODY AND THE GERII-PLASM}

As I have said, it is not unusual to speak of the unicellular animals and plants as sexual individuals, and where one of them is larger than the other it is sometimes called the female and the smaller the male. But in many-celled animals we mean by sex something different, for the term applies to the body or soma, and not to the reproductive cells at all. The reproductive cells are eggs and sperm. It leads to a good deal of confusion to speak of the reproductive cells as male and female. In the next chapter it will be pointed out that the eggs and sperm carry certain materials; and that certain combinations of these materials, after fertilization has occurred, produce females; other combinations produce males; but males and females, as such, do not exist until after fertilization has taken place.

The first step, then, in the evolution of sex was taken when colonies of many cells appeared. We find a division of labor in these many-celled organisms; the germ-cells are hidden away inside and are kept apart from the wear and tear of life. Their maintenance and protection are taken over by the other cells of the colony. Even among the simplest colonial forms we find that some colonies become specialized for the production of small, active germ-cells. These colonies 
are called the males, or sperm-producing colonies. The other colonies specialize to produce larger germ-cells the egrss. These colonies are called females or egg-producing colonies. Sex has appeared in the living world. To-day we are only beginning to appreciate the farreaching significance of this separation into the immortal germ-cells and the mortal body, for there emerges the possibility of endless relations between the body on the one hand and the germ-cells on the other. Whatever the body shows in the way of new characters or new ways of reacting must somehow be represented in the germ-cells if such characters are to be perpetuated. The germ-cells show no visible modification to represent their potential characters. Hence the classical conundrum - whether the hen appeared before the egg, or the egg before the hen? Modern biology has answered the question with some assurance. The egg came first, the hen afterwards, we answer dogmatically, because we can understand how any change in the egg will show itself in the next generation - in the new hen, for instance; but despite a vast amount of arguing no one has shown how a new hen could get her newness into the old-fashioned eggs.

Few biological questions have been more combated than this attempt to isolate the germ-tract from the influence of the body. Nussbaum was amongst the first, if not the first, to draw attention to this distinction, but the credit of pointing out its importance is gencrally given to Weismann, whose fascinating speculations start from this idea. For Weismann, the germcells are immortal - the soma alone has the stigma of death upon it. Each generation hands to the next 
one the immortal stream unmodified by the experience of the body. What we call the individual, male or female, is the protecting husk. In a sense the body is transient - temporary. Its chief "purpose" is not its individual life, so much as its power to support and carry to the next point the all important reproductive material.

Modern research has gone far towards establishing Weismann's claims in this regard. It is true that the germ-plasm must sometimes change - otherwise there could be no evolution. But the evidence that the germplasm responds directly to the experiences of the body has no substantial evidence in its support. I know, of course, that the whole Lamarckian school rests its argument on the assumption that the germ-plasm responds to all profound changes in the soma; but despite the very large literature that has grown up dealing with this matter, proof is still lacking. And there is abundant evidence to the contrary.

On the other hand, there is evidence to show that the germ-plasm does sometimes change or is changed. Weismann's attempt to refer all such changes to recombinations of internal factors in the germ-plasm itself has not met with much success. Admitting that new combinations may be brought about in this way, as explained for paramœeium, yet it seems unlikely that the entire process of evolution could have resulted by recombining what already existed; for it would mean, if taken at its face value, that by recombination of the differences already present in the first living material, all of the higher animals and plants were foreordained. In some way, therefore, the germ- 
plasm must have changed. We have then the alternatives. Is there some internal, initial or driving inmulse that has led to the process of evolution? Or has the enviromment brought about changes in the germplism? We can only reply that the assumption of an

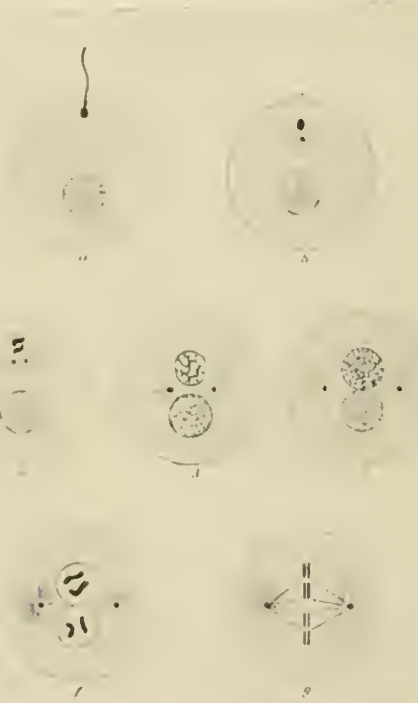

Fui, i. - Sichematic representation of the processes occurring during the fortilization and subsequent segmentation of the ovum. (Boveri, from Howell.)

internal force puts the problem beyond the field of scientific explanation. On the other hand, there is a small amount of evidence, very incomplete and insufficiont at present, to show that changes in the enviromment reach through the soma and modify the germinal material. 
It would take us too far from our immediate subject to attempt to discuss this matter, but it has been necessary to refer to it in passing, for it lies at the foundation of all questions of heredity and even involves, as we shall see later, the question of heredity of sex.

This brings us back once more to the provisional conclusion we reached in connection with the experiments on paramœeium. When the egg is fertilized by the sperm, Fig. 5, the result is essentially the same as that which takes place when two paramœeia fertilize each other. The sperm brings into the egg a nucleus that combines with the egg-nucleus. The new individual is formed by recombining the hereditary traits of its two parents.

It is evident that fertilization accomplishes the same result as conjugation. If our conclusion for paramœcium holds we can understand how animals and plants with eggs and sperm may better readjust themselves now to this, now to that environment, within certain limits. But we cannot conclude, as I have said, that this process can make any permanent contribution to evolution. It is true that Weismann has advanced the hypothesis that such recombinations furnish the materials for evolution, but as I have said there is no evidence that supports or even makes plausible his contention.

I bring up again this point to emphasize that while the conclusion we arrived at - a provisional conclusion at best - may help us to understand how sexual reproduction might be beneficial to a species in maintaining itself, it cannot be utilized to explain the progressive advances that we must believe to have taken place during evolution. 
TIF EARLY ISOLATION OF THE GERM-CELLS

There is much evidence to show that the germ-cells appear very early in the development of the individual when they are set aside from the cells that differentiate into the body cells. This need not mean that the germcells lave remained unmodified, although this is at
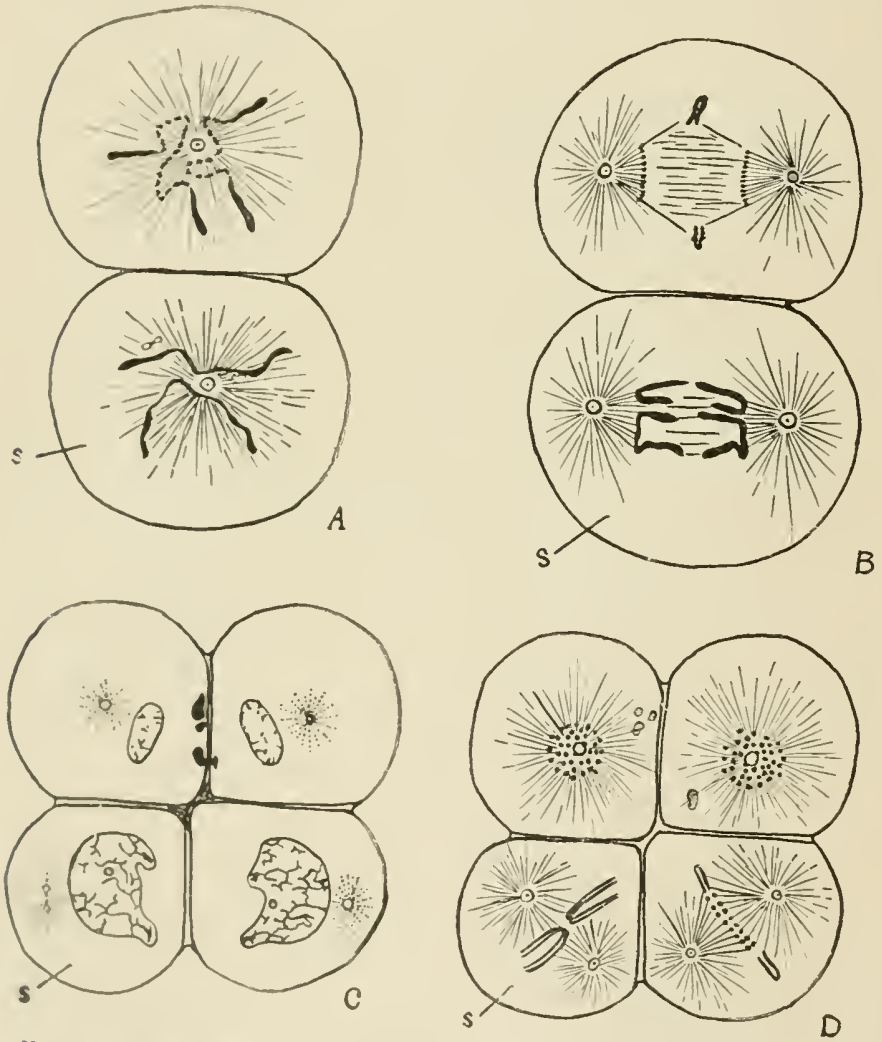

Fir, li. ('liromatin diminution and origin of the germ-cells in Ascaris. 
first sight the most natural interpretation. It might be said, indeed, that they are among the first cells to differentiate, but only in the sense that they specialize, as germ-cells.
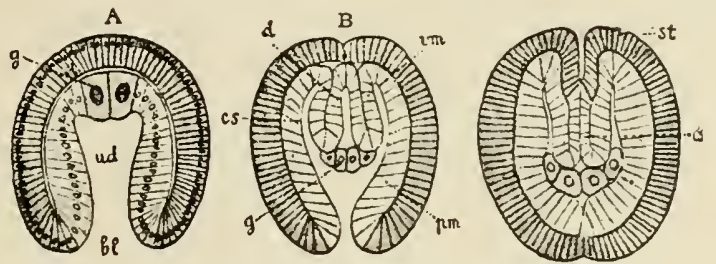

FIG. 7. - Origin of germ-cells in Sagitta. (From Korschelt and Heider.)

In a parasitic worm, ascaris, one of the first four cells divides differently from the other three cells. As seen in Fig. 6, this cell retains at its division all of its chromatin material, while in the other three cells some of the chromatin is thrown out into the cell-plasm. The
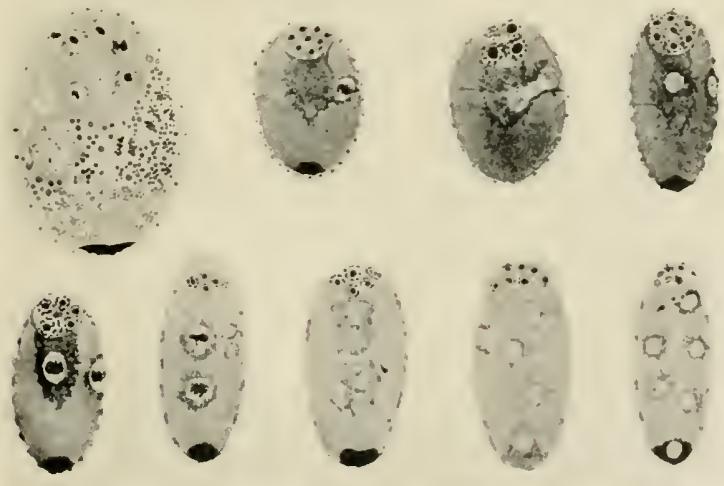

Fig. 8. - Origin of germ-cells in Miastor. Note small black protoplasmic area at bottom of egg into which one of the migrating segmentation nuclei moves to produce the germ-cells. (After Kahle.) 
single rell that retains all of the chromatin in its nucleus gives lise to the germ-cells.

In a marine worm-like form, sagitta, two cells can asily be distinguished from the other cells in the wall of the rligestive tract (Fig. 7). They leave their first position and move into the interior of the body, where they produce the ovary and testes.
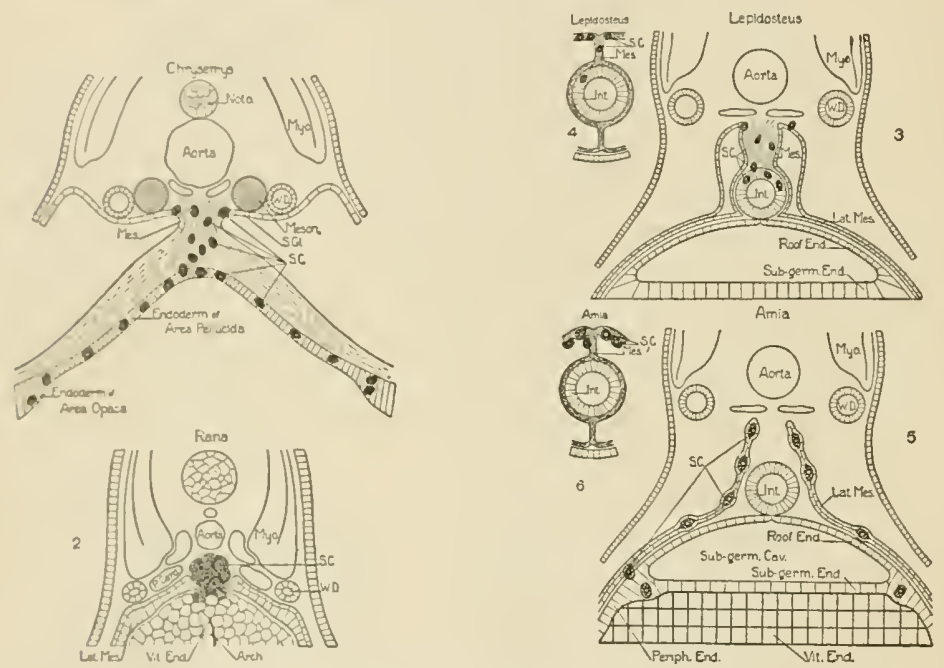

Fic, 9. - Origin of germ-cells in eertain vertebrates, viz. turtle, frog, gar-pike and bow-fin. The germ-cells as darker cells are seen migrating from tho disestive tract (endoderm). (After Allen.)

In several of the insects it has been shown that at a very early stage in the segmentation, one, or a few cells at most, lying at one end of the egg develop almost independently of the rest of the embryo (Fig. 8). Later they are drawn into the interior, and take up their final location, where they give rise to the germ-cells.

Even in the vertebrates, where, according to the 
earlier accounts, the germ-cells were described as appearing late in embryonic development, it has been shown that the germ-cells can be detected at a very early stage in the walls of the digestive tract (Fig. 9). Thence they migrate to their definitive position, and give rise to the cells from which the eggs or the sperm arise.

The germ-cells are in fact often the earliest cells to specialize in the sense that they are set aside from the other cells that produce the soma or body of the individual.

THE APPEARANCE OF THE ACCESSORY ORGANS OF REPRODUCTION

As animals became larger the problem of setting free the germ-cells was a matter of great importance. Systems of outlets arose - the organism became piped, as it were. In the lower animals the germ-cells are brought to the surface and set free directly, and fertilization is a question of the chance meeting of sperm and egg; for there is practically no evidence to show that the sperm is attracted to the egg and much evidence that it is not. Later, the copulatory organs were erolved in all the higher groups of animals by means of which the sperm of the male is transferred directly to the female. This makes more certain the fertilization of the egg.

In the mollusks, in the insects and crustaceans, and in the vertebrates the organs of copulation serve to hold the individuals together during the act of mating, and at the same time serve to transfer the semen of the male to the oviduct, or to special receptacles of the female. Highly elaborated systems of organs and special instincts, no less elaborate, serve to make the 
mnion posible. In sone types mating must occur for calch output of regrs, but in other cases the sperm is stored 11 ) in special receptacles connected with the ducts of the fomale. From these receptacles a few sperm at at time may be set free to fertilize each egg as it passes the opening of the receptaculum. In the queen bee enough sperm is stored up to last the queen for five or six years and enough to fertilize a million eggs.
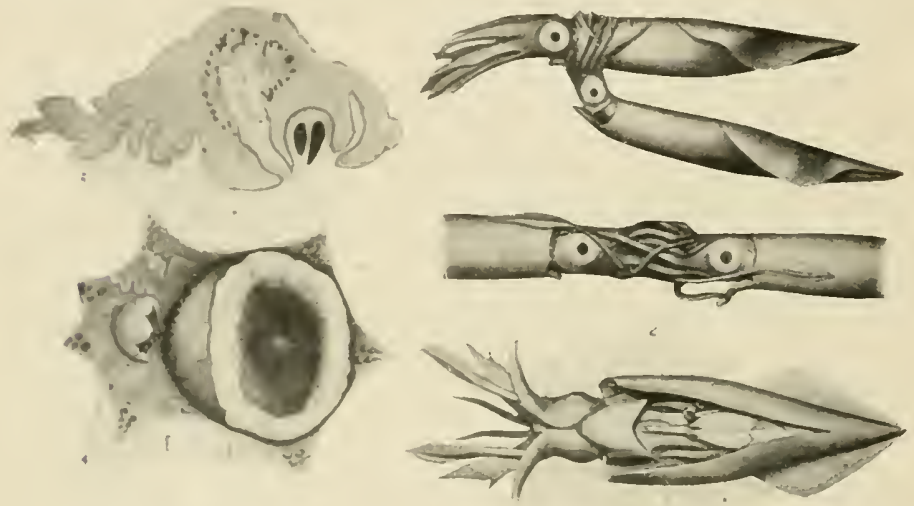

Fis; 10. - iquid: Two upper right-hand figures illustrate two methods of ropulation. Lower right-hand figure dissected to show spermatophore plarul in mantle eavity of female. Left-hand figure (below), spermatophore porkut behiul mouth of male; upper figure, section of same. (After Drew.)

There are a few cases where the transfer from the male to the female is brought about in a different way. The most striking cases are those of the squids and octopi, and of the spiders.

In the squid, the male and female interlock arms (Fig. 10). The male takes the packets of sperm (that are emitted at this time from the sperm-duct) by means of at special arm, and transfers the packets either to a 
special receptacle within the circle of arms of the female, or plants them within the mantle chamber itself of the female. Each packet of spermatozoa is contained in a long tube. On coming in contact with sea water the tube everts at one end, and allows the sperm to escape.
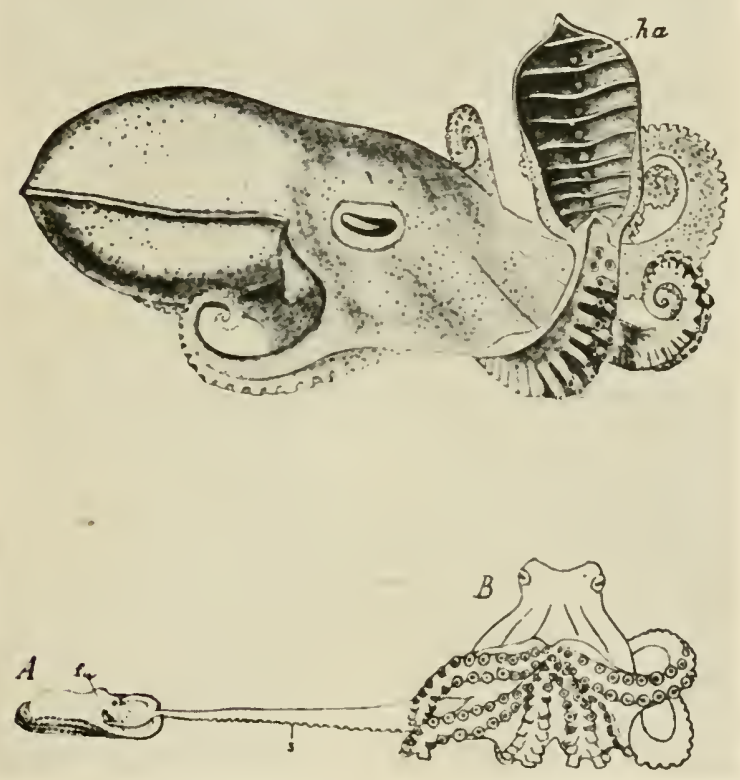

Fig. 11. - Octopus, male showing hectocotyl arm (ha). Copulation (below), small male, $A$; large female, $B$.

After separation the female deposits her strings of eggs, which are fertilized by the sperm escaping from the spermatophores. In octopus and its allies, one arm, that is used to transfer the spermatophores, is specially modified at the breeding season (Fig. 11). 
This arm is inserted by the male, as shown in the figure, within the mantle climmber of the female. In some species, Irgonauta irgo for instance (Fig. 12), the arm
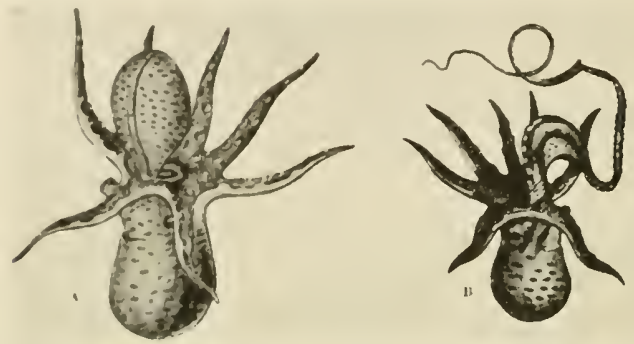

Fici. 12. Irgonatuta showing developing (A) and developed (B) hectorotyl arm, which, after being charged with spermatophores, is left in mantle of female.

is broken off, and remains attached by its suckers inside the mantle of the female. The eggs are later fertilized by sperm set free from this "hectocotylized" arm.

\section{TIIE SECONDARY SEXUAL CHARACTERS}

In the most highly evolved stages in the evolution of sex a new kind of character makes its appearance. This is the secondary sexual character. In most cases such characters are more elaborate in the male, but occasionally in the female. They are the most astonishing thing that nature has done: brilliant colors, plumes, combs, wattles, and spurs, scent glands (pleasant and unpleasant); red spots, yellow spots, green spots, topknots and tails, horns, lanterns for the dark, songs, howlings, dances and toumeys - a medley of odds and ends.

The most familiar examples of these characters are found in vertebrates and insects, while in lower forms 
they are rare or absent altogether. In mammals the horns of the male stag are excellent examples of secondary sexual characters. The male sea cow is much greater in size than the female, and possesses long tusks. The mane of the lion is absent in the lioness.

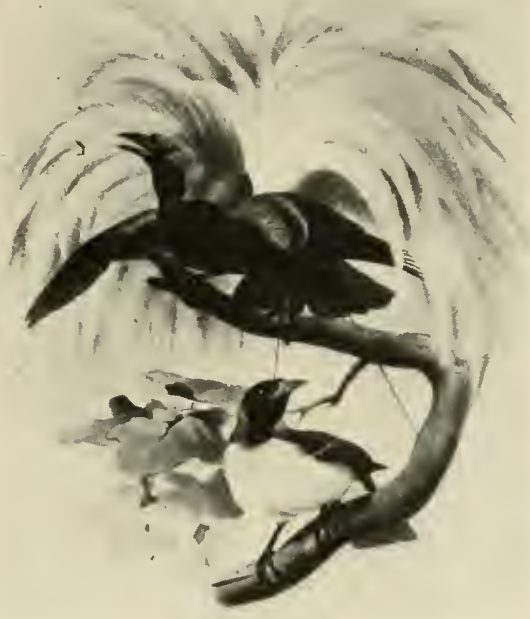

Fig. 13. - Great bird of Paradise, male and female. (After Elliot.)

In birds there are many cases in which the sexes differ in color (Figs. 13 and 14). The male is often more brilliantly colored than the female and in other cases the nuptial plumage of the male is quite different from the plumage of the female. For example, the black and yellow colors of the male bobolink are in striking contrast with the brown-streaked female (Fig. 15). The male scarlet tanager has a fiery red plumage with black wings, while the female is olive green. The male 
of the mallard duck hat a green head and a reddish hreast (Fig. 16), while the female is streaked with brown.

In insects the males of some species of beetles have horns on the head that are lacking in the female (Fig. 17). The males of many species of butterflies are colored differently from the females.

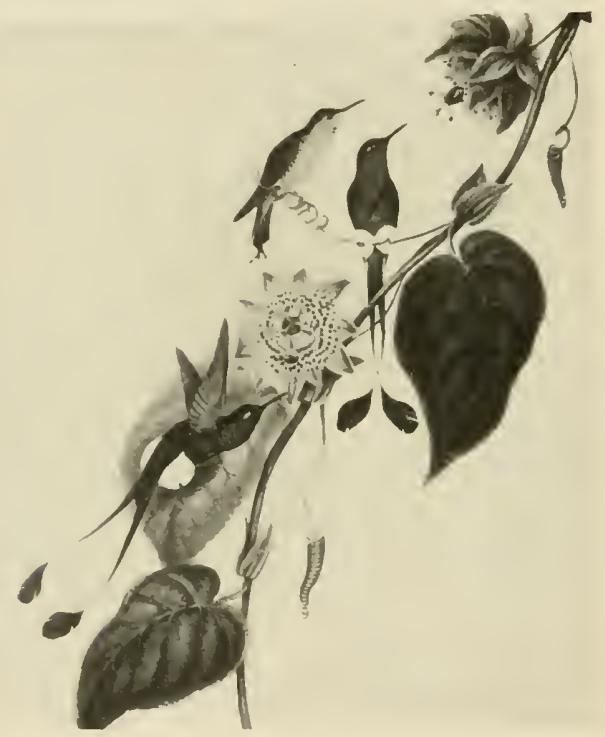

Fic, 1.1. - White-looted humming bird, two males and one female. (After Gould.)

The phosphorescent organ of our common firefly, Pholimes myralis, is a beautiful illustration of a secondatry sexual whacter. On the under surface of the male there are two bands and of the female there is a single band that ("an be ilhminated (Fig. 18). At night the males leave their eoncealment and fly about. A little later the females ascend to the tops of blades of grass 


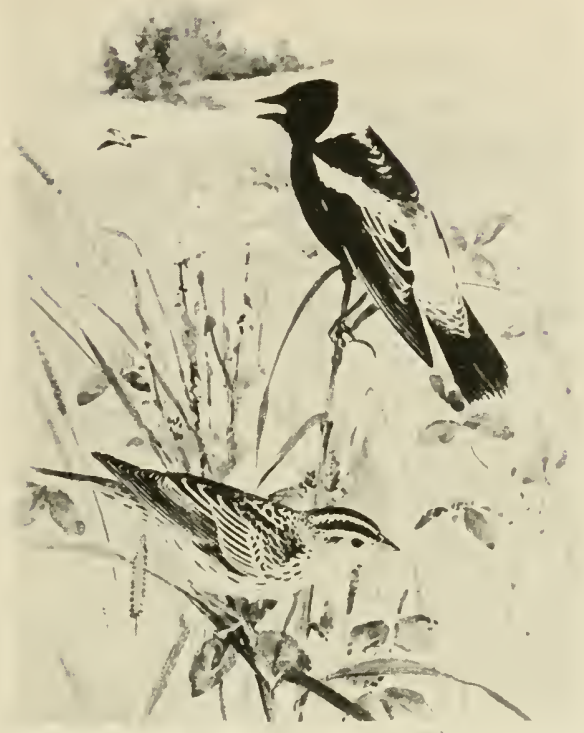

Frg. 15. - Male and female bobolink. (From "Bird Lore.")

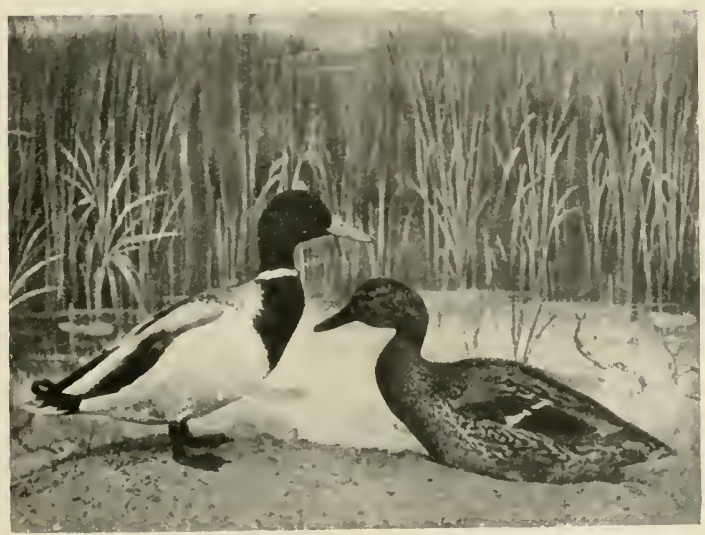

Fig. 16. - Male and female mallard duck. (From " Bird Lore.") 
and remain there withont glowing. A male passes by and flashes his light; the female flashes back. Instantly he tums in his course to the spot whence the signal eame and alights. He signals again. She replies. He ascends the blade, and if he camnot find her, he signals again and she responds. The signals con-

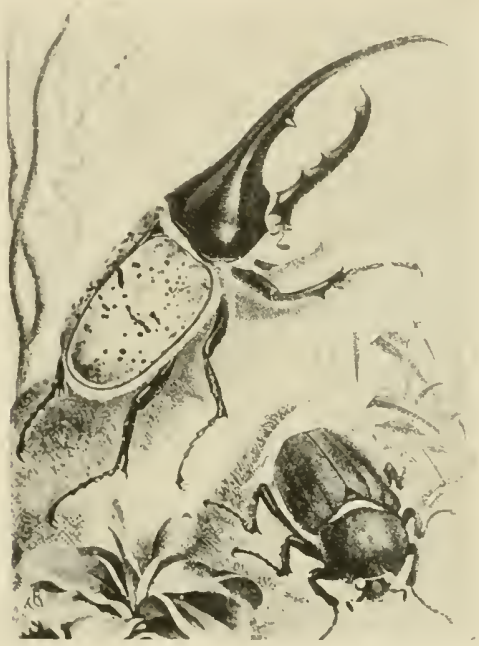

Fici. 17. - Male and female Hereules beetle. (After Kingsley.)

tinue until the female is found, and the drama of sex is finished.

Mast has recently shown that the female firefly does more than simply respond to the signal of the male. If a male flies above and to the right of the female, she bends her abdomen so that its ventral surface is turned upward and to the right. If the male is above and to the left, the light is turned in this direction. If the male 
is directly above, the abdomen of the female is twisted almost upward. But if the male is below her, she emits her light without turning the body. In the firefly the evidence that the phosphorescent organ is of use in bringing the sexes together seems well established.

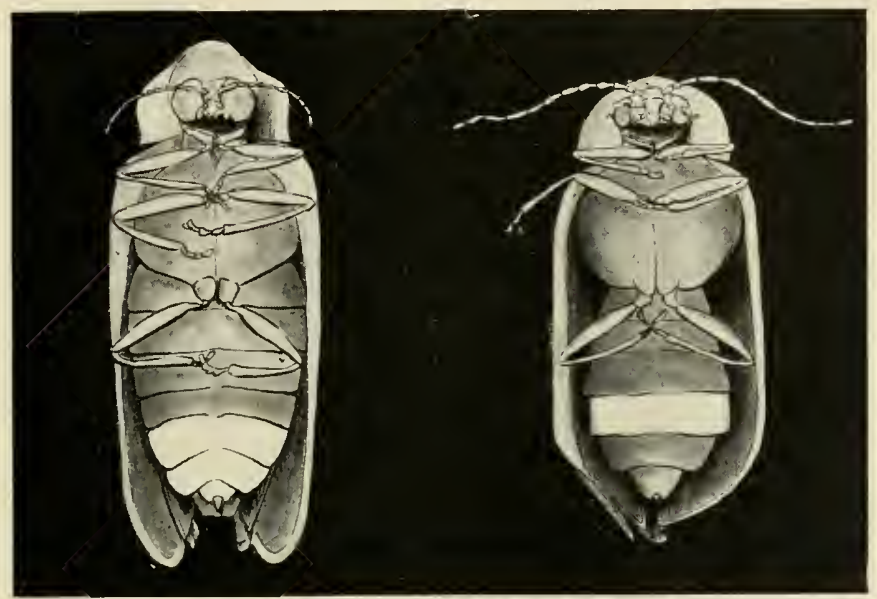

Frg. 18. - Male and female firefly.

Whether all secondary sexual organs are useful in mating is a question that must be referred to a later chapter.

THE SEXUAL INSTINCTS

Side by side with the evolution of these many kinds of structural difference the sexual instincts have evolved. It is only in the lowest forms that the meeting of the egg and sperm is left to chance. The instincts that bring the males and females together at the mating season, the behavior of the individuals at this time in 
lelation (o) each other, forms one of the most curious (hapters in the erolution of sex, for it involves courtship botween the males and females; the pairing or union of the sexes and subsequently the building of the nest, the care, the protection and feeding of the young, by one or both parents. The origin of these yyes of behavior is part of the process of evolution of sex; the mammer of their transmission in heredity and thoir segregation according to sex is one of the most difficult questions in heredity - one about which nothing was known until within recent years, when a begimning at least has been made.

1 few samples taken almost at random will illustrate some of the familiar features in the psychology of sex. Birds have evolved some of the most complicated types of courtship that are known. It is in this group, too, as we have seen, that the development of secondary sexual characters has reached perhaps its highest types. But it is not necessarily in the species that have the most striking differences between the sexes that the courtship is most claborate. In pigeons and their allies, for example, the courtship is prolonged and elaborate, yet the males and females are externally almost indistinguishable; while in the barnyard fowl and in ducks the process is relatively simple, yet chanti(leer is motoriously overdressed.

Even in forms so simply organized as the fishes it is known that the sexual instincts are well developed. In the common minnow, fundulus, the males develop in tho broding season elaborate systems of tactile organs. 'The male swims by the side of the female, pressing his body aguinst her side, which causes her to set free 
a few eggs. At the same time the male sets free the sperm, thereby increasing the chance that some of the spermatozoa will reach the egg.

In bees, the sexual life of the hive is highly specialized. Mating never occurs in the hive, but when the young queen takes her nuptial flight she is followed by the drones that up to this have led an indolent and useless life in the colony. Mating occurs high in the air. The queen goes to the new nest and is followed by a swarm of workers who construct for her a new home. Here she remains for the rest of her life, fed and cared for by the workers, who give her the most assiduous attention - an attention that might be compared to courting were it not that the workers are not males but only immature females. The occurrence of these instincts in the workers that never leave or rarely at least leave offspring of their own is a special field of heredity about which we can do little more than speculate. This much, however, may be hazarded. The inheritance of the queen and of the worker is the same. We know from experimental evidence that the amount of food given to the young grub, when it hatches from the egg, is the external agent that makes the grub a queen or a worker. In the worker the sex glands are little developed. Possibly their failure to develop may in part account for the different behavior of the workers and of the queen. I shall devote a special chapter to this question of the influence of the secretions of the sex glands or reproductive organs on the character of the body. We shall see that in some animals at least an important relation exists between them.

In the spiders the mating presents a strange spectacle. 
Lut us follow Montgomery's careful observations on Phidipmes purpuratus. The male spun a small web of threads from the floor to one side of his eage at an angle of $45^{\circ}$. "Four minutes later he deposited a minute drop of sperm on it, barely visible to the naked eye ; then extending his body over the web reached his palpi downwards and backwards, applying them alternately against the drop; the palpal organs were pressed, not against the free surface of the drop, but against the other side of the web." Later, a minute drop of sperm is found sticking to the apex of one of the palpi. In 1678 Lister had shown that the male applies his palpi to the genital aperture of the female; but not until $1 S 43$ was it found by Menge that the palpi carry the sperm drop.

In man, courtship may be an involved affair. Much of our literature revolves about this period, while painting and sculpture take physical beauty as their theme. Unsatiated with the natural differences that distinguish the sexes, man adds personal adormment which reaches its climax in the period of courtship, and leaves a lasting impression on the costuming of the sexes. Nowhere in the animal kingdom do we find such a mighty display; and clothes as ornaments excel the most elaborate developments of secondary sexual characters of creatures lower in the scale.

I have sketched in briefest outline some of the general and more familiar aspects of sex and the evolution of the sexes. In the chapters that follow we shall take up in greater detail many of the problems that have been only touched upon here. 


\section{CHAPTER II}

\section{The Mechanism of Sex-determination}

IN many species of animals and plants two kinds of individuals are produced in every generation. This process occurs with such regularity and persistence that our minds naturally seek some mechanism, some sort of orderly máchinery, by which this condition is brought about. Yet from the time of Aristotle almost to the present day the problem has baffled completely all attempts at its solution. However, the solution is very simple. Now that we hold the situation in our grasp, it seems surprising that no one was keen enough to deduce it by purely theoretical reasoning. At least the general principles involved might have been deduced, although we can see that without an intimate knowledge of the changes that take place in the germcells the actual mechanism could never have been foretold.

The bodies of animals and plants are composed of millions of protoplasm-filled compartments that are called cells. In the middle of each cell there is a sphere, or nucleus, containing filaments called chromosomes (Fig. 5).

At each division of a cell the wall of the nucleus is absorbed, and the thread-like chromosomes contract into rod-shaped, or rounded bodies (Fig. 6). Each chromosome splits lengthwise into halves; the halves 
are brought into relation with a spindle-shaped system of lines. and move apart along these lines to opposite sides of the cell. 'The protoplasm of the cell next eonstricts to produce two daughter cells, each containing a group of daughter chromosomes.

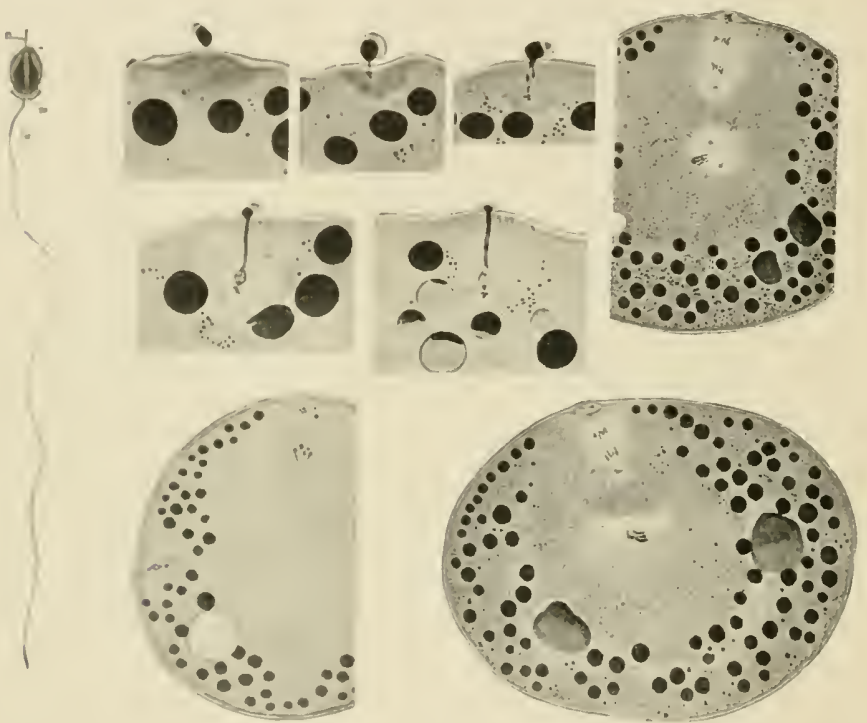

Fici. 19. - Fertilization and polur-body formation of Nereis. The four stmaller figuress show cutrance of sperm. The extrusion of the first pmlar body is shown in lower loft-hand figure and of the second polar body in the two large right-hand figures. The last three also show the formation of the sperm asters, which is the beginning of the first eleavage spindle in the e.ge. (After F. R. Lillie.)

The egg is also a cell, and in its earlier stages contains the simne number of chromosomes as do the other cells of the body; but after two peculiar divisions that take place at maturation the number of the chromosomes is reduced to half. 
But before this time the egg-cells divide, like all the other cells of the body. In this way a large number of eggs is produced. After a time they cease to divide and begin to grow larger, laying up yolk and other materials. At this time, the chromosomes unite in pairs, so that their number seems to be reduced to half the original number. At the final stage in the maturation of the egg, two peculiar divisions take place that involve the formation of two minute cells given off at one pole - the polar bodies. In some eggs, as in the sea urchin, the polar bodies are given off while the egg is still in the ovary and before fertilization; in other eggs, as in the frog, one polar body is given off before fertilization, the other after the sperm has entered; and in other eggs, as in nereis (Fig. 19), both polar bodies are given off after fertilization.

The formation of the polar bodies is a true celldivision, but one that is unique in two respects. First, one of the cells is extremely small, as seen in Fig. 19. The smallness is due to the minute amount of protoplasm that it contains. Second, the number of chromosomes at each division is the half or "haploid" number. There is much evidence to show that at one or at the other of these two divisions the two chromosomes that had earlier united are separated, and in this respect this division differs from all other cell-divisions. In consequence, the egg nucleus, that re-forms after the second polar body has been produced, contains only half the actual number of chromosomes characteristic of all the other cells of the female.

In the formation of the spermatozoa a process takes place almost identical with the process just described 
for the female (Fig. 20). In their earlier history the germ-cells of the male divide with the full number of chromosomes characteristic of the male, which may be one less chromosome than in the female. The early
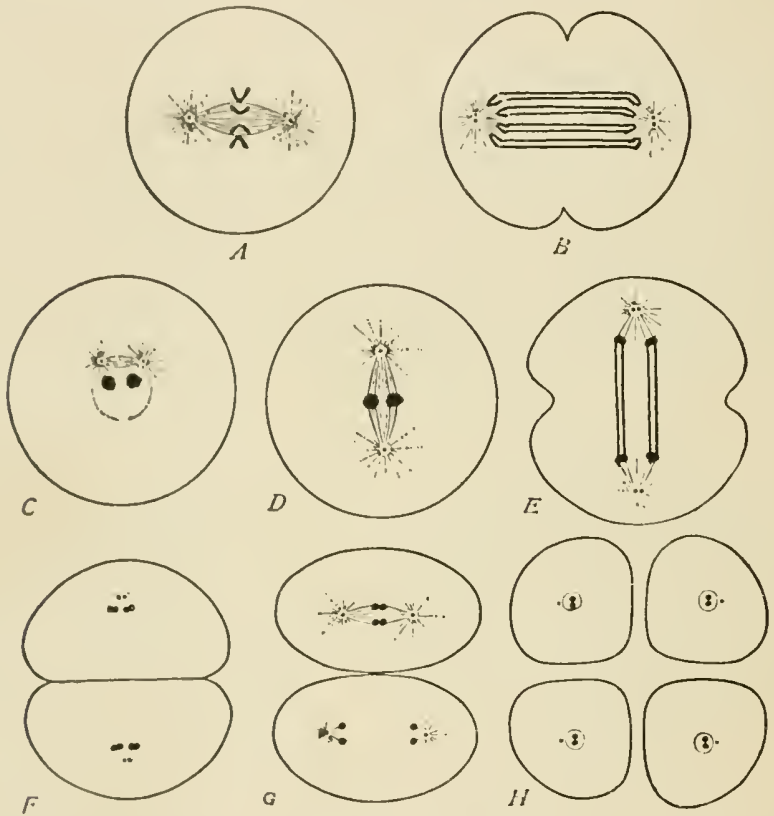

FIG, 20. - A-B, somatic cell division with four chromosomes, $C-H$, the two maturation divisions to produce the four cells $(H)$ that become spermatozo: (After Wilson.)

germ-cells then cease to divide for a time, and begin to grow, laying up yolk and other materials. At this time the chromosomes unite in pairs, so that the number appears to be redueed to half. Later two divisions oceur (Fig. 20, $D-H$ ), in one of which the united chromosmes separate. The male germ-cells differ, how- 
ever, from the female, in that at each of these two divisions the cells are equal in size. Thus four spermcells are produced from each original cell, all four produce tails, and become spermatozoa.

At the time of fertilization, when the spermatozoön touches the surface of the egg, the egg pushes out a cone of protoplasm at the point of contact (Fig. 19), and, lending a helping hand, as it were, to the sperm, draws it into the egg. The projecting cone of protoplasm is called the fertilization cone. In a few minutes the head of the sperm has entered. Its tail is often left outside. The head absorbs fluid from the egg and becomes the sperm nucleus, which passes towards the center of the egg. Here it comes to lie by the side of the egg nucleus, and the two fuse. The walls of the combined nuclei dissolve away and the chromosomes appear. Half of these are derived from the father through the nucleus of the sperm, and half from the mother through the egg nucleus. If we count the paternal chromosomes, there are half as many of them as there are chromosomes in each cell of the body of the father. Presently I shall point out that this statement is not always true, and on this little fact, that it is not quite true, hangs the whole story of sex-determination.

What is the meaning of these curious changes that have taken place in the egg and sperm? Why has the egg, before developing, twice thrown away its most valuable heritage - its chromatin material? We do not know with certainty, but one consequence at least stands out clearly! Before the egg gave off its polar bodies it had the full, or diploid, number of chromosomes. After this event it has only half as many. A 
similar reduction occurs in the sperm, excepting that no (hromatin is lost, but is redistributed amongst four spermatozoa. Egg and sperm-nucleus each have in consequence the haploid or half number. By combining they bring up the number to that characteristic of the species.

The history of the germ-cells, that we have just traced, is the background of our knowledge of the process of heredity in so far as observable changes in the germ-cells have been made out. We owe to Weismann more than to any other biologist the realization of the importance of these changes. It is true that Weismann contributed only a part of the actual facts on which the interpretation rests. Many workers, and a few leaders, have laboriously made out the complete account. But Weismann, by pointing out the supreme importance of the changes that take place at this time, has furnished a stimulus that has acted like yeast in the minds of less imaginative workers.

We are now in a position to apply this knowledge to the interpretation of the mechanism by means of which sex is determined.

\section{THE CYTOLOGICAL EVIDENCE}

If we study by means of modern histological methods the body cells of the male of the insect, Protenor belfragei, we find, when each cell is about to divide, that a group of chromosomes appears like that shown in Fig. 21, A. There are twelve ordinary oval chromosomes, and one much larger than the rest. This group of chromosomes is characteristic of all divisions of the cells of the body, regardless of whether the cells belong 
to muscle, skin, gland, ganglion, or connective tissue. The early germ-cells of the male, the so-called "spermatogonia," also have this same number. It is not until a later stage in their development that a remarkable change takes place in them. When this change occurs the thread-like chromosomes unite in pairs. This is the synapsis stage - the word means to fuse together.

It is the most difficult stage to interpret in the whole history of the germ-cells. In a few forms where the changes that take place have been seen to best advantage it is found that chromosomes are in the form of long threads and that these threads unite in pairs to make thicker threads. When the process is completed, we find half as many threads as there were before. This statement is not quite true. In the case of the male protenor, for instance, there are twelve ordinary chromosomes and one large one. The twelve unite in pairs at synapsis, so that there are six double chromosomes, but the large one has no mate (Fig. 21, B). When the others have united in synapsis, it has taken no part in the process, hence the reduced number of chromosomes in the male is seven - the seventh is the sex chromosome.

Two divisions now follow each other in rapid succession (Fig. 21, C, D). In the first division $(C)$ each chromosome divides - seven go to one pole and seven to the other pole. Two cells, the primary spermatocytes, are produced. Without resting, another division takes place $(D)$ in each of these two cells. It is the second spermatocyte division. Each of the six ordinary chromosomes divides, but the large sex chromosome does not divide, and, lagging behind the others, 
as shown in the figure $(I)$ ), it passes to one pole. Each secondary spermatoeyte produces, therefore, two cells nne with six, the other with seven chromosomes. These cells become spermatozoa $\left(E E^{\prime}\right)$, the ones with seven chromosomes are the female-producing spermatozoa, the ones with six chromosomes are the male-producing

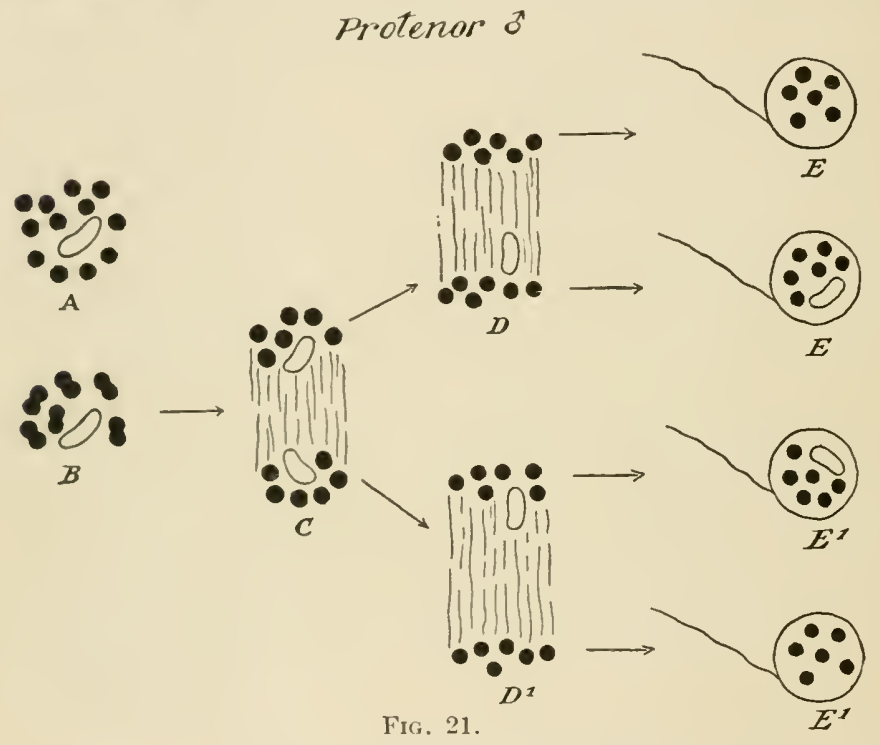

spermatozoa. These two classes of spermatozoa are present in equal numbers.

If we study the body cells of the female protenor, we find fourteen chromosomes (Fig. 22, A). Twelve of these are the ordinary chromosomes, and two, larger than the rest, are the sex chromosomes. At the synapsis stage all of the chromosomes unite in pairs, including the two sex chromosomes. When the process is finished, there are seven double chromosomes (Fig. 22, B). 
When the egg sends off its two polar bodies, the chromosomes divide or separate. At the first division seven chromosomes pass out $(C)$, and seven remain in the egg. At the next division the seven chromosomes in the egg divide again, seven pass out and seven remain

\section{Protenor P}

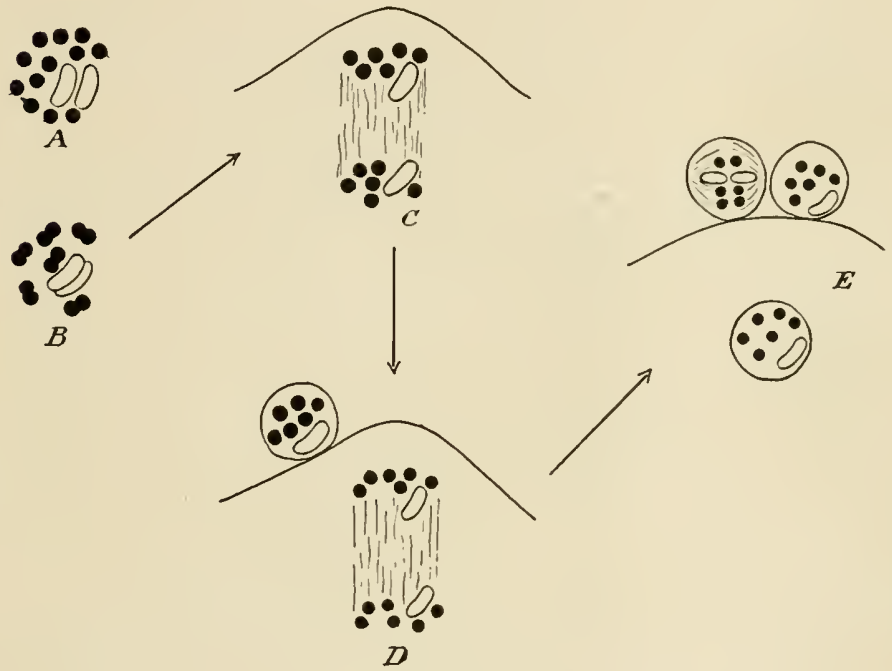

FIG. 22.

in the egg $(D)$. Of these seven, one chromosome, recognizable by its large size, is the sex chromosome. All the eggs are alike $(E)$. There is only one kind of egg, but there are two kinds of sperm. Any egg that is fertilized by a sperm carrying six chromosomes produces an individual with thirteen chromosomes. This individual is a male.

Any egg that is fertilized by a sperm carrying seven 
chromosomes produces an individual with fourteen rhromosones. This individual is a female.

In another species of insect, Lygaus bicrucis, the male differs from the female, not in having a different

\section{Lyp̧aens ỏ}
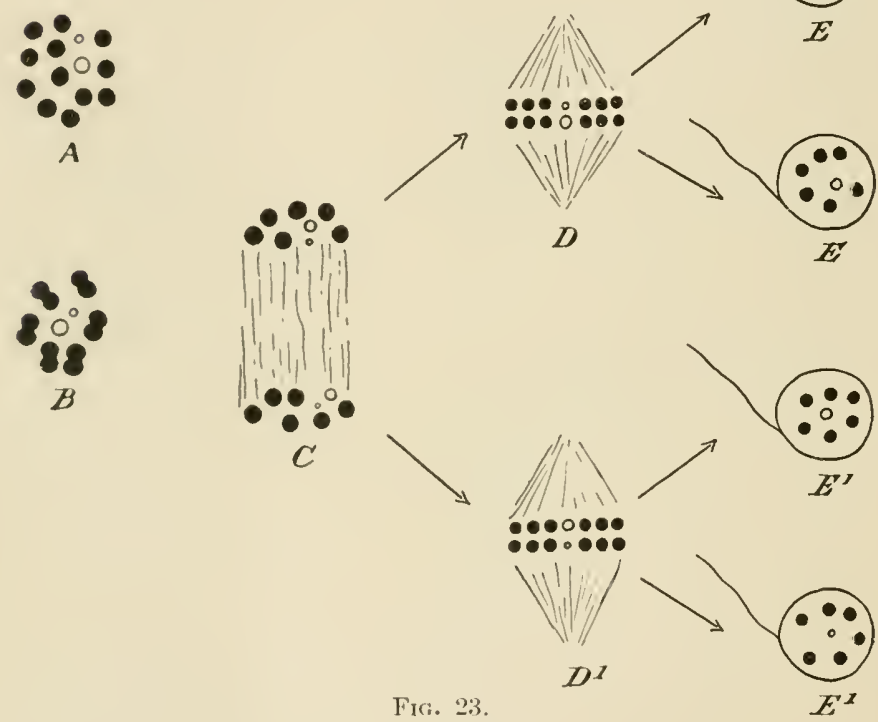

number of chromosomes as in protenor, but by the oceurrence of a pair of different-sized chromosomes.

The body cells of the male have twelve ordinary (hromosomes and two sex chromosomes - one larger, $X$, than the other, Y (Fig. 23, A).

Ifter symapsis there are six double chromosomes. and the two sex chromosomes, called $X$ and $Y$ (Fig. 23, D). 
At the first spermatocyte division all the chromosomes divide $(C)$. The two resulting cells have eight chromosomes, including $X$ and $Y$. At the second division $(D)$ the double chromosomes again divide, but $X$ and $Y$ do not divide. They approach and touch each other, and are carried into the spindle, where they separate from each other when the other ordinary chromosomes

\section{Lygaets of}
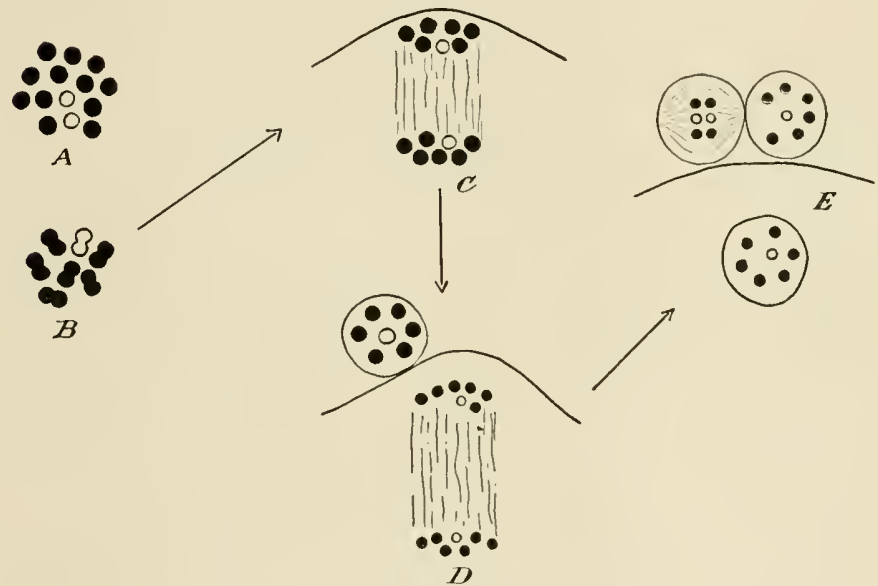

Fig. 24.

divide. Consequently there are formed two kinds of spermatozoa - one containing $X$ and the other $Y$ (Fig. 23, $E$ ).

In the body cells and early germ-tract of the female of lygæus (Fig. 24, A), there are twelve ordinary chromosomes and two sex chromosomes, $X$ and $X$. After reduction there are seven double chromosomes, the two $X$ 's having united when the other chromosomes 
united $(B)$. 'Two divisions take place $(C, D)$, when the two polar bodics are formed, leaving seven chromosomes in the egg $(E)$. Each egg contains as a result only one I chromosome.

Any egg of lygaus fertilized by a sperm carrying an $\mathrm{I}$ chromosome produces a female that contains two

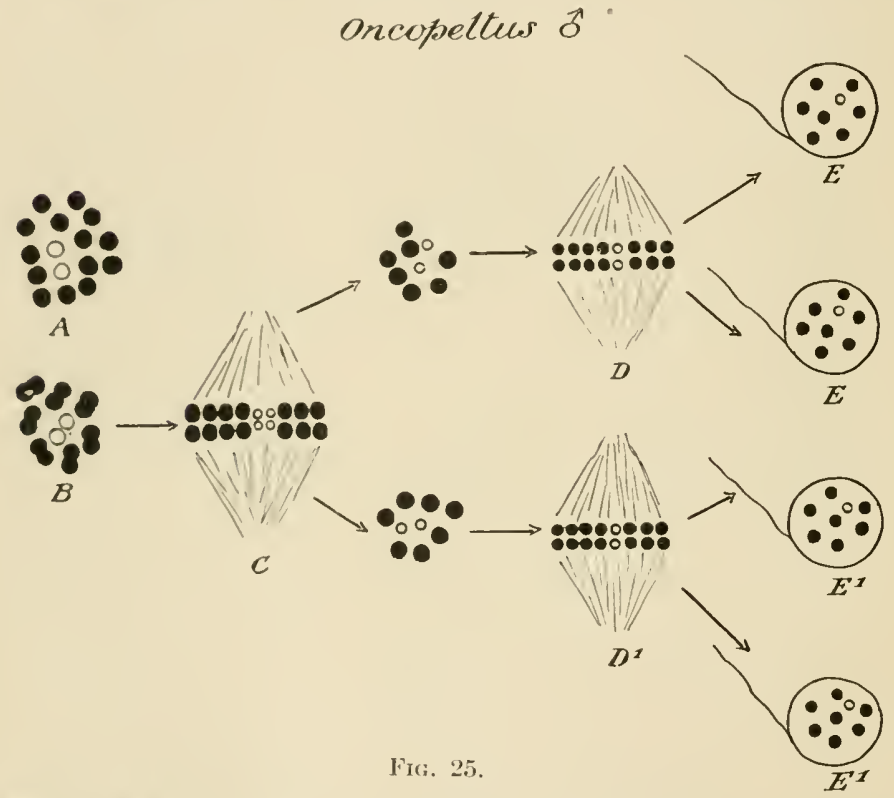

I's or Y.T. Any ege fertilized by a sperm containing a $Y$ chromosome produces a male that contains one $\mathrm{X}$ and one $\mathrm{Y}$, or $\mathrm{XY}$.

Another insect, Oncopeltus fasciatus, represents a third type in which the chromosome groups in the male and in the female are numerically alike and alike as to risible size relations. 
In the body cells of the male there are sixteen chromosomes (Fig. 25, A). After reduction there are nine chromosomes - seven in a ring and two in the middle $(B)$. The seven are the fused pairs or double chromosomes; the two in the middle are the sex chromosomes that have not fused.

\section{Oncopeltus of}
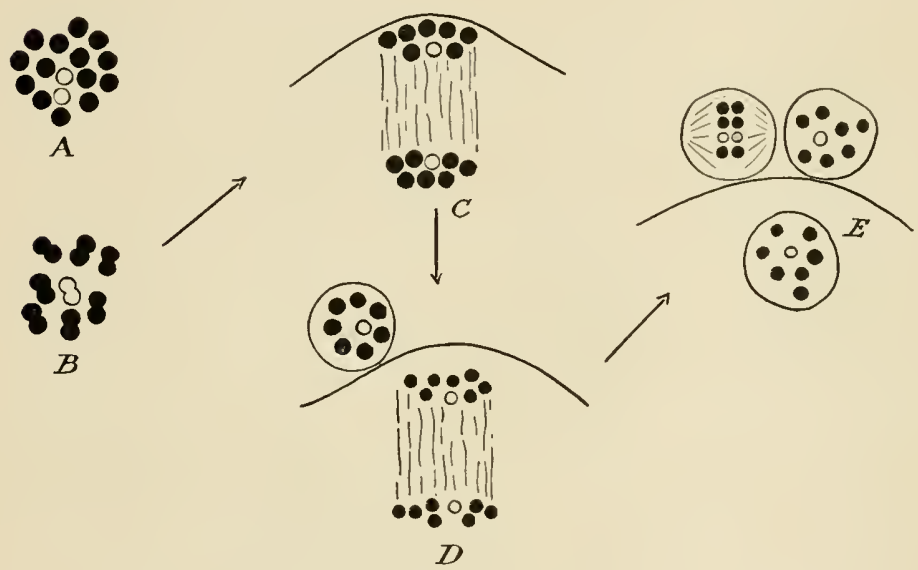

FIG. 26.

The evidence for this interpretation is circumstantial but sufficient.

At the first reduction division all nine chromosomes divide $(C)$. Just before the second division the two central chromosomes come together and remain in contact $\left(D D^{\prime}\right)$. All the double chromosomes then divide, while the two sex chromosomes simply separate from each other, so that there are eight chromosomes at each pole $(D E)$. 
In this case all of the spermatozoa $\left(E E^{\prime}\right)$ contain eight chromosomes. There is no visible difference between them. Nevertheless, there is reason for believing that here also there are two kinds of sperm. The principal reason is that there are all connecting stages between forms in which there is an unequal pair,

Ascaris $\delta$
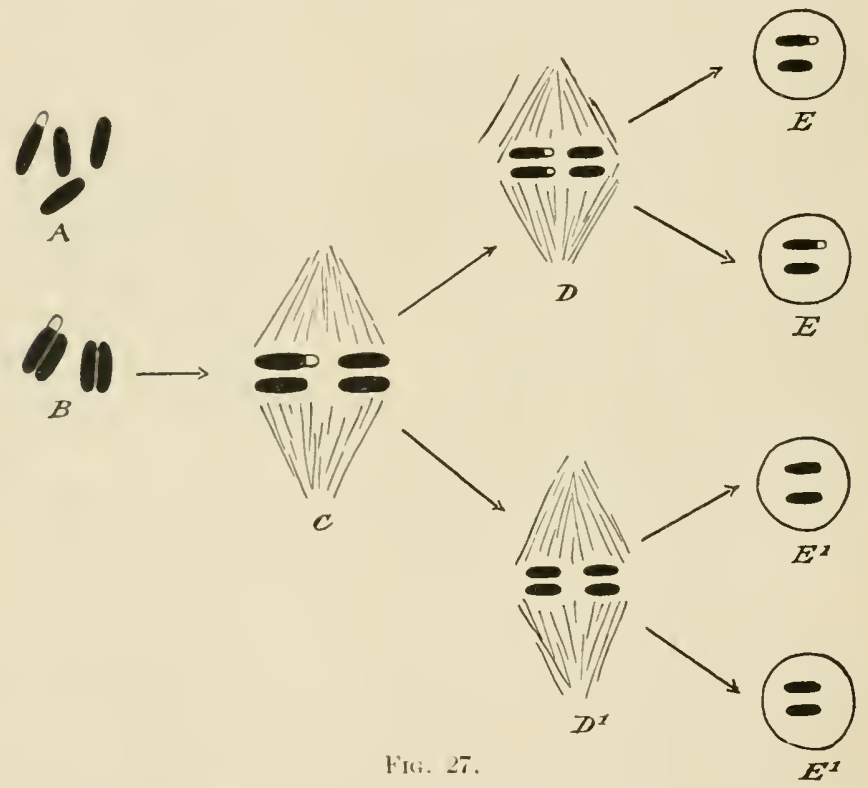

ats in lygasus, and forms with an equal pair, as in oncopeltus. Another reason is that the two sex chromosomes behave during the synipsis stages as do the $X Y$ chromosomes in related species. Moreover, the experimental evidence, of which I shall speak later, leads us to conMude that the determination of sex is not due only to 
a difference in size of $X$ and $Y$. The sex chromosomes must carry a host of factors other than those that determine sex. Consequently it is not surprising that in many species the sex chromosomes appear equal or nearly equal in size. It is a fortunate circumstance for us that in some species there is a difference in size or

$$
\text { Ascaris } q
$$

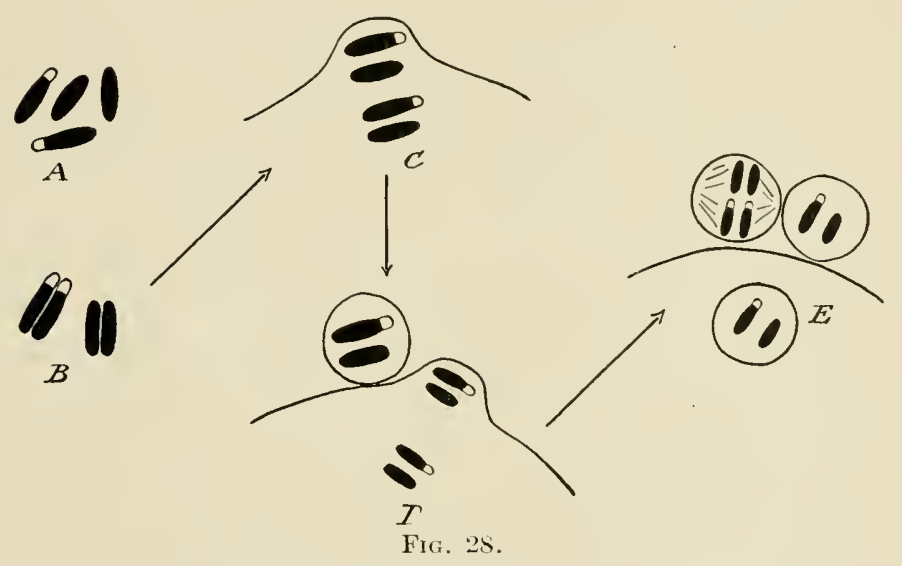

an unpaired sex chromosome; for, in consequence, we are able to trace the history of each kind of sperm in these cases; but it is not essential to the theory that $X$ and $Y$, when present, should be visibly different.

In the female of oncopeltus sixteen chromosomes occur as in the male (Fig. 26, $A$ ). The reduced number is eight double chromosomes $(B)$. At one of the two polar divisions eight chromosomes pass out, and eight remain in the egg $(C)$. At the second division also eight pass out, and eight remain in the egg $(D)$. 
I shall pass now to a fourth condition that has only recently cone to light. It is best shown in some of the nematode worms, for eximple, in the ascaris of the horse. Here the sex chromosomes are generally attached to other chromosomes. In this case, as shown by the diagram (Fig. 27, A), there is in the male a single $X$ attached to one of the other chromosomes. At the first spermatoeyte division it does not divide $(C)$, but gasises over bodily to one pole, so that two kinds of cells are produced. It the second spermatocyte division it divides, in the cell that contains it, so that each daughter cell gets one $X(D)$. Two classes of sperm result, two with $X(E)$, two without $\left(E^{\prime}\right)$.

In the female there are two $X^{\prime}$ 's, each attached to a chromosome (Fig. 2S). After the polar bodies are given off, one $X^{\prime}$ only is left in each $\operatorname{egg}(C, D, E)$. Sex is determined here in the same way as in the insects, described above, for there are two classes of sperm and but one class of eggs.

The discovery of the sex chromosome and its relation to sex is due to several investigators. In 1891 Henking first deseribed this body, and its unequal distribution, but was uncertain even as to its relation to the chromosomes. Paulmier (1899), Montgomery (1901), Sincty (1901), gave a correct description of its behavior in spermatogenesis. MeClung (1902) confirmed these discoveries, and suggested that the accessory, or odd chromosome, as it was then called, had some relation to sex, because of its unequal distribution in the sperms. He inferred that the male should have one more chromosome than the female, but he gave no evidence in support of this suggestion, which as we have 
seen is the reverse of the actual conditions. Stevens (1905) made out the relations of the $X Y$ pair of chromosomes to sex and Wilson in the same year (1905) the correct relation of the accessory chromosome to sex. The results described above for the insects are for the most part from Wilson's studies on the chromosomes; those for ascaris from the recent work of Sophia Frolowa, which confirms in the main the work of Boveri, Gulick, Boring, and Edwards.

In the fruit fly, Drosophila ampelophila, it appears from the recent work of Metz, that, in the male, there is an $X Y$ pair of sex chromosomes, instead of only an $X$, as Stevens supposed. The female has, of course, two $X$ 's. An analysis of certain experimental evidence has led H. J. Muller to the conclusion that probably the $Y$ chromosome carries no factors that influence development. If this proves true, we can better understand how it might be completely lost in certain types.

The whole history of the sex chromosomes of ancyrocanthus, a nematode worm, is strikingly shown in a recent paper by Carl Mulsow (Fig. 29 and 29a, A). This is a typical case in which the male has one less chromosome than the female, as in protenor. The case is striking because the chromosomes can be seen and counted in the living spermatozoa. Some sperm have six, some have five chromosomes. The spermnucleus can be identified in the egg after fertilization because it lies nearer the pole opposite to the polar bodies. The entering sperm nuclei show in half of the fertilized eggs six chromosomes and in the other half five chromosomes.

An interesting confirmation of these conclusions in 
regird to the relation between sex and the sex chromosomes wis found in another direction. It has long been known that the fertilized eggs of aphids or plant lice produce only fomales. The same thing happens in near relatives of the plant lice, the phylloxerans.

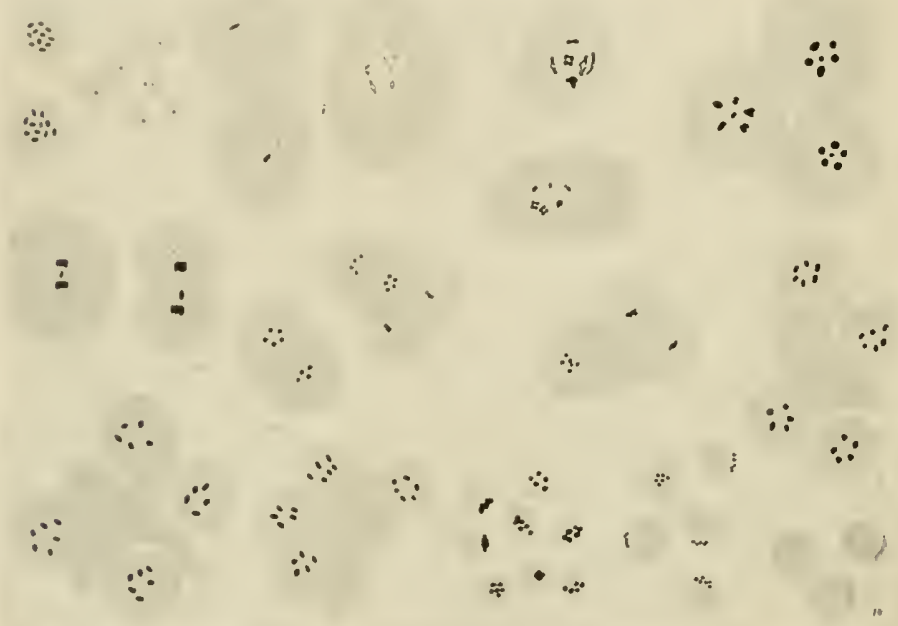

Fic, 29. - 1 and 2 are spermatogonia ; 3 , growth period ; 4-7, prophases ; $\rightarrow$ equatorial plate of first division, 9-10; 11 , spermatocytes of second order: 12-13, clivision of simme; 14-16, the four cells or spermatids that come from the same original eell, two with 5 , two with 6 chromosomes; 17 , spermatids: 1h, mature sperm; 19, living sperm. (After Mulsow.)

In these insects a study of the chromosomes shows that the male has one less chromosome than the female. It the first maturation division in the male (Fig. 30), all the chromosomes divide except one, the $\mathrm{X}$ chromosome, and this passes to one cell only. This cell is also larger than the sister cell. The small cell lacking the $I$ degenerates, and does not produce spermato- 
zoa. The large cell divides again, all of the chromosomes dividing. Two functional spermatozoa are produced, each carrying one sex chromosome. These spermatozoa correspond to the female-producing spermatozoa of other insects.

In the sexual female there is an even number of chro-

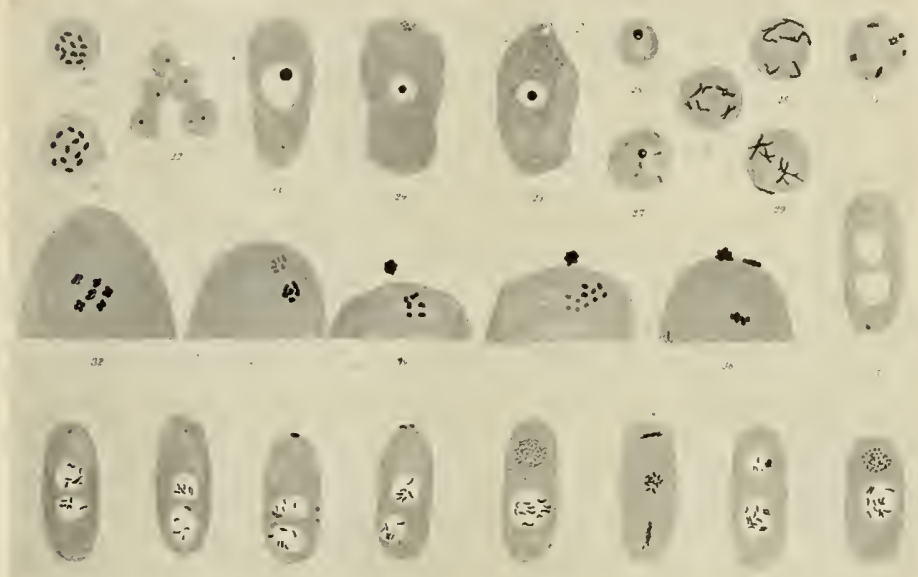

FIG. $29 a$. -20 and 21, oögonia (equatorial plate); 22, growth period; 23 , before fertilization; 24-25, entrance of sperm; $26-31$, prophases of first division; $32-33$, formation of first polar body; $34-36$, extrusion of same and formation of second polar body ; 37 , two pronuclei ; $38-41$, union of pronuclei ; 42-45, cleavage. (After Mulsow.)

mosomes - one more than in the male. They unite in pairs. When the two polar bodies of the sexual egg are formed, all the chromosomes divide twice, so that each egg is left with one sex chromosome.

It is now evident why only females are produced after fertilization. The female-producing sperm alone is functional. 


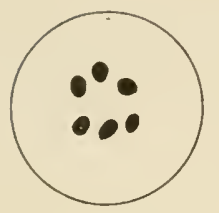

. 9 Soma
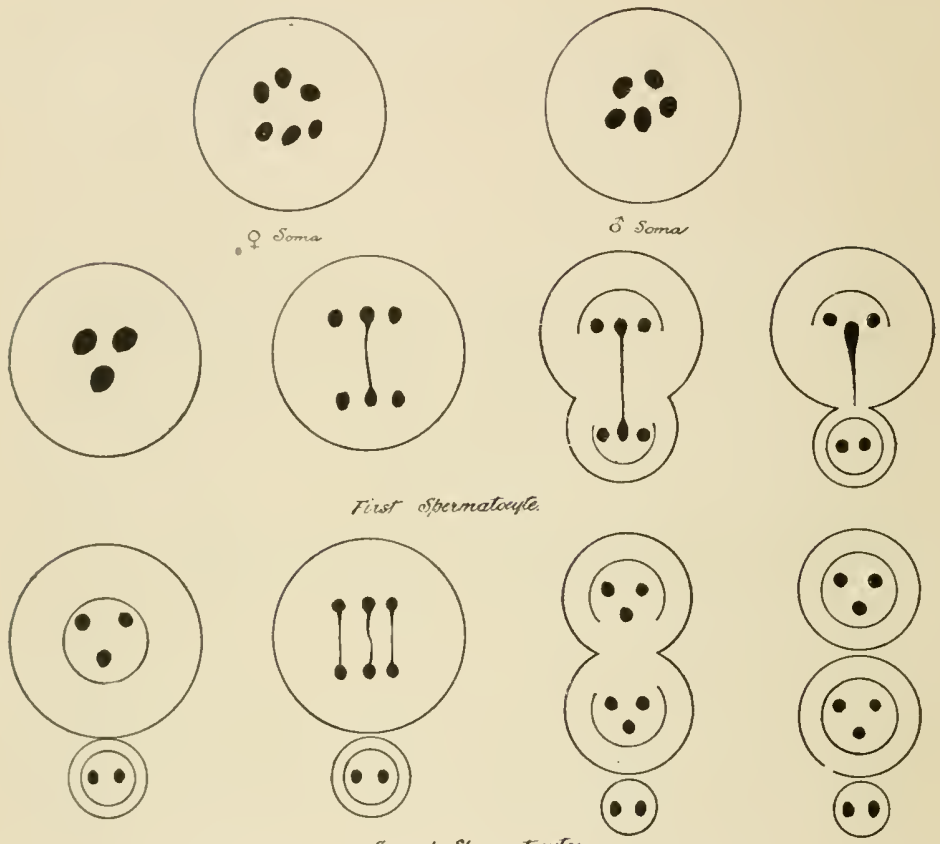

Second spermatoryte.
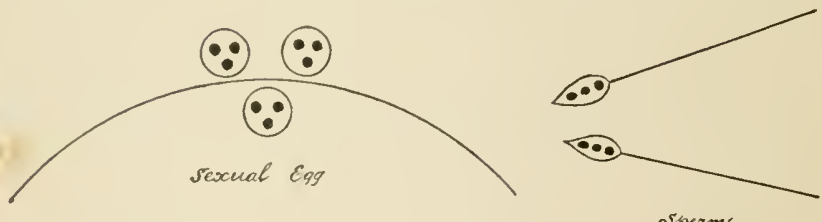

Spoerme.

F16. 30. - Diagram of chromosomes in Phylloxcra caryacaulis. Top line, somatic well of female with 6 chromosomes and somatic cell of male with 5 chromosomes. Second line, stages in first spermatocyte division producing a rudimentary cell (helow) with two chromosomes. Third line, second spermatocyte division into two equal cells. Fourth line, sexual egg ( 3 rhronosomes) and two polar hodies; and two functional, femaleproducing sperm with three chromosomes each. 
THE EXPERIMENTAL EVIDENCE

The experimental evidence, indicating that there is an internal mechanism for sex determination, is derived from two sources - from experimental embryology, and from a study of the heredity of sex-linked characters.

The evidence from embryology shows that the chromosomes are the bearers of materials essential for the production of characters. The evidence from heredity shows that certain characters follow the sex chromosomes.

It has long been taught that the hereditary factors are carried by the nucleus. The evidence for this was found in fertilization. When the spermatozoön enters the egg, it carries in, as a rule, only the head of the spermatozoön, which consists almost entirely of the nucleus of the original cell from which it comes. Since the male transmits his characters equally with the female, it follows that the nucleus is the source of this inheritance.

The argument has not been regarded as entirely conclusive, because the sperm may also bring in some of the protoplasm of the original cell - at least that part lying immediately around the nucleus. In addition a small body lying at the base of the sperm head seems also to be brought in by the male, and according to some observers it becomes the center about which the entire division system or karyokinetic spindle develops.

The most convincing evidence that the chromosomes are the most important elements in heredity is found in some experimental work, especially that of Boveri, Baltzer, and Herbst. Under certain circumstances in 
the sea-urchin two spermatozoa may enter a single egg. 'They both unite with the egg nucleus (Fig. 31). Each brings in 18 chromosomes. The egg contributes is chromosomes. There are in all 54, instead of 36 chromosomes, as in normal fertilization.
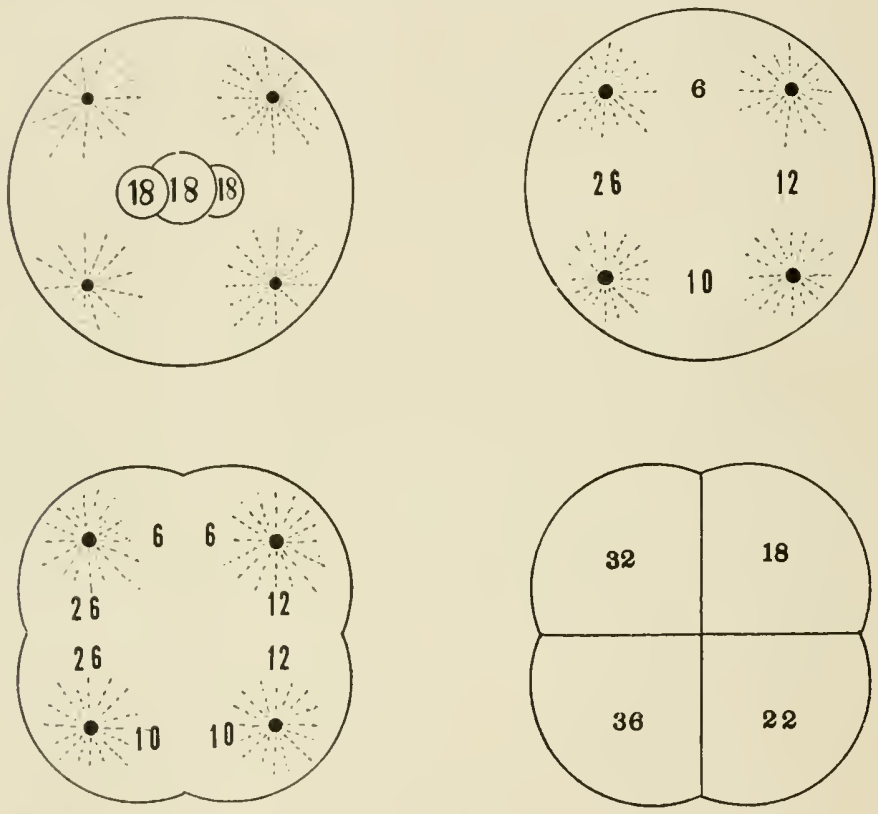

FIG. 31. - Dispermy and its effects in egg of sea urchin. (After Boveri.)

Around these chromosomes a double system of threads develops with four poles. The chromosomes become unequally distributed on the four spindles that develop. Each chromosome then divides, and half of each goes to the nearest pole. To some of the poles many chromosomes may pass, to other poles fewer. 
In order to simplify the case let us imagine that each sperm has only four chromosomes and the egg nucleus only four. Let us represent these by the letters as shown in Fig. 32. Any one of the four cells that is
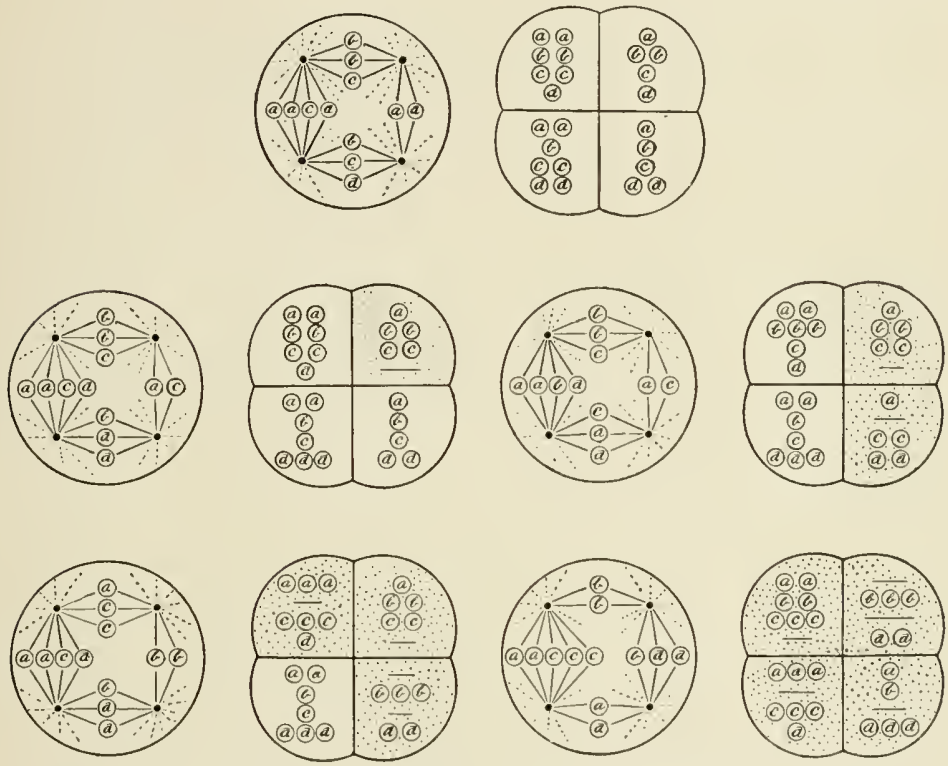

FIG, 32, - Diagram illustrating the irregular distribution of the chromosomes in dispermic eggs in an imaginary case with only four kinds of chromosomes, $a, b, c, d$. There are here three sets of each of these in each egg. The stippled cells are those that fail to receive one of each kind of chromosome. (After Boveri.)

produced at the first division of these dispermic eggs may contain a full complement of the chromosomes, or only some of them. The possibilities for four chromosomes are shown in the diagram. Any cell that does not contain at least these four chromosomes is shaded. One case is present in which all the four 
colls contain a complete assortment. If normal derelopment depends on an embryo containing in every cell at least one of each kind of chromosome, then in our simple case only one group of four cells has this posibility.

Boveri found that such dispermic eggs produce normal cmbryos very rarely. He calculated what the chance would be when three times 18 chromosomes are involved. The chance for normal development is probably not once in 10,000 times. He isolated many dispermic eggs and found that only one in 1,500 of the tetrad type developed normally.

Boveri went still further in his analysis of the problem. It had been shown for normal eggs that if at the two-celled stage the cells are separated, each forms a perfect embryo. This is also true for each of the first four cells of the normal egg.

Boveri separated the four cells of dispermic eggs and found that the quadrants not infrequently developed normally. This is what we should anticipate if those cells can develop that contain one of each kind of chromosome.

The evidence furnishes strong support of the view that the chromosomes are different from each other, and that one of each kind is necessary if development is to take place normally.

The evidence that Baltzer has brought forward is also derived from a study of sea-urchin eggs. It is possible to fertilize the eggs of one species with sperm of another species. The hybridizing is greatly helped by the addition of a little alkali to the sea water.

Baltzer made combinations between four species of 
sea-urchins. We may take one cross as typical. When eggs of strongylocentrotus are fertilized with sperm of sphærechinus, it is found at the first division of the egg that, while some of the chromosomes divide and pass normally to the two poles, other chromosomes remain in place, or become scattered irregularly between the two poles, as shown in Fig. 33 . When the division
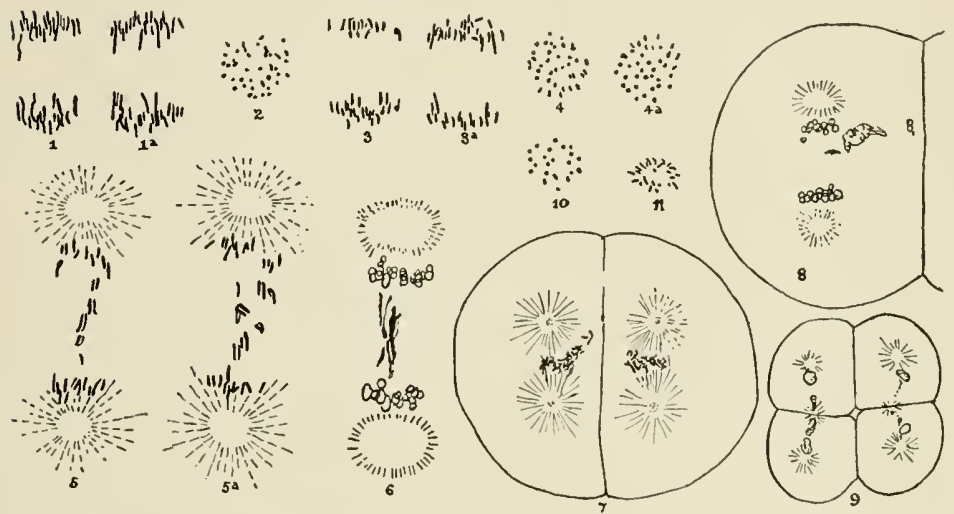

FIG. 33. - 1 and $1 a$, chromosomes in the normal first cleavage spindle of Sphærechinus; 2, equatorial plates of two-cell stage of same; 3-3a, hybrid, Sphreehinus by Strongyloeentrotus, spindle at two-cell stage; 4-4a, same equatorial plates; $5-5 a$, hylrid, Strong. by sphær., cleavage spindle in telophase; 6 , next stage of last; 7 , same, two-cell stage; 8 , same, later; 9 , same, four-cell stage ; 10 , same, equatorial plate in two-cell stage (12 chromosomes) : 11, same, from later stage, 24 chromosomes. (After Baltzer.)

is completed, some of these chromosomes are found outside of the two main nuclei. They often appear as irregular granules, and show signs of degeneration. They are still present as definite masses after the next division, but seem to take no further part in the development.

Baltzer has attempted to count the number of chromosomes in the nuclei of these hybrid embryos. The 
number is found to be about twenty-one. The maternal crgenclous contains eighteen chromosomes. It appears that only three of the paternal chromosomes have succeredor in getting into the regular cycle - fifteen of them have degenerated.

Baltzer thinks that the egg acts injuriously in this case on the chromosomes of foreign origin, especially on the fifteen that degenerate, so that they are elininated from the normal process.

The cmbryos that develop from these eggs are often abnormal. I few develop as far as the pluteus stage, when a skeleton appears that is very characteristic for each species of sca-urchin. The plutei of these hybrids are entirely maternal. This means that they are exactly like the plutei of the species to which the mother belongs.

The conclusion is obvious. The sperm of sphærechinus has started the process of development, but has produced no other effect, or has at most only slightly affected the character of the offspring. It is reasonable to suppose that this is because of the elimination of the paternal chromosomes, although the evidence is not absolutely convincing.

Let us now examine the reciprocal cross. When the egrgs of spharechinus are fertilized by the sperm of strongrlocentrotus, the division of the egg and of the chromosomes is entirely normal. All the chromosomes divide and pass to the poles of the spindle. The total number (36) must, therefore, exist in each cell, although in this case they were not actually counted.

The pluteus that develops has peculiarities of both maternal and paternal types. It is hybrid in structure. 
Both parents have contributed to its formation. It is not going far from the evidence to infer that the hybrid character is due to both sets of chromosomes being present in all of the cells.

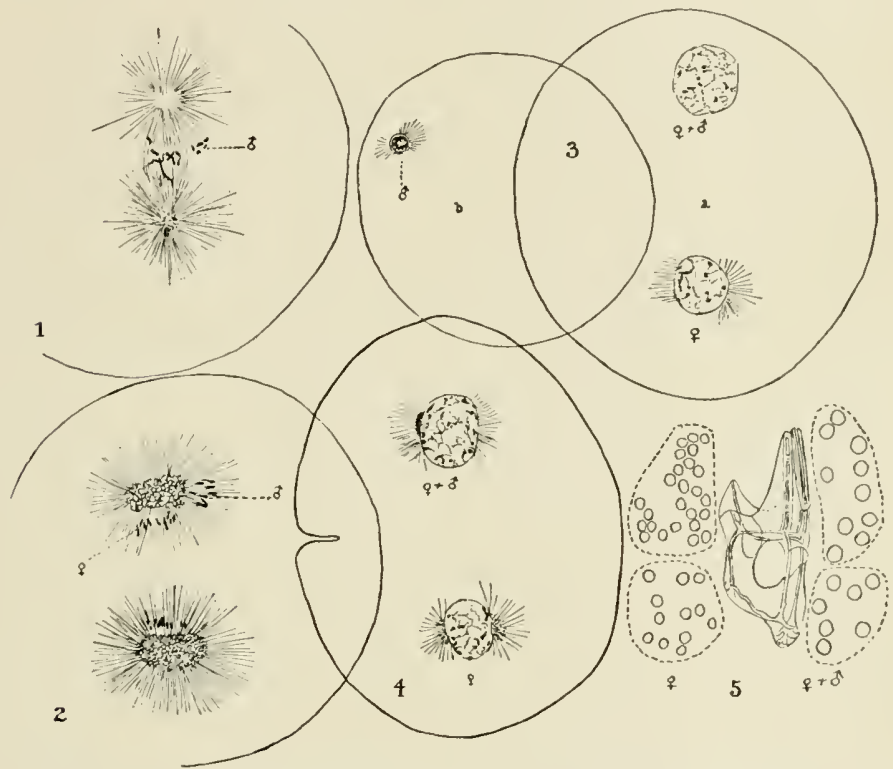

FIG. 34. - 1. The rhromosomes of the egg lie in the equator of the spindle, the chromosomes of the sperm lie at one side. 2. A later stage, showing all the paternal chromosomes passing to one pole. 3 (to the right). A later stage, a condition like the last. There is also a supernumerary sperm in the egg (to left, in another section.) 4. Same condition as last. 5. Pluteus larva that is purely maternal on one side and hybrid on the other. (After Herbst.)

The evidence that Herbst has brought forward is of a somewhat different kind. It supplements Baltzer's evidence and makes more probable the view that the chromosomes are essential for the development of the characters of the individual. 
Herbst put the egges of spherechinus into sea water to which a little ralerianic acid had been added. This is nne of the many methods that Loeb has discovered by which the egg may be induced to develop parthenogenetically, i.e. without the intervention of the spermatozoön. After five minutes the eggs were removed to pure sea water and the sperm of another species, strongylocentrotus, was added. The sperm penetrated some of the eggs. The eggs had already begun to undergo the changes that lead to division of the cell - the sperm entered ten minutes late. The egg proceeded to divide, the sperm failed to keep pace, and fell behind. Consequently, as shown in Fig. 34, the paternal chromosomes fail to reach the poles when the nuclei are re-formed there. The paternal chromosomes form a nucleus of their own which comes to lie in one of the two cells. In consequence one cell has a nucleus that contains only the maternal chromosomes; the other cell contain's two nuclei, one maternal and the other paternal. In later development the paternal nucleus becomes incorporated with the maternal nucleus of its cell. There is produced an embryo which is matemal on one side and hybrid on the other. Herbst found in fact that half-and-half plutei were not rare under the conditions of his experiment.

This evidence is almosi convincing, I think, in favor of the riew that the chromosomes are the essential bearers of the hereditary qualities. For in this case, whether the protoplasm of the embryo comes from the exg or the sperm also, the fact remains that the half with double nuclei is hybrid. Even if the spermatozoön brought in some proto- 
plasm, there is no reason to suppose that it would be distributed in the same way as are the paternal chromosomes.

\section{EVIDENCE FROM SEX-LINKED INHERITANCE}

The experimental evidence based on sex-linked inheritance may be illustrated by the following examples.

The eyes of the wild fruit-fly, Drosophila ampelophila, are red. In my cultures a male appeared that had white eyes. He was mated to a red-eyed female. The offspring were all red-eyed - both males and females (Fig. 35). These were inbred and produced in the next generation red-eyed females, red-eyed males, and white-eyed males (Fig. 35). There were no whiteeyed females. The white-eyed grandfather had transmitted white eyes to half of his grandsons but to none of his granddaughters.

Equally important are the numerical proportions in which the colors appear in the grandchildren. There are as mary-femates as the two classes of males taken together; half of the males have red eyes and half have white eyes. The proportions are therefore $50 \%$ red females, $25 \%$ red males, $25 \%$ white males.

Only white-eyed males had appeared at this time. It may seem that the eye color is confined to the male sex. Hence the origin of the term sex-limited inheri- $\checkmark$ tance for cases like this. But white-eyed females may be produced easily. If certain of the red-eyed granddaughters are bred to these white-eyed males, both white-eyed females and males, and red-eyed females and males, appear (Fig. 37). The white eye is therefore not sex-limited but sex-linked. 
With these white-eyed females it is possible to make the reciprocal cross (Fig. 36). A white-eyed female was mated to a red-eyed male. All of the daughters had red eyes and all the sons had white eyes. These were then inbred and gave red-cyed males and females,
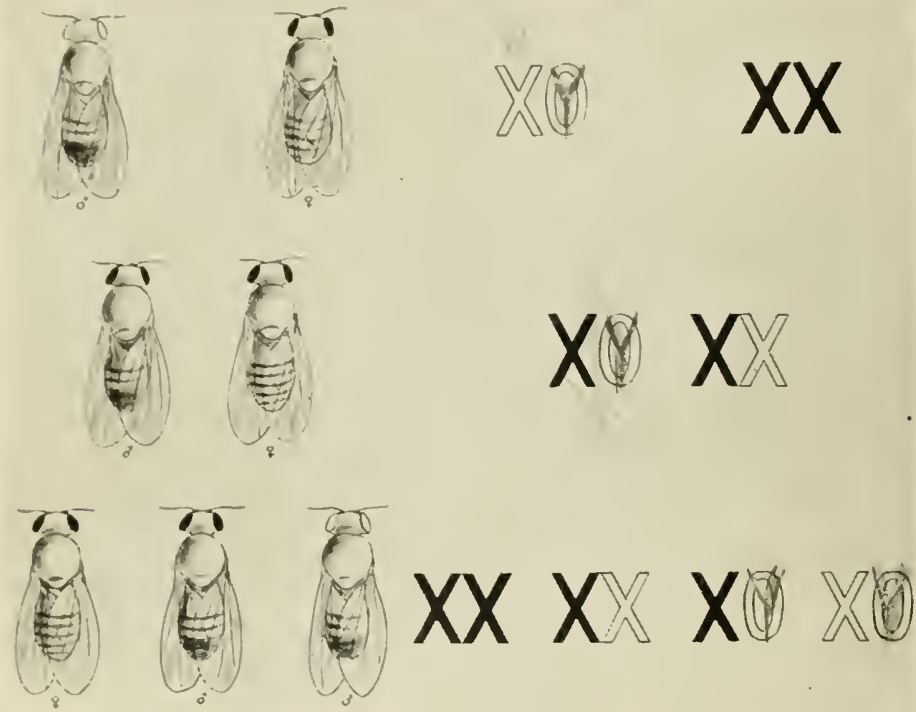

Fir. 35. - fex-linked inheritance of white and red eyes in Drosophila. l'arents, white-ryed $\hat{\delta}$ and red-eyed $q ; F_{3}$, red-eyed $\hat{\delta}$ and $q ; F_{2}$ red(ved $q$, red-ryed $\delta$ and white-eyed $\delta$. To right of flies the history of the se'x chronosonjes $I X$ is shown. The black $I$ earries the factor for red reses, the open $I$ the fartor for white es es; the cirele stands for no $X$.

and white-eyed males and females in equal numbers (Fig. 36).

The heredity of this eye color takes place with the utmost regularity, and the results show that in some wily the mechanism that is involved is closely bound up) with the mechanism that produces sex. 
Other combinations give results that are predictable from those just cited. For instance, if the $F_{1}$ red-eyed female from either of the preceding crosses is mated to a white-eyed male, she produces red-eyed males and females, and white-eyed males and females, as shown in
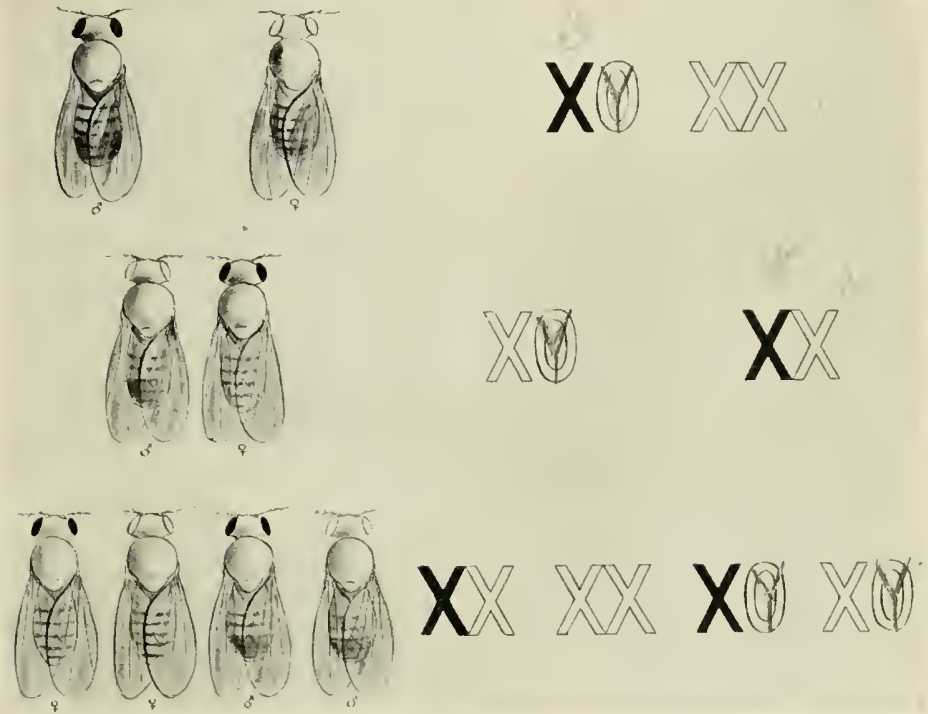

FIG. 36. - Reciprocal cross of Fig. 35. Parents, white-eyed $q$ and red-eyed $\hat{\delta}$, (criss-cross inheritance). $F_{1}$, red-eyed $\hat{t}$ white-eyed $\hat{\delta}$. $\mathrm{F}_{2}$, red-eyed $q$ and $\hat{\delta}$; white-eyed $q$ and $\delta$. To right, sex chromosomes (as in Fig. 35).

Fig. 37 (upper two lines). If the $F_{1}$ red-eyed male from the first cross (Fig. 35) is bred to a white-eyed female, he will produce red-eyed daughters and whiteeyed sons. Fig. 37 (lower two lines').

The same relations may next be illustrated by another sex-linked character. 
A male with short or miniature wings appeared in my cultures (Fin. 3S). Mated to long-winged females only long-winged offspring were produced. When these were mated to each other, there were produced

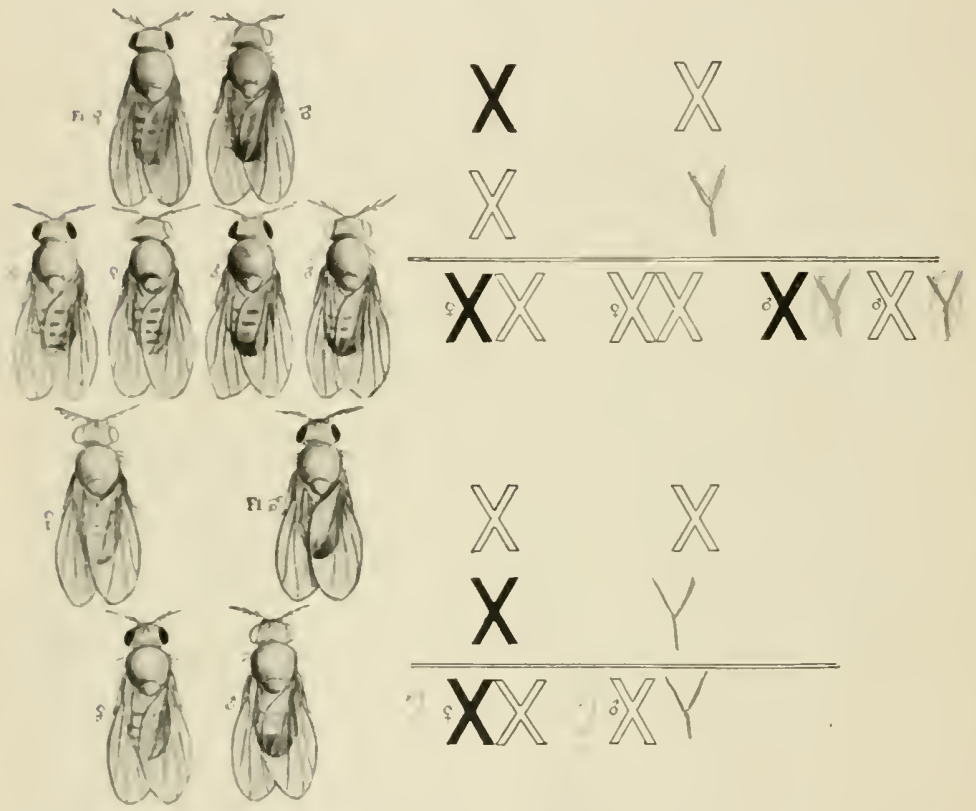

Fiti. 37. - Upper series, back cross of $F_{1} f$ to white $\delta$. Lower series back cross of $F_{1}$ red-eyed $\hat{\delta}$ to white $Q$.

long-winged females ( $50 \%)$, long-winged males $(25 \%)$ and miniature-winged males $(25 \%)$.

It is possible to produce, in the way described for eye color, miniature-winged females.

When such miniature-winged females are mated to long-winged males, all the daughters have long wings, and all the sons have miniature wings (Fig. 39). If 
these are now mated, they produce, in equal numbers, long-winged males and females and miniature-winged males and females.

The same relations may again be illustrated by body color.
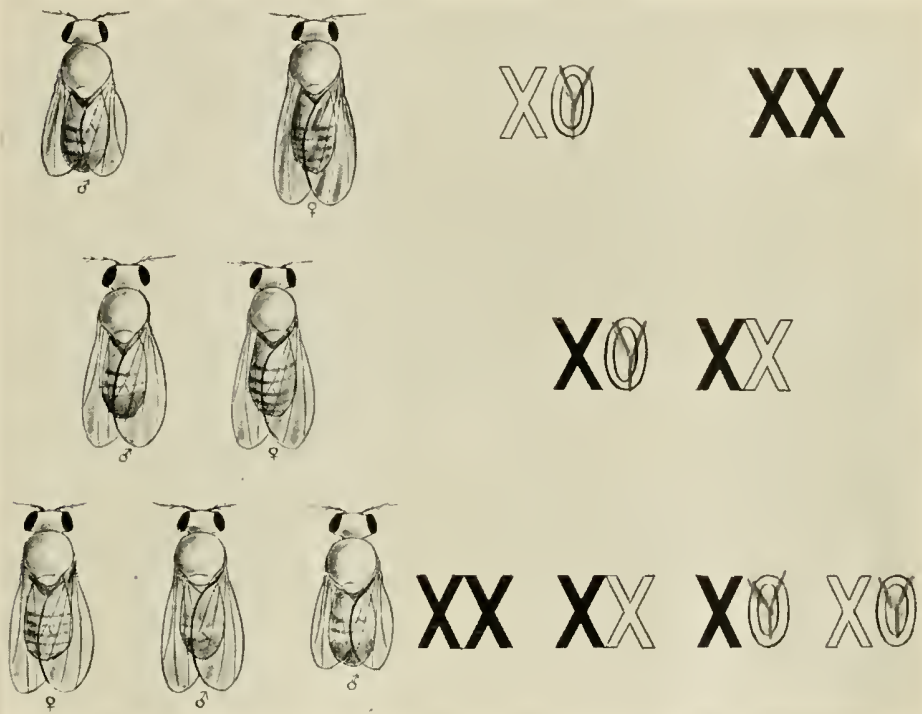

F1G. 38. - Sex-linked inheritance of short ("miniature") and long wings in Drosophila. Parents, short-winged $\hat{\delta}$, long-winged $q . F_{1}$ long-winged $\hat{\sigma}$ and $\hat{q} . \mathrm{F}_{2}$ long-winged $q$ and $\hat{\sigma}$ and short-winged $\hat{\delta}$. Sex chromosomes to right. Open $X$ carries short wings.

A male appeared with yellow wings and body. Mated to wild gray females he produced gray males and females. These mated to each other gave gray females $(50 \%)$, gray males $(25 \%)$, and yellow males $(25 \%)$.

As before, yellow females were made up. Mated to gray males they gave gray females and yellow males. 
These inbred gave gray males and females and yellow males and females, in equal numbers.

These "ases serve to illustrate the regularity of this type of inheritance and its relation to sex. In the fruit fly we have found as many as twenty-five sex-linked
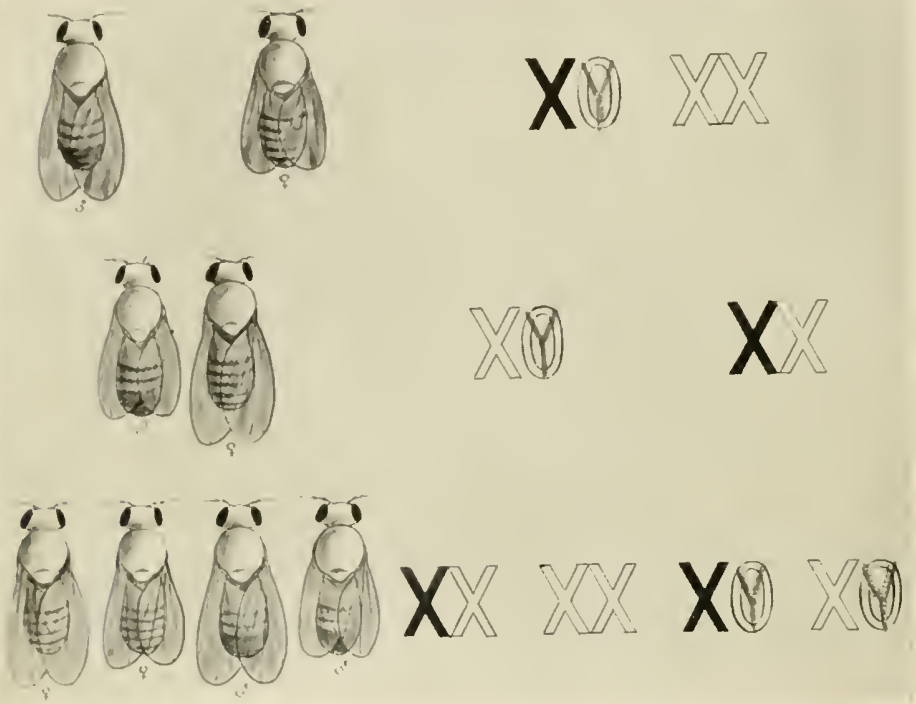

Fig. 39. - Reciprocal cross of Fig. 38. Parents, long-winged $\hat{\delta}$ and shrre-winged $\$ . \quad F_{1}$ long-winged $q$, short-winged $\hat{\delta}, F_{2}$ long-winged $q$ and $\hat{\delta}$, short-winged $q$ and $\hat{\delta}$. Sex chromosomes as in last.

factors. There are other kinds of inheritance found in these flies, and at another time I shall speak of some of these ; but the group of sex-linked factors is of special importance because through them we get an insight into the heredity of sex.

In the next chapter, when we take up in detail Mendelian heredity, I shall try to go further into the ex- 
planation of these facts. For the present it will suffice to point out that the cases just described, and all like them, may be accounted for by means of a very simple hypothesis. We have traced the history of the $X$ chromosomes. If the factors that produce white eyes, short (miniature) wings, and yellow body color are carried by the $X$ chromosomes, we can account for these results that seem at first sight so extraordinary. The history of the sex chromosomes is accurately known. Their distribution in the two sexes is not a matter of conjecture but a fact. Our hypothesis rests therefore on a stable foundation.

At the risk of confusion I feel bound to present here another type of sex-linked inheritance. In principle it is like the last, but the actual mechanism, as we shall see, is somewhat different. Again I shall make use of an illustration. If a black Langshan hen is mated to a barred Plymouth Rock cock, all the offspring will be barred (Fig. 40). If these are inbred, there are produced barred females and males, and black females. The numerical proportion is 50 per cent barred males, 25 per cent barred females, and 25 per cent black females.

The black hen has transmitted her character to half of her granddaughters and to none of her grandsons. The resemblance to the case of the red-eyed, whiteeyed flies is obvious, but here black appears as a sexlinked character in the females.

The converse cross is also suggestive. When a barred hen is mated to a black cock, all the daughters are black and all the sons are barred (Fig. 41). When these are inbred, there are produced black males and females and barred males and females in equal num- 
bers. Igain, the resemblance of the reciprocal cross to one of the combinations for eye color is apparent. In fact, this case can be explained on the same prin(aiple as that used for the flies, except that in birds it is
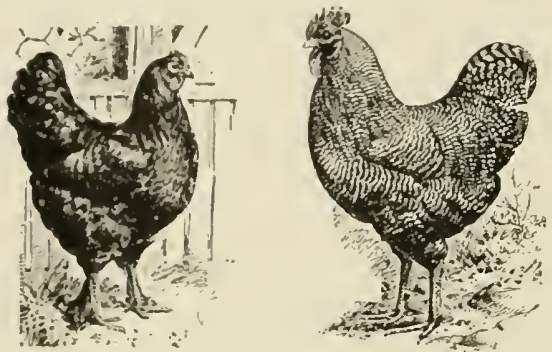

Parents
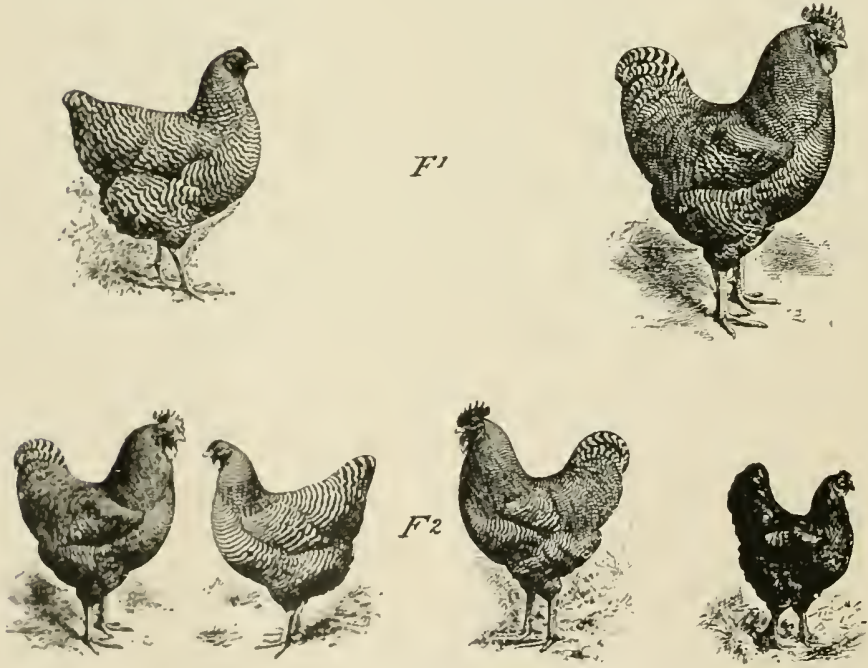

Fui. 40 - Six-liukerl inheritance in fowls. Toper line black laugshan lwh :nul harred Plymouth Rock eock. Second line, $F_{1}$, barred cock and hert. Third line, $F_{2}$, three batred (cook, hen, cork) and one black (hen). (Cuts from "Reliable Poultry Jourual,") $\quad F_{1}$ and $F_{2}$ for color only. 
the female that produces two kinds of eggs; she is heterozygous for a sex factor while the male produces only one kind of spermatozoön.
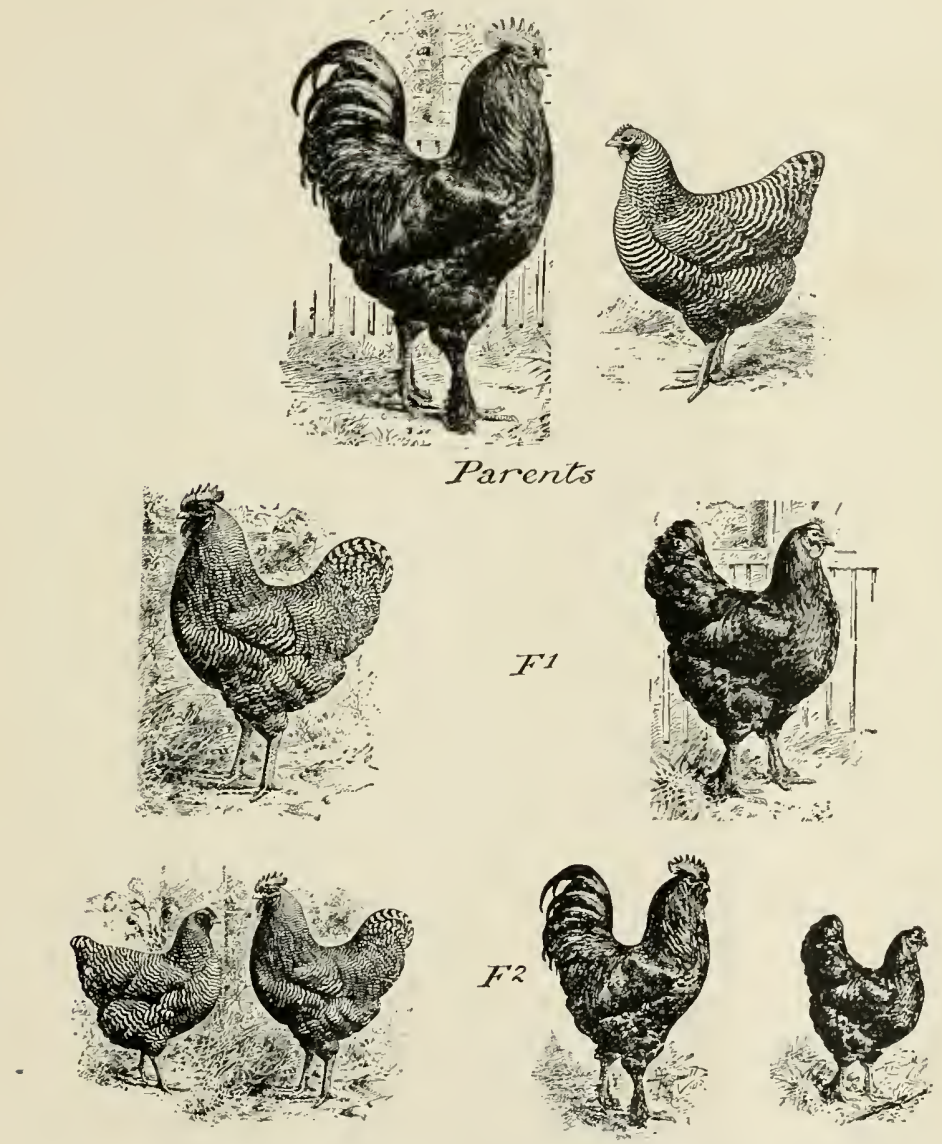

Fig. 41. - Reciprocal cross of Fig. 40. Upper line, black cock and barred hen. Second line, $F_{1}$, barred cock and black hen. Third line, $F_{2}$, barred hen and cock, black rock and hen. (Cuts from "Reliable Poultry Journal.") $\quad F_{1}$ and $F_{2}$ correct for color pattern only. 
We lack here the certain evidence from cytology that we have in the ease of the insects. Indeed, there is some cytologieal evidence to show that the male bird is heterozygous for the sex chromosome. But the evidence does not seem to me well established; while the experimental evidence is definite and has been independently obtained by Bateson, Pearl, Sturtevant, Davenport, Goodale and myself. However this may be, the results show rery clearly that here also sex is connected with an internal mechanism that is concerned with other characters also. This is the mechanism of Mendelian heredity. Whether the chromosomes suffice or do not suffice to explain Mendelian heredity, the fact remains that sex follows the same route taken by characters that are recognized as Mendelian.

To sum up: The facts that we have considered furnish, I believe, demonstrative evidence in favor of the view that sex is regulated by an internal mechanism. The mechanism appears, moreover, to be the same mechanism that regulates the distribution of certain characters that follow Mendel's law of inheritance. 


\section{CHAPTER III}

\section{The Mendelian Principles of Heredity and Their Bearing on Sex}

THE modern study of heredity dates from the year 1865, when Gregor Mendel made his famous discoveries in the garden of the monastery of Brünn. For 35 years his paper, embodying the splendid results of his work, remained unnoticed. It suffered the fate that other fundamental discoveries have sometimes met. In the present case there was no opposition to the principles involved in Mendel's discovery, for Darwin's great work on "Animals and Plants" (1868), that dealt largely with problems of heredity, was widely read and appreciated. True, Mendel's paper was printed in the journal of a little known society - the Natural History Society of Brünn, - but we have documentary evidence that his results were known to one at least of the leading botanists of the time.

It was during these years that the great battle for evolution was being fought. Darwin's famous book on "The Origin of Species" (1859) overshadowed all else. Two systems were in deadly conflict - the long-accepted doctrine of special creation had been challenged. To substitute for that doctrine the theory of evolution seemed to many men of science, and to the world at large, like a revolution in human thought. It was in fact a great revolution. The problems that bore on the 
question of how the higher animals and plants, and man himself, arose from the lower forms secmed the chief goal of biological work and thought. The outcome was to establish the theory of evolution. The circumstantial evidence that was gathered seemed so fully in accord with the theory of evolution that the theory became widely accepted. The acute stage was passed, and biologists found themselves in a position to examine with less haste and heat many other phenomena of the living world equally as important as evolution.

It gradually became clear, when the clouds of controversy had passed, that what I have ventured to call the "circumstantial evidence" on which the theory of evolution so largely rested, would not suffice as a direct proof of evolution. Investigation began to turn once more to that field of observation where Darwin had found his inspiration. The causes of variations and the modes of inheritance of these variations, the very foundations of the theory of evolution, were again studied in the same spirit in which Darwin himself had studied them. The return to Darwin's method rather than to Darwin's opinions marks the beginning of the new era.

In 1900 three botanists were studying the problem of heredity. Each obtained evidence of the sort Mendel had found. Happily, Mendel's paper was remembered. The significance of his discovery now became apparent. De Tries, Correns, and Tschermak brought forward their evidence in the same year (1900). Which of the three first found Mendel cannot be stated, and is of less importance than the fact that they ap- 
-he significance of his work, and realized rade. From this time on the recognition of Mendel's discovery as of fundamental importance was assured. Bateson's translation of his paper made Mendel's work accessible to English biologists, and Bateson's own studies showed that Mendel's principles apply to animals as well as to plants.

\section{THE HEREDITY OF ONE PAIR OF CHARACTERS}

Mendel's discovery is sometimes spoken of as Mendel's Principles of Heredity and sometimes as Mendel's Law. The former phrase gives a better idea perhaps of what Mendel really accomplished, for it is not a little difficult to put his conclusions in the form of a law. Stated concisely his main discovery is this:-in the germ-cells of hybrids there is a free separation of the elements derived from the two parents without regard to which parent supplied them.

An example will make this more obvious. Mendel crossed an edible pea belonging to a race with yellow seeds to a pea belonging to a race with green seeds (Fig. 42). The offspring or first filial generation $\left(F_{1}\right)$ had seeds all of which were yellow. When the plants that bore these seeds were self-fertilized, there were obtained in the next generation, $F_{2}$, both yellow and green peas in the proportion of 3 yellows to 1 green (Fig. 42). This is the well-known Mendelian ratio of $3: 1$.

The clue to the meaning of this ratio was found when the plants of the second generation $\left(F_{2}\right)$ were selfbred. The green peas bred true; but the yellows were of two 
kinds - some produeed yellow and green seeds again in the ratio of $3: 1$; others produced only yellow peas. Now, if the yollows that bred true were counted, it was found that the number was but one-third of all the gellows.

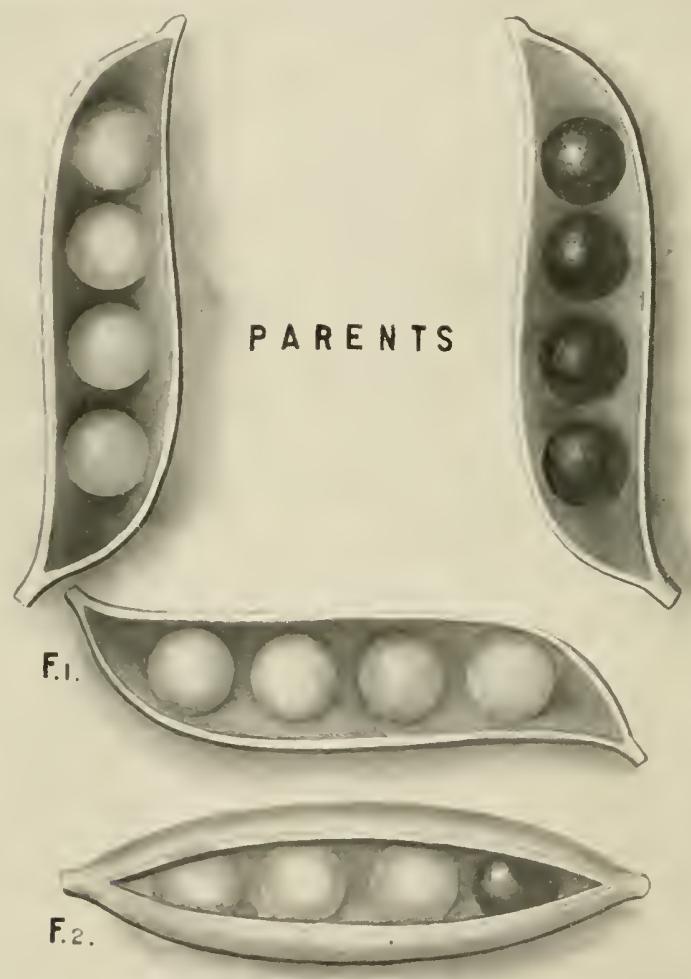

Fir: 42. Illustrating Minuld's cross of yollow (lighter color) and green (lark color) peas. 
In other words, it was shown that the ratio of 3 yellows to 1 green was made up of 1 pure yellow, 2 hybrid yellows, 1 pure green. This gave a clue to the principles that lay behind the observed results.

Mendel's chief claim to fame is found in the discovery of a simple principle by means of which the entire series of events could be explained. He pointed out that if the original parent with yellow $\left(P_{1}\right)$ carried something in the germ that made the seed yellow, and the original parent with green seeds $\left(P_{1}\right)$ carried something that made the seed green, the hybrid should contain both things. If both being present one dominates the other or gives color to the pea, all the peas in the hybrid generation will be of one color - yellow in this case. Mendel assumed that in the germ-cells of these hybrids the two factors that make yellow and green separate, so that half of the germ-cells contain yellow-producing material, and half contain greenproducing material. This is Mendel's principle of separation or segregation. It is supposed "to occur both in the male germ-cells of the hybrid flower, i.e. in the anthers, and also in the ovules. If self-fertilization occurs in such a plant, the following combinations are possible: A yellow-bearing pollen grain may fertilize a "yellow" ovule or it may fertilize a "green" ovule. The chances are equal. If the former occurs, a pure yellow-seeded plant will result; if the latter a hybrid yellow-seeded plant. The possible combinations for the green-producing pollen are as follows: A "green" pollen grain may fertilize a "yellow" ovule, and produce a hybrid, yellow-seeded plant, or it may fertilize a "green" ovule, and produce a green-seeded 
plant. If these meetings are random, the general or average outcome will be: 1 pure yellow, 2 hybrid yellows, and 1 pure green.

It is now apparent why the pure yellows will always breed true, why the yellow-greens will split again into yellow: and greens (or $1: 2: 1$ ), and why the pure greens breed true. By this extremely simple assumption the entire outcome finds a rational explanation.
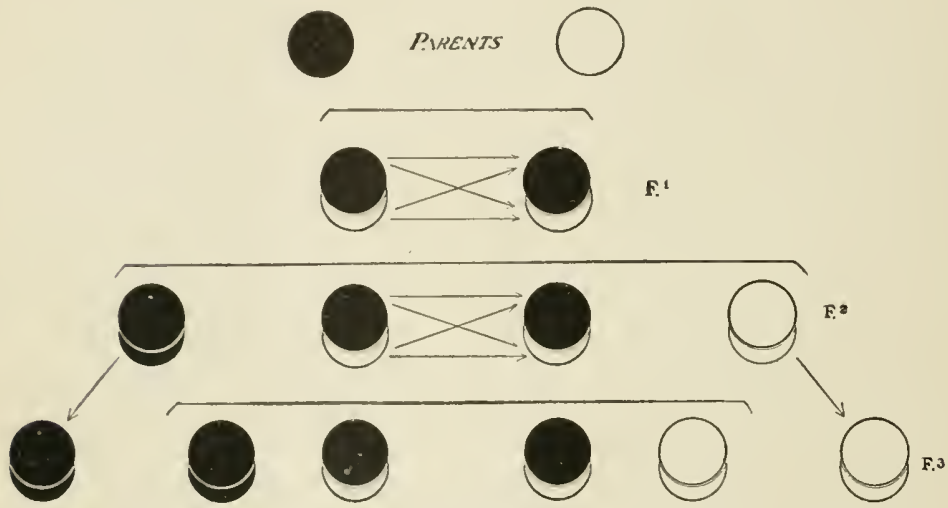

Fis. 43. - " Checker" "lizgram to show segregation and recombination of farturs. In upper line, a black bearing gamete is supposed to unite with a white bearing gramete to give the zygotes shown in $F_{1}$, each of which is heterozygous for black-white here represented as allelomorphs, etc.

The same scheme may be represented by means of the above "checker" diagram (Fig. 43). Black crossed to white gives hybrid black, $F_{1}$, whose germ-cells are black or white after segregation. The possible combination of these on random meeting at the time of fertilization is shown by the arrows in $F_{1}$ and the results are shown in the line marked $F_{2}$. There will be one pure black, to two black-and-whites, to one pure white. 
The first and the last will breed true, if self-fertilized, because they are pure races, while the black-and-whites will give once again, if inbred, the proportions $1: 2: 1$.

A better illustration of Mendel's principles is shown in the case of the white and red Mirabilis jalapa described by Correns. This case is illustrated in Fig. 44,

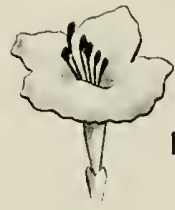

PARENTS
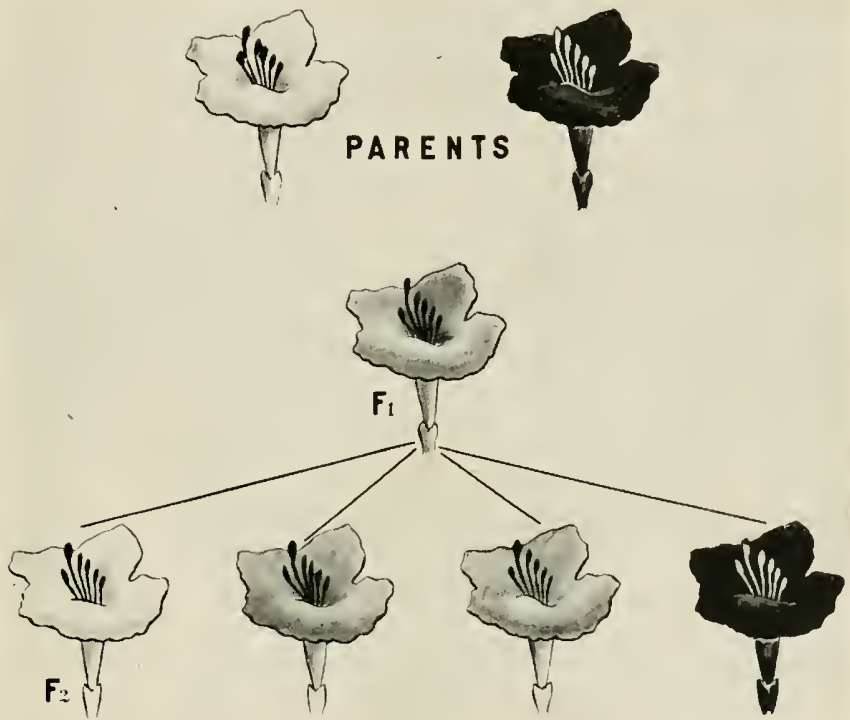

FIg. 44. - Cross between white and red races of Mirabilis Jalapa, giving a pink hybrid in $F_{1}$ which when inbred gives, in $F_{2}, 1$ white, 2 pink, 1 red.

in which the red flower is represented in black and the pink is in gray. The hybrid, $F_{1}$, out of white by red, has pink flowers, i.e. it is intermediate in color. When these pink flowers are self-fertilized they produce 1 white, 2 pink, and 1 red-flowered plant again. The history of the germ-cells is shown in Fig. 45. The germ- 
cell of the $F_{1}$ pink flower segregates into "white" and "red," which by chance combination give the white pink, and red flowers of $F_{2}$. The white and red flowers are pure; the pink heterozygous, i.e. hybrid or mixed. In this case neither red nor white dominates, so that the hybrid can be distinguished from both its parents.
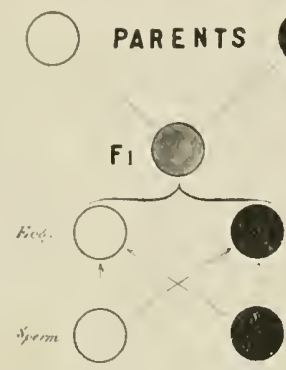

F 2
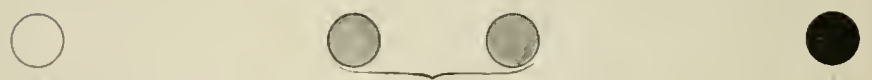

F.3
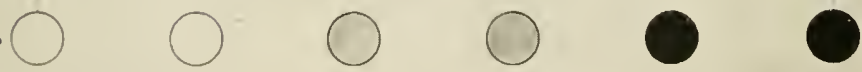

Fu, 45. - Illustrating history of gametes in eross shown in Fig. 44 . A white and a red bearing gamete mite to form the pink zygote in $F_{1}$, whose gumetes, hy segregation, are red and white, which by random combinations give the $F_{2}$ zygotes, ete.

Mendel tested his hypotheses in numerous ways, that I need not now discuss, and found in every case that the results coincided with expectation.

THE IEIE!ITY OF A SEX-LINKED CHARACTER

We are now in a position to see how Mendel's funda- 
mental principle of segregation applies to a certain class of characters that in the last chapter I called "sexlinked" characters.

Diagram 35 (page 64) will recall the mode of transmission of one of these characters, viz. white eyes.

Let us suppose that the determiner for white eyes is carried by the sex chromosome. The white-eyed male has one sex chromosome of this kind. This sex chromosome passes into the female-producing spermatozoön.

Such a spermatozoön fertilizing an egg of the redeyed fly gives a female with two sex chromosomes one capable of producing red, one capable of producing white. The presence of one red-producing chromosome suffices to produce a red-eyed individual.

When the $F_{1}$ female produces her eggs, the two sex chromosomes separate at one of the two maturation divisions. Half of the eggs on an average will contain the "white" sex chromosome, half the "red." There are, then, two classes of eggs.

When the $F_{1}$ male produces his sperm, there are also two classes of sperm - one with the "red" sex chromosome (the female-producing sperm), and one without a sex chromosome (the male-producing sperm).

Chance meeting between eggs and sperm will give the classes of individuals that appear in the second filial generation $\left(F_{2}\right)$. It will be observed that the Mendelian ratio of 3 red to 1 white appears here also. Segregation gives this result.

The explanation that has just been given rests on the assumption that the mechanism that brings about 
the distribution of the red-and the white-producing factors is the same mechanism that is involved in sex detemination. On this assumption we can readily understand that any character that is dependent on the sex chromosomes for its realization will show sex-linked inheritance.

The reciproeal cross (Fig. 36) is equally instructive. If a white-eyed female is mated to a red-eyed male, all the daughters are red-eyed like the father, and all the sons are white-eyed like the mother. When these, $F_{1}$, flies are bred to each other there are produced redeyed females $(25 \%)$, white-eyed females $(25 \%)$, redeyed males $(25 \%)$, and white-eyed males $(25 \%)$. The explanation (Fig. 36; page 65) is in principle the same as for the other cross. If, for instance, we assume that the two $X$ chromosomes in the white-eyed female earry the factors for white, all the eggs will carry one white-producing $X$. The red-eyed male will contain one $X$ chromosome which is red-producing and passes into the female-producing sperm. The other sperm will not contain any sex chromosome, and hence lacks the factors for these eye colors. When the female-producing sperm, that carries the factor for red, fertilizes a "white" egg, the egg will give rise to a female with red eyes, because of the presence of one red-producing chromosome. When the male-producing sperm fertilizes any egg, a white-eyed son will be produced, because the single sex chromosome which he gets from his mother is white-producing.

The production of four elasses of individuals in the second generation works out on the same scheme, as shown in the diagram. The inheritance of white and 
red eyes in these cases is typical of all sex-linked inheritance. In man, for instance, color blindness, so common in males and rare in females, follows the same rules. It appears that hemophilia in man and night-blindness are also examples of sex-linked inheritance. These cases, as already stated, ivere formerly included under the term "sex-limited inheritance," that implies that a character is limited to one sex, but we now know that characters such as these may be transferred to the females, hence the term is misleading. Their chief peculiarity is that in transmission they appear as though linked to the factor for sex contained in the sex chromosome, hence I prefer to speak of them as sex-linked characters.

If our explanation is well founded, each sex-linked character is represented by some substance - some material particle that we call a factor in the sex chromosome. There may be hundreds of such materials present that are essential for the development of sexlinked characters in the organism.

The sex chromosomes must contain, therefore, a large amount of material that has nothing whatever to do with sex determination; for the characters in question are not limited to any particular sex, although in certain combinations they may appear in one sex and not in the other.

What then, have the sex chromosomes to do with sex? The answer is that sex, like any other character, is due to some factor or determiner contained in these chromosomes. It is a differential factor of such a kind that when present in duplex, as when both sex chromosomes are present, it turns the scale so that a female 
is produced-when present in simplex, the result is to produce a male.

In other words, it is not the sex chromosomes as a whole that determine sex, but only a part of these chromosomes. Hence we ean understand how sex is determined when an unequal pair of chromosomes is present, as in lygxus. The smaller chromosome lacks the sex differential, and probably a certain number of other materials, so that sex-linked inheritance is possible here also. Moreover, in a type like oncopeltus, where the two sex chromosomes are alike in size, we infer that they too differ by the sex differential. If all the other factors are present, as their size suggests, sex-linked inheritance of the same kind would not be expected, but the size difference observable by the microscope is obviously too gross to make any such inference eertain. We have come to see that it was a fortunate coincidence only that made possible the discovery of sex determination through the sex chromosomes, because the absence of the sex factor alone in the $Y$ chromosome might have left that chromosome in the male so nearly the same size as the $X$ in the female that their relation to sex might never have been suspected. When, however, one of the sex chromosomes began to lose other materials, it beeame possible to identify it and discover that sex is dependent upon its distribution.

THE HEREUITY OF TWO PAIRS OF CHARACTERS

Mendel observed that his prineiples of heredity apply not only to pairs of characters taken singly, but to cases where two or more pairs of characters are involved. 
An illustration will make this clear. There are races of edible peas in which the surface is round; other races in which the surface is wrinkled. Mendel crossed a pea that produces yellow round seeds with one that produces wrinkled green seeds.

The result of this cross was a plant that produced yellow round peas (Fig. 46). Both yellow and round are therefore dominant characters. When these $F_{1}$ plants were self-fertilized, there were produced plants some of which bore yellow round peas, some yellow wrinkled peas, some green round peas and some green wrinkled peas. These were in the proportion of $9: 3: 3: 1$.

The explanation of the result is as follows: One of the original plants produced germ-cells all of which bore determiners for yellow and for round peas, $Y R$; the other parent produced gametes all of which bore determiners for green and for wrinkled, GW (Fig. 47). Their combination may be represented:

$$
Y R \text { by } G W=Y R G W
$$

The germ-cells of the hybrid plant $Y R G W$ produced germ-cells (eggs and pollen) that have either $Y$ or $G$, and $R$ or $W$. Expressed graphically the pairs, the so-called allelomorphs, are:

$$
\frac{Y}{G} \cdot \quad \cdot \frac{R}{W}
$$

and the only possible combinations are $Y R, Y W, G R$, $G W$. When pollen grains of these four kinds fall on the stigma of the same kind of hybrid plant whose ovules are also of the four kinds the following chance combinations are possible: 


\begin{tabular}{|c|c|c|c|}
\hline$Y R$ & $Y R$ & $Y R$ & $Y R$ \\
$Y R$ & $Y W$ & $G R$ & $G W$ \\
\hline$Y W$ & $Y W$ & $Y W$ & $Y W$ \\
$Y R$ & $Y W$ & $G R$ & $G W$ \\
\hline$G R$ & $G R$ & $G R$ & $G R$ \\
$Y R$ & $Y W$ & $G R$ & $G W$ \\
\hline$G W$ & $G W$ & $G W$ & $G W$ \\
$Y R$ & $Y W$ & $G R$ & $G W$ \\
\hline
\end{tabular}

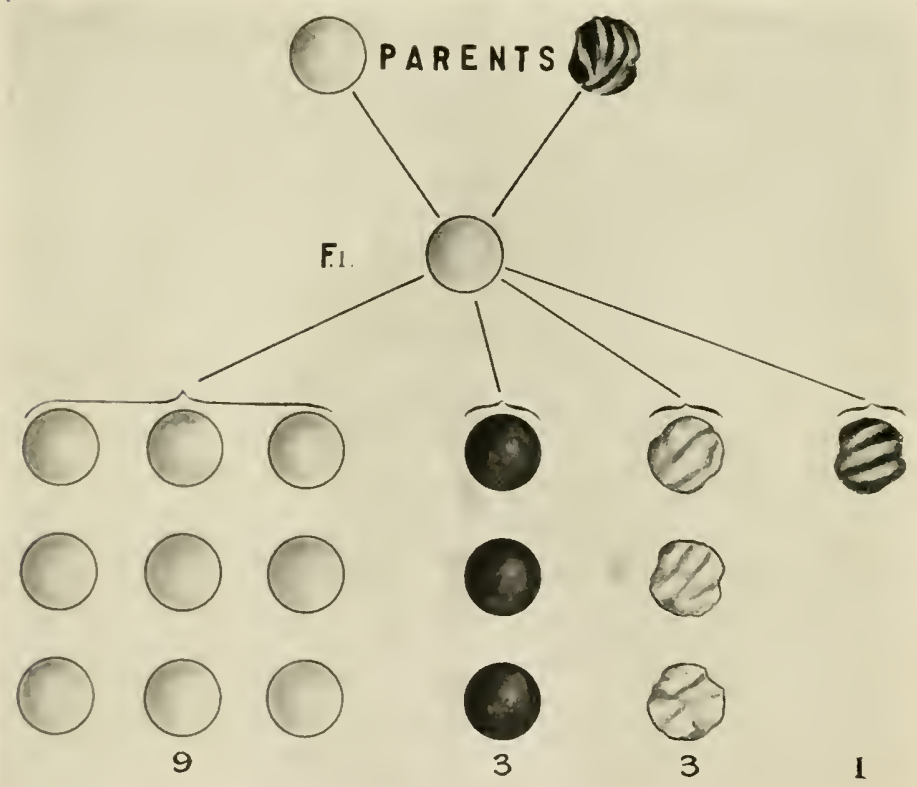

IIG. 46. - Illustrating M endel's cross of yellow-round with green-wrinkled peas. The figures show the peas of $F_{1}$ and $F_{2}$ in the latter in the characteristic ratio of $9: 3: 3: 1$. 
THE MENDELIAN PRINCIPLES OF HEREDITY 87
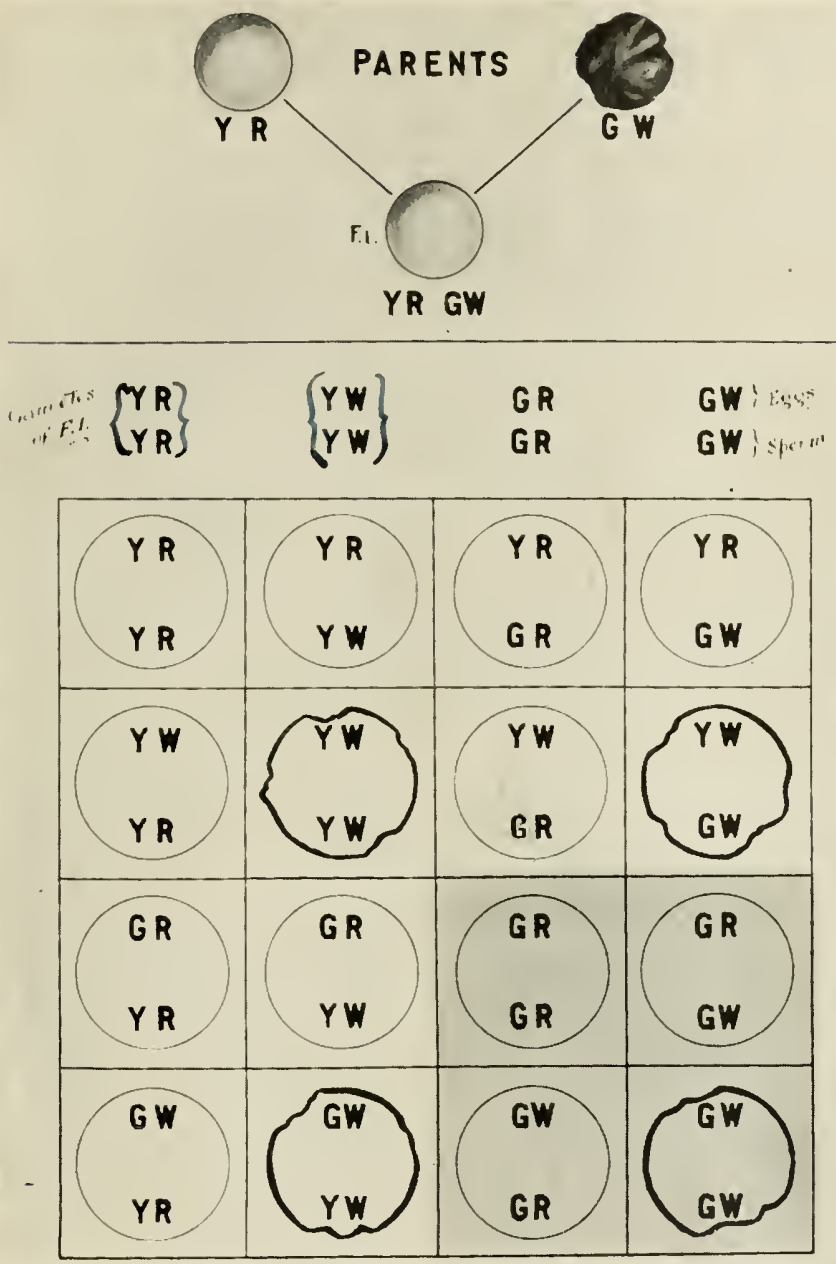

Fig. 47. - Illustrating the history of the gametes of the cross represented in Fig. 46. The composition of the parents $Y R$ and $G W$ and of the $F_{1}$ hybrid $Y R G W$ is given above. The four classes of ovules and of pollen are given in the middle of the figure. These by random combinations give the kinds of zygotes represented in the squares below. 
In each combination in the table the character of the plant is determined by the dominant factors, in this case yellow and round, hence:

$$
9 \text { IR : } 3 Y H: 3 G R: 1 G W
$$

This result works out on the assumption that there is independent assortment of the original determiners that entered into the combination. The determiner for yellow and the determiner for round peas are assumed to act independently and to segregate from green and wrinkled that entered from the other parent. The $9: 3: 3: 1$ ratio rests on this assumption and is the actual ratio realized whenever two pairs of characters frecly Mendelize.

\section{THE HEREDITY OF TWO SEX-LINKED CHARACTERS}

The inheritance of two sex-linked characters may be illustrated by an imaginary case in which the linkage of the factors to each other is ignored. Then the same case may be given in which the actual results obtained, involving linkage, are discussed.

The factors in the fruit fly for gray color, $G$, and for red eye, $R$, are both sex-linked, i.e. contained in the $X$ chromosome. Their allelomorphs, viz., yellow color, $Y$, and white eye, $W$, are also sex-linked. When a gray red-eyed female is mated to a yellow white-eyed male, the daughters and sons are gray-red, GR. Their origin is indicated in the following scheme:

$$
\begin{aligned}
& \text { Ciray-red \& } \\
& G R X-G R \quad X \\
& \text { Yellow-white ठ } \\
& F_{1} \\
& Y \text { IV } \mathrm{X} \\
& \left\{\begin{array}{lllllll}
G & R & X & Y & W & X & \text { Gray-red \& } \\
G & R & X & \cdot & \cdot & \cdot & \text { Gray-red o }
\end{array}\right.
\end{aligned}
$$


In the gray-red $F_{1}$ female there will be the possibility of interchange of the $G$ and $Y$, and of the $W$ and $R$ factors, so that gametes of four kinds will be formed, namely, $G R X-G W X-Y R X-Y W X$. For the moment we may assume free interchange of factors; and therefore these four classes of eggs will exist in equal numbers.

In the gray-red $F_{1}$ male there is but one $X$ chromosome that contains the factors $G$ and $R$. There will be then only one kind of female-producing sperm, viz., GRX; and one kind of male-producing sperm, the latter containing no $X$, and therefore none of the factors in question. The chance meeting of these two classes of sperm and the four classes of eggs gives the following results :

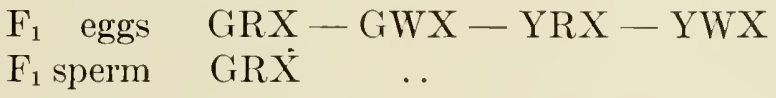

Females.

Males.

GRXGRX gray-red. - GRX gray-red. GRXGWX gray-red. - GWX gray-white. GRXYRX gray-red. - YRX yellow-red.

GRXYWX gray-red. - YWX yellow-white.

All the females are gray with red eyes, since these are the dominant characters. There are four classes of males. These males give a measure of the kinds of eggs produced by the females, since the male-producing sperms, having no sex chromosomes, do not affect the sex-linked characters derived through the sex chromosome of the $F_{1}$ female. The expected proportion is therefore: 


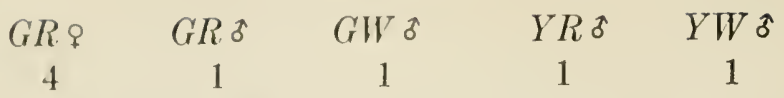

These results are illustrated by means of Fig. 48, in which the yellow color of the fly is indicated by stippling the body and wings, and the red eyes by black. The $\mathrm{X}$ chromosome is also marked and colored
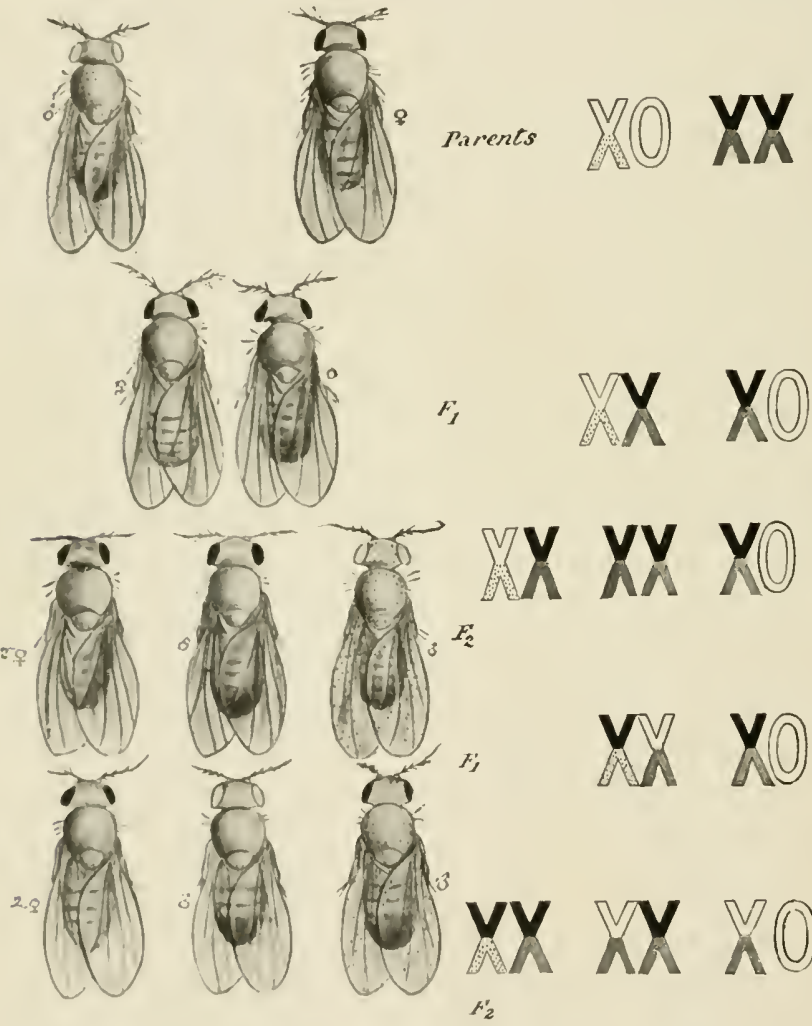

Fig. 4S. - Inheritance of vellow-white ( $\delta$ ) and gray-red ( $q$ ) of Drosophila. In $F_{1}$ both sexes are gray-red. In $\mathrm{F}_{2}$ are produced $4 G R$ -

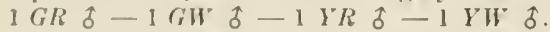


in the same way as the flies; thus the two $X$ 's in the red-eyed gray female are half black (for red) and half gray; the single $X$ in the white-eyed yellow male is half white and half stippled.

In the $F_{1}$ generation the $X$ chromosomes are first represented as they came in (second line), i.e. with their original composition. The next line gives the three large classes that result, viz., $2 G R$ 으-1 $G R$ 。 $-1 Y W \delta$. But if free interchange takes place in the female, some of the eggs will have chromosomes like those in the fourth line, viz. $Y R$ and $G W$. Such eggs will give the classes represented in the lowest line,

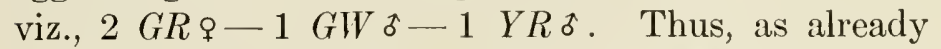
explained, there results one kind of female and four kinds of males.

I said that the proportion $4: 1: 1: 1: 1$ is the ideal result in the cross between the yellow-white and the gray-red flies. This ideal scheme is not realized because of a complication that comes in. The complication is due to linkage or a tendency to hang together of the characters that go in together. We must now take up this question. It is one of the most modern developments of the Mendelian theory - one that at first seemed to throw doubt on the fundamental idea of random assortment that gives Mendel's proportion $9: 3: 3: 1$. But I believe we can now offer a reasonable explanation, which shows that we have to do here with an extension of Mendelism that in no sense invalidates Mendel's principle of segregation. It not only extends that principle, as I have said, but gives us an opportunity to analyze the constitution of the germ-plasm in a way scarcely dreamed of two or three years ago. 
The actual numbers obtained in the GR by $Y W$ cross are as follows. These are the figures that Dexter has obtained:

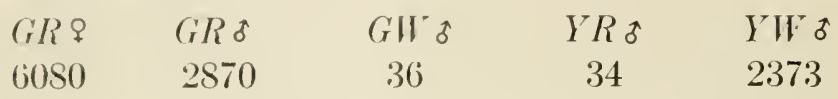

The apparent discrepancy between the expected and the realized ratios is due to the linkage of the factors that went into the cross. For instance, the factors for gray and red that went in with one chromosome are linked; likewise their allelomorphs, yellow and white. As shown by the analysis, the $F_{1}$ female offspring will have two sex chromosomes, one of each sort one from the father, the other from the mother. But the male will have but one sex chromosome derived from the mother.

If in the germ-cells of the $F_{1}$ females there were random assortment of the allelomorphs in the sex chromosomes, the ideal ratio of $4: 1: 1: 1: 1$ would, as has been said, be realized. But if the red and gray factors tend to remain together since they go in together in the one chromosome, and the yellow and white in the other chromosome tend to remain together, and if the chances are about 84 to 1 that the factors that enter together remain together, the realized ratio of $170: \$ 4: 1: 1: \$ 4$ will be found.

Experiments show that, for these two factors, the chances are about 84 to 1 that the factors that go in together remain together; hence the departure from Mendel's ratios for these two pairs of characters. We may make a general statement or hypothesis that covers eases like these, and in fact all cases where 
linkage occurs: viz. that when factors lie in different chromosomes they freely assort and give the Mendelian expectation; but when factors lie in the same chromosome, they may be said to be linked and they give departures from the Mendelian ratios. The extent to which they depart from expectation will vary with different factors. I have suggested that the departures may be interpreted as the distance between the factors in question.

\section{A THEORY OF LINKAGE}

In order to understand more fully what is meant by linkage on the interpretation that I have here followed, it will be necessary to consider certain changes that take place in synapsis. The sex chromosomes

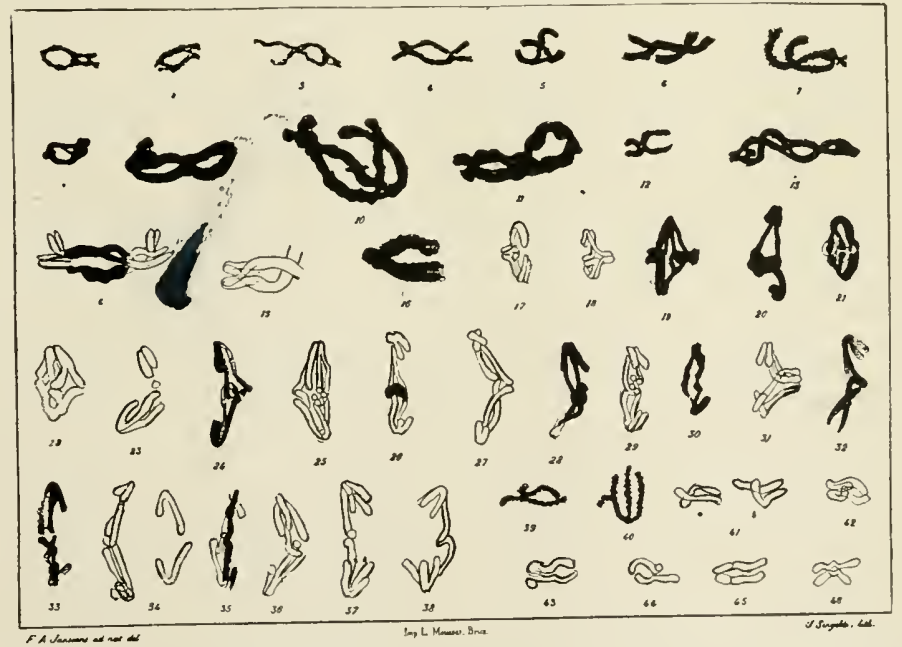

Fig. 49. - Illustrating chiasma-type theory. 1 and 2, from Triton cristatus, 3-46, chromosomes of Batracoseps attenuatus. Note especially the chiasma shown in 13 . (After Janssens). 
(when two are present as in the female), like all other chromosomes, unite in pairs at the synaptic period. A recognized method of uniting is for like chromosomes to come to lie side by side.

Before they separate, as they do at one of the two maturation divisions, each chromosome may be seen to be split throughout the length. Thus there are

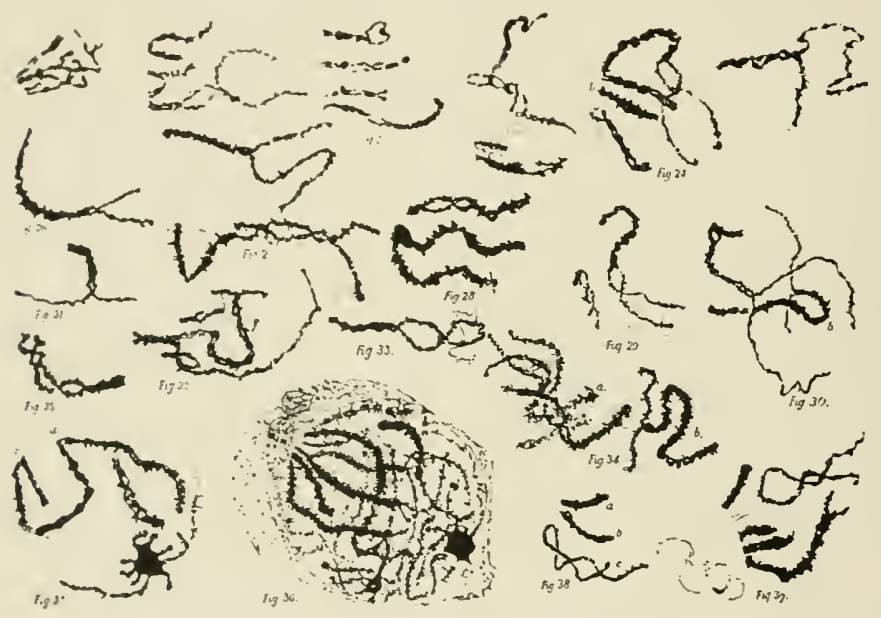

Fig. $50 .-$ ('hromatin filaments in the amphitene stage from spermatoeytes of Batracoseps. (After Janssens.)

formed four parallel strands each equiralent to a chromosome - the tetrad group. At this time Janssens has found that cross unions between the strands are sometimes present (Fig. 49). In consequence a strand is made up of a part of one chromosome and a part of another. Whether this cross union can be reforred to an earlier stage - at the time when the two like chromosomes come together, when they can be 
seen to twist around each other (Fig. 50) - is not certain; but the fact of the existence of cross connections is the important point. A consequence of this condition is that the chromosomes that come out of the tetrad may represent different combinations of those that united to form the group. On the basis of this observation we can explain the results of associated inheritance. For, to the same extent to which the chromosomes that unite remain intact, the factors are linked, and to the extent to which crossings occur the exchange of factors takes place. On the basis of the assumption of the linear arrangement of the factors in the chromosomes the distance apart of the factors is a matter of importance. If two factors lie near together, the chance of a break occurring between them is small in proportion to their nearness. We have found that some factors cross over not once in a hundred times. I interpret this to mean that they lie very near together in the chromosome.

Other factors cross over to various degrees; in the extreme cases the chance is one to one that they cross over. In such cases the factors lie far apart - perhaps near the ends of the chromosome.

The strongest evidence in favor of this view is found when the constant relation of the factors to each other is considered. If, for instance, we know the distance from $A$ to $B$ (calculated on the basis of crossing over) and from $B$ to $C$, we can predict what $A$ and $C$ will do when they are brought into the hybrid from two parents. If a fourth factor, $D$, is discovered and its distance from $A$ is made out, we can predict before the experiment is made what will take place when $D$ and 
$B$ or $D$ and $C$ are combined. 'The prediction has been fulfilled so many times and in so many ways that we feel some assurance that we have discovered here a working hypothesis of considerable interest. If the hypothesis becomes established, it will enable us to analyze the structure of the chromosomes themselves in the sense that we can determine the relative location of factors in the chromosomes. If, as seems not improbable, the chromosomes are the most important element in Mendelian inheritance, the determination of the linear series of factors contained in them becomes a matter of great theoretical interest; for we gain further insight into the composition of the material on which heredity itself depends.

There is a corollary to this explanation of crossing over that has a very direct bearing on the results. In the male there is only one $X$ chromosome present. Hence crossing over is impossible. The experimental results show that no crossing over takes place for sex-linked factors in the male of drosophila.

Other factors, however, lie in other chromosomes. In these cases the chromosomes exist in pairs in the male as well as in the female. Does crossing over occur here in both sexes? Let me illustrate this by an example. In drosophila the factor for black body color and the factor that gives vestigial wings lie in the same chromosome, which we may call the second chromosome. If a black, long-winged female is crossed with a gray vestigial male, all the offspring will be gray in color and have long wings, since these are the dominant characters. If these $F_{1}$ flies are inbred, the following classes will appear: 
THE MENDELIAN PRINCIPLES OF HEREDITY 97
Gray Long
Black Long
1146
Gray Vestigial
2316

It will be noted that there are no black vestigial flies. Their absence can be explained on the assumption that no crossing over in the male, between the factors in the second chromosome, has taken place.

But if another generation $\left(F_{3}\right)$ is raised, some black vestigial flies appear. With these, it is possible to test the hypothesis just stated. If, for instance, some of the long, gray, $F_{1}$ females are mated to black vestigial males, the following classes are produced:

$\begin{array}{cccc}G L & B L & G V & B V \\ 578 & 1413 & 1117 & 307\end{array}$

The results are explicable on the view that crossing over takes place in the germ-cell of the $F_{1}$ female, and that the chance that such will occur is as 1 to 3 .

But if the long-winged, gray, $F_{1}$ males are crossed to black vestigial females, only the following classes are produced:

$\begin{array}{ll}B L & G V \\ 992 & 721\end{array}$

These results are in accord with the hypothesis that no crossing over takes place between the second chromosomes in the $F_{1}$ male. Why crossing over should occur in the $F_{1}$ female, and not in the $F_{1}$ male, we do not know at present; and until the synaptic stages in the males and females have been carefully studied, we must wait for an answer to the question. 


\section{THREE SEX-LINKED FACTORS}

When three sex-linked factors exist in the same chromosomes, we have a method by means of which the "crossing-over" hypothesis may be put to a further test. Sturterant has recently worked over the evidence
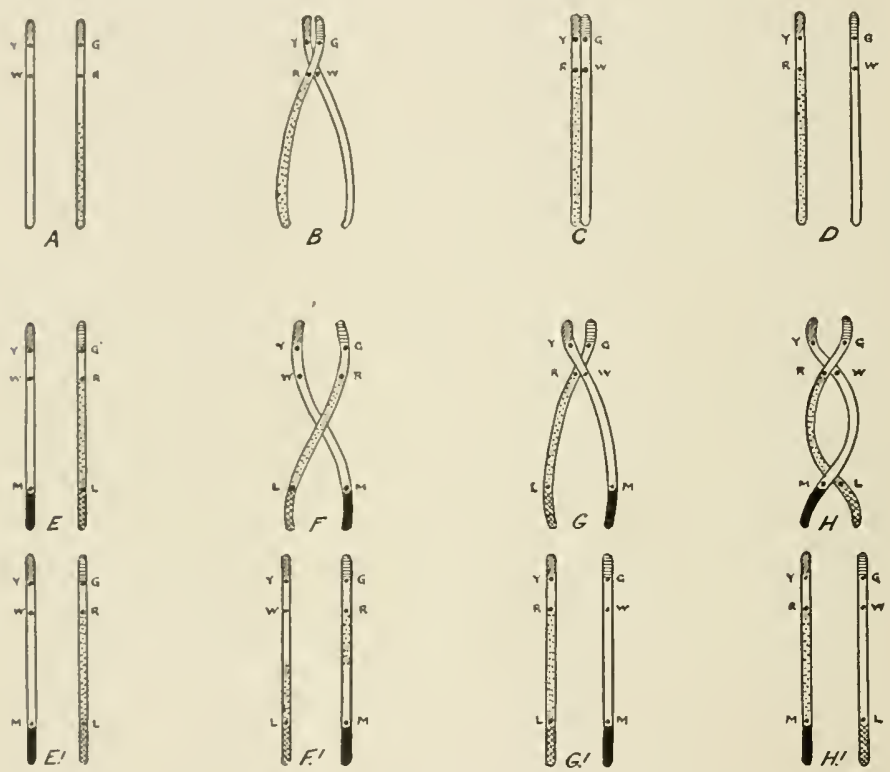

FIG. 51. - A-D, IIF and $G R$ that enter (A), crossing over to give $Y R$ and $G W$ as secn in $D$. $E-E_{1}$, no crossing over. $F-F_{1}$, crossing between $W M$ and $R L$. $G-G_{H_{1}}$, crossing between $Y W$ and $G R$. $H-H_{1}$, double crossing over of $Y W M$ and $G R L$, to give $Y R . M$ and $G W L$.

for a case of this kind. He analyzed the data of the cross between a fly having gray color, red eyes, long wings, mated to a fly with yellow color, white eyes, and miniature wings. The relative location of these three factors is shown in the above diagram (Fig. 51, 
$E, F, G, H)$. The $F_{1}$ flies gave the expected results. These inbred gave the following $F_{2}$ significant classes : ${ }^{1}$

\begin{tabular}{ll|cc||cc|cc} 
GRL & YWM & GWM & YRL & GRM & YWL & GWL & YRM \\
2089 & 1361 & 17 & 23 & 887 & 817 & 5 & 0
\end{tabular}

In these results the classes where single crossing over is shown are $G W M(17)$ and $Y R L$ (23) (Fig. 51, G, $G^{\prime}$ ) and $G R M$ (887) and $Y W L$ (817) (Fig. 51, $F, F^{\prime}$ ). There are two classes, namely, GWL (5) and $Y R M$ (0) (Fig. 51, $H, H^{\prime}$ ), which involve double crossing over. In order that they may take place, the two sex chromosomes in the female must break twice and reunite between the factors involved, as shown in the diagram. Such a redistribution of the parts of the homologous chromosomes would be expected to occur rarely, and the small number of double crossovers recorded in the results is in accord with this expectation.

In these questions of linkage we have considered some of the most recent and difficult questions in the modern study of heredity. We owe to Bateson and his collaborators the discovery of this new departure. In plants they have recorded several cases of linkage, and other authors, notably Correns, Baur, Emerson, East, and Trow have described further cases of the same kind. Bateson has offered an interpretation that is quite different from the one that I have here followed. His view rests on the assumption that separation of factors may take place at different times, or periods, in the development of the germinal tissues.

${ }^{1}$ The classes omitted are those that do not bear on the question in hand. 
In a word, he assumes that assortment is not confined to the final stages in the ripening of the germ-cells, but may take place at any time in the germ-tract. It seems to me, however, if the results can be brought into line with the known changes that take place in the germ-cells at the time when the maternal and - paternal chromosome unite, that we have not only a simpler method of dealing with these questions, but it is one that rests on a mechanism that can be studied by actual observation. Moreover, on purely a priori grounds the assumptions that I have made seem much simpler and more tangible than the assumptions of "reduplication" to which Bateson resorts.

But leaving these more theoretical matters aside, the evidence from a study of sex-linked characters shows in the clearest manner that they, while following Mendel's principle of segregation, are also undeniably associated with the mechanism of sex. There is little doubt that sex itself is inherited in much the same way, since we can explain both in terms of the same mechanism. This mechanism is the behavior of the chromosomes at the time of the formation of the germcells. 


\section{CHAPTER IV}

Secondary Sexual Characters and their Relation to Darwin's Theory of Sexual Selection

In his "Origin of Species" Darwin has defined Sexual Selection as depending "on a struggle between the individuals of one sex, generally the males, for the possession of the other sex. The result is not death to the unsuccessful competitor, but few or no offspring. Sexual selection is, therefore, less rigorous than natural selection. Generally, the most vigorous males, those which are best fitted for their places in nature, will leave most progeny. But in many cases, victory depends not so much on general vigor, as on having special weapons, confined to the male sex. A hornless stag or spurless cock would have a poor chance of leaving numerous offspring. Sexual selection, by always allowing the victor to breed, might surely give indomitable courage, length to the spur, and strength to the wing to strike in the spurred leg, in nearly the same manner as does the brutal cock-fighter by the careful selection of his best cocks."

Darwin continues: "Amongst birds, the contest is often of a more peaceful character. All those who have attended to the subject, believe that there is the severest rivalry between the males of many species to attract, by singing, the females. The rock-thrush of Guiana, birds of paradise, and some others, con- 
gregate, and successive males display, with the most elaborate care, and show off in the best manner, their gorgeous plumage; they likewise perform strange antics before the females, which, standing by as spectators, at last choose the most attractive partuer."

Here we have two different pictures, each of which attempts to give an account of how certain differences between the sexes have arisen - differences that we ('all "secondiry sexual characters."

On the one hand we deal with a contest between the males; on the other with choice by the female. 'The modus operandi is also different. After battle the successful male takes his pick of the females. If the scheme is to work, he must choose one that will leave the most offspring.

On the other hand, we have the tourney of love. The males "show off"; the females stand by spellbound and "at last choose the most attractive partner."

Now, concerning this display of the males, I beg leave to quote a paragraph from Wallace's "Natural Selection and Tropical Nature" :

"It is a well-known fact that when male birds possess any unusual ornaments, they take such positions or perform such evolutions as to exhibit them to the best advantage while endeavoring to attract or charm the females, or in rivalry with other males. It is therefore probable that the wonderfully varied decorations of humming-birds, whether burnished breastshiclds, resplendent tail, crested head, or glittering back, are thus exhibited; but ahmost the only actual obscrvation of this kind is that of Mr. Belt, who describes how two males of the Florisuga mellivora displayed 
their ornaments before a female bird. One would shoot up like a rocket, then, suddenly expanding the snow-white tail like an inverted parachute, slowly descend in front of her, turning around gradually to show off both back and front. The expanded white tail covered more space than all the rest of the bird, and was evidently the grand feature of the performance. Whilst one was descending the other would shoot up and come slowly down expanded."

There is just a suspicion in my mind that these males were otherwise engaged, for while I know nothing about the habits of these humming birds I find on the next page of "Tropical Nature" this statement:

"Mr. Gosse also remarks: 'All the hummingbirds have more or less the habit, when in flight, of pausing in the air and throwing the body and tail into rapid and odd contortions. This is most observable in Polytmus, from the effect that such motions have on the long feathers of the tail. That the object of these quick turns is the capture of insects, I am sure, having watched one thus engaged.'"

If what I have just said implies that I take a lighthearted or even facetious attitude toward Darwin's theory, I trust that my position will not be misunderstood. Darwin brought together in his book on the "Descent of Man" a mass of interesting observations for which he suggested a new theory. No one can read his wonderful book without the keenest interest, or leave it without high admiration for the thoroughness with which the subject is treated ; for the ingenuity and skill with which the theory is applied to the facts, and, above all, admiration for the moderation, modesty, 
and honesty with which objections to the theory are ronsidered.

I will let no one admire Darwin more than I admire Dirwin. But while affection and respect and honor are the finest fruits of our relation to each other, we cannot let our admiration for the man and an ever ready recognition of what he has done for you and for me prejudice us one whit in favor of any scientific theory that he proposes. For in Science there is no authority! We should of course give serious consideration to any theory proposed by a man of such wide experience and trained judgment as Darwin ; but he himself, who broke all the traditions of his race, would be the first to disclaim the value of evidence accepted on authority.

From the definition of sexual selection with which we started it may be said that Competition and Courtship stand for the two ways in which Darwin supposes the secondary sexual characters to have arisen.

Competition amongst the males is only a form of natural selection, as Darwin himself recognized (if we leave out of account the further assumption that the victor chooses his spoils). We may dismiss this side of the problem as belonging to the larger field of natural selection, and give our attention mainly to those secondary sexual characters that Darwin supposes to have arisen by the female choosing the more ornamented suitor.

I shall first bring forward some of the more striking examples of secondary sexual characters in the animal kinglom. These characters are confined almost exclusively to three great groups of animals - Insects, 
Spiders, and Vertebrates. There are a few scattered instances found in other groups, but they are rare. In the lowest groups they are entirely absent, and are
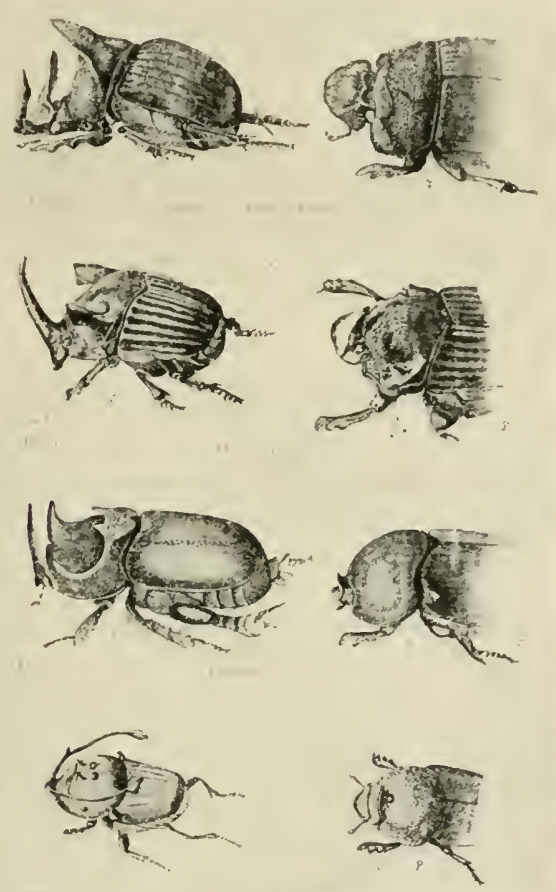

FIG. 52. - Four species of beetles in which the male (to the left) has horns which are absent in the female (to the right). (After Darwin.)

not found at all in plants; or rather, if characteristic differences exist in plants, they are not called by this name - for plants cannot see or move and therefore cannot court each other. 
In fact, sight in the sense of forming visual pictures can occur only when eyes are well developed. This
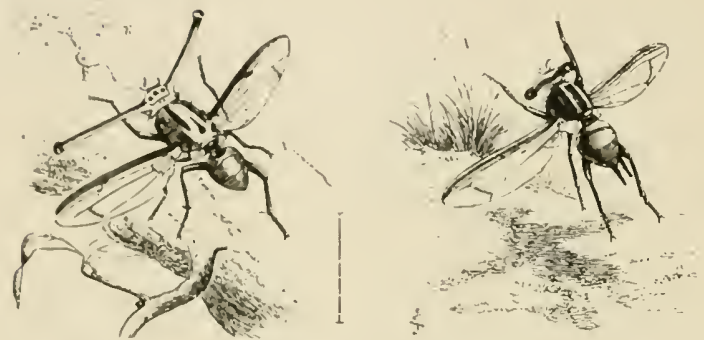

FIc. 53. - Male (to left) with long eve stalks and female (to right) of a fly, Achia longividens. (After Wood.)

may be taken to score a point in favor of Darwin's hypothesis.

In the group of insects the most noticeable differences occur in the butterflies and moths, and in flies. A few cases are found in the beetles and bugs. The male cicada's shrill call is supposed to attract the
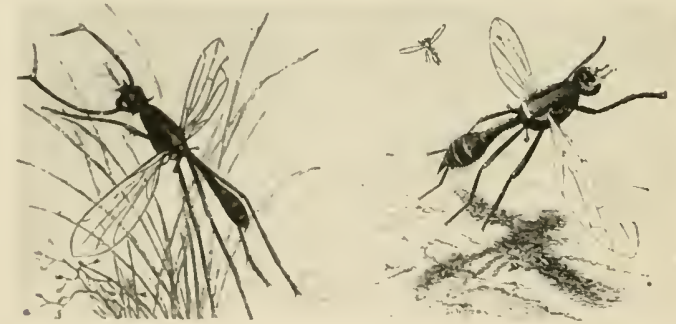

Fig. 54. - Male to left with horns and female to right without horns of a fly, Elaphomyia. (After Wood.)

females. The males of certain beetles have horns the female lacks them (Fig. 52).

In a genus of flies the eyes are stalked, and the 
eyes of the male have stalks longer than those of the female (Fig. 53). In another genus of flies there are horns on the head like the antlers of the stag (Fig. 54).

In the spiders the adult males are sometimes very small in comparison with the females (Fig. 55). The size difference may be regarded as a secondary sexual

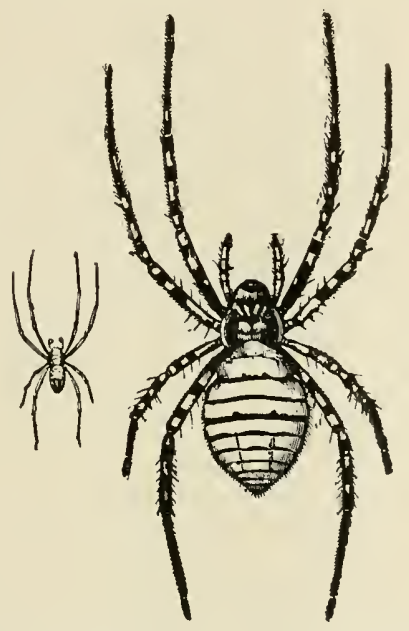

Fig. 55. - Male (to left) and female (to right) of a spider, Argiope aurelia. (From "Cambridge Natural History.")

character. Darwin points out, since the male is sometimes devoured by the female (if his attentions are not desired), that his small size may be an adaptation in order that he may more readily escape. But the point may be raised as to whether he is small in order to escape; or whether he is eaten because he is small.

In one of our native spiders, Habrocestum splendida, the adult males and females are conspicuously different 
in eolor - the male more highly colored than the female. In another native species, Maevia vittata, there are two kinds of males, both colored differently from the female.

Passing over the groups of fishes and reptiles in which some striking cases of differences between the sexes occur, we come to the birds, where we find the best examples of secondary sexual characters.

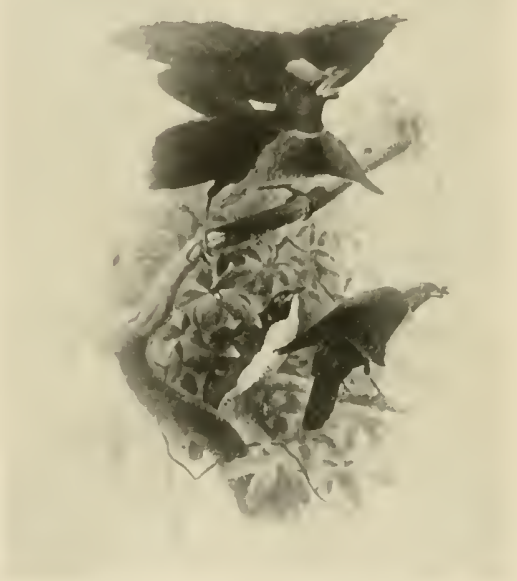

Fic. 56. - Superb bird of paradise. (After Elliot.)

In the white-booted humming bird (Fig. 14) two of the tail feathers of the male are drawn out, their shafts denuded of the vanes except at the tip where the feather ends in a broad expansion.

In the great bird of paradise, of the Aru Islands (Fig. 13), the male has wonderful plumes arising from the sides that can be erected to produce a gorgeous display. 
The female is modestly clothed. In the male of the superb bird of paradise (Fig. 56), the mantle behind the neck, when erected, forms a striking ornament; and on the breast there is a brilliant metallic shield.

In the six-shafted bird of paradise (Fig. 57) the male has on its head six feathers with wiry shafts,

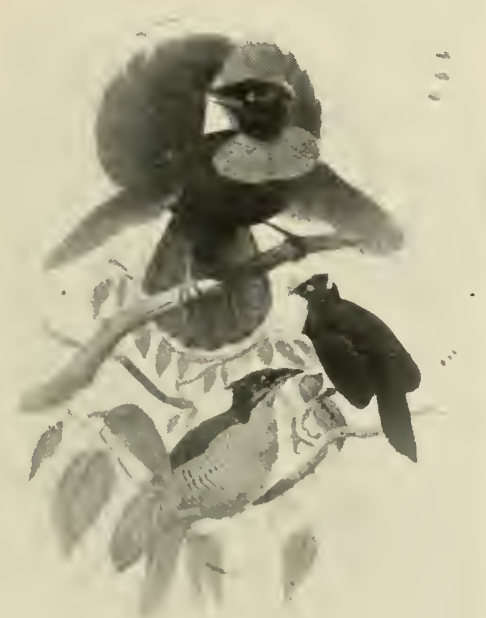

FIG. 57. - Six-shafted bird of paradise. (After Elliot.)

ornaments that occur in no other birds. In the king bird of paradise there are remarkable fans at the sides of the body of the male that can be expanded. The feathers of the fan are emerald-tipped. The two middle feathers of the tail are drawn out into "wires" with a green web at one side of the tip.

In mammals, secondary sexual differences are very 
common, although startling differenees in eolor are rather rare. In the male the coat of fur is often darker than that of the female.

In many deer the antlers are present in the male alone. In Steller's sea-lion the male is much larger and stronger than the female. In a race of the Asiatic elephant the male has tusks much larger than those of the female.

If we fix our attention exclusively on these remarkable

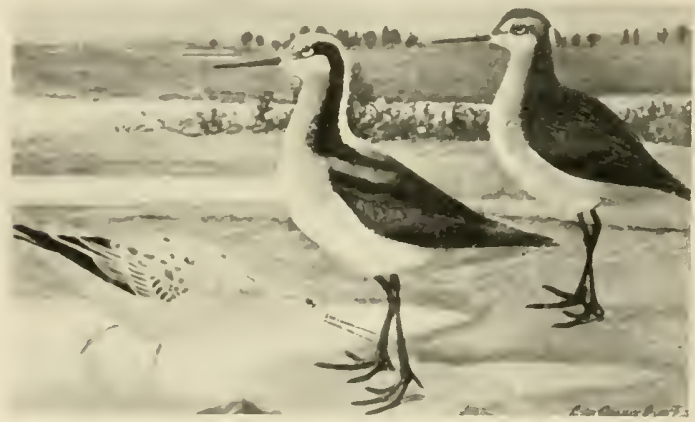

Furi, 5s. - Wilson's phalarope, female (in center), male (to right and behind). A birl in winter plumage is at the left. (Fron Eaton, "Birds of New York.")

eases where differences between the sexes exist, we get a one-sided impression of the development of ornamentation and color differences in animals. We must not forget that in many cases males and females are both highly colored and exactly alike. We forget the parrots, the cockatoos, the kingfishers, the crowned pigeons, toucans, lories, and some of the starlings; the "brilliant todies" and the "sluggish jacamars" whose brilliant metallie golden-green breasts riva? 
those of the humming-birds; we forget the zebras, the leopards; the iridescent interiors of the shells of many mollusks; the bright reds and purples of starfish, worms, corals, sea anemones, the red, yellow, and green sponges, and the kaleidoscopic effect of the microscopic radiolarians ; - a brilliant array of color.

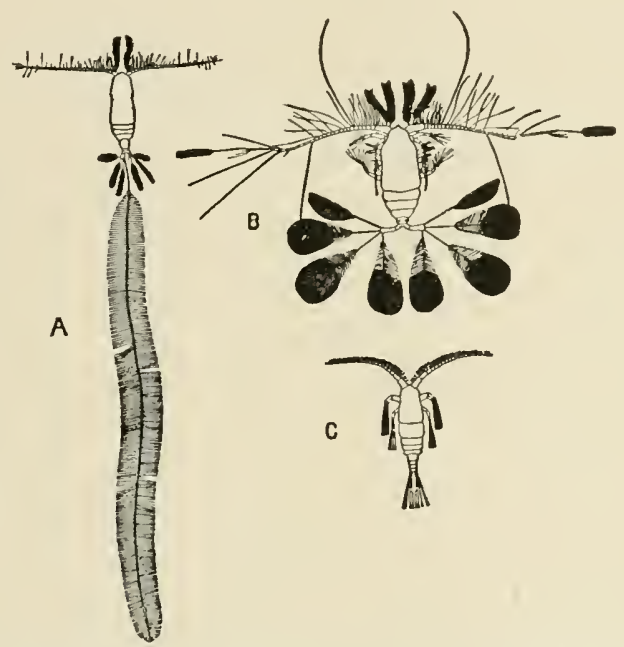

Fig. 59. - (A), female of a copepod, Calocalanus plumulosus. (B), a female of Calocalanus parvus. (C), male of last. (After Giesbrecht.)

In the egret both males and females have remarkable nuptial plumes, which, had they been present in one sex alone, would have been classified as secondary sexual characters. It does not appear that selection had anything to do with their creation.

Our common screech owl exists in two colored types sharply separated. No one is likely to ascribe these differences to sexual selection, yet if one sex had been 
red and the other gray, the difference would have been put down to such selection. There are also eases like the phislarope, shown in Fig. 5S, where the female is more highly ornamented than the male. In fact, for these cases, Darwin supposed that the males select the females; and in support of this view he points out that the females are more active, while the male conccrns himself with the brooding of the eggs. In some of the marine copepods female ornamentation is carried to even a higher point. In Calocalanus plumosus the female has one of the tail seta drawn out into a long feather-like structure (Fig. 59). In another species, $C$. para, all eight setre of the tail of the female are feather-like (Fig. 59, B), while the male (Fig. 59, C) lacks entirely these "ornaments."

In some butterflies also, two, three, or more types of females are known, but only one male type. I shall have occasion later to consider this case.

\section{COURTSHIP}

The theory of sexual selection hinges in the first place on whether the female chooses amongst her suitors.

It has been objected that the theory is anthropomorphic - it ascribes to beetles, butterflies, and birds the highly developed esthetic sense of man. It has been objected that the theory leaves unexplained the development of this esthetic sense itself, for unless the female lept in alvance of the male it is not self-evident why she should go on selecting the more highly ornamented. If she has advanced csthetically, what has brought it about? In answer to this last question 
Allen suggests that if the word conspicuousness is substituted for the word beauty, the objection may to some extent be met. The more conspicuous male would be more likely to attract attention and be selected.

It has been pointed out that there is more than a suspicion that the contests of the males for the females are sham affairs. They are like certain duels. There is seldom any one hurt. There are very few records of injured males, but many accounts of tremendous battles. And he who fights and runs away will live to mate another day.

It is clear, I think, that the case against the theory must rest its claims on actual evidence rather than on arguments or poetry pro or con. Darwin admitted that the evidence was meager. Since his time something more has been done. Let us consider some of this new evidence.

It will be conceded, I think, that Alfred Wallace, through his wide experience with animals in their native haunts, is in a position to give weighty evidence concerning the behavior of animals. He was with Darwin a co-discoverer of the theory of Natural Selection and cannot be supposed to be prejudiced against the selection principle. Yet Wallace has from the beginning strongly opposed the theory of sexual selection. Let me quote him:

Referring to Darwin's theory of Sexual Selection -

"I have long held this portion of Darwin's theory to be erroneous - and have held that the primary cause of sexual diversity of color was the need of protection, repressing in the female those bright colors which are normally produced in both sexes by general laws." 
Again, Wallace says: "To conscious sexual selection - that is, the actual choice by the females of the more brilliantly colored males or the rejection of those lesis gaily colored - I believe very little if any effect is directly due. It is undoubtedly proved that in birds the females do sometimes exert a choice; but the eridence of this fact, collected by $\mathrm{Mr}$. Darwin ('Descent of Man,' chap. xiv), does not prove that color detcrmines that choice, while much of the strongest evidence is directly opposed to this view."

Again, Wallace says: "Amid the copious mass of facts and opinions collected by Mr. Darwin as to the display of color and ornaments by the male birds, there is a total absence of any evidence that the females, as a rule, admire or even notice this display. The hen, the turkey, and the peafowl go on feeding, while the male is displaying his finery; and there is reason to believe that it is his persistency and energy rather than his beauty which wins the day.'

Hudson, who has studied the habits of birds in the field, asks some very pertinent questions in connection with their performances of different kinds. "What relation to the passion of love and to the business of courtship have these dancing and rocal performances in nine cases out of ten? In such cases, for instance, as that of the scissor-tail tyrant-bird, and its pyrotechnie displays, when a number of couples leave their nests containing eggs and young to join in a wild aërial dance; the mad exhibition of grouped wings; the triplet dances of the spur-winged lapwing, to perform which two birds already mated are compelled to call in a third bird to complete the set; the harmonious 
duets of the oven-birds and the duets and choruses of nearly all the wood-hewers, and the wing-slapping aërial displays of the whistling widgeons, - will it be seriously contended that the female of this species makes choice of the male able to administer the most vigorous and artistic slaps?"

He continues: "How unfair the argument is, based on these carefully selected cases, gathered from all regions of the globe, and often not properly reported, is seen when we turn to the book of nature and closely consider the habits and actions of all the species inhabiting any one district." Hudson concludes that he is convinced that anybody who will note the actions of animals for himself will reach the conviction, that "conscious sexual selection on the part of the female is not the cause of music and dancing performances in birds, nor of the brighter colors and ornaments that distinguish the male."

In the spiders Mr. and Mrs. Peckham have described in detail the courtship of the males. They believe that his antics are specifically intended to attract the female. They point out that his contortions are of such a sort that his brightest spots are turned toward the female. But, as he makes in any case a hundred twists and turns, there is some danger of misinterpreting his poses. Montgomery, who has studied spiders of other groups, reaches the conclusion that here the male is contorted through fear of the female. The male goes through some of the same turns if approached by another male. The courtship of the male spider is, he thinks, a motley of fear, desire, and general excitement. 
The cridence that the Peckhams have given, even if taken to mean that the motions of the male attract the attention of the female, - and I can see no reason why this may not be the case, - fails nevertheless to show that the female selects, when she has a chance, the more highly colored male.

Mayer, and Mayer and Soule have made many experiments with moths. The moth promethea, Callo-
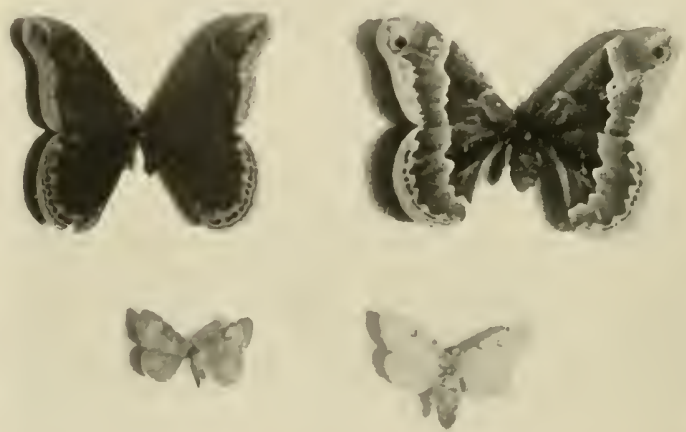

Fig. 60. - Above, Callosamia promethia, male to left, female to right. lonow Porthetria dispar, male to left, female to right.

samia promethea, is distinctly sexually dimorphic, as shown in Fig. 60. Mayer's experiments show that the male finds the female entirely by the sense of smell. The wings of some 300 males were painted with scarlet or green. They mated as often as did the normal male with which they competed.

Where the wings of males were stuck on the female in place of her own wings, no disturbance in the mating was observed. Conversely, normal females accepted 
males with female wings as readily as they accepted normal males.

In the gipsy moth (Porthetria dispar), the male is brown and the female white (Fig. 60). Here again it was found that the males are guided solely by the odor of the female.

The silkworm moth is also sexually dimorphic. Kellogg has shown that males with blackened eyes find a female with as much precision as does a moth with normal eyes.

If the antennæ are cut off, however, the male can not find the female unless by accident he touches her. He then mates. The female has scent glands whose odor excites the male with normal antennæ even at some distance. Chemotaxis and contact are the active agents in mating. The eyes do little or nothing.

Andrews has found that touch determines mating in the crayfish. Pearse has obtained similar results. Chidester has shown the same thing for crabs. Holmes found this kind of behavior in Amphipoda. Fielde and Wheeler have also found that in ants sex-discrimination is through smell or by what Forel calls contact-odors.

Montgomery and Porter recognize touch as the most important factor in mating in spiders. Petrunkewitsch has shown that in the hunting spider vision also helps the sexes to find each other. Tower has found that contact or odor rather than sight is the important condition in mating in leptinotarsa.

I am able to give the unpublished results of $\mathrm{A} . \mathrm{H}$. Sturtevant on the mating of the fruit fly, drosophila. The male carries on an elaborate courtship in the sense that he circles around the female, throws out one 
wing, then the other, and shows other signs of excitement. The male has sex combs on his fore legs, the female lack's them. Lutz cut them off and gave the female a choice between such a male and a normal male. One was chosen as often as the other. The wings of the male and female are wonderfully iridescent. Sturtevant cut off the wings of a male and matched him anainst a normal male. The female showed no marked preference. The converse experiment, when a clipped female competed with a normal female, showed no selection on the part of the males.

If instead of allowing two males (a normal and a clipped) to compete for one female, a female is given to cach male separately, and the interval before mating is noted, it is found that on an average this interval is 18 minutes for the normal and 40 minutes for the clipped. If any such difference existed in the first case, when the two males were competing, we should expect a much greater sclection in favor of the normal male than was actually found. This would seem to mean that the female is more quickly aroused by the normal male, and hence when both males are present she will accept the clipped male more quickly than when he alone is present. This suggests that normal courtship precipitates copulation.

In the following experiments the female was offered a choice between a new type (mutant) with white eyes and a normal male. Conversely, the white-eyed female had a like alternative. The evidence shows that the more vigorous male - the red-eyed male - is more successful.

Since vision itself is here involved, for the whiteeyed flice are probably partly blind, the observations 
RED VERSUS WHITE EYES.

$\operatorname{Red} \sigma \quad\left\{\begin{array}{l}\text { Red } q-54 \\ \text { White } q-82\end{array}\right.$

White $\sigma \begin{cases}\text { Red } q & -40 \\ \text { White } q & -93\end{cases}$

Red $q \quad\left\{\begin{array}{l}\text { Red } \sigma^{x}-53 \\ \text { White } \sigma^{7}-14\end{array}\right.$

White $+\left\{\begin{array}{l}\text { Red } \sigma-62 \\ \text { White } \sigma-19\end{array}\right.$
GRAY VERSUS YELLOW COLOR.

$$
\begin{aligned}
& \text { Gray } \diamond \begin{cases}\text { Gray } q & -25 \\
\text { Yellow } q & -31\end{cases} \\
& \text { Yellow } \sigma \begin{cases}\text { Gray } q & -12 \\
\text { Yellow } q & -30\end{cases} \\
& \text { Gray } q\left\{\begin{array}{l}
\text { Gray } \sigma^{7}-60 \\
\text { Yellow } \sigma^{\pi}-12
\end{array}\right. \\
& \text { Yellow 우 }\left\{\begin{array}{l}
\text { Gray } \sigma-25 \\
\text { Yellow } \sigma-8
\end{array}\right.
\end{aligned}
$$

NORMAL VERSUS CLIPPED WINGS.

Normal $q\left\{\begin{array}{l}\text { Clipped } \delta-51 \\ \text { Normal } \delta-67\end{array}\right.$

Normal $\approx\left\{\begin{array}{l}\text { Clipped } q-27 \\ \text { Normal } q-25\end{array}\right.$
GRAY-WHITE VERSUS YELLOWWHITE.

Gray $\sigma \quad\left\{\begin{array}{l}\text { Gray } q-11 \\ \text { Yellow } q-4\end{array}\right.$

Gray $+\left\{\begin{array}{l}\text { Gray } \sigma^{\star}-21 \\ \text { Yellow } \delta-3\end{array}\right.$

were repeated with a new type that had yellow wings. The gray male is more successful and the yellow females less resistant. The results are in accord with the assumption that greater vigor is an important factor in success.

The following mating bears on this point. Sturtevant used in competition a red- and a vermilioneyed male. The latter seems as vigorous as is the red-eyed type. The results were :

$$
\text { Red } q \begin{cases}\text { Red } \delta & 11 \\ \text { Vermilion } \delta & 14\end{cases}
$$

showing that the red-eyed male has no advantage when the males are equally vigorous.

This evidence, taken as a whole, seems to me to show with some probability that sight plays a minor rôle in 
(ourtship. It is so inferior to vigor, to the sense of smell and to touch in the lower animals at least, that it is very questionable whether it has had anything more to do with mating than helping the sexes find each other.

\section{VIGOR AND SECONDARY SEXUAL CHARACTERS}

We have seen that Darwin himself has stated explicitly that unless the secondary sexual characters are associated with greater vigor, or productivity, nothing can be accomplished.

It will be recalled that Wallace, who disbelieved in Darwin's theory of sexual selection, attempted to account for the appearance of secondary sexual characters on the ground of the greater vigor of the male (he sometimes says vitality and again activity of the male) at the breeding season. The vigor is assumed to be associated with the development of the sex glands at this time. This may be admitted, but whether the rigor is the result of the sex glands, or the sex glands of the rigor, is a nice point that I shall not try to decide. It may appear that Wallace's view is in part justified from the facts that we have examined. But I do not think so. In the first place, he attempts the impossible task of explaining the outgrowths and colors that appear in special regions by the local activity of the muscles (for example) in those regions. The facts before us do not support any such interpretation. The Peckhams easily overturn his argument, as applied to spiders.

Siecond, in birds, to which Wallace mainly refers, the sex glands of the male do not affect the secondary 
sexual characters of the male, while the sex glands of the female suppress these characters.

Wallace's theory leaves out of account the hereditary factor that is also present and which acts quite apart from the physiological effects of the sex glands.

Cunningham, who has more recently written on the same subject, accepts the hormone hypothesis as the basis for all cases of secondary sexual characters. But he fails to make good his view when it is applied to insects, for reasons that we shall take up later. $\mathrm{He}$ is especially concerned, however, in the attempt to make plausible his own hypothesis that secondary sexual characters have arisen through the use of the parts, or through special nervous or blood supplies to certain localities of the body which become suffused during sexual excitement. In both cases he thinks the increased local activity will cause the cells to produce hormones that will be dispersed throughout the body, and absorbed by other cells. The germ-cells will in this way get their share and carry over the hormone to the next generation.

Cunningham forgets one important point. If these imaginary hormones can get out of cells and into germcells, they can get out of the germ-cells again. Hence in the long period of embryonic and juvenile existence through which the individual passes before the secondary sexual characters appear they would surely be lost from the body like any other ordinary hormone.

\section{CONTINUOUS VARIATION AS A BASIS FOR SELECTION}

And now let us turn to an entirely different aspect of the matter. What could selection do, admitting that selection may take place. For fifty years it has been 


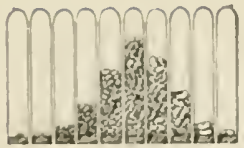

$\boldsymbol{A}$

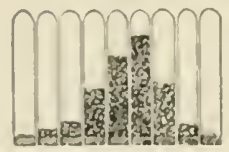

B
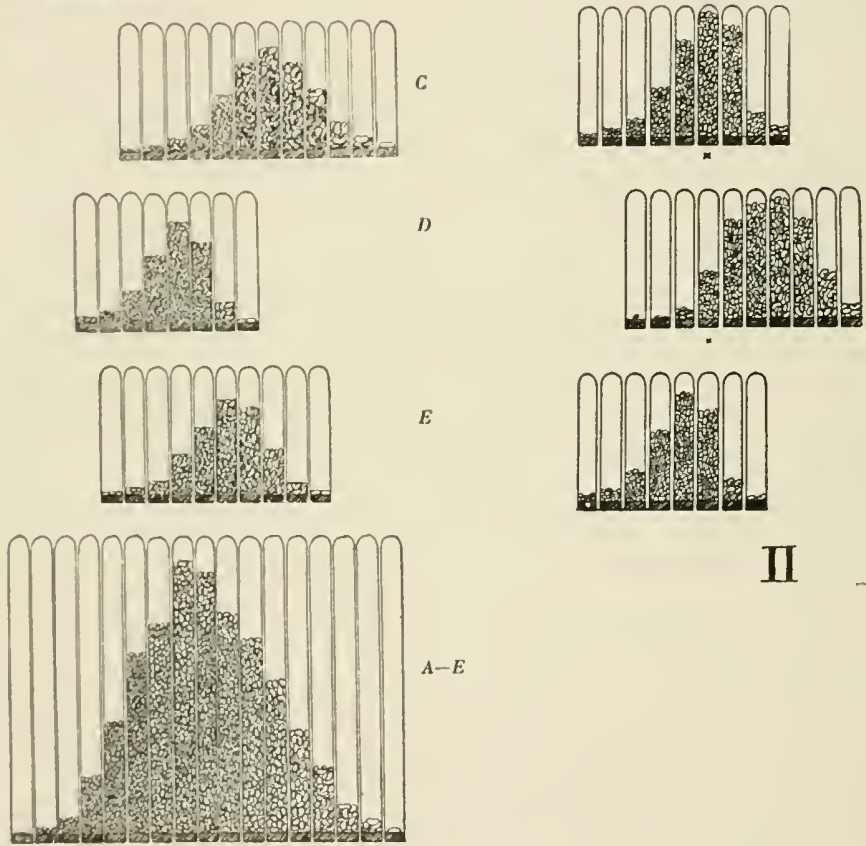

II

\section{1}

Frg. 61. - I. Diagram of five pure lines of beans $(A, B, C, D$, and $E)$ and a population formed by their union, $A-E$. II. Diagrams illustrating a mure line of beans and two new biotypes derived from it. The upper diagram indirates the original biotype; the second and third diagram inricate the elongated (narrower) and shorter (broader) type of beans. $X$ indicates the average class of the original biotype. (After Johannsen.) 
taken for granted that by selecting a particular kind of individual the species will move in the direction of selection.

A few examples will bring the matter before us. If we take a peck of beans and put all of those of one size in one cylinder and those of other sizes in other cylinders, and place the cylinders in a row, we get a result like that in Fig. 61, $A-E$. If we imagine a line joining

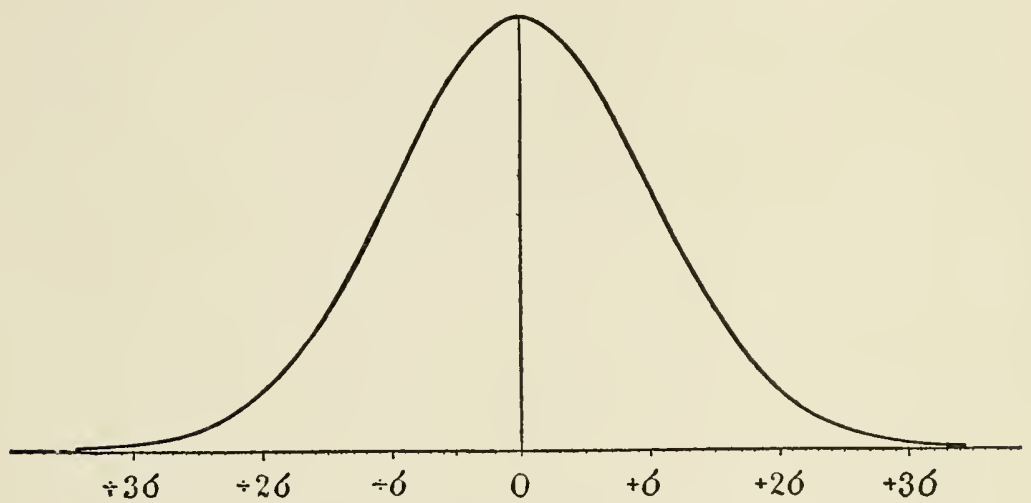

FIG. 62. - The normal binomial curve or the "ideal curve" of distribution. At the base line, the directions from the average value (o) are indicated with the standard deviation $(\sigma)$ as unity. (After Johannsen.)

the tops of the beans, the line gives a curve like that shown in Fig. 62. This is known as the curve of probability. The curve can be, of course, most readily made by making the measurements directly. Most individuals of such a population will have the character developed to the degree represented by the highest point in the curve. Now if two individuals standing at one side (let us say with the character in question better developed than the average) become the parent 
of the next generation, their offipring will make a new "urve that has moved, so to speak, in the direction of selection (Fig. 6i3).

If again two more extreme individuals are selected, another step is taken. The process is assumed to go on as long as the selection process is maintained.

So the matter stood until a Danish botanist, Johamnsen, set seriously to work to test the validity of the issumption, using a race of garden beans for his measurements. He discovered in the first place that popu-

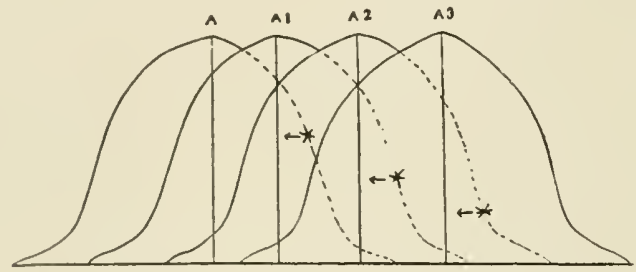

Fin, 63, - Schenlitic representation of the type-shifting effect of selection from the point of view of Galton's regression theory. The ${ }^{*}$ marks the point on the curves of $A_{1}, A_{1}, A_{2}$ from which the selection is supposed to be marle. (Goldschmidt.)

lations are made up of a number of races or "pure lines." When we select in such a population we sort out and scparate its constituent races, and sooner or later under favorable conditions can get a pure race. Selection has created nothing new; it has picked out a particular preëxisting race from a mixed population.

Johamsen has shown that within a pure line selection produces no effect, since the offspring form the same group with the same mode as the group from which the parents came. The variability within the pure lines is generally ascribed to environmental influences 
which are recurrent in each generation. The germplasm is homogeneous for all members of the pure line, while in a mixed population the germ-plasm is not the same for all individuals.

Darwin himself saw this to some extent, for he has repeatedly pointed out that selection depends on the materials offered to it by variation; that in itself it can produce nothing. Yet from Darwin to Johannsen the teaching of the post-Darwinians has been such as to lead most people to believe that selection is a causative or creative principle that will explain the progressive development of animals and plants.

DISCONTINUOUS VARIATION OR MUTATION AS A BASIS FOR SELECTION

The second great movement since Darwin has been to show that hereditary variations do not give a continuous series but a discontinuous one. Bateson and De Vries brought forward some twelve years ago evidence, in favor of this view, that has gone on increasing in volume at an amazing rate.

I cannot attempt to discuss this evidence here, but I may point out the bearing of the new point of view on the meaning of secondary sexual characters.

In a number of butterflies there occur two or three or even more different kinds of females. One of the most remarkable cases of the kind is that of Papilio polytes that lives in India and Ceylon. It has a single male type and three types of females (Fig. 64).

Wallace, who first observed that the three types of female belong to one male type, argued that two of these three types owe their origin to their resen- 
blance to butterflies of other species that are protected, namely, Papilio aristolochin and $P$. hector. These
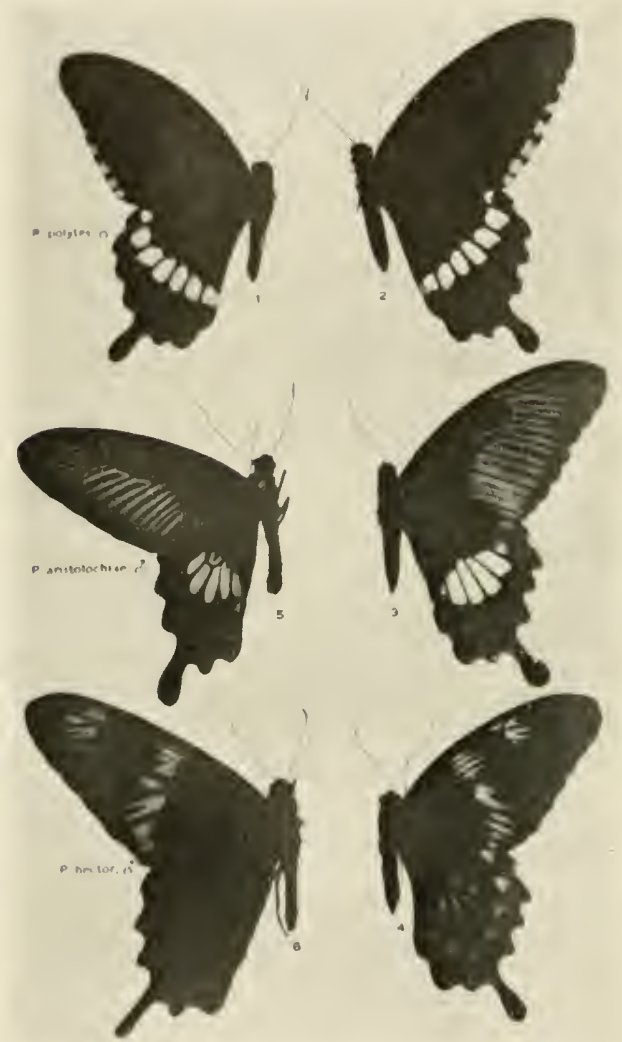

Fir. 61. - Papilio polytes; male (upper left) and three types of female (tu right). The "models," which two of these females are supposed to "unimic," are shown to their left. (After Punnett.)

two feed on the poisonous plant aristolochia and are said to be unpalatable. The two aberrant types of, $P$. polytes bearing a close resemblance to these two 
species have been dubbed the hector form and the aristolochia form.

Wallace, and those who adhere to the same view, believe that the resemblance of the model and the mimic has come about through the accumulation of minute variations which have survived as a result of their advantages. In a word, the process of natural selection is assumed to have gradually brought about the evolution of these two new types of females.

This case has been recently examined by Punnett.

Punnett says that while in cabinet specimens the resemblance between the model and the mimic is remarkably close, yet in the living animals, with their wings spread out, the resemblance is less marked, especially the resemblance between the hector model and the polytes mimic. At a distance of a few yards the difference between the two is easily seen.

When flying the differences are very apparent. "The mode of flight of $P$. polytes is similar for all three forms, and is totally distinct from that of $P$. hector and $P$. aristolochia." In flight the latter pursue an even course, while the polytes form follow a lumbering up and down course. Punnett thinks these differences are so distinct that they are "unlikely to be confounded by an enemy with any appreciation of color or form.'

Moreover, in Ceylon at least, the distribution of the model and its mimic is very different from what is expected on the theory of mimicry. He concludes that the facts relative to their distribution "are far from lending support to the view that the polymorphic females of $P$. polytes owe their origin to natural selec- 
tion, in the way that the upholders of the theory of mimiery would lead us to suppose."

After considering the difficulties that the theory of mimicry has to contend with, Punnett points out that dimorphic and polymorphic species are not uncommon in butterflies, and that in many of these cases there can be little or no question of mimicry having anything
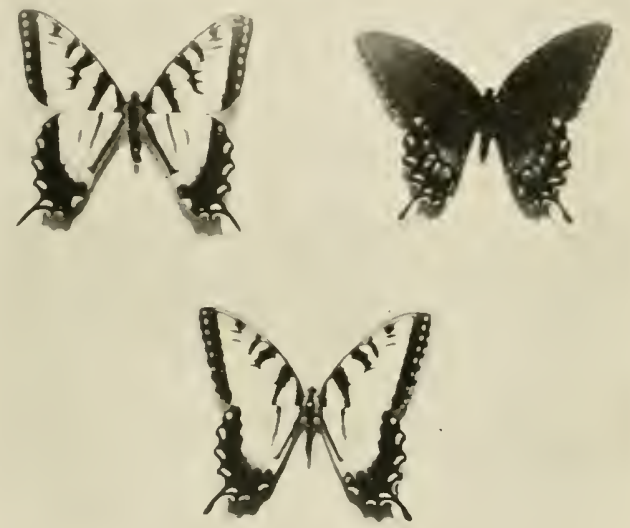

Jir. 65. - Papilio turnus; female (above) and male (below), and the variety P. turnus olaucus (above, right) which appears only in the female.

to do with the matter. It is well known that in Lepidoptera the modified form commonly belongs to the female sex. In one ease (Abraxas grossulariata) it is known that the aberrant female type appears sporadically, as a sport, and follows Mendel's law of segregation. Punnett shows how the recurrence of the single type of male and the three types of females of polytes may also be accounted for by the recognised methods of Mendelian inleritance. He points out that by the assumption that 
these types have suddenly appeared as mutants many of the difficulties of the older theories are avoided, and that such an assumption is in harmony with an ever increasing body of evidence concerning variation and heredity. On this view "natural selection" plays no part in the formation of these polymorphic forms," nor does sexual selection. The absence of transitional forms is explicable on this

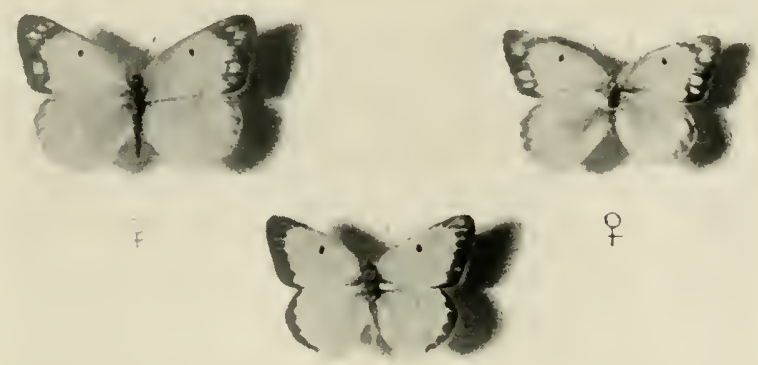

Fig. 66. - Colias philodice, showing two female forms above and one male form below.

view, and unaccountable on the other theory. In fact polymorphic forms, if they appear, would be expected to persist if they are not harmful to the species.

We have in this country several species of butterflies in which polymorphism exists. In the north the species Papilio turnus (Fig. 65) is alike in the male and in the female. But in the south two types of females exist - one like the male and the other a black type. 
In the Eastern States there is a butterfly, Colias philodice, in which two types of female exist (Fig. 66). Gerould has studied the mode of inheritance of these two types and finds that they conform to a scheme in which the two females differ by a single factor. The evidence is strongly in favor of the view that one of these forms has arisen as a mutation. There is no need to suppose that sexual selection has had anything to do with its origin, and no evidence that it owes its existenee to mimicry of any other species.

Finally, I should like to speak of a case that has come under my own observation. One of the mutants that appeared in a culture of drosophila had a new eye color that was called eosin. In the female the eye is much deeper in color than in the male. The race maintains itself as a bicolor type without any selection.

\section{CONCLUSIONS}

In conclusion let me try to bring together the main considerations that seem to me to throw serious doubts on Darwin's theory of sexual selection.

First. Its fundamental assumption that the evolution of these characters has come about through the "will," "choice," or selection of the female is questionable, because of want of evidence to show that the females make their choice of mates on this basis. There is also some positive evidence to show that other conditions than selection of the more ornamented individual (because he is the more ornamental) are responsible for the mating.

Second. We have come to have a different conception of what selection (an do than the sliding scale 
assumption that has been current, at least by implication, in much of the post-Darwinian writings.

Third. Recent advances in the study of variations have given us a new point of view concerning the nature of variation and the origin of variations. If we are justified in applying this new view to secondary sexual characters, the problem appears greatly simplified. 


\section{CHAPTER V}

The Effects of Castration and of Transplantation on the Secondary Sexual Characters

IN several of the preceding chapters $I$ have spoken in some detail of sex-linked inheritance. In sex-linked inheritance we deal with a class of characters that are transmitted to one sex alone in certain combinations, and have for this reason often been called sex-limited characters; but these same characters can be transferred by other combinations, as we have seen, to the other sex, and are therefore not sex-limited.

In contrast to these characters secondary sexual characters appear in one sex only and are not transferable to the other sex without an operation. For instance, the horns of the stag and the colors and structures of certain male birds are in nature associated with one sex alone.

It has long been recognized in mammals and birds that there is a close connection between sexual maturity and the full development of the secondary sexual characters. This relation suggests some intimate correlation between the two. It has been shown, in fact, in some mammals at least, that the development of the secondary sexual characters does not take place, or that they develop imperfectly, if the sex glands are removed. It may appear, therefore, that we are dealing here with a purely physiological process, and that 
the development of these structures and colors is a byproduct of sex itself, and calls for no further explanation.

But the question cannot be so hastily dismissed. This can best be shown by taking up at once the material at hand.

\section{OPERATIONS ON MAMMALS}

In the deer, the facts are very simple. If the very young male is castrated before the knobs of the antlers have appeared, the antlers never develop.

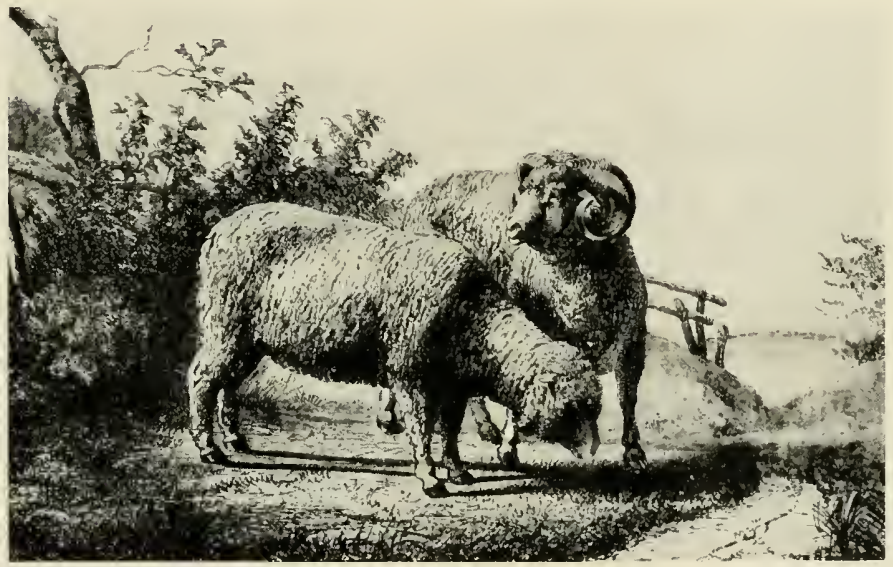

Fig. 67. - Merino; male (horned) and female (hornless).

If the operation is performed at the time when the antlers have already begun to develop, incomplete development takes place. The antlers remain covered by the velvet and are never thrown off. They are called peruke antlers. If the adult stag is castrated when the horns are fully developed, they are precociously 
dropped, and are replaced, if at all, by imperfect antlers, and these are never renewed.

These facts make it clear that there is an intimate relation between the orderly sequence of development of the horns in the deer and the prese ce of the male sexual glands.

In the ease of sheep, the evidence is more explieit. Here we have earefully plamned experiments in which both sexes have been studied; and there are breeding
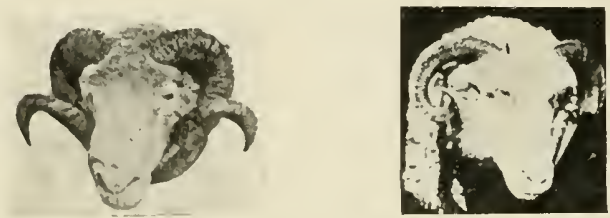

FIG. 6s. -- Dorset; male (horned) and female (horned).

experiments also, in which the heredity of horns has been examined.

In some breeds of sheep, as in the Merinos and Herdwicks, horns are present in the males, absent in the females (Fig. 67). In other breeds of sheep, as in Dorsets, both males and females have horns (Fig. 68 ). In still other breeds both sexes lack horns, as in some of the fat-tailed sheep of Africa and Asia (Fig. 69).

Marshall has made experiments with Herdwicks a race of sheep in which the rams have large, coiled horns and the ewes are hornless. Three young rams (3, 4, and 5 months old) were castrated. The horns had begun to grow $(3,41 / 2$, and 6 inches long) at the time of operating. They ceased to grow after the operation. 
A similar operation was also carried out on females. Three Herdwick ewe lambs (about 3 months old) were operated upon. After ovariotomy, the animals were kept for 17 months, but no horns appeared, although in one, small scurs developed, in the other two scarcely even these. It is cle.r that the removal of the ovaries does not lead to the development of horns like those in the male.

Now, the interipretation of this case can be made only when taken in connection with experiments in heredity. There is a crucial experiment that bears on this question. Arkell found when a Merino ewe (a race with horned males and hornless females) was bred to a ram of a hornless breed, that the sons had horns. In this case the factor for horns must have come from the hornless mother, while the development of the horns was made possible by the presence of the male glands. It is evident therefore in the castration experiment that a factor for horns is inherited by both sexes, but in order that the horns may develop fully, the male glands must be present and functional.

In the Dorset, both sexes are horned, the horns of the females are lighter and smaller than the horns of the ram (Fig. 68). In the castrated males the horns are like those of the females. In this case we must suppose that the hereditary factor for horns suffices to carry them to the point in development reached by the females. To carry them further the presence of the sex glands of the male is necessary.

In the case of the hornless breeds I do not know of any evidence from castration or ovariotomy. We may suppose, either that the factor for horns is absent ; or, 
if present, some inhibitory factor must bring about suppression of the horns. The former assumption seems nore probable, for, as I shall point out, certain experiments in heredity indicate that no inhibitor is present in hornless breeds.

The series is completed by cases like that of the eland and the reindeer. Both males and females

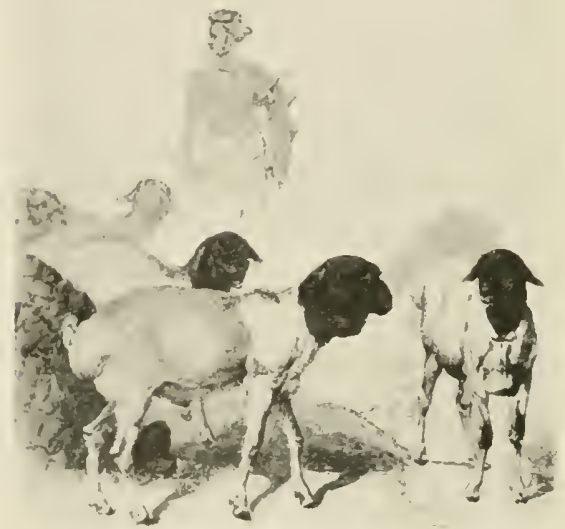

Fig. 69. - Fat-tailed hornless sheep (Ovis aries stratopyga persicci).

have well-developed horns. In this case the hereditary factors suffice in themselves for the complete development of horns, for even after castration the horns develop.

We have anticipated to some extent the conclusions arrived at by breeding experiments in these races of sheep. The best-known case is that of Wood, who crossed homed Dorsets and homless Suffolks. As 
shown in the picture (Fig. 70) the sons had horns the daughters lacked them. When these are inbred, their offspring are of four kinds, horned males, hornless males, horned females, hornless females.

It seems probable that these four classes appear in the following proportions :

Horned $\delta$ Hornless $\delta$ Horned $q$ Hornless $q$ 3 1 1 3

The explanation that Bateson and Punnett offer for this case is as follows: The germ-cells of the horned race
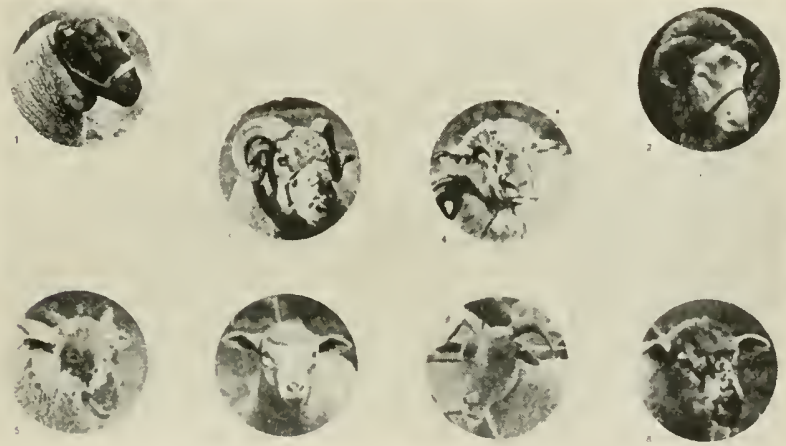

Fig. 70, - 1, Suffolk (ram), hornless in both sexes; 2, Dorset (ewe), horned in both sexes; $3, F_{1}$ ram, horned ; $4, F_{1}$ ewe, hornless; $5-8$, the four types of $\mathrm{F}_{2} ; 5$ and 6 are rams. 7 and 8 are ewes. The hornless rams are pure for absence of horns, and the horned ewes are pure for the presence of horns. Figs. 5 and 6 represent lambs. (Bateson, after Wood.)

(both male and female) carry the factor for horns $(H)$; the germ-cells of the hornless race lack the factor for horns $(h)$. The female is assumed to be homozygous for the sex factor, i.e. two sex chromosomes $(X)$ are present; while the male has only one sex chromosome 
carried by the female-producing sperm. The analysis is then as follows: One "dose" of horns $(H)$ in the male produces horns, but two doses are necessary for the female.

$\begin{array}{ll}\text { Hornlesis f } & h \mathrm{X}-h \mathrm{X} \\ \text { Homed o } & H \mathrm{X}-H \\ F_{1} & H \mathrm{H} h \mathrm{X} \text { hornless } \\ & H h X \quad \text { horned o }\end{array}$

Gametes Eggs $H \mathrm{X}-h \mathrm{X}$ of $F_{1}$ (sperm $H \mathrm{X}-h \mathrm{X}-\mathrm{H}-\mathrm{h}$

$F_{2}$ Fenales

$H X H \mathrm{X}$ horned

$H \mathrm{X} h \mathrm{X}$ hornless

$h X H X$ hornless

$h X h X$ hornless

$$
F_{2} \text { MaLes }
$$

$H H X$ horned

$H h X$ horned

$h H X$ horned

$h h X$ hornless

As pointed out by Punnett a test of the correctness of this interpretation is found by breeding the $F_{1}$ hornless female to a hornless male (of a hornless breed). It is assumed that such a female carries the factors for horns in a heterozygous condition; if so, then half of her sons should have horns, as the following analysis shows:

$$
\begin{aligned}
& F_{1} \text { Hornless of } H X-h X \\
& \text { Hornless of } h \mathrm{X}-h \\
& \text { h } \mathrm{X} H \mathrm{Y} \text { hornless } q \\
& h X h X \text { hornless q } \\
& h H X \text { horned o } \\
& h h \mathrm{X} \text { hornless } \delta
\end{aligned}
$$



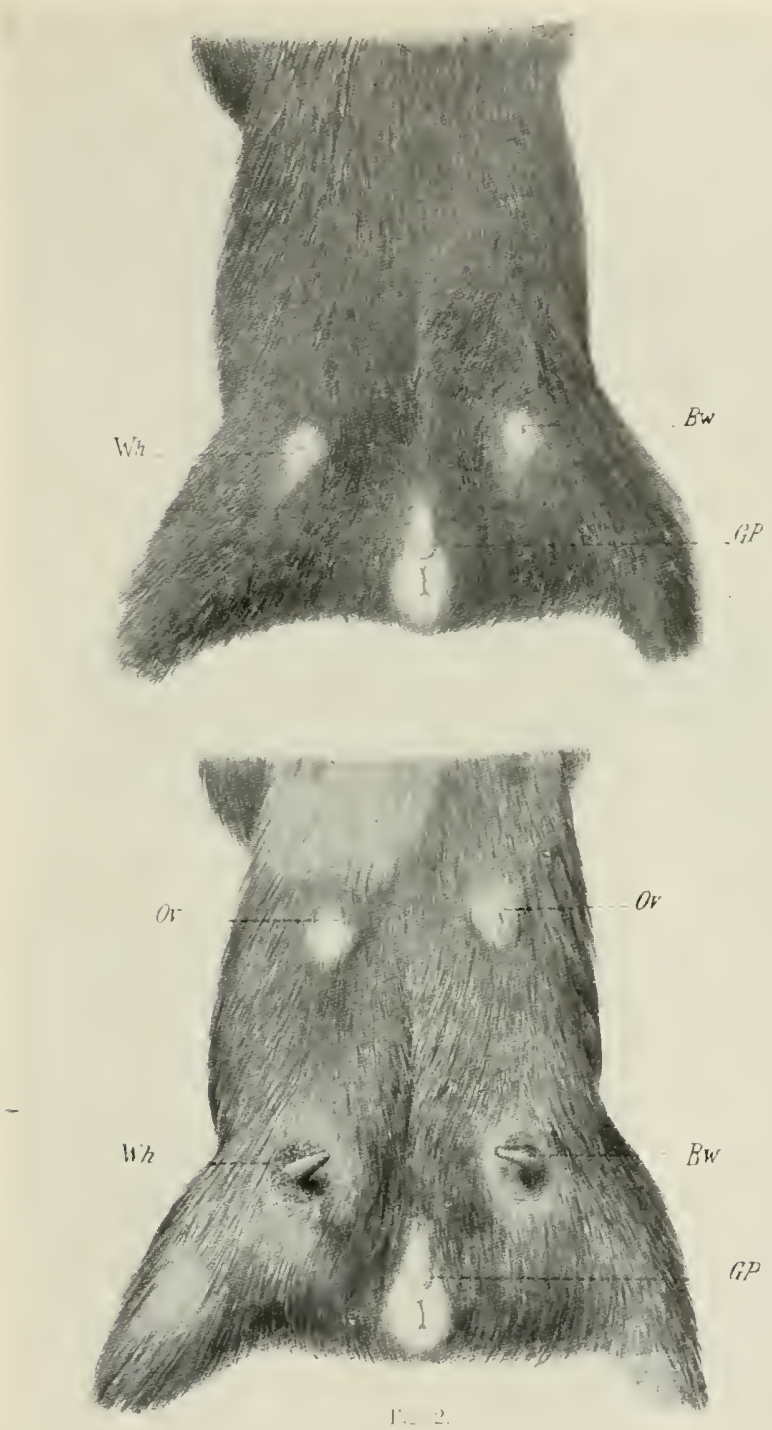

Fig. 71. - Upper figure normal male guinea pig (from below), to show mammary glands. Lower figure, a feminized male; i.e. castrated when three weeks old and pieces of ovaries transplanted beneath the skin, at $O v$. 
The actual result conforms to the expectation. The results of both of the experiments are consistent with the riew that one factor for horns in the male produces horns, which we may attribute to the combined action of the inherited factor and a secretion from the testes which reënfores the action of the latter. This, however, should be tested by castrating the $F_{1}$ males. In the females, one factor for horns fails to produce horns, while two factors for horns cause their derelopment.

Aside from some of the domesticated animals (horses, cattle, (logs, eats, pigs), the only other mammals on which critical experiments have been made - if we exclude man - are the rat and the guinea pig. The next case is unique in that the ovary was transplanted to a male.

Steinach removed the sex glands from the male guinea pig and rat and transplanted into the same animals the ovaries of the female, which established themselves. Their presence brought about remarkable effects on the castrated male. The mammary glands, that are in a rudimentary condition in the male, become greatly enlarged (Fig. 71). In the rat the hair assumes the texture of that of the female. The skeleton is also more like that of the female than the male. The size of the feminized rats and guinea pigs is less than that of normal (or of castrated) males and like that of the female (Fig. 72). Finally, in their sexual behavior, the feminized rats were more like females than like males. These cases are important because they are the only ones in which successful transplanting of the ovary into a male has been accomplished in vertebrates. 

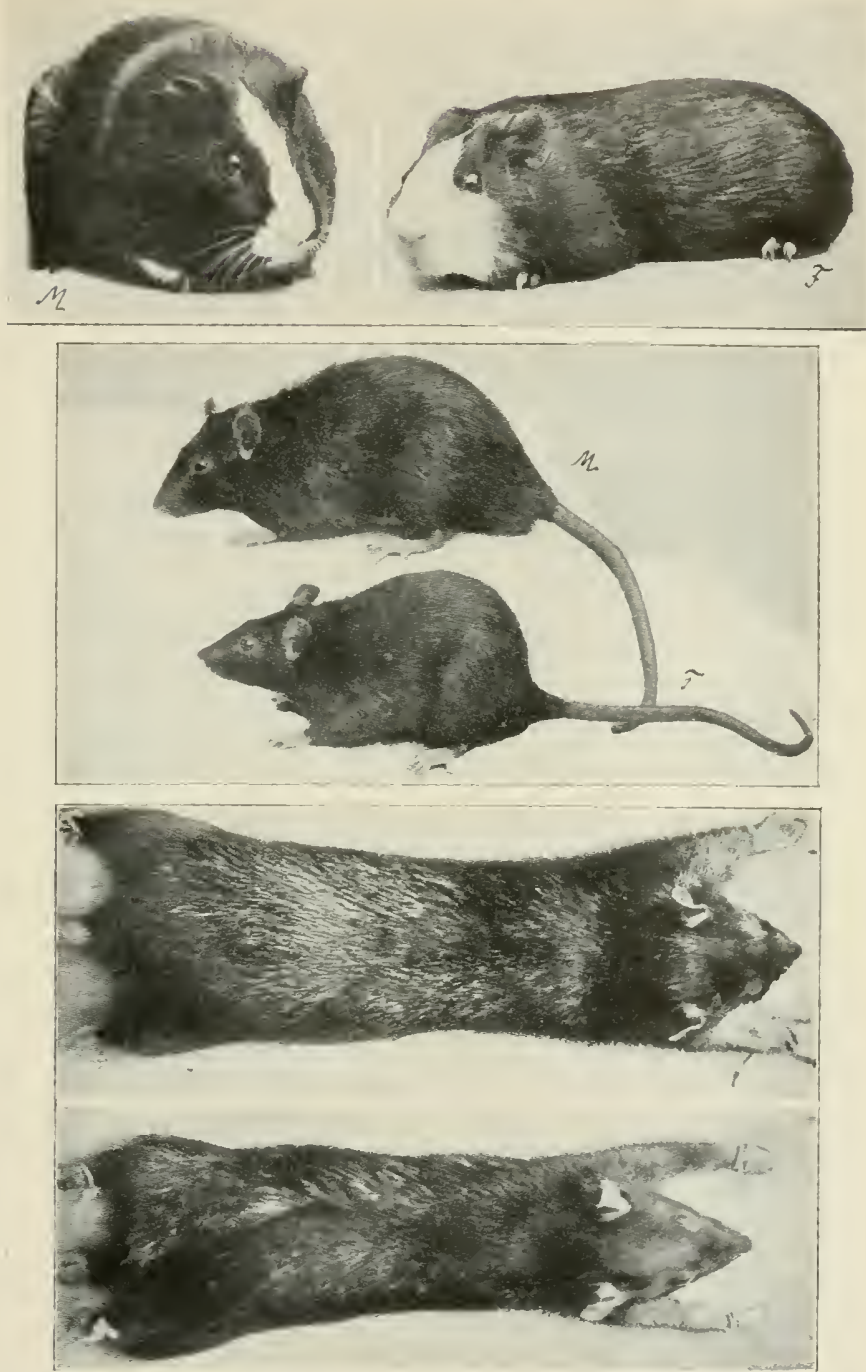

Fig. 72 . - Two upper figures, normal male guinea pig to left, $\boldsymbol{M}$, and his brother, $F$, to right - a feminized male. Two middle and two lower figures, a normal male at $\boldsymbol{M}$, and his feminized brother, $F$. (After Steinach.) 
In striking contrast to these results with mammals are those with birds, where in recent years we have gained some definite information concerning the development of secondary sexual characters.

I am fortunate in being able to refer to several cases - the most successful on record - carried out by my friend, H. D. Goodale, at the Carnegie Laboratory at Cold Spring Harbor. One "case" is that of a female Mallard duck from which the ovary was completely removed when she was a very young bird. Figure 16 illustrates the striking difference between the normal male and the female Mallard. In the spayed female the plumage is like that of the male.

Darwin records a case in which a female duck in her old age assumed the characteristics of a male, and similar cases are recorded for pheasants and fowls.

Croodale also removed the ovary from very young chicks. He found that the female developed the secondary sexual plumage of the cock.

How shall we interpret these cases? It is clear that the female has the potentiality of produeing the full plumage of the male, but she does not do so as long as the ovary is present. The ovary must therefore be supposed to prevent, or inhibit, the development of secondary sexual characters that appear therefore only in the male.

The converse operation - the removal of the male glands from the male - is an operation that is very common among poultrymen. The birds grow larger and fatter. They are known as capons. In this case 
the male assumes his full normal plumage with all of his secondary male sexual characters. It is said that the comb and wattles and to some extent the spurs are less developed in the capon than in the normal male. But aside from this it is quite certain that the development of the secondary sexual plumage in the

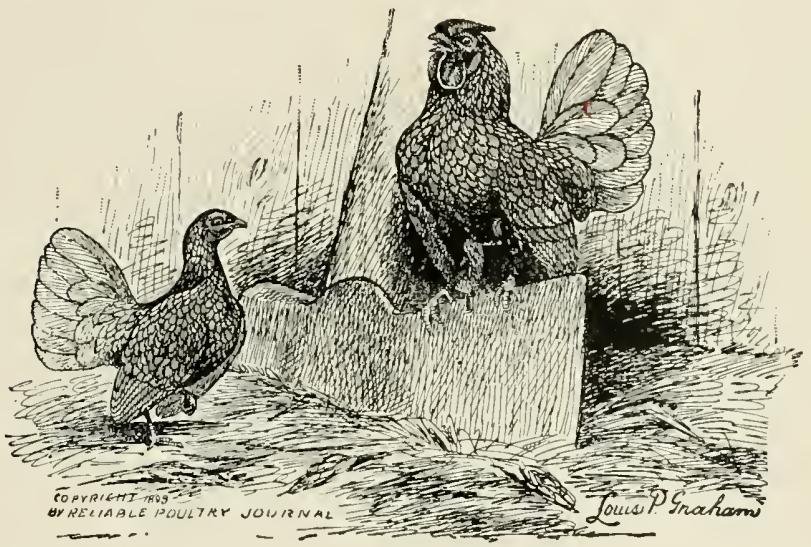

FIG. 73. - Male and female Seabright. Note short neek feathers and incomplete tail cover in male. In the Seabright coek the sickle feathers on back at base of tail are like those of the hen. (After "Reliable Poultry Journal.")

male is largely independent of the presence of the sex glands.

The method of inheritance of the secondary sexual characters in birds has been little studied. Davenport has reported one case, but I am not sure of his interpretation. ${ }^{1}$ I have begun to study the question by using Seabright bantams, in which the male lacks some

${ }^{1}$ Because it is not evident whether the secondary sexual characters as such are involved or only certain general features of coloration. 
of the secondary sexual characters of the domestic races, notably the saddle feathers, as shown in Fig. 73. A male seabright was mated to a black-breasted game female. The son was hen-feathered and like the Seabright father in this respect. Evidently in this case the secondary sexual character in question is dominant and is transmitted from father to son.

In the reciprocal cross one hen was obtained which was back-crossed to a recessive male. She produced both hen-feathered and normally feathered sons. The character appears therefore to be sex-limited but not sex-linked. If hen-feathering in the Seabright be represented by $S$ and its normal allelomorph by $s$, the first cross would be as follows:-

Game $q \quad s F-s$

Seabright $\delta \quad S-S$

$$
\begin{array}{lll}
F_{1} & S s F & \text { female } \\
& S s & \text { hen-feathered male }
\end{array}
$$

$$
\begin{array}{lc}
\text { Eggs of } F_{1} & S F-s F-S-s \\
\text { Sperm of } F_{1} & S-s
\end{array}
$$

\begin{tabular}{|c|c|c|}
\hline$S S F$ & $S S$ & hen-feathered \\
\hline Ss $F$ & Ss & hen-feathered \\
\hline & $s S$ & hen-feathered \\
\hline & si & cock-feathered \\
\hline
\end{tabular}

$F_{2}$ Females $\quad F_{2}$ Males

In conclusion, then, in mammals the secondary sexual characters owe their development to the testes. The testes add something to the common inheritance. But in birds the ovary takes something away. 


\section{OPERATIONS ON AMPHIBIA}

The male triton develops each year a peculiar fin or comb on the back and tail. Bresca has found that after castration the comb does not develop. If present at the time of castration, the comb is arrested, but only after several months. Certain color marks peculiar to the male are not lost after castration. If the comb is removed in normal males, it regenerates, but less perfectly in castrated males. If a piece of the dorsal fin of the female is transplanted to a normal male in normal position, it may later produce the comb under the influence of the testes.

In the frog there appears at the breeding season a thickening of the thumb. Castrated males do not produce this thickening.

If it is present in a male at the time of castration it is thrown off, according to Nussbaum, but according to Smith and Shuster its further progress only is arrested. According to Nussbaum and Meisenheimer injection of pieces of testes beneath the skin of a castrated male cause the thumb development to take place, or to continue, but Smith and Shuster question this conclusion.

Such are the remarkable relations that these experiments have brought to light. How, we may ask, do the sex glands produce their effect, in the one case to add something, in the other to suppress something?

It has often been suggested these glands produce their effects through the nervous system by means of the nerves to or from the reproductive organs. This has been disproved in several cases by cutting the 
nerves and isolating the glands. The results are the same as when they are left intact.

This brings us to one of the most interesting chapters of modern physiology, the production and influence of Internal Secretions.

\section{INTERNAL SECRETIONS}

It has become more and more probable that the effects in question are largely brought about by internal secretions of the reproductive organs. These secretions are now called "hormones" or "exciters." They are produced not only by glands that have ducts or outlets, but by many, perhaps by all, organs of the body. Some of these secretions have been shown to have very remarkable effects. A few instances may be mentioned by way of example.

The pituitary body produces a substance that has an important influence on growth. If the pituitary body becomes destroyed in man, a condition called gigantism appears. The bones, especially of the hands and feet and jaws, become enlarged. The disease runs a short course, and leads finally to a fatal issue.

The thyroid and parathyroid bodies play an important rôle in the economy of the human body through their internal secretions. Removal leads to death. I discased condition of the glands is associated with at least six serious diseases, amongst them cretinism.

The thymus secretion is in some way connected with the reproductive organs. Vincent suggests that "the thymus ministers to certain needs of the body before the reproductive organs are fully developed." 
Extirpation of the adrenal bodies, another ductless gland, leads to death. Injury to these bodies causes Addison's disease.

Finally, the reproductive glands themselves produce internal secretions. In the case of the male mammal it has been shown with great probability that it is the supporting tissues of the glands, and not the germ-cells, that produce the secretion. Likewise, in the case of the ovary, it appears that the follicle cells of the corpus luteum give rise to an important internal secretion. If the sac-like glands are removed, the embryo fails to become attached to the wall of the uterus of the mother. If the ovary itself is removed from a young animal, before corpora lutea are formed, the uterus remains in an infantile condition.

From a zoölogical point of view the recent experiments of Gudernatsch are important. He fed young frog tadpoles with fresh thyroid glands. "They began very soon to change into frogs, but ceased to grow in size. The tadpoles might begin their metamorphosis in a few days after the first application of the thyroid, and weeks before the control animals did so."

In contrast to these effects Gudernatsch found that tadpoles fed on thymus grew rapidly and postponed metamorphosis. They might even, in fact, fail to change into frogs and remain permanently in the tadpole condition. If thyroid extracts produce dwarfs; thymus extracts make giant tadpoles that never become adults.

These examples will suffice to show some of the important effects on growth that these internal secretions may bring about. 


\section{OPERATIONS ON INSECTS}

The Insects eonstitute the third great group in which seeondary sexual characters are common.

The first operations on the reproductive organs were earried out by Oudemans on the gipsy moth, Ocneria (Porthetria) dispar. The male and female are strikingly different. Oudemans removed the testes from

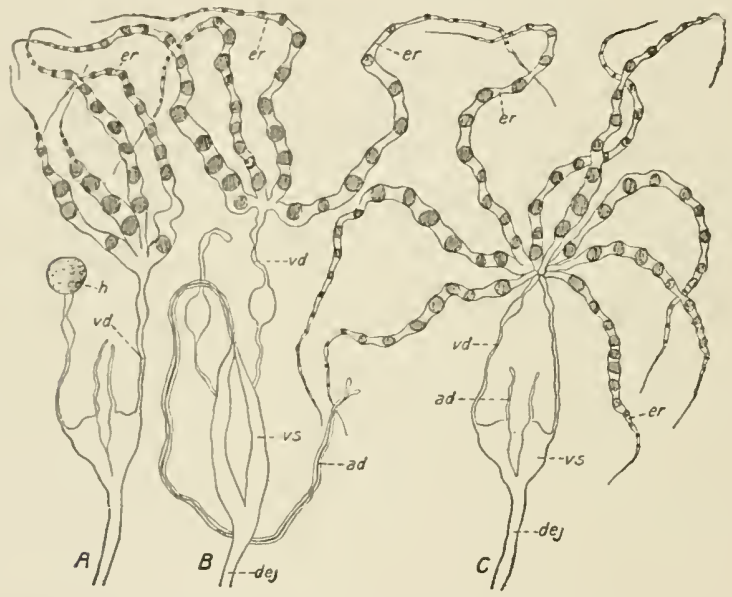

Fig. 74. Ovaries of Lymantria (Porthetria) dispar transplanted to male. They have established comnection with the sperm ducts. (After Kopec.)

young eaterpillars and found no change in the color, or size, of the male. He also removed the ovaries from young eaterpillars, and again found no effect in the female. The same experiments were later earried out on a large scale by Meisenheimer, who obtained similar results. Meisenheimer went further, however, and performed another operation of great interest. He removed the male glands from a male and implanted in their 
place the ovary of a female, while it was still in a very immature condition. The caterpillar underwent its usual growth, changed to a chrysalid, and then to a moth. The moth showed the characters of the male. The presence of the ovary had produced no effect whatever on the body character of the individual. When this individual was dissected, Meisenheimer found that the ovary had completely developed. It contained mature eggs, and the ovary had often established connection with the outlets of the male organs that had

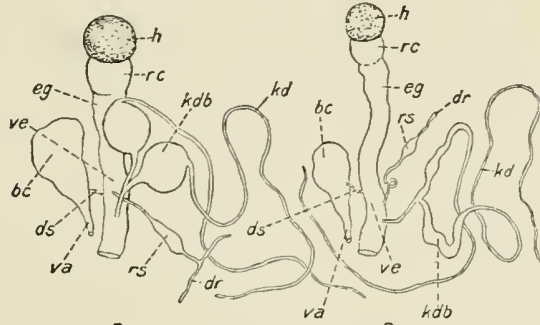

$A$

$B$

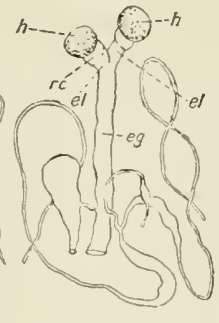

c

Fig. 75. - Testes of Lymantria (Porthetria) dispar transplanted to female. They have connected with the oriducts. (After Kopec.)

been left behind, as seen in Fig. 74, taken from Kopec's description.

The converse experiment was also made. The ovaries were removed from young caterpillars, and in their place were implanted the male sex glands from a young male caterpillar. Again no effects were produced on the moth, which showed the characteristic female size and color. On dissection the testes were also found to have grown to full size and to have produced spermatozoa (Fig. 75).

These remarkable results, confirmed by Kopec, show 
that in these insects the essential organs of reproduction have no influence on the secondary sexual characters of the individual. They show furthermore that the male generative organs will develop as well in the female as in the body of the male itself, and vice versa.

It is evident, then, in insects (there is a similar, but less complete, scries of experiments on the cricket),
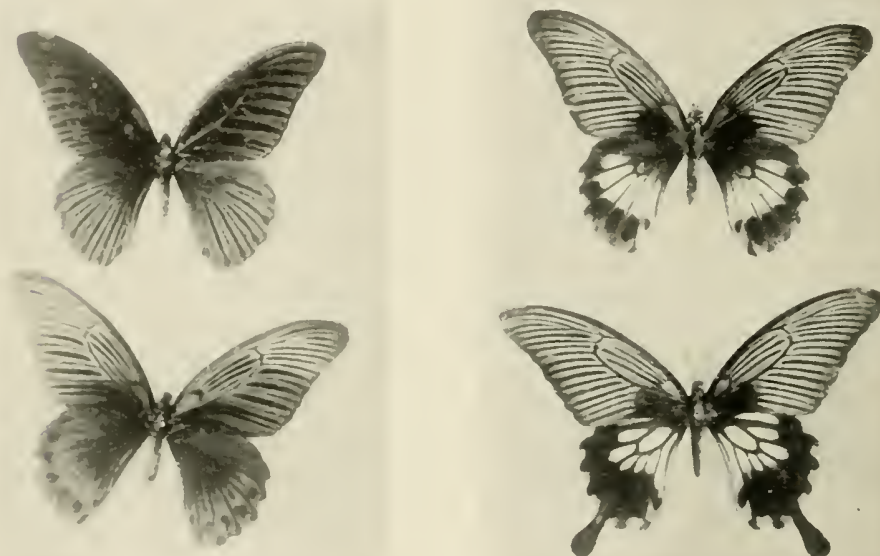

Fici. 76. - Papilio Memnon. 1, male; 2, 3, 4, three types of females. (After Meijere.)

that the heredity of the secondary sexual characters can be studied quite apart from the influence of the sex glands. How, then, are they inherited so that they appear in one sex and not in the other sex? Within the last two or three years the inheritance of the secondary sexual differences in insects has been studied.

First, there is the case of the clover butterfly, Colias philodice, that Cierould has worked out, where there 
are two types of females and one kind of male (Fig. 66).

Without giving the analysis of this case I may say that the results can be explained on a Mendelian basis. The peculiar feature of Gerould's explanation is that two doses of the yellow-producing determiner in the female give yellow color - one dose gives white. In the male, on the other hand, one dose of yellow gives yellow.

The second case is that of Papilio memnon, worked out by de Meijere from the experiments of Jacobson. There is one male type and three female types, Fig. 76. De Meijere accounts for the results of matings in this species recorded by Jacobson on the assumption of three factors, one for each type of female. The three factors are treated as allelomorphs, and therefore only two of them can be present in any one individual, and since they are allelomorphs they will pass into different gametes. The order of dominance is Achates, Agenor, Laomedon. The male carries these same factors, but they are not effective in him. Baur accounts for the results in a somewhat different way, but involving ordinary Mendelian conceptions.

An interesting case is that reported by Foot and Strobell. They crossed a female of a bug, Euschistus variolarius, the male of which has a black spot on the end of the body (the female lacking the spot), with a male of Euschistus serous that lacks the spot both in the males and the females (Fig. 77). The daughters had no spot; the sons had a faint spot, less developed than in variolarius. When these $\left(F_{1}\right)$ offspring were inbred, they obtained 249 females without a spot, 
107 males with a spot (developed to different degrees), and St males without a spot. The authors give no explanation of their results - but they use the re-
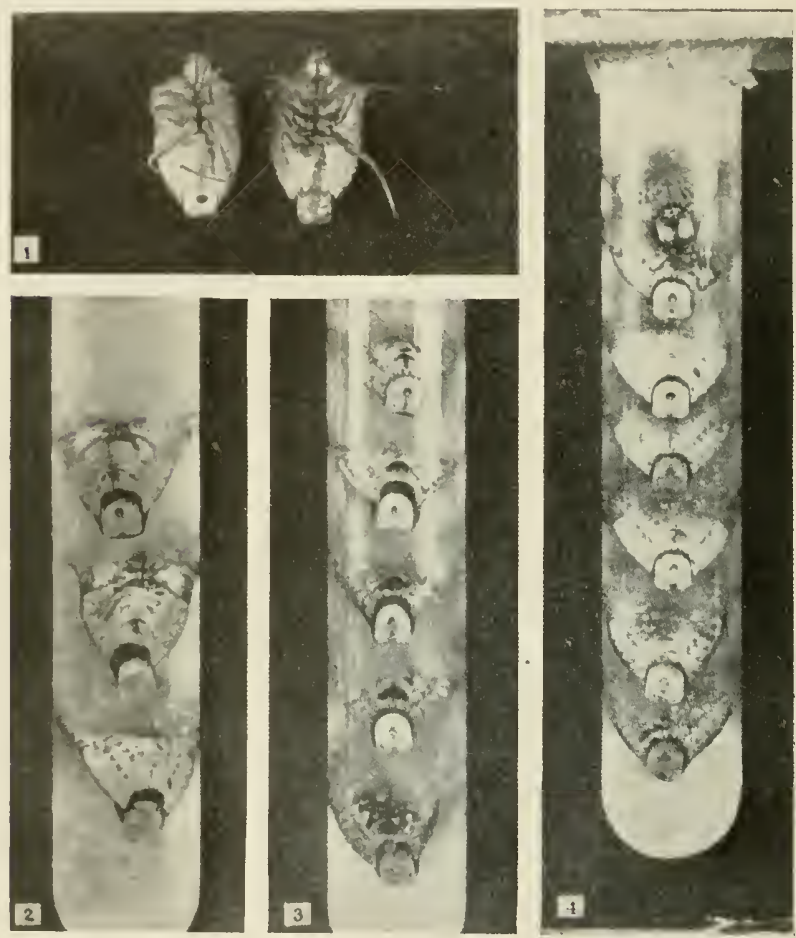

Fig. 77. - To left, in 1, is male of Euschistus variolarius, to right male of $E$. servus. 2 and 3 show eight $F_{2}$ males; 4 shows seven $F_{2}$ males from another mating. (After Foot and Strobell.)

sults to discredit some of the explanations, that rest on the assumption that the chromosomes are the chief factors in Mendelian heredity. I venture, nevertheless, to suggest the explanation shown on the accom- 
panying diagram (Fig. 78). The analysis rests on the assumption that neither one, nor two doses of $S$ in the female is able to produce a spot, while in the male one dose of $S$ suffices.

\begin{tabular}{|c|c|c|c|}
\hline $\begin{array}{l}\text { E. variola } \\
\text { E. servus }\end{array}$ & & $\begin{array}{l}S X- \\
s X-\end{array}$ & \\
\hline$F_{1}$ & & $\begin{array}{l}s X S X \\
s X S\end{array}$ & $\begin{array}{l}\text { spotless } \\
\text { spotted }\end{array}$ \\
\hline $\begin{array}{c}\text { Gametes } \\
\text { of } F_{1}\end{array}$ & $\begin{array}{l}\text { Eggs } \\
\text { Sperm }\end{array}$ & $\begin{array}{l}s X-s \\
s X-s\end{array}$ & $\begin{array}{l}X \\
X-s-S\end{array}$ \\
\hline \multirow{2}{*}{$F_{2}$} & & $\begin{array}{l}s X s X \\
s X S X \\
S X s X \\
S X S X\end{array}$ & spotless $q$ \\
\hline & & $\begin{array}{l}s X s \\
s X S \\
S X s \\
S X S\end{array}$ & $\begin{array}{ll}\text { spotless } & \delta \\
\text { spotted } & \delta \\
\text { spotted } & \sigma \\
\text { spotted } & \delta\end{array}$ \\
\hline
\end{tabular}

FIG. 78. - Diagram to show inheritance of spot when E. variolarius ( $q$ ) is mated to E. servus $\left(\sigma^{\circ}\right) . \quad S=$ spot. $s=$ no spot. $X=$ sex chromosome, that does not carry the factor $S$ for spot.

It is very important to understand just what is meant by this ; for otherwise it may seem only like a restatement of the facts. In the $F_{2}$ female with the formulæ $S X S X$, with two doses of the $S$ factor, no spot is assumed to appear (nor in the hybrid female $S X s X$ ). At first sight it seems that a female having the formula $S X S X$ is only double the male with $s X S$, especially if small $s$ is interpreted to mean absence of spots. But this view, in fact, involves a misconception of what the factorial hypothesis is intended to mean. 
To make this clearer, I have written out the case more fully :

$$
\begin{array}{lr}
X A B C S & X A B C S \text { ㅇ } \\
X A B C S & A B C s \delta
\end{array}
$$

In this, as in all such Mendelian formulæ, the result (or character) that a factor produces depends on its relations to other things in the cell (here $A B C$ ). We are dealing, then, not with the relation of $X$ to $S$ alone, but this relation in turn depends on the proportion of both $X$ and $S$ to $A B C$. It is clear, if this is admitted, that the two formulæ above - the one for the male and the other for the female-are neither identical nor multiples.

It wili be noted that in only one of these attempts to explain in insects the heredity of the secondary sexual characters have the factors for the characters been assumed to be carried by the sex chromosomes. If one accepts the chromosome basis for heredity, these results may be explained on the assumption that the factors lie in other chromosomes than the sex chromosomes.

In the next case, however, that I shall bring forward the factors must be assumed to be in the sex chromosomes themselves.

The mutant of drosophila with eosin eyes that arose in my cultures is the case in question. The female has darker eyes than the male. The experimental evidence shows that the factor for eosin is carried by the sex chromosomes. In the female it is present, therefore, in duplex, or, as we say, in two doses; in the male in one dose. 
The difference in color can be shown, in fact, to be due to this quantitative relation. If, for instance, an eosin female is mated to a white-eyed male, her daughters have light eyes exactly like those of the eosin male. The white-eyed fly lacks the eosin factor in his sex chromosomes (as suitable matings show), hence the hybrid female has but one dose of eosin, and in consequence her eye color becomes the same as the male.

In this case a sex-linked character is also a secondary sexual character because it is one of the rather unusual cases in which a factor in two doses gives a stronger color than it does in one dose.

\section{PARASITIC CASTRATION OF CRUSTACEA}

Let us turn now to a group in which nature performs an interesting operation.

Giard first discovered that when certain male crabs are parasitized by another crustacean, sacculina (a cirriped or barnacle), they develop the secondary sexual characters of the female. Geoffrey Smith has confirmed these results and carried them further in certain respects. Smith finds that the spider crab, Inachus mauritanicus, is frequently infected by Sacculina neglecta (Fig. 79). The parasite attaches itself to the crab and sends root-like outgrowths into its future host. These roots grow like a tumor, and send ramifications to all parts of the body of the crab.

The chief effect of the parasite is to cause complete or partial atrophy of the reproductive organs of the crab, and also to change the secondary sexual characters. Smith says that of 1000 crabs infected by 
saceulina, $70 \%$ of both males and females showed alterations in their secondary sexual characters.

As a control, 5000 individuals not infected were examined, only one was unusual, and this one was a hermaphrodite (or else a crab recovered from its parasite).

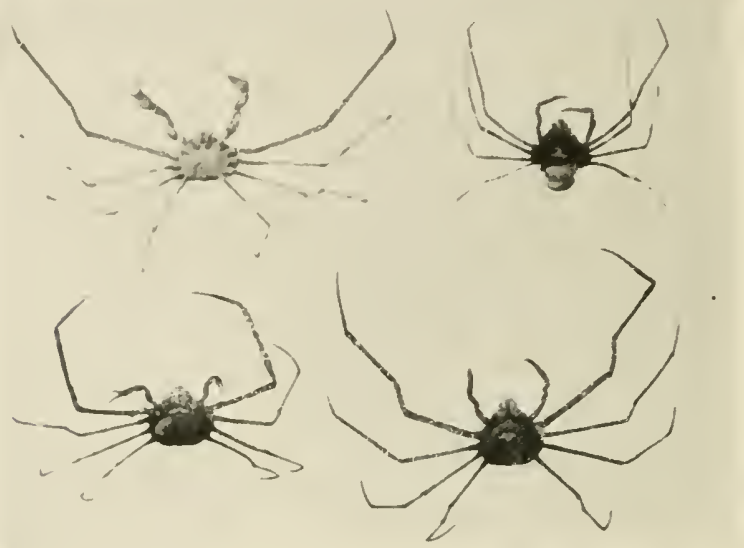

FIs. 79. - A male of Inachus mauritanicus (upper left hand). Female of Inachus scorpi (lower left hand). Male of Inachus mauritanicus carrying on its abdomen two specimens of Danalia curvata and a small Sacculina neglecta (upper right hand). Male of Inachus mauritanicus with a Sacculina ncglecta on it (lower right hand). The abdomen and chelæ of the host are intermediate in character between those of an ordinary male and female. (After Geoffrey smith.)

As the figures (Fig. 80) show, the adult male has large claws; the female, small ones. He has a narrow abdomen; she has a broad one. In the male there is a pair of stylets on the first abdominal ring (and a pair of greatly reduced appendages behind them). The adult female has four biramous abdominal appendages with hairs to carry the eggs. 

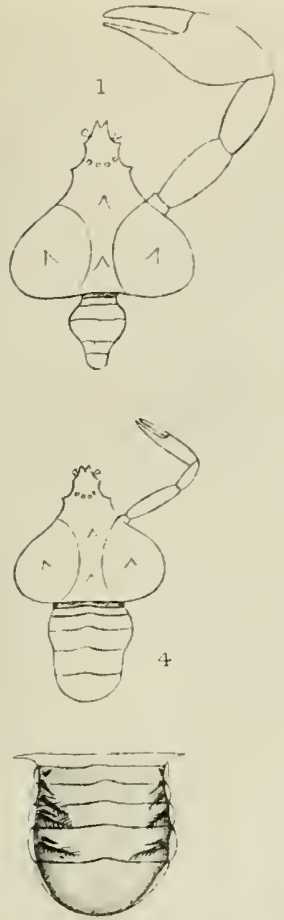

8.

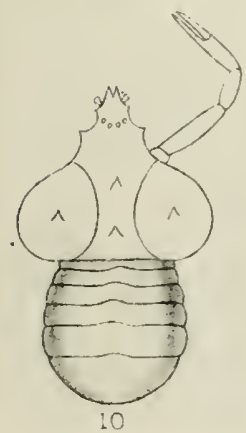

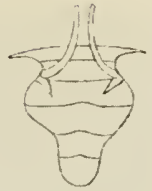

2

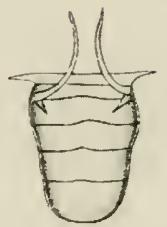

5

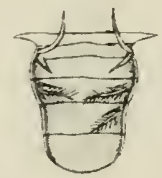

6

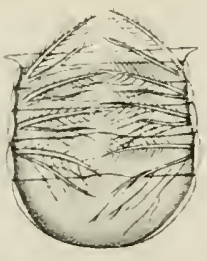

11

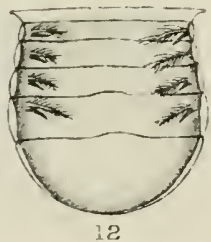

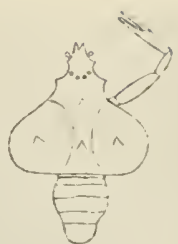

3
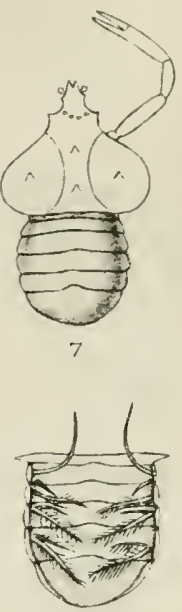

9

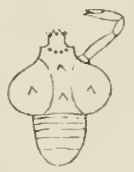

13

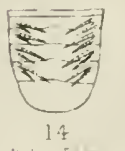

Fig. 80, - 1, adult normal male; 2, under side of abdomen of normal 
The infected males "show every degree of modification towards the female type." The legs are small, the abdomen broad, the stylets reduced, and the typical biramous appendages with hairs appear.

When the female crab is infected she does not change "toward" the male type, although the ovary may be destroyed. The only external change is that the abdominal appendage may be reduced.

In a hermit crab, Eupagurus meticulosus, infected by Peltogaster curvatus, similar results have been obtained. The infected male assumed the ordinary sexual characters of the female, but the females showed no change towards the male.

In these cases it seems probable that the testes of the male suppress the development of the secondary sexual characters that appear ordinarily only in the females. The case is the reverse of that of the birds and different again from that of the mammals.

In birds and mammals the secondary sexual characters are in many cases directly dependent on the internal secretions of the sex glands. These secretions are carried alike to all parts of the body, hence the absence of bilateral gynandromorphs in these groups.

adult male; 3, male infected with saceulina, showing reduetion of ehela and slight broadening of abdomen; 4,5 , showing attenuated copulatory styles and slight hollowing ont of abdomen; 6 , under side of abdomen of a similar male specimen, showing reduetion of eopulatory styles and presenee of asymmetrically plaeed swinmerets eharacteristic of female; 7 , infected male which has assumed emplete female appearanee; $\delta$, under side of abdomen of 7 , slowing redneed copulatory styles and swimmerets; 9 , under side of ablomen of similar male specimen with well-developed eopulatory styles and swimmerets; 10 , adult frmale, normal; 11 , under side of abdomen of 10, showing swimmerets and trough-shaped abdomen; 12, under side of abdomen of infected female, showing reduetion of swimmerets; 13, immature frmale showing small flat abdomen; 14, under side of abdomen of 13 , showing flat surface and rod-like swimmerets. (After Geoffrey Smith.) 


\section{CONCLUSIONS}

In conclusion it is evident that the secondary sexual characters in four great groups, viz. mammals, birds, crustacea, and insects, are not on the same footing. Their development depends on a different relation to the reproductive organs in three of the groups, and is independent of the reproductive organs in the fourth. It is not likely, therefore, that their evolution can be explained by any one theory, even by one so broad in its scope as that of sexual selection.

If, for example, in the mammals a more vigorous male, due to greater development of the testes, were "selected" by a female, the chances are that his secondary sexual characters will be better developed than are those of less vigorous males, but he is selected, not on this account, but because of his vigor. If a male bird were "selected" on account of greater vigor, it does not appear that his secondary sexual characters would be more excessively developed than those of less vigorous males, provided that his vigor were due to the early or greater development of the testes. If in birds the male by selecting the female has brought about the suppression of the male plumage, which is their common inheritance, he must have done so by selecting those females whose ovaries produced the greatest amount of internal secretions which suppresses male-feathering. Moreover, he must have selected, not fluctuating variations, but germinal variations. In insects the development of the secondary sexual characters is not connected with the condition of the reproductive organs, but is determined by the complex 
of factors that determines sex itself. If selection acts here, it must act directly on germinal variations, that are independent in origin of the sex-determining factor, but dependent on it for their expansion or suppression.

These considerations make many of the earlier statements appear crude and unconvincing; for, they show that the origin of the secondary sexual characters is a much more complex affair than was formerly imagined.

These same considerations do not show, however, that if a new germinal character appeared that gave its possessor some advantage either by accelerating the opposite sex to quicker mating or by being correlated with greater vigor and thereby making more certain the discovery of a mate, such a character would not have a better chance of perpetuation. But in such a case, the emphasis no longer lies on the idea of selection with its emotional implications, but rather on the appearance of a more effective machine that has arisen, not because of selection, but, having arisen quite apart from any selective process, has found itself more efficient. Selection has always implied the idea that it creates something. Now that the evidence indicates that selection is not a guaranteed method of creating anything, its efficiency as a means of easy explanation is seriously impaired. 


\section{CHAPTER VI \\ Gynandromorphism, Hermaphroditism, Parthenogenesis, and Sex}

Three different sex conditions occur in animals and plants that have a direct bearing on problems of Heredity and Sex.

The first condition is called Gynandromorphism a condition in which one part of the body is like the male, and the other part like the female.

- The second condition is called Hermaphroditism a condition in which the individuals of a species are all alike - maleness and femaleness are combined in the same body. Two sets of reproductive organs are present.

The third condition is called Parthenogenesis a condition in which the eggs of an animal or plant develop without being fertilized.

\section{GYNANDROMORPHISM}

Gynandromorphs occur most frequently, in fact almost exclusively, in insects, where more than one thousand such individuals have been recorded. They are most abundant in butterflies, common in bees (Fig. 81) and ants, rarer in other groups. They occur relatively more often, when two varieties, or species, are crossed, and this fact in itself is significant. A few examples will bring the cases before us.

In my cultures of fruit flies several gynandro- 
morphs have arisen, of which two examples are shown in Fig. S2. In the first case the fly is female on one side, as shown by the bands of her abdomen, and male on the other side (upper right-hand drawing).

In the second case the fly looked like a female seen from above. But beneath, at the posterior end, the genital organs of the male are present, and normal

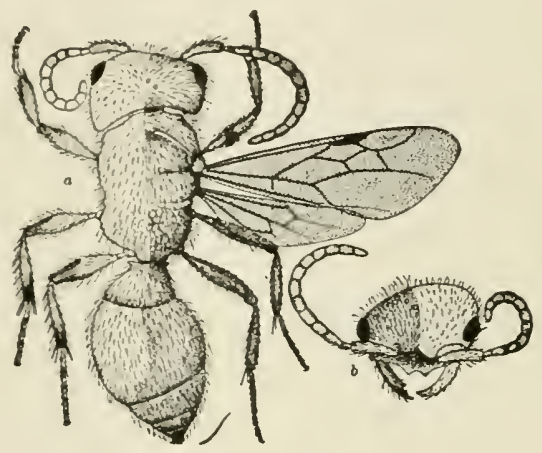

F1G. 81. - A gynandromorph mutillid wasp, Pseudomethoca canadensis, male on right side, female on left side. (After Wheeler.)

in structure. In the latter case the fly is ostensibly a female, except for the male organs of reproduction. How can we interpret these cases? We find a clue, I think, in the bee. It is known that if the egg of the bee is fertilized, it produces a female - only female-producing sperms are formed. If it is unfertilized, it produces a male. In the bee two polar bodies are produced, and after their extrusion the number of chromosomes is reduced to half, as in ordinary cases. The haploid number produces a male; the double number produces a female.

Boveri pointed out that if through any chance the 
entering sperm should fail to reach the egg nucleus before it divides, it may then fuse with one of the halves of the egg nucleus after that divides. From the
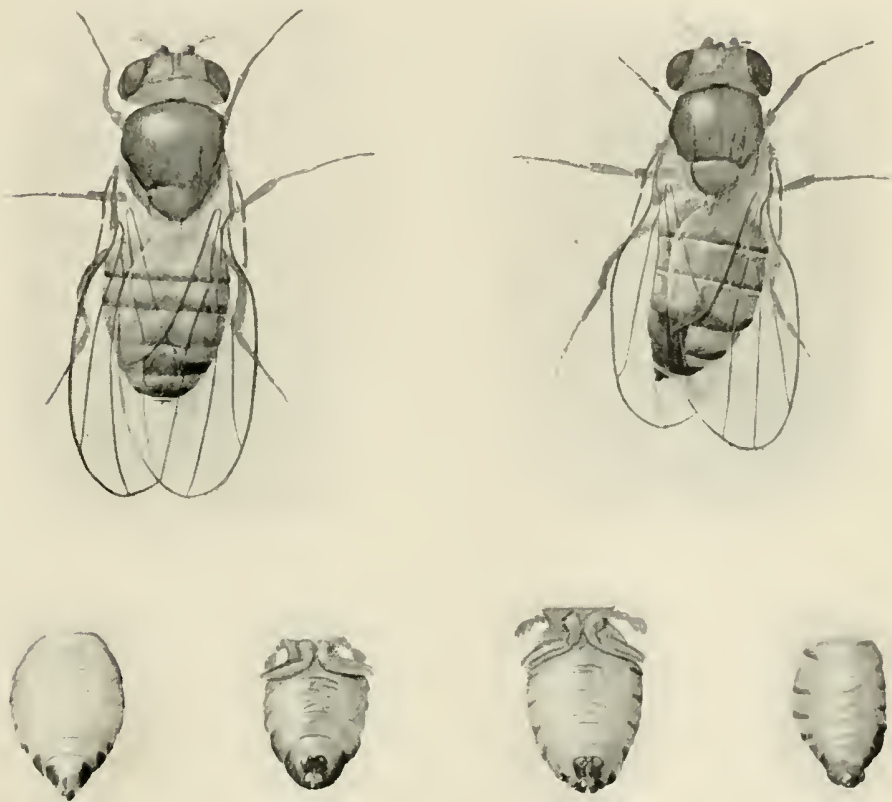

Fig. 82. - Two gyuandromorphs of Drosophila ampelophila. Upper left-hand figure, female dorsally, male ventrally (as seen in third figure, lower line). Upper right-hand figure, male on left side, female on right, and correspondingly the under side shows the same difference (lower row, last figure to right. Lower row from left to right; normal female, normal male, vertical gynandromorph and lateral gynandromorph.

half of the egg containing the double nuclei female structures will develop; from the other half, containing the half number of chromosomes, male structures (Fig. 83, A). Here we have a very simple explanation of the gynandromorphism. 
There is another way in which we may imagine that the results are brought about. It is known that two or

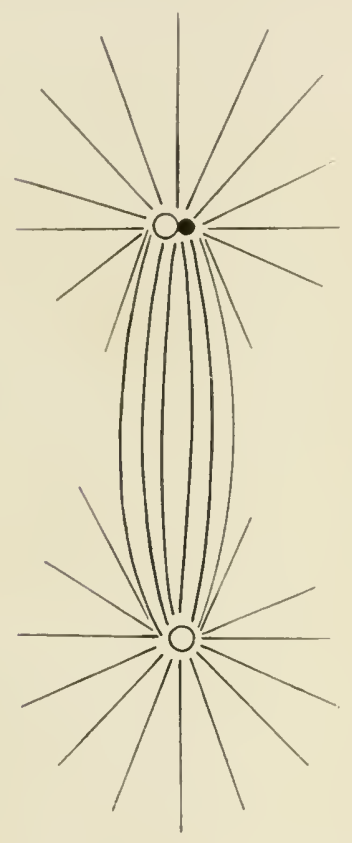

A

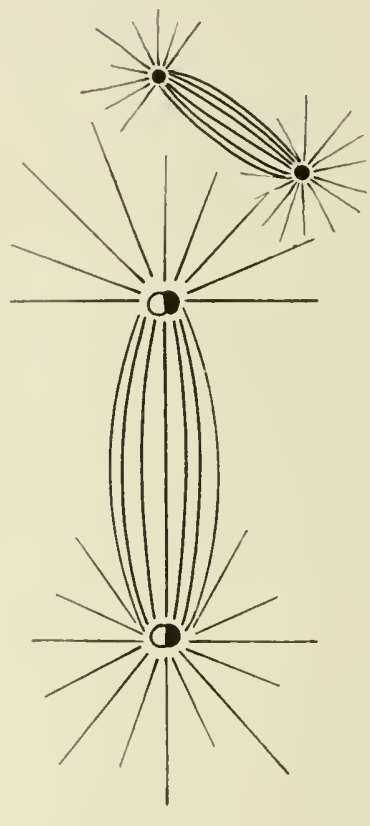

FIG. 83. - Diagram, illustrating on left (A) Boveri's hypothesis, on right (B) the author's hypothesis, of gynandromorphism.

more spermatozoa frequently enter the egg of the bee. Should only one of them unite with the egg nucleus, the parts that descend from this union will be female. If any of the outlying sperm should also develop, 
they may be supposed to produce male structures (Fig. 83, B).

The first case of the fly, in which one half the body is male and the other female, would seem better in accord with Boveri's hypothesis. In its support also may be urged the fact that Boveri and Herbst have shown that the belated sperm-nucleus may unite with one of the two nuclei that result from the first division of the egg nucleus.

On the other hand, the second case of the fly (where only a small part of the body is male) may be better accounted for by my hypothesis. It is known that single sperms that enter an egg without a nucleus, or even with one, may divide. The two hypotheses are not mutually exclusive, but rather supplementary.

Toyama has described a gynandromorph in the silkworm that arose in a cross between a race with a banded caterpillar (the female parent) and a race with a white caterpillar (the male parent). As shown in Fig. 84, the gynandromorph was banded on the left (maternal) side and white on the other (right) side. When the adult moth emerged, the left side was female and right side was male. Since the sperm alone bore the white character, which is a recessive character, it appears that the right side must have come from sperm alone. This is in accordance with my hypothesis, but I have also shown that Gynandromorphs may arise through somatic dislocations of the sex chromosomes in the early embryo. Gynandromorphs are not uncommon in insects, rare (or never present) in birds and mammals.

The explanation of this difference is found, I think, in 


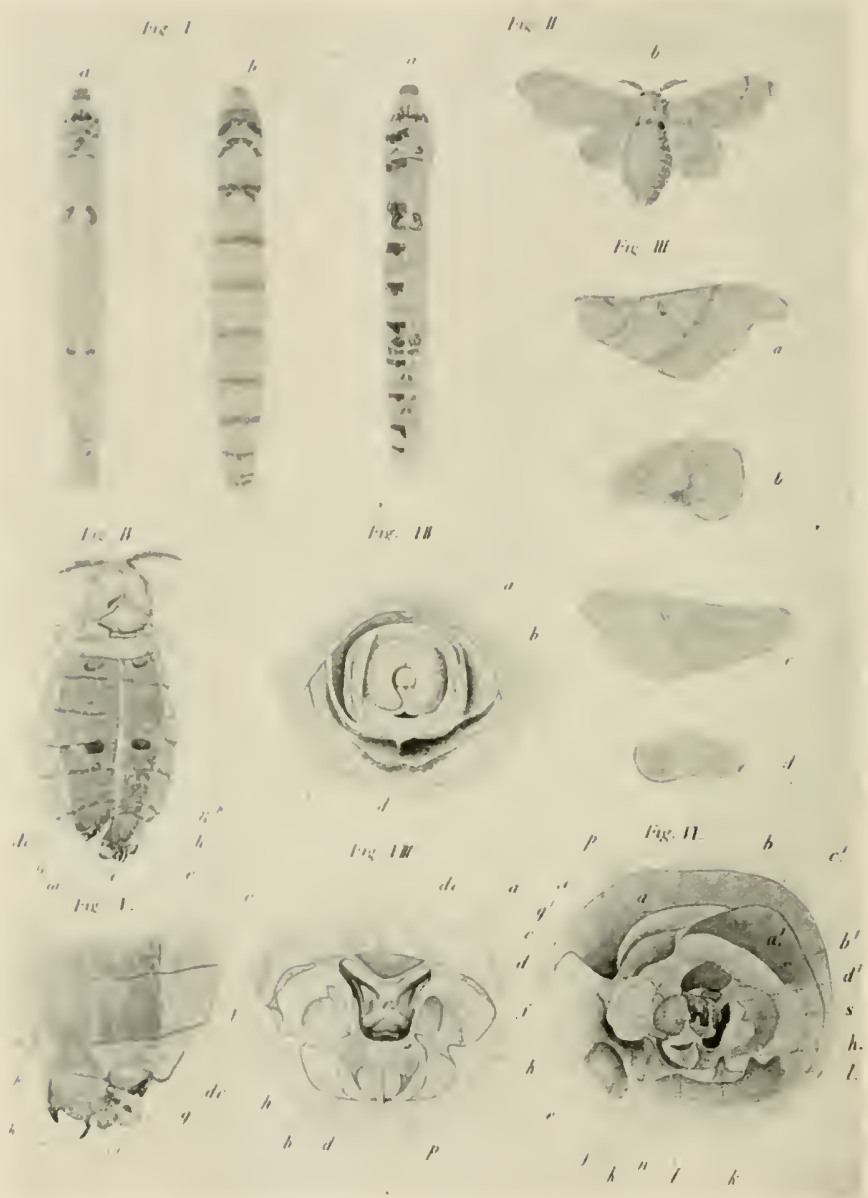

FIG. at. - I, $a$, plain, $b$, striped caterpillar of silkworm. II, $a$, gynandromorph silkworm, b, moth of same. III, wings of last. IV, dorsal view of same moth. V, abdomen of same. VI, end of abdomen of same moth. VII, normal female, and VIII, a normal male. (After Toyama.) 
the relation of the secondary sexual characters to the sex glands. In insects the characters in question are not dependent on the presence or absence of these glands. Hence, when such conditions occur after fertilization, as those I have just considered, each part may develop independently of the rest.

\section{HERMAPHRODITISM}

In almost all of the great groups of animals a condition is found in which complete sets of ovaries and testes occur in the same individual. This condition is called "hermaphroditism." In some groups of animals, as in flatworms, leeches, mollusks, hermaphroditism is the rule, and it is the common condition in flowering plants. Sometimes there is only one system of outlets for eggs and sperm, but not infrequently each has a separate system.

Here there is no problem of the production of males and females, for one kind of individual alone exists. But what determines that in one part of the body male organs develop, and in another part a female system?

Two views suggest themselves, either somatic segregation, or regional differentiation. By somatic segregation I mean that at some time in the development of the embryo - at some critical division - a separation of chromosomes takes place so that an egg-producing group and a sperm-producing group is formed. There is no direct evidence in support of this view.

Another view is that the formation of ovary and testis is brought about in the same way as all differentiations of body organs, as for example the 
formation of liver and lungs and pancreas from the digestive tract. The following case may perhaps be considered as supporting such an hypothesis. In a hermaphroditic worm, Criodrilus lacuum the ovaries lie in the thirteenth and the testes in the tenth and eleventh segments. If the anterior end be eut off, a new one regenerates, as shown by Janda (Fig. 85),
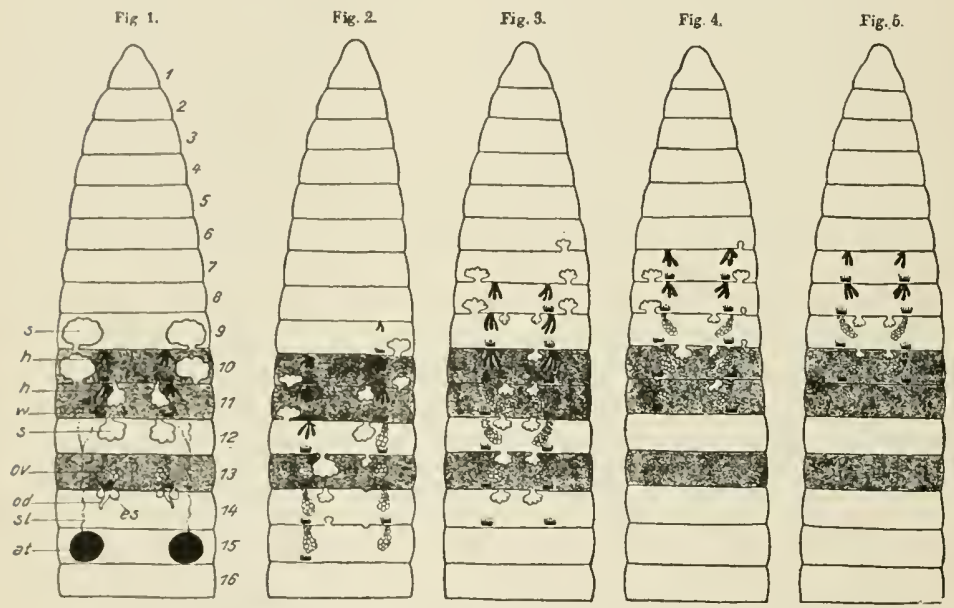

Frg. sij. - 1, anterior end of normal eriodrilus, showing reproductive system; 2-5, regenerated anterior ends. (After Janda.)

in which the ovaries and testes reappear approximately in their appropriate regions. It is true their location is more liable to vary than in the normal worm, but this is unimportant.

In the Gephyrean worm, Bonellia viridis, the degenerate male is parasitic on the female. Baltzer has discovered that every fertilized egg is potentially a male or a female. For, if the swimming larvæ have a chance 
to settle down on an adult bonellia they become males; but if the larvæ have no such opportunity a long period without further development intervenes, and later the larvæ become, for the most part, females, a few become males, and a few hermaphrodites. Bonellia appears therefore to be a protandric hermaphrodite, - like many plants. Somewhat similar relations are known for $H y d r a$ viridis, as shown by Nussbaum, and by Whitney.

In cases where a sexual generation alternates with a hermaphroditic generation, the problem of the two

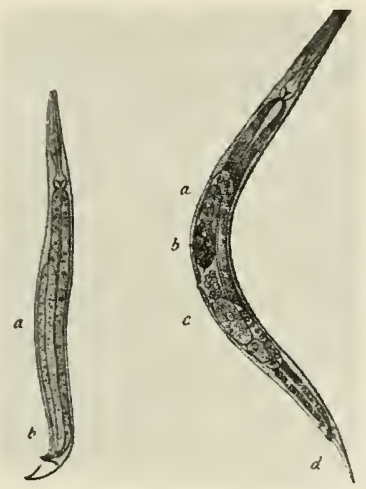

FIG. 86. - Rhabditis nigrivenosa, male (left) and female (right). (After Leunis.)

sexes reappears. There is but one case in animals that has been adequately worked out. A nematode worm, Rhabditis nigrovenosa, lives as a parasite in the lungs of frogs. It is an hermaphrodite. Its eggs give rise to another generation that lives in mud and slime. In this generation two kinds of individuals are present - true males and females (Fig. 86). The females produce eggs, that are fertilized, and develop 
into the hermaphrodites which find their way again into the lungs of frogs.

Boveri and Schleip have worked out the history of the chromosomes in this case. The cells of the

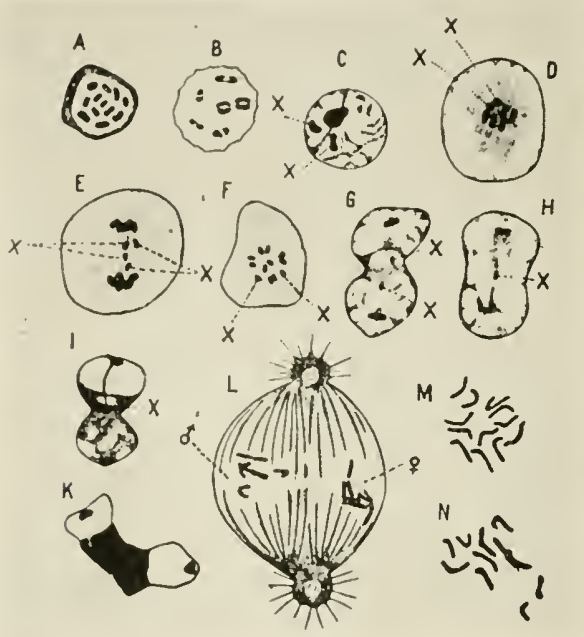

Fıg. \7. - Cliromosones of Angiostomum. (A), oögonia; (B), equatorial plate of first maturation division: $(C)$, young spermatoeyte; $(D)$, first spernutoryte division in metaphase; $(E)$, same in anaphase; $(F)$, spermatocyte of second division; $(G)$, and $(H)$, division of same; $(I)$, and $(K)$, loss of $X$ at plane of division; $(L)$, first segmentation division of a male enbryo; two sets of chromosomes ( 5 and $6=11$ respectively) separate; ( $M$ I ) equatorial plate of dividing cell of female embryo $=12$ ehromosomes; $(N)$, same from male embryo $=11$ ehromosomes. (After Schleip.)

hermaphrodite have twelve chromosomes (Fig. 87). The eggs, after extruding two polar bodies, have six chromosomes. The spermatozoa that develop in the body of the same animal have six or five chromosomes each, because one chromosome is lost in half 
of the cells by being left at the dividing line between the two cells. We can understand how two kinds of individuals are produced by the hermaphrodites from the two classes of sperm combining at random with the eggs.

These two kinds of individuals are females with twelve chromosomes, and males with eleven chromosomes. How then can we get back to the hermaphroditic generation? Boveri and Schleip suggest that the males again produce two kinds of spermatozoa, they have shown this to be the case in fact, - and that the male-producing spermatozoa become functionless. Here we have at least an outline of some of the events in the life cycle of this worm in relation to the chromosomes, but no explanation of hermaphroditism.

Turning to plants, there are the interesting experiments of the Marchals with mosses. They show that the sporophyte is hermaphroditic and has the factors for maleness and femaleness combined as a result of fertilization; while in the formation of the spores the factors in question are separated.

Blakeslee has found somewhat similar relations in certain of the molds. The spores in molds contain more than one nucleus, therefore it is not clear how segregation in the sense used for other cases applies here.

In the flowering plants that are hermaphroditic we have Correns' experiments, in which he crossed an hermaphroditic type of Bryonia alba with a type $B$. dioica in which the sexes are separate. The cross when made one way gives only females, while 
the reciprocal cross gives males and females in equal numbers. Correns' interpretation is shown in the lower part of the next diagram.

\section{Bryouin dioica and B. alba}

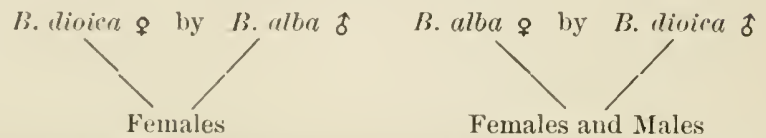

Currens' Erplanation

\begin{tabular}{|c|c|}
\hline $\begin{array}{cl}F-F & \text { B. dioica o } \\
(F, I)-(F, Y) & \text { B. alba } 5\end{array}$ & $\begin{array}{cl}(F, H)-(F M) & B . \text { alla } \% \\
F-M & \text { B. dioica of }\end{array}$ \\
\hline$F(F \cdot M)$ & $\begin{array}{l}F(F, Y) \text { female } \\
M(F, Y) \text { male }\end{array}$ \\
\hline
\end{tabular}

It is based in the first case on the assumption that the hermaphroditic condition of $B$. alba is recessive to the diceious condition of $B$. dioica, and that the female

\section{Lychnis dioica}

\section{Female FF male Ff. Hermaph. FH.}

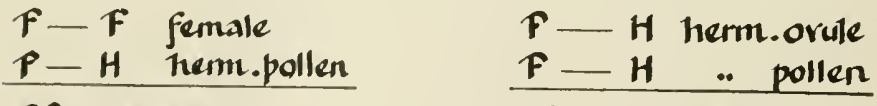

FF females

FH herm.
FF females

FH herm.

$F-H$ herm. orule

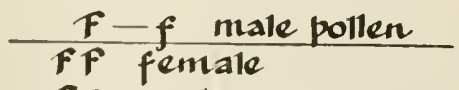

Ff male

FIG. 88. - Diagram to illustrate G. H. Shull's results on Lychnis dioica. The symbols here used are not those used by Shull. Two types are assumed not to appear, viz. $I I I$ and $H f$. Third cross should give $F H$ also. 
dioica is homozygous for the sex factor. The reciprocal cross is explained on the basis that maleness dominates femaleness. The sex-determining factors must here be different from cases like the insects.

Shull obtained as a mutant a hermaphroditic plant of Lychnis dioica. The next diagram (Fig. 88) gives the principal facts of his crosses. When a female plant is fertilized by the pollen of the hermaphrodite, two kinds of offspring are produced -- females and hermaphrodites. When the hermaphrodite is selffertilized, the same two classes are produced. When the ovule of the hermaphrodite is fertilized by the pollen from the male plant, two kinds of offspring are again produced - female and male. Shull's interpretation is too involved to give here. In the diagram the scheme is worked out on the purely arbitrary scheme that the hermaphrodite is $F H$, in which $F$ is a female factor, and $H$ a modification of it which gives hermaphroditism. This leads to the further assumption that ovule and pollen, bearing the $H$ factor, cannot produce a plant nor can the combination $f H$. This scheme is only intended as a shorthand way of indicating the results, and not as an interpretation of actual conditions.

\section{PARTHENOGENESIS}

A third important condition in which the heredity of sex is involved is found in parthenogenesis.

It has long been known to biologists, that in many different species of animals and plants eggs develop without being fertilized. This is recognized as a regular method of propagation in some species. The 
eggs are produced in the same way as are other eggs. They are produced in ovaries that have the same structure as the ovaries that give rise to ordinary eggs. Parthenogenetic eggs differ from spores, not only in their origin in an ovary, but in that they also produce polar bodies like ordinary eggs. Most, but not all, parthenogenetic eggs give rise, however, to only one polar body. Some of them at least fail to pass through the stage of synapsis, and, in consequence, they retain the full number of chromosomes.

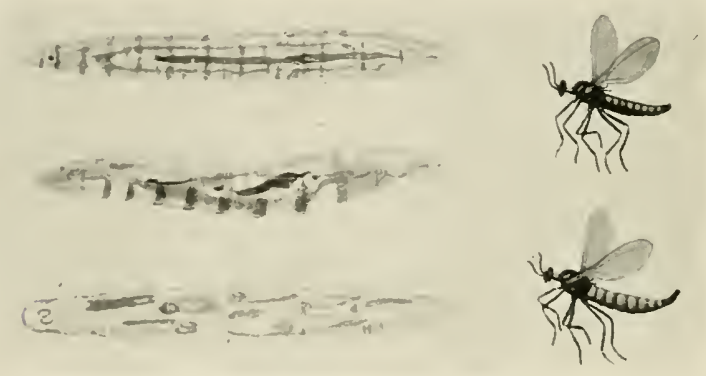

FIG. 89. - Miastor, sexual male and female (to right). Three larvæ with young inside (to left).

A few examples will bring the main facts before us.

A fly, miastor, appears in the spring of the year under two forms, male and female (Fig. 89). The eggs are fertilized and each produces a worm-like larva. This larva produces eggs while still in the larval stage. The eggs develop without fertilization, and produce new larve, which repeat the process. This method of propagation goes on throughout the rest of the year until finally the adult winged flies reappear.

The bee is the most remarkable instance, for here 
the same egg will produce, if it is fertilized, a female (queen or worker), or, if it is not fertilized, a male (drone). If the queen deposits an egg in a cell of the comb that has been built for a queen or a worker, she fertilizes the egg ; if in a drone cell, the egg is not fertilized. We need not conclude that the queen knows what she is about - the difference in shape of the drone cell may suppress the reflex, that in the other cases sets free the sperm.

The case of the bee has attracted so much attention that I may be allowed to pause for a moment to point out some of the most recent results connected with the formation of the germ-cells.

The egg produces two polar bodies - the process being completed after the sperm has entered the fertilized egg (Fig. 90). Eight chromosomes are present at each division. Eight remain in the egg (these are double chromosomes - therefore 16). The sperm brings in 8 (double) chromosomes so that the female comes to have 16 single chromosomes in her cells. There is only one kind of spermatozoön, as shown by the figure, for the first spermatocyte division is abortive - all the chromosomes passing into one cell only, and the second division gives rise to a small cell, that does not produce a spermatozoön, and a large cell that becomes a spermatozoön.

If the egg is not fertilized, it also gives off two polar bodies. It has 8 chromosomes left. The male develops with the half number. The formula for the female will be $X A B C D X A B C D$ and for the male $X A B C D$.

If the bee conforms to the ordinary type for insects, 
we may suppose that one sex chromosome is present in the male or at least one differential factor for sex, and that it is present in all the functional spermatozoa. The female will then have two such chromosomes and come under the general scheme for insects.
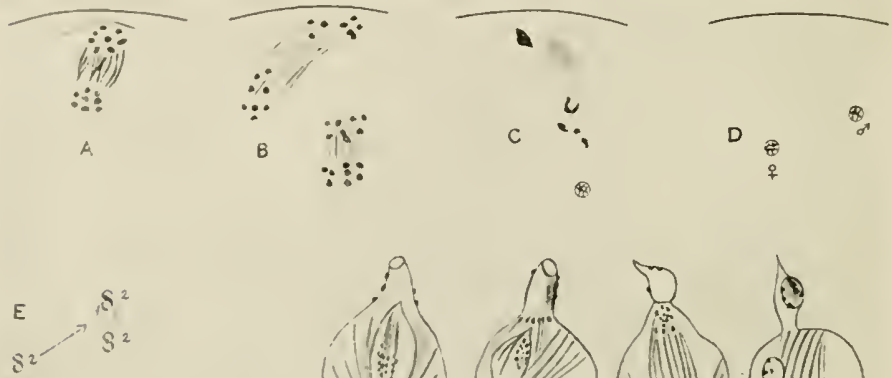

$s^{2}$

$\delta 10^{\circ}$

iti $+16=32$ i
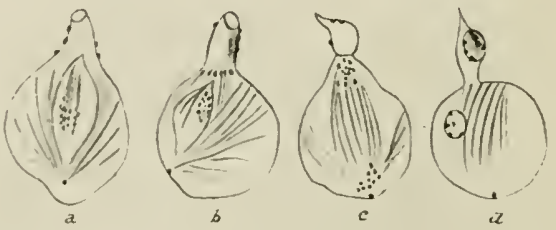

$160^{\circ}$

F.

FIG. 90. - Oögenesis and spermatogenesis in bee. Four upper figures, $A-D$, show formation of first $(A)$, and second $(B)$ polar bodies. Only inner group of chromosomes remains $(C)$ to form egg nucleus. Entrance of sperm nucleus in $D$. $E$ show's scheme of these two divisions involving eight double $\left(\$^{2}\right)$ chromosomes. $F$, first and second spermatocyte divisions, the first, $a, b$, abortive, leading to pinching off of a small cell without a nucleus, the serond, $c, c$, leading to formation of a large (functional) and an abortive cell (above).

In the gall fly, Neuroterus lenticularis, parthenogenetic females appear early in the spring. Their eggs produce females and males - the second generation. The fertilized eggs of these females give rise the following year to the spring parthenogenetic females. Doncaster has found that each parthenogenetic female 
produces eggs, all of which give rise to females or else to males. In connection with this fact he finds that the eggs of some females do not give off any polar bodies but retain the full number (20) of chromosomes.

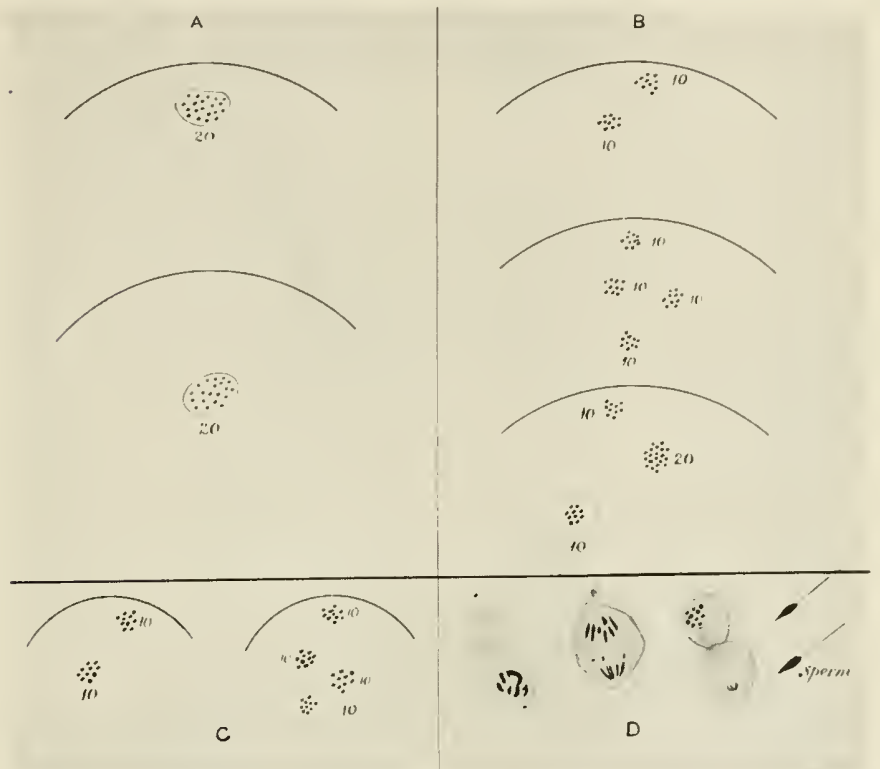

Fig. 91. - Illustrating chromosome cycle in Neuroterus. A, one type of spring female, whose eggs (containing 20 chromosomes) produce no polar bodies. Only sexual females result. $B$, the other type of spring female whose eggs form two polar bodies, leaving 10 chromosomes in egg. These eggs give rise to males. $C$, ripening of egg of sexual female (2d generation), and $D$, spermatogenesis of male (second generation).

These eggs produce sexual females (in left-hand side of Fig. 91). From the eggs of other parthenogenetic females two polar bodies are given off, and the half (10) number of chromosomes is left in the egg (see right-hand side of Fig. 91). These eggs produce males. The life 
cycle finds its explanation in these relations except that the origin of the two kincks of parthenogenetic females is unexplained. If we were justified in assuming that two classes of female-producing spem are made in the male, eron this point would be cleared up, for in this

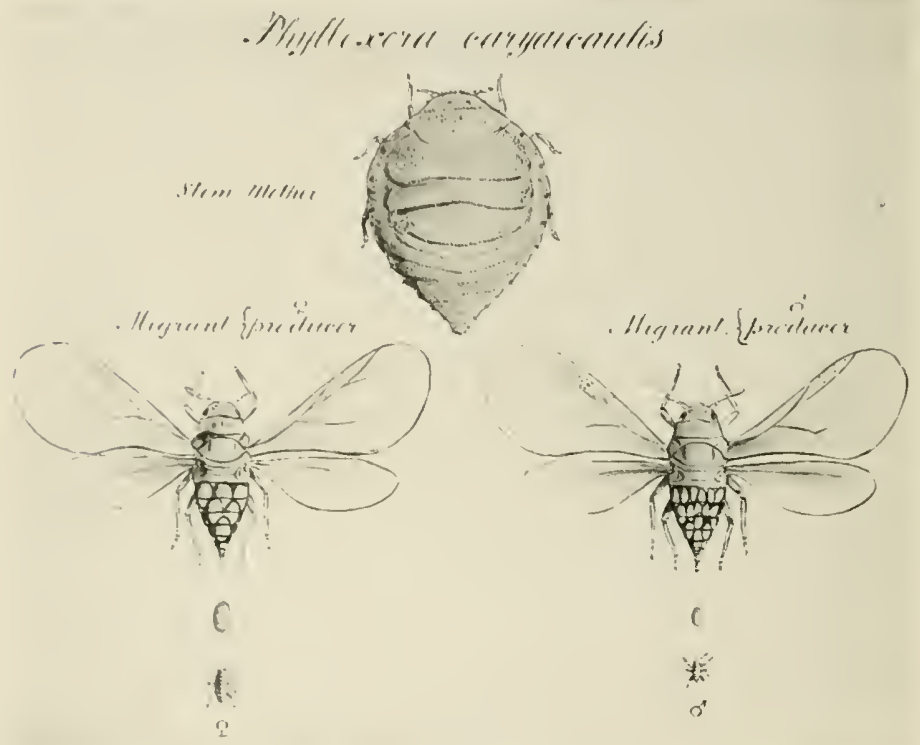

Iric. 92. - Life rycle of Phylloxera caryacaulis.

way the two classes of parthenogenetic females could be explained.

In another gromp of insects, the aphids and phylloxerans, the situation is different.

In the phylloxerans of the hickories there emerges in the spring, from a fertilized egg, a female known as the stem mother (Fig. 92). She pierces a young leaf 
with her proboscis, which causes a proliferation of the cells of the leaf. Eventually the leaf cells grow so fast that the stem mother is overarched in the gall that she has called forth.

Inside the gall she begins to lay her eggs. From these eggs emerge young individuals that remain in the gall until they pass their last molt, when they become winged migrants. Externally all the migrants are alike; but if they are dissected, it will be found that some of them have large eggs, some small eggs. But all the offspring of the same mother are of one or of the other sort.

The migrants crawl out of the opening in the gall and fly away. Alighting on other hickories, they quickly deposit their eggs. From the large eggs the sexual females emerge. They never grow any bigger than the egg from which they hatched. In fact, they have no means of feeding, and contain only one large egg with a thick coat - an egg almost as large as the female herself.

From the small eggs of the migrants, minute males are produced - ripe at their birth. They fertilize the sexual female. She then deposits her single egg on the bark of the hickory tree. From this egg (that lies dormant throughout the entire summer and following winter) there emerges next spring a female, the stem mother of a new line.

Here we find three generations in the cycle - two of which reproduce by parthenogenesis. The first parthenogenetic generation gives rise to two kinds of individuals - one makes large eggs, the other small eggs. The large eggs produce sexual females, the small eggs males. 
A study of the ehromosomes has explained how some of these changes in successive generations are brought about. It has explained, for instance, how males are produced by parthenogenesis, and why the sexual egg produces only females. Let us take up the last point first.

When the spermatocytes are produced, we find, as in many other insects, that at one division a sex chromosome passes to one cell only (Fig. 93). Two classes of cells are produced - one with three, one with two, chromosomes. The latter degenerates, and in consequence only the female-producing spermatozoa become functional. All fertilized eggs give rise therefore to females.

The second point that has been made out concerns the production of the male. When the small egg produces its single polar body, all of the chromosomes divide, except one, which passes out entire into the polar body. In consequence the number of chromosomes left in the egg is one less than the total number. In a word, there are five chromosomes in the male, while there are six chromosomes in the female (Fig. 93). By throwing out one chromosome, the change is effected. The chromosome is the mate of the sex chromosome, that appeared as a lagging chromosome in the spermatogenesis.

In the large egg no such diminution takes place, consequently the diploid number of ehromosomes is present in the female. These unite in pairs and are reduced to three when the two polar bodies of the sexual egg are produced.

We see that by means of the chromosomes we can 
bring this case into line with the rest of our information bearing on the relation of the chromosomes to sex. One important point still remains to be explained. What causes some of the migrants to produce large
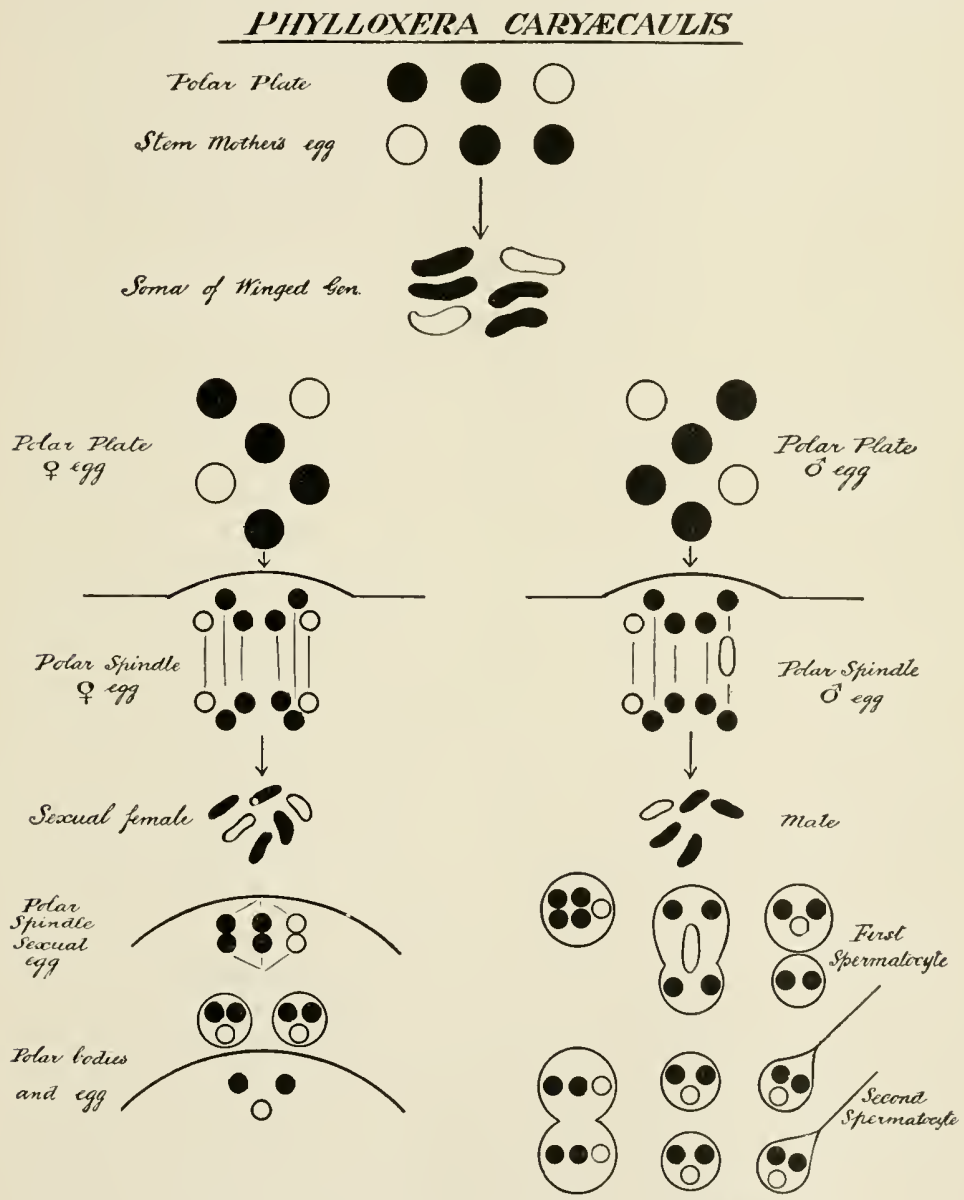

FIG. 93. - Chromosomal cycle of P. caryccaulis. 
cogs and others small eggs? 'There must be either two kinds of stem mother's or one kind with double potentiality. Inasmuch as in other parthenogenetic types there is experimental evidence to prove that environmental conditions determine which alternative state, whether male-producing or female-producing individual, is realized, so here we may, provisionally, follow the same interpretation. Once the course is determined the subsequent internal events follow for two gencrations in a definite order. If the stem mother has been affected in one way, all of her daughters produce large eggs; if in the other way, small eggs.

In another group of animals, the daphnians, parthenogenetic species occur, that, in certains respects, are like the phylloxerans; but these species illustrate also another relation of general interest.

The fertilized winter egg produces always a female, the stem mother, which gives rise by parthenogenesis to offspring like herself, and the process may continue a long time. Each female produces one brood, then another and another. The last broods fail to develop, and this is a sign that the female has nearly reached the end of her life.

But a parthenogenetic female may produce one or two large resting eggs instead of parthenogenetic females, and the same female may at another time produce a brood of males. The large resting eggs are inclosed in a thick outer protecting case. They must be fertilized in order to develop, yet they do not develop at once, but pass through an enforced, or a resting, stage that may be shortened, if the egg is dried and then returned to water. 


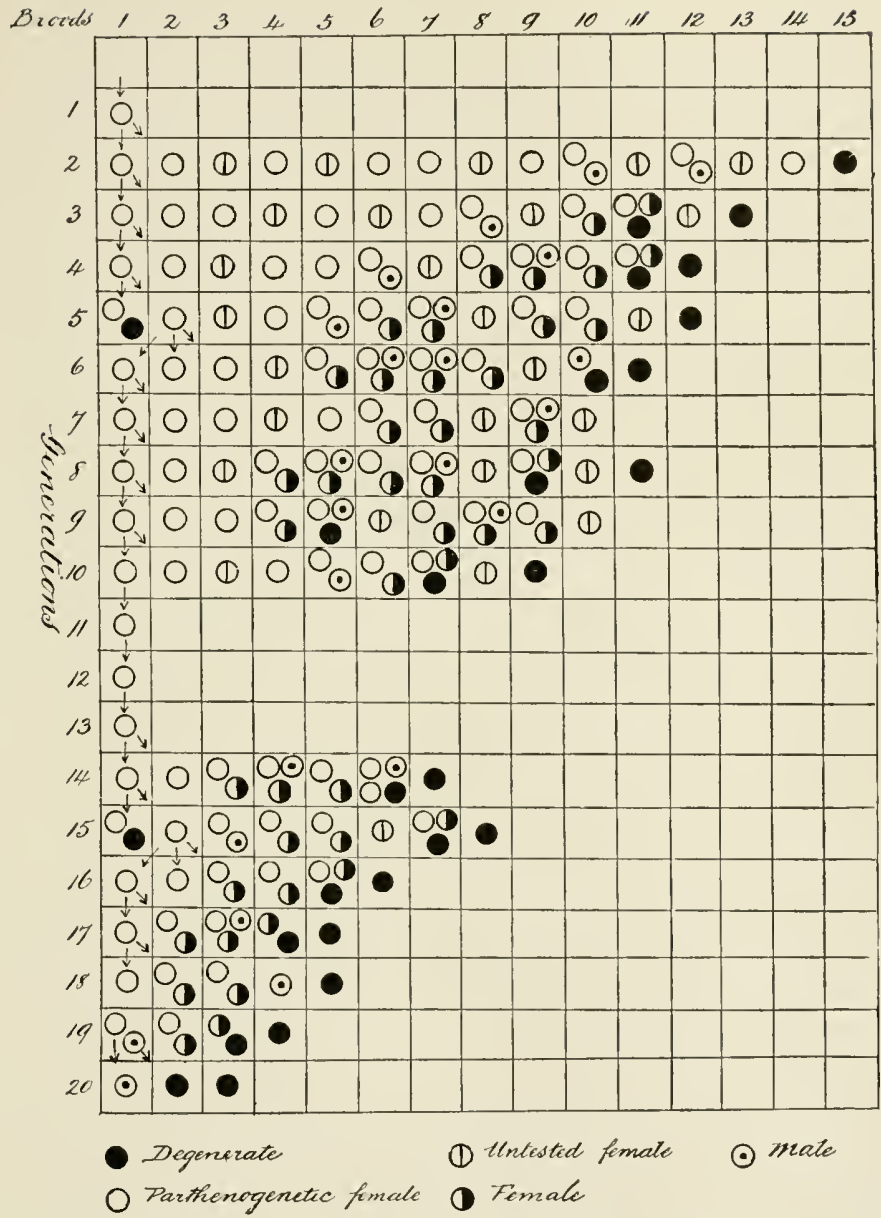

Fig. 94. - Life cycle of Simocephalus; successive broods in horizontal lines, successive generations in vertical lines. (After Papanicolau.) 
In this life history we do not know what changes take place in the chromosomes. It has, however, often been claimed in this ease that the transition from parthenogenesis to sexual reproduction is due to changes in the environment.

In fact, this is one of the stock cases cited in the older literature to show that sex is determined by external agents. It was said, that if the environment causes males to appear, then sex is determined by the environment. But as a matter of fact, in so far as changes in the environment affect this animal, they cause it to cease reproducing by parthenogenesis, and induce sexual reproduction instead. The evidence is consistent in siowing that any external change that affects the mode of reproduction at all calls forth either sexual eggs or males. The machinery of parthenogenesis is switched off, and that for sexual reproduction is turned on.

The discrepancies that appear in the older accounts are probably due, as Papanicolau suggests, to different observers using females that belong to different phases of the parthenogenetic cycle. Papanicolau, starting in each case with a winter egg, finds that as successive broods are produced the color of the parthenogenetic eggs can be seen to undergo a progressive change from blue to violet. As the change progresses the chance that males and sexual eggs ("females") will appear is greater. Until towards the end of the life of the individual the males and females come, as it were, of themselves (Fig. 94). If, however, individuals of successive broods are subjected to cold, it is found that while earlier broods do not respond, later ones respond 
more and more easily and change over to the sexual phase of the cycle.

What has just been said about the successive broods might be said equally of the first-born offspring of the successive generations, as Papanicolau's table shows (Fig. 94). Later born offspring respond more readily than do those that are historically nearer to the fertilized egg.

More recently Grosvenor and Smith have found for Moina that if females are reared alone (at $25^{\circ}-30^{\circ} \mathrm{C}$.) no sexual broods appear, while parallel cultures of females crowded together give 30 or higher per cents of males. Agar has carried isolated females through 46 parthenogenetic generations and has found that mothers from late brood also give only parthenogenetic offspring in a suitable environment.

A third type, Hydatina senta (Fig. 95), an almost microscopic wormlike animal belonging to the rotifers, reproduces by parthenogenesis.

The resting egg always gives rise to a parthenogenetic female, i.e. she also reproduces by parthenogenesis. Whitney has obtained 500 generations produced in this way. But from time to time another kind of individual appears. She is externally like the parthenogenetic female, but has entirely different capacities. Her eggs may be fertilized, and if they are they become resting eggs inclosed in a hard case. The sperm enters when the eggs are immature and still in the ovary of the mother. The presence of a spermatozoön in an egg determines that the egg goes on to enlarge and to produce its thick coat. But if perchance no males are there to fertilize the eggs, this same female produces a 
crop of male eggs that develop into males without being fertilized at all.

There are several facts of unusual interest in the

\section{HYDATINA SENTA}

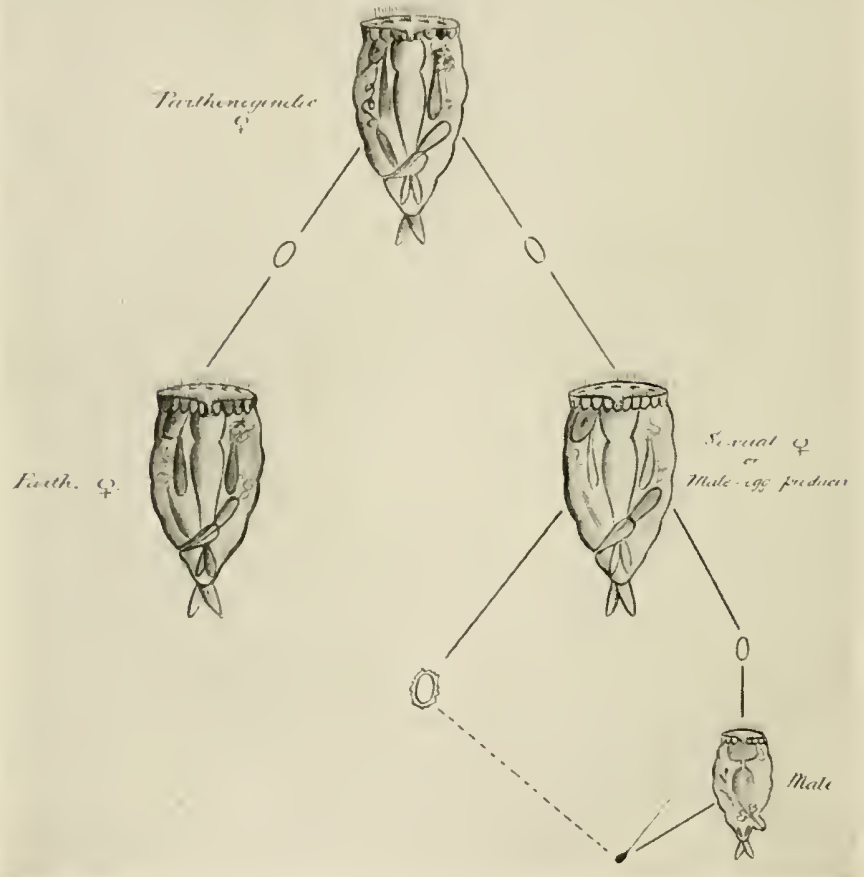

FIG. 95. - Life cycle of Hydatina senta.

life history of hydatina, but we have occasion to consider only one of them. It has been claimed in this ease also that external conditions determine the production of males. A more striking example of the erroneous- 
ness of this general conclusion would be hard to find; for, in the first place, as we have seen, the same individual that produces males will produce out of the same eggs females if she happens to be fertilized. In the second place the older evidence which was supposed to establish the view that certain specified changes in the environment cause the production of males has been overthrown.

The French zoölogist, Maupas, is deserving of high praise for working out some of the most essential facts in the life cycle of hydatina, and for opening up a new field of investigation. But the evidence which he brought forward to show that by a low temperature a high production of males is caused has not been confirmed by very careful and extensive repetition of his experiments by Whitney and by A. F. Shull. The evidence that Nussbaum obtained which seemed to him to show that food conditions determined the production of males has likewise not borne the test of more recent work by Punnett, Shull, and Whitney.

It has been found, however, that the production of the sexual phase of the cycle can be suppressed so that the animals continue almost indefinitely propagating by parthenogenesis. In several ways this may be accomplished. If hydatina is kept in a concentrated solution of the food culture, the sexual phase does not appear. The result has nothing to do with the abundance of food, for, if the food be filtered out from the fluid medium, the filtrate gives the same result. The following table given by Shull shows this very clearly. 


\begin{tabular}{|c|c|c|c|c|c|c|c|c|c|}
\hline \multirow{3}{*}{$\begin{array}{l}\text { SHRIsio } \\
\rightarrow 8\end{array}$} & \multirow{3}{*}{$\begin{array}{l}\text { W ITEK } \\
8 \%\end{array}$} & \multicolumn{8}{|c|}{ (HL) CULTIKE FILTRATE } \\
\hline & & \multicolumn{2}{|c|}{ Mne-fourth } & \multicolumn{2}{|c|}{ One-half } & \multicolumn{2}{|c|}{ Three-fourths } & \multicolumn{2}{|c|}{ Undiluted } \\
\hline & & $\Rightarrow q$ & \& & 89 & \& & c $q$ & \& & $\delta q$ & $q q$ \\
\hline $21 ;$ & $17 \%$ & $2 \pi$ & 407 & 15 & 850 & 8 & 362 & 0 & $3: 37$ \\
\hline $11 / 11$ of $\delta ?$ & 12.8 & \multicolumn{2}{|c|}{5.7} & \multicolumn{2}{|c|}{4.1} & \multicolumn{2}{|c|}{2.1} & \multicolumn{2}{|c|}{0.0} \\
\hline
\end{tabular}

Showing the number of male- and female-producers in the progeny of five sister individuals of IIydatina senta, one line being reared in spring water, the others in various concentrations of the filtrate from old food cultures.

Mitchell found that a sudden change in food causes male-producing individuals to appear in Asplanchna; and Whitney can now produce, at will, in Hydatina a high percentage of male producers. Females feeding on the colorless flagellate Polytoma were fed on the green flagellate Duniella, and gave birth to $80 \%$ of male producers; while the control female fed on Polytoma gave birth to only $9 \%$ of male producers. Since the eggs of the male producer give rise to sexual females, or to males, according to whether they are fertilized or whether they are not, sex itself is not here determined by the environment, but by fertilization; the environment determines the kind of reproduction.

\section{ARTIFICIAL PARTHENOGENESIS}

We have now considered some of the most striking examples of natural parthenogenesis in the animal kingdom. The facts show that fertilization of the egg is not in itself essential for development. The in- 
dividuals that develop from parthenogenetic eggs are as vigorous as those from eggs that have been fertilized. We have seen that such eggs without being fertilized are capable of producing sexual females and males. In one case, at least, we have seen how the process is accomplished.

When we review the facts of natural parthenogenesis, we find certain relations that arrest our attention.

Most parthenogenetic eggs give off only a single polar body, while fertilized eggs without exception give off two polar bodies. This difference is clearly connected with the fact that in parthenogenetic eggs the full number or diploid number of chromosomes is retainéd by the egg. ${ }^{1}$ In fertilized eggs half the chromosomes are thrown out in one of the two polar bodies. The number is made good by the chromosomes brought in by the spermatozoön.

But this difference does not in the least explain natural parthenogenesis; for we have experimental evidence to show, that an egg will develop when only half the number of chromosomes is present - one set will suffice.

There is another fact about parthenogenetic eggs that has, I believe, been generally overlooked. Many of these eggs begin to develop into an embryo before they reach the full size of the fertilized eggs of the same species. This is true at least of the eggs of aphids, phylloxerans, daphnians, and rotifers. I interpret this

${ }^{1}$ According to my observations on aphids and phylloxerans, the synapsis stage is omitted in parthenogenetic eggs, hence there is no union (or reduction) of the chromosomes. The omission of this stage may have something to do with parthenogenesis, although it is not evident what the relation may be. 
to mean that the eggs begin their development before there has been produced over their surface a layer that in the mature egg seems to have an important influence in restraining sexual eggs from development.

This brings us at once to a consideration of what keeps sexual eggs from developing until they are fertilized.

In recent years a great variety of methods has been discovered by means of which sexual eggs can be made to develop without fertilization. This process is called artificial parthenogenesis. We owe especially to Professor Jacques Loeb the most successful accomplishment of this important feat. The discovery in his hands has led to very great advances in our understanding of the developmental process.

The chief importance of Loeb's work lies, in my opinion, not only in the production of embryos without fertilization (nature has long been conversant with such methods), but in other directions as well.

First, it has thrown light on the nature of the inhibitory process that holds back the sexual egg from developing until the sperm enters.

Second, the information gained in this way tells us something of how the sperm itself may act on the egg and start it on its course.

Third, it opens up the opportunity of studying certain problems comnected with the determination of sex that can be gained in no other way.

Let me attempt briefly to elaborate some of these points.

In many eggs, perhaps in all, a membrane is produced 
at the surface of the egg immediately after the sperm has entered. Here we have ocular evidence that fertilization effects a change in the surface layer of the egg.

It has been shown that after this membrane is formed, the permeability of the egg to salts and other agents is affected and that the processes of oxidation are greatly accelerated.

In other words, the interior of the unfertilized egg is separated by means of its membrane from many things in the surrounding medium - oxygen and the salts in sea-water, for example. The egg after fertilization lives in a new world.

These same changes are brought about by those external agents that cause artificial parthenogenesis. Loeb has shown by a thorough study of the conditions that any substance that causes cytolysis (a typical form of cell destruction) will induce parthenogenesis if applied to the surface of the egg only.

Loeb has shown that development depends not only on a change in the surface of the egg, but on other changes also. Hence his most successful methods are those in which two agents are applied successively to the egg - one affects primarily the surface, the other the interior of the egg. If, for example, the eggs are placed in a solution of a fatty acid, the membrane is produced. The egg is then removed to pure sea water from which oxygen has been driven out and left there for three hours. After its return to sea water it will produce a normal embryo.

If, instead of putting the egg into water without oxygen, a hypertonic solution of salts is used $(50 \mathrm{cc}$. 
of sea water plus $S$ ec. of $21 \frac{2}{2 a C l}$ ), the development may be carried through.

Loeb concludes that the oxidations set up in the egg by a change in its outer surface affect the egg itself injuriously; and unless they are removed or the effects are counterbalanced by some other change (as when a hypertonic solution is used) the egg goes to pieces. Hence he believes that the sperm has a double rôle in fertilization. First it changes the surface layer and increases in consequence the oxidations in the egg; second, the sperm brings into the egg some substance that counteracts poison produced by the oxidation itself.

This is what fertilization accomplishes from a physiological point of view. In addition, we have seen that fertilization brings into the egg certain materials whose presence affects the characters of the individuals that develop from it. This is what fertilization does from the point of view of the student of heredity.

Let us turn for a moment, in conclusion, to the question of sex of animals that come from artificially parthenogenetic eggs.

In natural parthenogenesis such eggs may develop into males, sexual females, or parthenogenetic females.

But in artificial parthenogenesis the egg has already undergone reduction in its chromosomes and is represented by half of the female formula as far as the chromosomes are concerned. The half formula will be $X A B C$ for the type with homozygous female. Since the egg has one $X$ it may be expected to become 
a male, but if sex is a relation of $X$ to $A B C$, one cannot be certain that it might not be a female.

In cases where the female is heterozygous for the sex factor, as in birds and some sea urchins, the formula for the female would be $X A B C D-Y A B C D$ and for the male $Y A B C D-Y A B C D$. There would be two types of eggs, $X A B C D$ and $Y A B C D$. The former might be expected to produce a female, the latter probably a male if such eggs were incited artificially to develop.

Concerning the sex of the embryos so far produced by artificial parthenogenesis, we know of only two cases. These two cases are Delages' result for the sea urchin, in which he got one male, and Loeb's and Bancroft's case for the frog, in which they believe that the two young obtained were males.

What to expect on theoretical grounds is uncertain. We have only two facts that bear on the question. In the parthenogenetic eggs of the aphid, with the formula $X A B C A B C$ we get a male. In the case of the bee the formula is $X A B C$, which also gives a male. All else is hypothetical and premature, but if these two formulæ are correct, it appears that one $X$ gives a male and that maleness is not due to a quantitative relation between $X$ and one or two sets of the other chromosomes. It is the quantity of something in $X$, not the relation of this to the rest of the chromosomes. 


\section{CHAPTEP VII}

\section{Fertility}

DARWIN's splendid work on cross- and self-fertilization, his study of the mechanism of cross-fertilization in orchids, and his work on the different forms of flowers of plants of the same species, mark the beginning of the modern study of the problem of fertility and sterility. Darwin carried out studies on the effects of cross-fertilization in comparison with self-fertilization and reached the conclusion that the offspring resulting from cross-fertilization are more vigorous than the offspring from self-fertilization. No one can read his books dealing with these questions without being impressed by the keemness of his analysis and the open-minded and candid spirit with which the problems were handled. Since Darwin's time we have not adranced very far beyond the stage to which Darwin carried these questions. We have more extensive experiments and some more definite ways of stating the results, but Darwin's work still stands as the most important contribution that has been made to this subject.

The credit of the second adrance belongs to Weismamn. His speculations concerning the effects of mixing of the germ-plasms of the two individuals, that combine at the time of fertilization, not only aroused renewed interest in the nature of the process of sexual reproduction, but brought to light also the 
effects of recombination of the different sorts of qualities contained in the parental strains. His attack on the hypothesis of rejuvenation that was so generally held at that time did very great service in exposing the mystical nature of such an imagined effect of crossfertilization. In particular, Weismann's endeavor to connect the theory of recombination with the facts of maturation of the egg and sperm has opened our eyes to possibilities that had never been realized before. His work has led directly to the third advance that has been made in very recent years, when the results of Mendelian segregation have been applied directly to the study of fertility and sterility.

As I have said, Darwin's work showed that crossfertilization is generally beneficial. The converse proposition has long been held that continued inbreeding leads to degeneration and to sterility. This opinion rests largely on the statements of breeders of domesticated animals and plants, but there is also a small amount of accurate data that seems to support this view. I propose first to examine this question, and then consider what cross-fertilization is supposed to do, in the light of the most recent work.

Weismann inbred white mice for 29 generations, and Ritzema-Bos bred rats for 30 generations. In each case the number of young per litter decreased in successive generations, more individuals were sterile and many individuals became weakened. This evidence falls in line with the general opinion of breeders.

On the other hand, we have Castle's evidence on inbreeding the fruit fly through 59 generations. He found some evidence of the occurrence of sterile pairs 
(mainly females), but we must be careful to distinguish between the appearance of sterile individuals in these cultures and the lessened fertility that may be shown by the stock in general. The recent work of Hyde on these same flies has shown that the appearance of sterile individuals may be an entirely different question from that of a decrease in general fertility. The latter again may be due to a number of quite different conditions. Castle and his co-workers found that the sterile individuals could be eliminated if in each generation the offspring were selected from pairs that had not produced sterile individuals. Hyde has found, in fact, that one kind at least of sterile females owe their sterility to a definitely inherited factor that can be eliminated as can any other Mendelian recessive trait. Moenkhaus, who has also extensively studied the problem of inbreeding in these flies has likewise found that his strains could be maintained at their normal rate of propagation by selecting from the more fertile pairs.

If we eliminate from the discussion the occurrence of sterile individuals, the question still remains whether the output of the fertile pairs decreases if inbreeding is carried on through successive generations. There is some substantial evidence to show that this really takes place, as the following figures taken from Hyde's results show.

$\begin{array}{cccccccc}F_{1} & F_{2} & F_{3} & F_{4} & F_{5} & F_{6} & - & F_{13} \\ 368 & 209 & 191 & 184 & 65 & 119 & & 156\end{array}$

At the end of thirteen generations the fertility of the stock was reduced by half, as determined in this 
case by the average number of flies per pair that hatch. But this is not a measure of the number of eggs laid or of those that are fertilized.

Whether inbreeding where separate sexes exist is similar to self-fertilization in hermaphroditic forms is not known. Darwin gives results of self-fertilization in I pomœa purpurea for ten generations. The effects vary so much in successive generations that it is not possible to state whether or not the plant has become less fertile. His evidence shows, however, that the crossfertilized plants in each of the same ten generations are more vigorous than the self-fertilized plants, but this does not prove that the latter deteriorated.

The problem has been studied in other ways. Some animals and plants propagate extensively by parthenogenesis; others by means of simple division.

Whitney and A. F. Shull kept parthenogenetic strains of Hydatina senta for many generations. Whitney carried a strain of this sort through 500 generations. Towards the end the individuals became weak, the reproductive power was greatly diminished, and finally the strain died out. No attempt was made to breed from the more fertile individuals, although to some extent this probably occurred at times. If we admit that weakened individuals appear sometimes in these lines and their weakness is inherited, then each time such an individual happened to be picked out a step downward would be taken; when the more fertile individuals chanced to be selected, the strain would be temporarily held at that level. But on the whole the process would be downwards if such downward changes are more likely to occur than upward ones. 
'This is an assumption, but perhaps not an unreasonable one. Let me illustrate why I think it is not unreasonable. If the highest possible point of productivity is a complex condition due to a large number of things that must be present, then any change is more likely to be downward, since at the beginning the high-water mark had been reached. In time casual selection would be likely to pick out a poor combination - if this happened once the likelihood of return would be small.

As we have seen (Chapter I) Maupas found in a number of protozoa that if he picked out an individual (after each two divisions) to become the progenitor of the next generation, the rate of division after a time slowed down. The individuals became weaker and finally the race died out. Calkins repeated the experiments with paramœecium on a larger scale and obtained similar results. The question arose whether the results were not due to the hay infusion lacking certain ehemical substances that in time produced an injurious effeet. Calkins tested this by transferring his weakened strains to different eulture media. The result was that the race was restored to more than its original vigor. But very soon degeneration again set in. A new medium again restored vigor to some degree, but only for a short time, and finally the oldest eulture died out in the $742 \mathrm{~d}$ generation. It was evident, therefore, that if the slackened rate of division and other evidences of degeneration were in part due to the medium, yet some of the effects produced were permanent and eould not be effaced by a return to a more normal medium. Then came Woodruff's experiments. He kept his paramœcia on 
a mixed diet - on the kind of materials that it would be likely to meet with in nature, alternating with hay and other infusions. He found no degeneration, and at his last report his still vigorous strain was in the 3000 th generation.

Recently Woodruff has found in his long-lived race that under proper conditions individuals will conjugate. Woodruff and Erdmann found in this race, although not allowed to conjugate, that periodically the macronucleus breaks down and several micromere divisions take place. Finally a new nuclear apparatus of micronuclear origin is reconstructed. The process is comparable to the nuclear changes prior to conjugation except that the last micronuclear division is omitted. This periodic change is not peculiar to this race of Paramœcium, but appears in other races that regularly conjugate.

Let us turn now to the other side of the question and see what results cross-fertilization has given.

Hyde has found that if two strains of flies with low fertility are crossed, there is a sudden increase in the output, as seen in the diagram (Fig. 96). The facts show clearly an improvement. More eggs of each strain are fertilized by sperm from the other strain than when the eggs are fertilized by sperm from the same strain. ${ }^{1}$ In this case the results are not due to a more fertile individual being produced (although this may be true) but to foreign sperm, acting better than the strain's own sperm. The evidence, as such,

${ }_{1}^{1}$ The upper line $F_{1}-F_{13}$ gives the average output of flies per pair. Below this line the percentages mean the number of isolated eggs that hatched. 
does not show whether this is due to each strain having degenerated in certain directions, or to some other kind of a change in the heredity complex.

The egg counts show that in the inbred stock many of the eggs are not fertilized, or if fertilized (32\%) they still fail to develop. This means a decrease in fertility in the sense in which that word is here used. The offspring that arise from the cross-fertilization of these strains are more vigorous than their parents, if their increased fertility be taken as the measure of their vigor. The latter result is not shown in the table, for here $52 \%$ and $58 \%$ are the percentages of fertile eggs produced when the two strains are crossed.

\section{History of Inpred Stock.}

$\begin{array}{lllllllllllll}\mathrm{F}_{1} & 2 & 3 & 4 & 5 & 6 & 7 & 8 & 9 & 10 & 11 & 12 & F_{13}\end{array}$ $\begin{array}{lllllllllllll}368 & 209 & 191 & 184 & 65 & 119 & & & & & & & \end{array}$

\section{eross of $F_{13}$ by $T_{\text {runcale }}$}

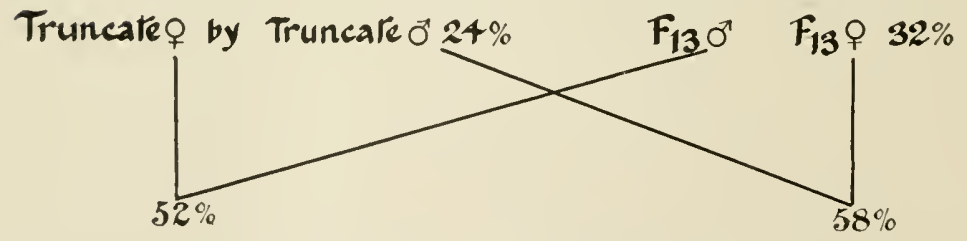

FIG. 96. - The horizontal line $F_{1}-F_{13}$ gives the average number of flies per pair that emerged from inbred stock, deereasing from 368 to 156 per pair. Below is shown the results of a cross between a race of Truneates (short wings) and $F_{13}$. The pereentages here gire the number of eggs that hatehed in each case.

Darwin found that cross-fertilization was beneficial in 57 species of plants that he studied. In the 
case of primula, which is dimorphic, he found not only that self-fertilization gave less vigorous plants, but that when pollen from a long-styled flower of one plant fertilizes the pistil of another long-styled plant the vigor of the offspring is less than when the same kind of pollen is used to fertilize the pistil of a short-styled flower. The next table gives the detailed results.

\begin{tabular}{|c|c|c|c|c|c|}
\hline Nature OF UNION & $\begin{array}{l}\text { NuMBER OF } \\
\text { Flowers } \\
\text { FertiLized }\end{array}$ & $\begin{array}{l}\text { Number } \\
\text { of Seed } \\
\text { Capsules }\end{array}$ & $\begin{array}{l}\text { MAXimuM } \\
\text { OF SEEDSiN } \\
\text { ANY ONE } \\
\text { CAPSULE }\end{array}$ & $\begin{array}{l}\text { Minimum } \\
\text { of Seeds in } \\
\text { Any One } \\
\text { Capsule }\end{array}$ & $\begin{array}{l}\text { Average } \\
\text { No. of } \\
\text { Seeds per } \\
\text { Capsule }\end{array}$ \\
\hline $\begin{array}{l}\text { Long-styled form by } \\
\text { pollen of short- } \\
\text { styled form: } \\
\text { Legitimate union. }\end{array}$ & 10 & 6 & 62 & 34 & 46.5 \\
\hline $\begin{array}{l}\text { Long-styled form by } \\
\text { own-form pollen: } \\
\text { Illegitimate union. }\end{array}$ & 20 & 4 & 49 & 2 & 27.7 \\
\hline $\begin{array}{l}\text { Short-styled form by } \\
\text { pollen of long- } \\
\text { styled form: } \\
\text { Legitimate union. }\end{array}$ & 10 & 8 & $6 \hat{1}$ & 37 & 47.7 \\
\hline $\begin{array}{l}\text { Short-styled form by } \\
\text { own-form pollen: } \\
\text { Illegitimate union. }\end{array}$ & 17 & 3 & 19 & 9 & 12.1 \\
\hline $\begin{array}{c}\text { The two legitimate } \\
\text { unions together. }\end{array}$ & 20 & 14 & 62 & 34 & 47.1 \\
\hline $\begin{array}{c}\text { The two illegitimate } \\
\text { unions together. }\end{array}$ & 37 & 7 & 49 & 2 & 21.0 \\
\hline
\end{tabular}

We know now that these two types of plants - longstyled and short-styled - differ from each other by a single Mendelian factor. We may therefore state 
Darwin's result in more general terms. The heterozygous plant is more vigorous than the homozygous plant. Moreover, in this case it is not the presence of the dominant factors that makes greater vigor (for the short-styled plant containing both dominants is less vigorous than the heterozygous), but the presence of two different factors that gives the result.

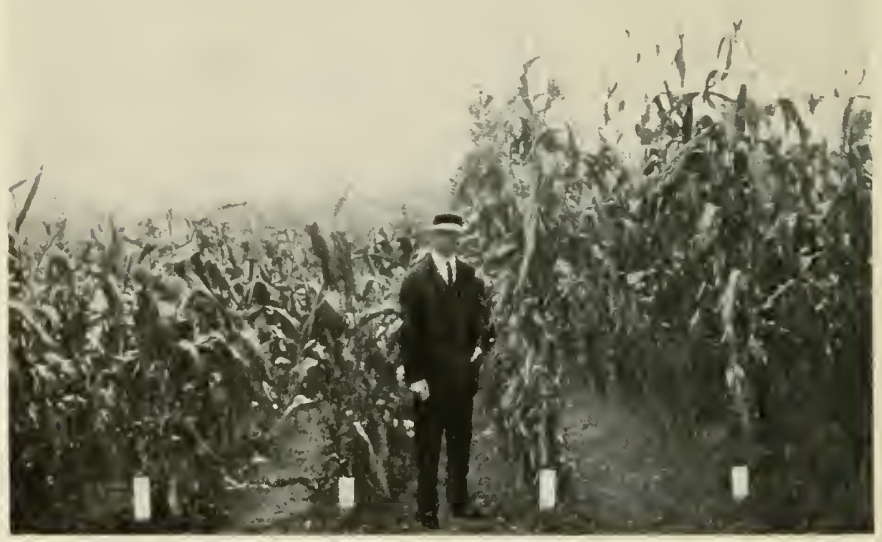

Fig. 97. - At left of figures there are two strains of pure bred corn and at right the hybrids produced by crossing those two pure strains. (After East.)

The most thoroughly worked out case of the effects of inbreeding and eross-breeding is that of Indian corn. In recent years East and G. H. Shull have studied on a very large scale and with extreme care the problem in this plant. Their results are entirely in accord on all essential points, and agree with those of Collins, who has also worked with corn.

East and Shull find that when two strains of corn 
(that have been to a large extent made pure) are crossed, the offspring is more vigorous than either parent (Fig.

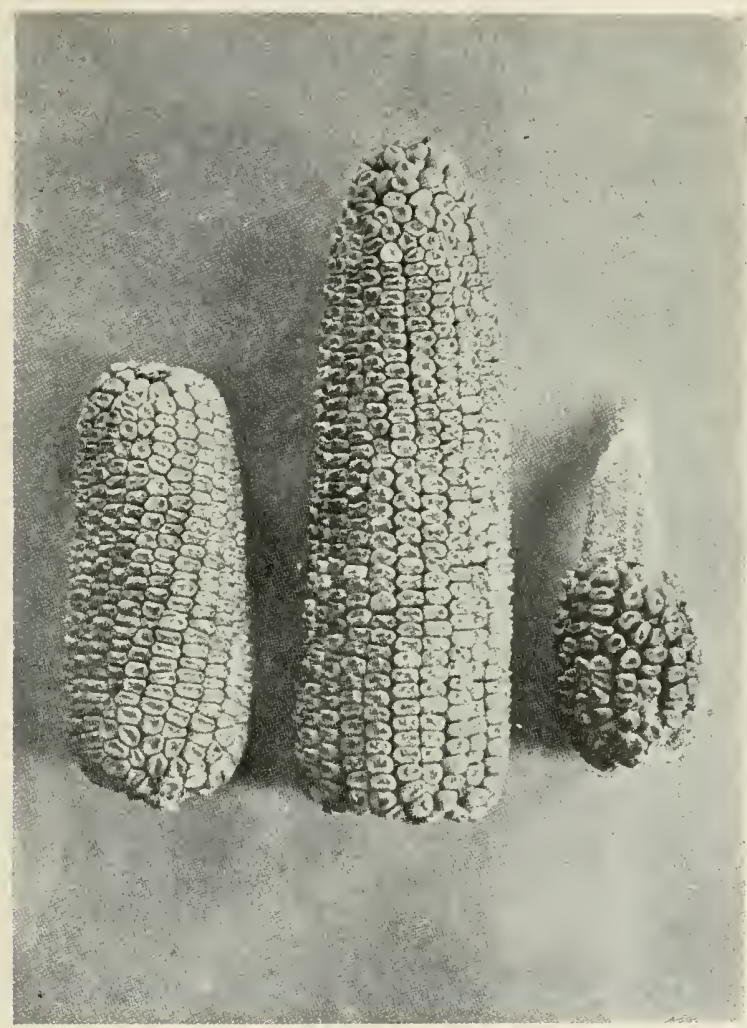

FIG. 98. - At left an ear of Leaming Dent corn, and another at right after four years of inbreeding. The hybrid between the two is shown in the middle ear. (After East.)

97). This is clearly shown in the accompanying pictures. Not only is the hybrid plant taller and stronger, but in consequence of this, no doubt, the yield of corn 
per bushel is much increased, as shown in the next figure (Fig. 9S).

When the vigorous $F_{1}$ corn is self-fertilized, it produces a very mixed progeny, more variable than itself. Some of the $F_{2}$ offspring are like the original grandparental strains, some like the corn of first generation, and other's are intermediate (Fig. 99).

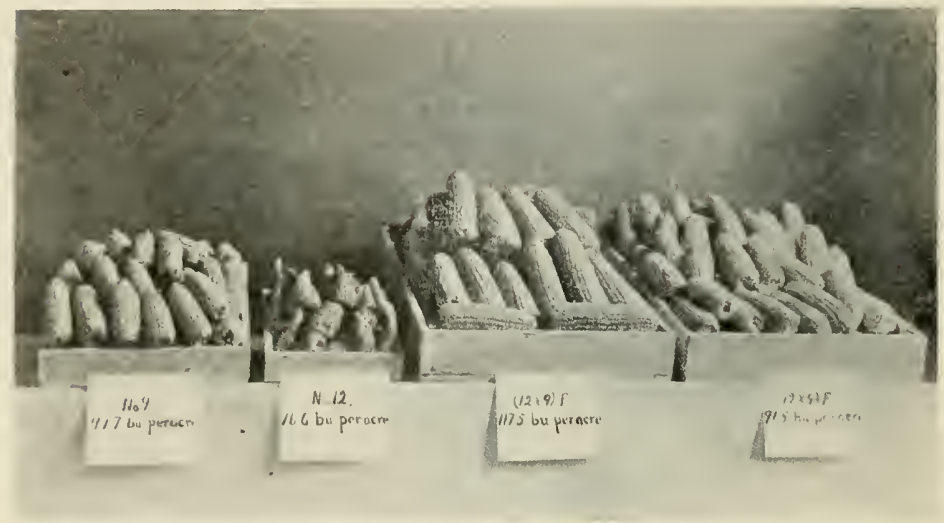

F'1G. 99. - No. 9 and No. 12, two inbred strains of Leaning Dent corn compared with $F_{1}$ and $F_{2}$ (to right). (After East.)

It will not be possible for us to go into an analysis of this case, but Shull and East have shown that the results are in full harmony with Mendelian principles of segregation. The vigor of the $F_{1}$ corn is explained on the basis that it is a hybrid product. To the extent to which the two parent strains differ from each other, so much the greater will be the vigor of the offspring.

This seems an extraordinary conclusion, yet when tested it bears the analysis extremely well.

Shull and apparently East also incline to adopt the 
view that hybridity or heterozygosity itself is the basis for the observed vigor; but they admit that another interpretation is also possible. For instance, each of the original strains may have been deficient in some of the factors that go to make vigor. Together they give a more vigorous individual than themselves.

Whitney ran one line of hydatina through 384 parthenogenetic generations, when it died (Line $A$ ). Another line was carried through 503 generations, and at the last report was in a very weakened condition (Line $B)$. When the former line was becoming extinct, he tried inbreeding. From the fertilized eggs he obtained a new parthenogenetic female. It showed scarcely any improvement. The other line gave similar results. In one case he again inbred for a second time. He found that the rates of reproduction of lines $A$ and $B$ were scarcely, if at all, improved.

Whitney then crossed lines $A$ and $B$. At once an improvement was observed. The rate of reproduction (vigor) was as great as that in a control line (reared under the same conditions) that had not deteriorated.

The experiments of A. F. Shull on hydatina were somewhat different. He began with the twelfth generation from a sexual egg. The line was supposedly not in a weakened condition. He inbred the line and obtained from the fertilized egg a new parthenogenetic series. After a few generations he inbred again. The results are shown in the next table. It is clear that there has been a steady decline despite sexual reproduction, measured by four of the five standards that Shull applied, namely, size of family of parthenogenetic iemales, and of sexual females, number of eggs per day, 
Showing Decreasli of Vigor, as Mrasured by Various Characters, ix Six Successively Inired Parthenogenetic Lines of Hydatina senta

\begin{tabular}{|c|c|c|c|c|c|c|c|}
\hline \multirow{2}{*}{$\frac{x}{\underline{J}}$} & \multirow{2}{*}{ Character to he Measured } & \multicolumn{6}{|c|}{$\begin{array}{l}\text { Number of PartheNogenetic } \\
\text { LiNe }\end{array}$} \\
\hline & & 1 & 2 & 3 & 4 & 5 & 6 \\
\hline \multirow[t]{6}{*}{ I. } & Size of family of parthenogenetic female. . & $4 \mathrm{s.4}$ & 42.5 & 46.8 & 42.5 & $3 I .0$ & 22.6 \\
\hline & Size of family of fertilized sexual female . & 16.7 & 12.8 & 12.8 & 11.5 & 6.3 & 7.3 \\
\hline & Number of eggs laid per day . . . . . & 11.0 & 11.4 & 10.3 & 10.0 & 9.2 & 7.5 \\
\hline & Number of days required to reaeh maturity & 2.27 & 1.66 & 2.25 & 1.93 & 2.25 & 2.12 \\
\hline & $\begin{array}{l}\text { Proportion of eases in which first daughter } \\
\text { did not beeome parent. . . . . . }\end{array}$ & $1 / 11$ & $1 / 3$ & & $3 / 16$ & $0 / 4$ & $5 / 8$ \\
\hline & Same in percentages . . . . . . . . . . . . . & \multicolumn{2}{|c|}{14.2} & \multicolumn{2}{|c|}{25.0} & \multicolumn{2}{|c|}{41.6} \\
\hline \multirow[t]{6}{*}{ II. } & Size of f:umily of parthenogenet is female. & 48.4 & 30.8 & 41.0 & 37.0 & 33.8 & 24.8 \\
\hline & Size of family of fertilized sexual female. & 16.7 & 13.7 & 13.5 & 15.2 & 10.1 & 7.6 \\
\hline & Number of ergs laid per day . . . . . . & 11.0 & 11.6 & 7.9 & 7.7 & 9.6 & s.6 \\
\hline & Number of days required to reach maturity & 2.27 & 1.55 & 2.57 & 2.20 & 1.90 & 2.00 \\
\hline & $\begin{array}{l}\text { Proportion of cases in which first daughter } \\
\text { did not become parent . . . . . . . }\end{array}$ & $1 / 11$ & $4 / 9$ & $2 / 7$ & $2 / 10$ & $8 / 20$ & $7 / 16$ \\
\hline & 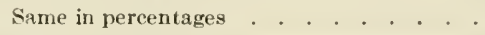 & \multicolumn{2}{|c|}{25.0} & \multicolumn{2}{|c|}{23.5} & \multicolumn{2}{|c|}{41.6} \\
\hline
\end{tabular}

number of times the first daughter was too weak to become the mother of a new line. It is clear that inbreeding did not lead to an increase in vigor.

In paramocium there is also some new evidence. Calkins in 1904 brought about the conjugation of two individuals of a weak race in the 354 th generation. From one of the conjugants a new line was obtained that went through another cycle of at least 376 generations in culture, while during the same time and under similar conditions the weakened race from which the conjugants were derived underwent only 277 generations.

Jennings has recently reported an experiment in which some paramoecia, intentionally weakened by breeding in a small amount of culture fluid, were 
allowed to conjugate. Most of the lines that descended from several pairs showed no improvement but soon died out. In only one case was an individual produced that was benefited by the process.

Jennings' results are, however, peculiar in one very important respect. He did not use a race that had run down as a result of a long succession of generations, but a race that he had weakened by keeping under poor conditions. We do not know that the result in this case is the same as that in senile races or inbred races of other workers. It is not certain that the hereditary complex was affected in the way in which that complex is changed by inbreeding. He may have injured some other part of the mechanism.

Jennings interprets conjugation in paramœcium to mean that a recombination of the hereditary factors takes place. Some of these combinations may be more favorable for a given enviromment than are others. Since these will produce more offspring, they will soon become the predominant race.

The next diagram (Fig. 100) will serve to recall the principal facts in regard to conjugation in paramocium. Two individuals are represented by black and white circles. At the time of conjugation the small or micronucleus in each divides $(B)$, each then divides again $(C)$. Four nuclei are produced. One of these micronuclei, the one that lies nearest the fusion point, divides once more, and one of the halves passes into the other individual and fuses there with another nucleus. The process is mutual. Separation of the two individuals then takes place and two ex-conjugants are formed. Each has a new double nucleus. This nu- 
cleus divides $(G)$ and each daughter nucleus divides again $(H)$, so that each ex-conjugant has four nuclei.

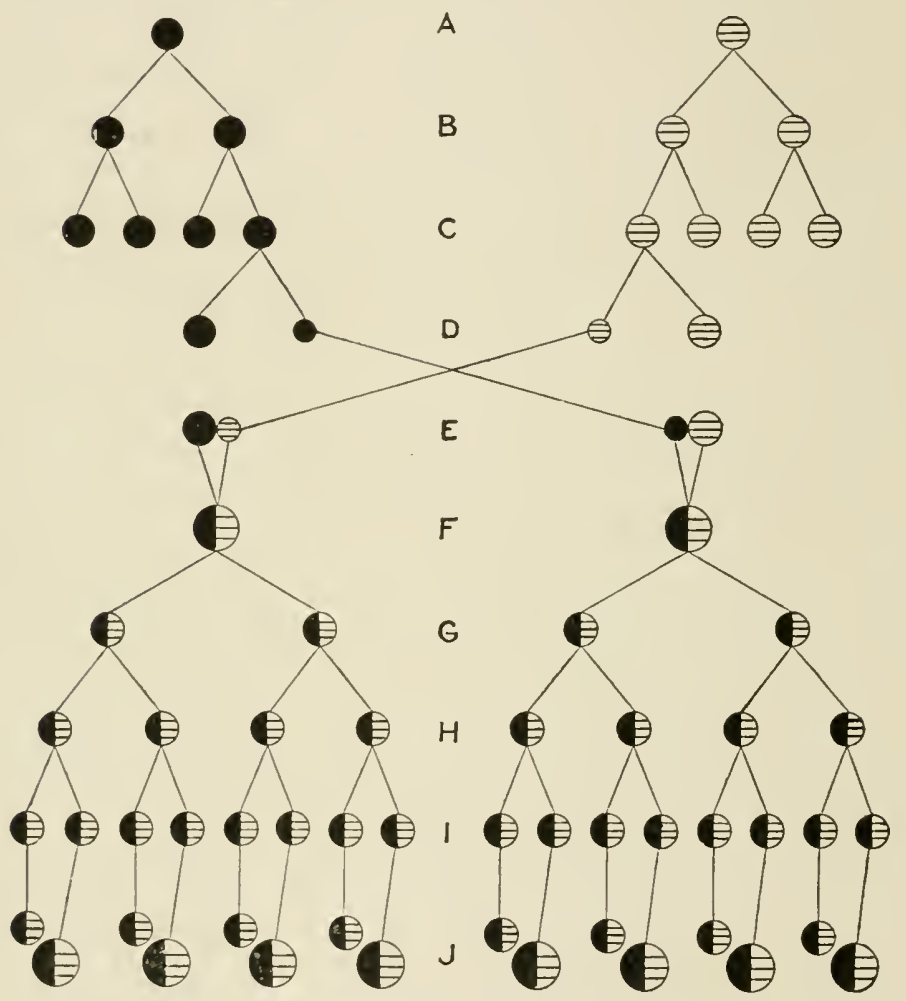

FIG. 100. - Diagram to show the history of the micronuclei of two Paramocia during $(A-F)$ and after $(F-J)$ ronjugation. Compare this diagram with Fig. 2.

Another division gives eight nuclei in each. The paramœeium itself next divides - each half gets four nuclei. A second division takes place, and each gets two of the nuclei. Four new individuals result. In each of 
these individuals one of the nuclei remains small and becomes the new micronucleus, the other enlarges to form the new macronucleus. Thus from each exconjugant four new paramøecia are produced, which now proceed to divide in the ordinary way, i.e. the micronucleus and the macronucleus elongate and divide at each division of the animal.

It is customary to regard some phase in this process as involving a reduction division in the sense that a separation of the paired factors takes place. If this occurs prior to interchange of micronuclei $(E)$, then each ex-conjugant corresponds to an egg after fertilization. It is conceivable, however, that segregation might occur in the two divisions that follow conjugation, which would give a different interpretation of the process than the one followed here.

On the first of these two hypotheses two new strains result after conjugation. Each is a recombination of factors contained in the two parents. If the two parents were alike, i.e. homozygous, in many factors, and different, i.e. heterozygous, in a few, the two individuals would be more alike than were the original races from which they came. This is, in fact, what Jennings has shown to be the case, at least he has shown that on the average the ex-conjugants are more like each other than were the original strains.

Calkins has obtained some new and important facts concerning the likeness and unlikeness of the new strains that result from conjugation. He has used wild, i.e. not weakened, individuals, and has followed the history of the four lines resulting from the first four individuals produced by each ex-conjugant. The 
history of six such ex-conjugants is shown in the next diagram (Fig. 101). The four lines, "quadrants," $(1,2,3,4)$ that are descended from each of six exconjugants (viz. $G, H, L, M, Q, B$ ) are shown. At intervals large numbers of the populations were put under conditions favorable to conjugation and the

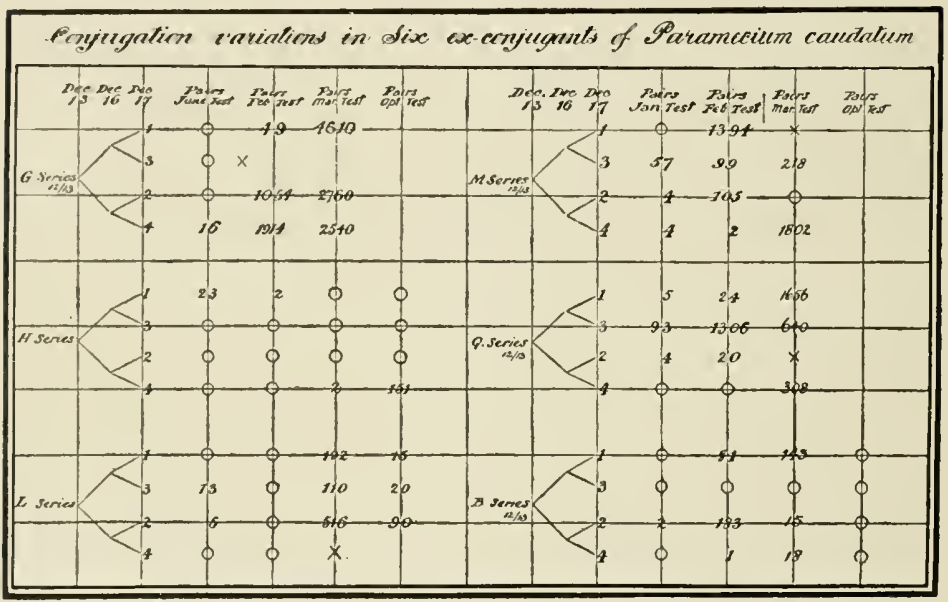

FIG. 101. - History of $\operatorname{six}(G, H, L, M, Q, B)$ ex-conjugants. In each the descendants of the first four individuals (after conjugation) is shown; the numbers indicate the pairs of conjugants counted when the test was marke. $X$ indicates deaths; $O$ indicates that no conjugation took place. (After Calkins.)

number of conjugating pairs counted. The results are shown in the diagram. The circles indicate no conjugations; $X$ indicates the death of the strain. In the $G$ and in the $M$ series many conjugations took place. In other series conjugation did not take place until much later. Striking differences appear in the different quadrants although they were kept under similar conditions. 
But even amongst, the four lines descended from the same ex-conjugant marked differences exist. These differences cannot be attributed to constitutional differences unless a segregation of factors takes place after conjugation or unless it can be shown that these differences are not significant. In the light of these conflicting results on paramœeium it may seem unsafe to draw any far-reaching conclusions concerning the nature of sexual reproduction in general from the evidence derived from these forms. In the higher animals, however, the evidence that segregation takes place prior to fertilization and that recombinations result can scarcely be doubted.

\section{THEORIES OF FERTILITY}

Let us now try to sum up the evidence in regard to the influence of cross-fertilization. This can best be done by considering the three most important hypotheses that have been brought forward to explain how crossing gives greater vigor.

Shull and East explain the vigor of the hybrid by the assumption that it contains a greater number of different factors in its make-up than either of its parents. They support the view by an appeal to the next $\left(F_{2}\right)$ generation from such hybrids that shows a lower range of vigor, because, while a few individuals of this generation will be as mixed as the hybrid $\left(F_{1}\right)$, and therefore like it, most of them will be simpler in composition. This interpretation is also supported by the evidence that when pure lines (but not necessarily, however, homozygous lines) are obtained by self-fertilizing the offspring of successive generations from 
these first hybrids, further decline does not take place.

In alternative view, that is also Mendelian, has been offered by Bruce and by Keeble and Pellew. Vigor, it is maintained, is in proportion to the number of dominant factors, and in proportion to the number of these factors present whether in a hybrid or in a homozygous (duplex) condition.

On this view the hybrid is vigorous, not because it is hybridous, so to speak, but because in its formation a larger number of dominant factors (than were present in either parent) have been brought together.

A third riew is also compatible with the evidence, namely, that there may exist factors that are themselves directly concerned with fertility. There is one such case at least that has been thoroughly analyzed by Pearl.

Pearl studied for five years the problem of fertility in two races of fowls, viz. barred Plymouth rocks and Cornish Indian games. The main features of his results are shown in the diagram (Fig. 102). He finds that the winter output of eggs, which is correlated with the total production, is connected with two factors. One factor, designated by $L_{1}$, is a non-sex-linked character. If it is present, an average of less than 30 eggs is produced in the winter season. There is another factor, $L_{2}$, that is present in the barred rocks, but not in the Indian game. If present alone, the winter output is again about 30 eggs on an average. If, however, both $L_{1}$ and $L_{2}$ are present, the winter output is more than 30 and may be as great as 90 , or in rare cases $100-120$ eggs. 
The peculiarity about this discovery is that the second factor', $L_{2}$, is sex-linked, which means in this case that it is carried by the eggs that will produce the males in the next generation, and not by the eggs that will produce the daughters. Hence if the daughters of highproducing hens are selected, one does not get in them

\begin{tabular}{|c|c|c|}
\hline $\begin{array}{l}\text { Low } \\
\text { (zeroon }\end{array}$ & F. $\begin{aligned} L_{1}-L_{1} \\
l_{1}-l_{1}\end{aligned}$ & $\begin{array}{l}\mathrm{F}_{1} \mathrm{l}_{2}-\mathrm{L}_{2} \text { Lorro } \\
\mathrm{l}_{2}-\mathrm{l}_{2} \text { (Zeroo) }\end{array}$ \\
\hline & 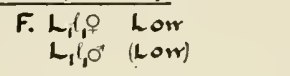 & $\begin{array}{ll}\mathrm{F} \cdot l_{2} l_{2} & \text { Zcroo } \\
L_{2} l_{2} & \text { (Low)o }\end{array}$ \\
\hline & $\begin{array}{r}F \cdot L_{1} l_{2}=L_{1} l_{2} \\
L_{2} l_{1}-L_{2} l_{1}\end{array}$ & $\begin{array}{l}\text { Low }+ \\
\text { (Low) } 0^{\prime \prime}\end{array}$ \\
\hline & F. $\begin{aligned} L_{1} l_{2} L_{2} l_{1} \\
L_{1} l_{2} L_{2} l_{1}\end{aligned}$ & $\begin{array}{l}\text { Hig̣h } \\
\text { Hig̣h)o }\end{array}$ \\
\hline
\end{tabular}

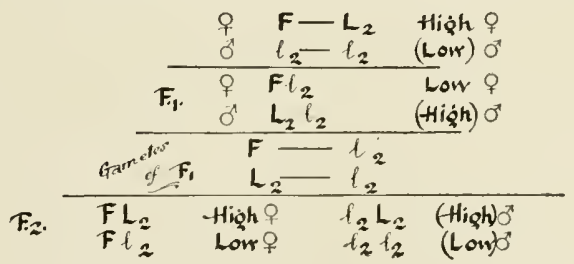

FIG. 102. - Illustrating Pearl's hypothesis. $F=$ female factor present in half of the eggs and determining sex. $L_{1}=$ factor for low egg production; $l_{1}$, its allelomorph for zero production of winter eggs. $L_{2}=$ factor for high winter production; $l_{2}$, its allelomorph.

the high productiveness of the mother. It is her sons that inherit the character, although they cannot show it except in their offspring.

Aside from whatever practical interest these results may have, the facts are important in showing that such a thing as a factor for fertility itself may be present, without otherwise being apparent, and that this factor 
taken in comnection with another (or others) gives high productirity.

The other point to which I wish to call attention relates to a different matter. We have met with some cases where lowered fertility was due to eggs failing
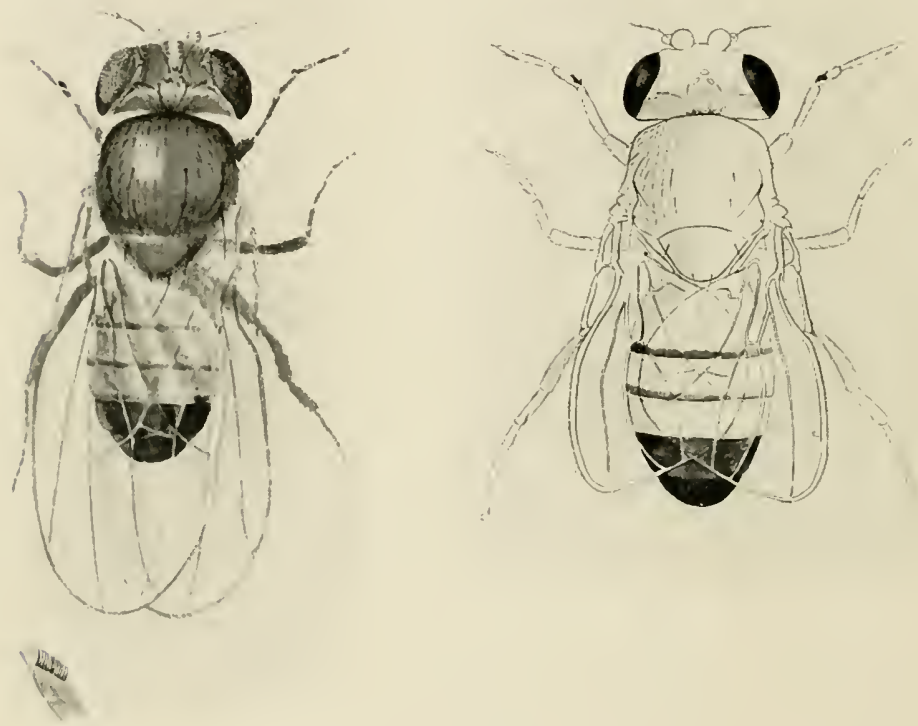

Fig. 103. - Normal male of Drosophila (on left) and male with "rudimentary" wings (on right). Note sex comb (lower left).

to a greater or less degree to be fertilized by sperm of the same strain.

A striking case of this kind is found in a mutant of the fruit fly that appeared in my cultures. The mutant has rudimentary wings (Fig. 103). The females are absolutely infertile with males of the same kind. 
If they are mated to any other male of a different strain, they are fertilized. The males, too, are capable of fertilizing the eggs of other strains, in fact, are quite fertile.

The factor that makes the rudimentary winged fly is of such a sort that it carries infertility along with it - in the sense of self-infertility. This result has nothing to do with inbreeding, and the stigma cannot be removed by crossing out and extracting.

A somewhat similar factor, though less marked, is found by Hyde in certain of his inbred stock to which I have referred. As his experiments show, the infertility in this case is not due to lack of eggs or sperm, but to a sort of incompatibility between them so that not more than 20 per cent of the eggs can be fertilized by males of the same strain.

In the flowering plants where the two sexes are often combined in the same individual, it has long been known that there are cases in which self-fertilization will not take place. The pollen of a flower of this kind if placed on the stigma of the same flower or of any other flower on the same plant will not fertilize the ovules. Yet the pollen will fertilize other plants and the ovules may be fertilized by foreign pollen.

Correns has recently studied that problem and has arrived at some important conclusions. He worked with a common plant, Cardamine pratensis. In this plant self-fertilization is ineffectual. He crossed plant $B$ with plant $G$, and reared their offspring. He tested these with each other and also crossed each of them back to its parents that had been kept alive for this purpose. The latter experiment is simple and more in- 
structive. His results and his theory ean best be given together.

Correns assumes that each plant contains some factor that produces a secretion on the stigma of the flowers. This secretion inhibits the pollen of the same plant from extending its pollen tube. He found, in fact, that the pollen grains do not grow when placed on the stigma of the same plant. All plants will be hybrid

\section{Back Cross in Cardnmine pretensis (conens)}

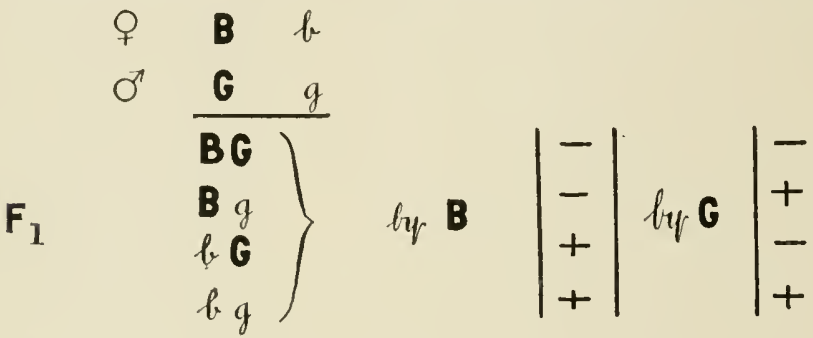

Fig. 104. - Illustrating the crossing of the types $B b$ and $G g$ to give four classes: $B G, B g, b G, b g$. Each of these is then back-crossed either to $B$ or to $G$ with the positive $(+)$ or negative (-) results indicated in the diagram.

for these factors, hence plant $B$ will produce two kinds of germ-cells, $B$ and $b$. Similarly, plant $G$ will produce two kinds of germ-cells, $G-g$. If these two plants are crossed, four types will be produced. When these are back-crossed to the parents, the expectation is shown in the diagram (Fig. 104). Half the combination should be sterile and half should be fertile. This is, in fact, what occurs, as shown in the same diagram. The - signs indicate that fertilization does not oceur, while the + signs indicate successful fertilization.

Correns' theory is also in aceord with other com- 
binations that he made. There can be little doubt that he has pointed out the direction in which a solution is to be found.

There is a somewhat similar case in animals. In one of the Ascidians, Ciona intestinalis, an hermaphrodite, the sperm will not fertilize the eggs of the same individual. But the sperm will fertilize eggs of other individuals, and vice versa. Castle first found out this fact, and I have studied it on a large scale. The diagram (Fig. 105) gives an example of one such experiment made recently by W. S. Adkins.

Five individuals are here used. The eggs of one individual, $A$, were placed in five dishes (horizontal line); likewise those of $B, C, D, E$. The sperm of $A$, designated by $a$ (vertical lines) was used to fertilize the eggs, $A, B, C, D, E$; likewise the sperm $b, c, d, e$. The self-fertilized sets form the diagonal line in the diagram and show no fertilization. The other sets show various degrees of success, as indicated by the percentage figures. These results can best be understood, I think, by means of the following hypothesis. The failure to self-fertilize, which is the main problem, would seem to be due to the similarity in the hereditary factors carried by eggs and sperm; but in the sperm, at least, reduction division has taken place prior to fertilization, and therefore unless each animal was homozygous (which from the nature of the case cannot be assumed possible) the failure to fertilize cannot be due to homozygosity. But both sperm and eggs have developed under the influence of the total or duplex number of hereditary factors; hence they are alike, i.e. their protoplasmic substance has been 
under the same influences. In this sense, the ease is like that of stock that has long been inbred, and has

\section{Self and Cross Fertilization in Ciona.}

\begin{tabular}{|c|c|c|c|c|}
\hline $\mathbf{A}^{\mathrm{a}}$ & $\mathbf{A}^{\mathrm{b}}$ & $\mathbf{A}^{\mathrm{c}}$ & $\mathbf{A}^{\mathrm{a}}$ & $\mathbf{A}^{\mathrm{e}}$ \\
0 & 87 & 92 & 84 & 96 \\
\hline $\mathbf{B}^{\mathrm{a}}$ & $\mathbf{B}^{\mathrm{b}}$ & $\mathbf{B}^{\mathrm{c}}$ & $\mathbf{B}^{\mathrm{d}}$ & $\mathbf{B}^{\mathrm{e}}$ \\
\hline 38 & 0 & 35 & 98 & 97 \\
\hline $\mathbf{C}^{\mathrm{a}}$ & $\mathbf{C}^{\mathrm{b}}$ & $\mathbf{C}^{\mathrm{c}}$ & $\mathbf{C}^{\mathrm{d}}$ & $\mathbf{C}^{\mathrm{e}}$ \\
\hline 93 & 96 & 0 & 97 & 96 \\
\hline $\mathbf{D}^{\mathrm{a}}$ & $\mathbf{D}^{\mathrm{b}}$ & $\mathbf{D}$ & $\mathbf{D}^{\mathrm{c}}$ & $\mathbf{D}^{\mathrm{c}}$ \\
\hline 91 & 98 & 77 & 0 & 89 \\
\hline $\mathbf{E}^{\mathrm{a}}$ & $\mathbf{E}^{\mathrm{b}}$ & $\mathbf{E}^{\mathrm{c}}$ & $\mathbf{E}^{\mathrm{a}}$ & $\mathbf{E}^{\mathrm{c}}$ \\
\hline 96 & 92 & 60 & 74 & 0 \\
\hline
\end{tabular}

Fig. 105. - The oblique line of letters $A^{a}, B^{b}, C^{c}, D^{d}, E^{e}$, gives the selffcrtilized sets of eggs; the rest $A^{b}, A^{c}$, etc., the cross-fertilized sets. $A, B$, $C, D, E=\mathrm{eggs} ; a, b, c, d, e,=$ sperm of same individuals. (From unpublished work of W. S. Adkins.)

come to have nearly the same hereditary complex. If this similarity decreases the chances of combination between sperm and eggs, we can interpret the results. Correns' results may come under the same interpretation. 
I have tried to bring together the modern evidence that bears on the problems of fertility and sterility. It is evident that there are many obscure relations that need to be explained. I fear that, owing to the difficulty of summarizing this scattered and diverse material, I have failed to make evident how much labor and thought and patience has been expended in obtaining these results, meager though they may appear.

But while it is going to take a long time and many heads and hands to work out fully these problems, there can be little doubt that the modern method is the only one by which we can hope to reach a safe conclusion. 


\section{CHAPTER VIII}

Special Cases of Sex-Inheritance

THE mechanism of sex-determination that we have examined gives equal numbers of males and females. But there are known certain special cases where equality does not hold. I have selected six such cases for discussion. Each of these illustrates how the mechanism of sex-determination has changed to give a different result; or how, the mechanism remaining the same, some outside condition has come in that affects the sex ratio.

It is so important at the outset to clearly recognize the distinction between sex-determination and sex ratio, that I shall take this opportunity to try to make clear the meaning of this distinction. The failure to recognize the distinction has been an unfailing source of misunderstanding in the literature of sex.

(1) A hive of bees consists of a queen, thousands of workers, and at certain seasons a few hundred drones or males. The workers are potentially females, and these with the queen give an enormous preponderance of females. In this case the explanation of the sex ratio is clear. Most of the eggs laid by the queen are fertilized, and in the bee all fertilized eggs become females, because as we have seen there is only one class of spermatozoa produced, and not two as in other insects.

There is a parallel and interesting case in one of the wasps deseribed by Fabre. The female lays her eggs 
as a rule in the hollow stems of plants, each egg in a separate compartment. In some of the compartments she stores away much more food than in others. From these compartments large females hatch. From compartments where less food is stored the smaller males are produced. It may seem that the amount of food stored up determines the sex of the bee. To test this Fabre took out the excess of food from the large compartments. The wasp that emerged, although small for want of food, was in every case a female. Fabre enlarged the smaller compartments and added food. The wasp that came out was a male, larger than the normal male.

It is evident that food does not determine the sex, but the mother wasp must fertilize the eggs that she lays in chambers where she has stored up more food, and not fertilize those eggs that she deposits in compartments where she has accumulated less food.

(2) A curious sex ratio appeared in one race of fruit flies. Some of the females persisted in producing twice as many females as males. This was first discovered by Miss Rawls. In order to study what was taking place, I bred one of these females that had red eyes to a white-eyed male of another stock. All the offspring had red eyes, as was to be expected. I then bred these daughters individually to white-eyed males again (Fig. 106). Half of the daughters gave a normal ratio; the other half gave the following ratio:

$\begin{array}{cccc}\text { Red } & \text { Red } & \text { White } & \text { White } \\ \uparrow & \delta & \uparrow & \delta \\ 50 & 0 & 50 & 50\end{array}$


It is evident that one class of males has failed to appear - the red males. If we trace their history through these two generations, we find that the single sex chro-

A

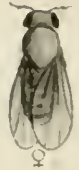

B
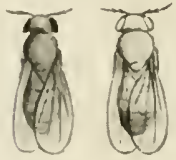

우
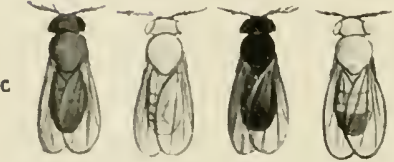

९
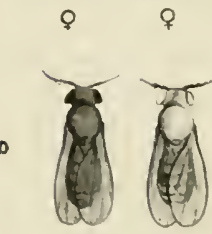

१
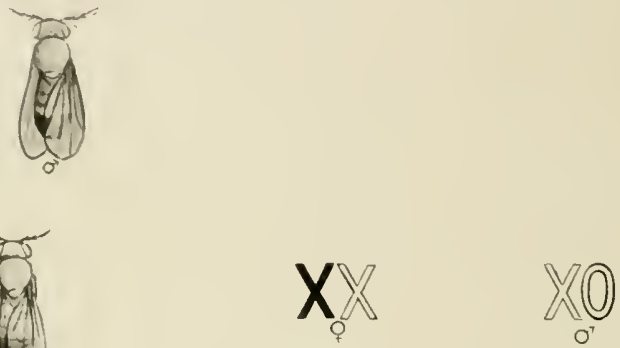

$\mathrm{O}^{\top}$

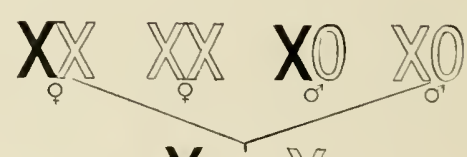

Gameles

$\sum$ 웅

(0) $\sigma^{\prime \prime}$
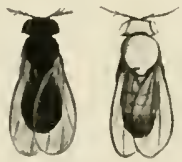

o

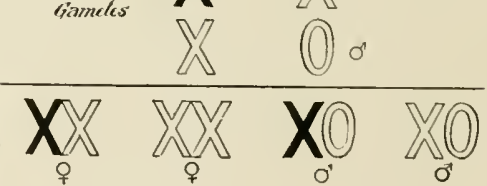

Fig. 106. - Diagram to show the heredity of the lethal factor (carricd by black $\mathbb{I}$ ). A, resl-cyed female, earrying the factor in one $X$, is bred to normal white-cyed male. $B$, her red-eyed daughter, is bred again to a normal white-eyed male, giving theoretieally the four elasses shown in $C$, but one of the classes fails to appear, viz. the red-eyed male (colored black in the diagram). The analysis (to right) shows that this male has the fatal $\mathbf{X}$. One of his sisters has it also, but is saved by the other $X$. She is the red-eyed female. If she is bred to a white-eyed male, she gives the results shown in $D$, in which one class of males is again absent, viz. the red-eyed male. In this diagrim the black $X$ represents red eyes and lethal (as though conpletely linked). 
mosome that each red male contains is one of the two chromosomes present in the original red-eyed grandmother. If this chromosome contains a factor which if present causes the death of the male that contains it, and this factor is closely linked to the red factor, the results are explained. All the females escape the fatality, because all females contain two sex chromosomes. If a female should contain the fatal factor, her life is saved by the other, normal, sex chromosome. The hypothesis has been tested in numerous ways and has been verified. We keep this stock going by mating the red females to white males. This gives contimually the $2: 1$ ratio. The white sisters, on the other hand, are normal and give normal sex ratios.

(3) Another aberrant result, discovered by C. B. Bridges, is shown by a different race of these same fruit flies. It will be recalled that when an ordinary whiteeyed female is bred to a red-eyed male all the sons have white eyes. But in the race in question a different result follows, as shown by the diagram. From 90 to 95 per cent of the offspring are regular, but 5 per cent of the females and 5 per cent of the males are unconformable, yet persistently appear in this stock.

The results can be explained if we suppose that the egg contains two $X$ 's and a $Y$ chromosome and in consequence the two $X$ 's may pass out into one of the polar bodies, in which case the red-eyed males will develop if the egg is fertilized by a female-producing sperm; or the two $X$-chromosomes will both stay in the egg, and give a kind of female with three sex chromosomes.

Here also numerous tests can be made. They verify 
the expectation. Thus by utilizing sex chromosomes that carry other sex-linked characters than white eyes, it can be shown that the results are really due to the whole sex chromosome being involved, and not to parts of it. The result is of unusual interest in another direction; for it shows that the female-producing
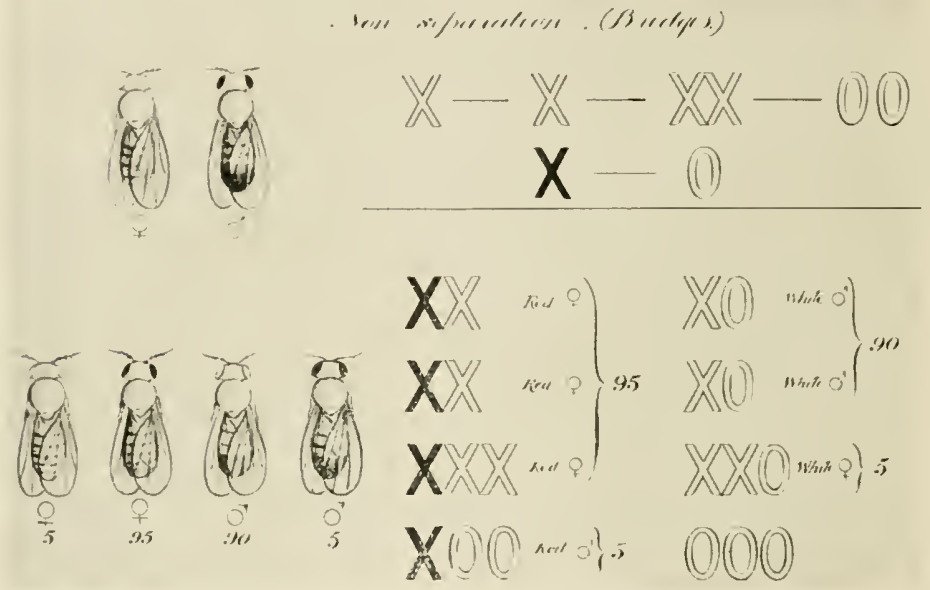

Flg. 107. - Non-disjunction. A non-disjunction female produces four types of eggs, viz, $\mathrm{XY}-\mathrm{X}-\mathrm{XY}-\mathrm{Y}$. Such a female will give, with a normal male, $X Y$, the classes indicated on the diagram. $Y$ should be substituted for $O$ in the diagram. The non-disjunction $q$ is $X X Y$.

sperm will make a male if it enters an egg from which both sex chromosomes have been removed. It is therefore not the female-producing sperm, as such, that gives a female under normal conditions, but this sperm plus the sex chromosome already present in the egg that gives an additive result - a female.

(4) In the group of nematode worms belonging especially to the genus Rhabditis, there are some extraor- 
dinary perversions of the sex ratios. The table gives the ratios that Maupas discovered. Not only are the

Diplogaster robustus . . . . . . 0.13 male

Rhal,ditis guignardi . . . . . . 0.15 male

Rhabditis dulichura $\quad . \quad$. . . . 0.7 male

Rhabditis caussaneli . . . . . 1.4 males

Rhabditis elyaus . . . . . . . 1.5 males

Rhabditis coronata . . . . . . . 5.0 males

to 1000 females

Rhahditis perrieri . . . . . . 7.0 males

Rhabditis marionii . . . . . . . 7.6 males

Rhabditis duthiersi . . . . . 20.0 males

Rhabditis viguieri . . . . . . 45.0 males

males extremely rare - almost reaching a vanishing point in certain cases - but they have lost the instinct to fertilize the female.

The females, on the other hand, have acquired the power of producing sperm, so that they have passed over into the hermaphroditic state. The behavior and history of the sperm that the females produce has only recently been made out by Miss Eva Krüger. It is found that a spermatozoön enters each egg and starts the development, but takes no further part in the development (Fig. 108). The egg may be said to be half fertilized. It is a parthenogenetic egg and produces a female.

(5) Some very high male ratios have been reported by Guyer in cases where birds of very different families have been crossed - the common fowl by the guinea hen, individuals of different genera of pheasants bred to each other and to fowls, etc. Hybrids between different genera gave $74 \delta-13 \%$. Hybrids between different species of the same genus $72 \delta-18 \%$. In most of these cases, as Guyer points out, the sex is 
recorded from the mounted museum specimen which has the male plumage. But it is known that the reproductive organs of hybrids, extreme as these, are generally imperfect and the birds are sterile. It has been

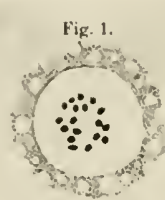

Fig. 4

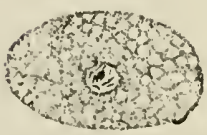

Fig. 7.

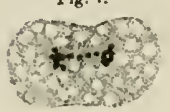

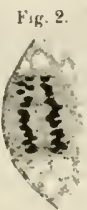

Fig. 5.
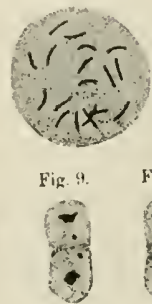
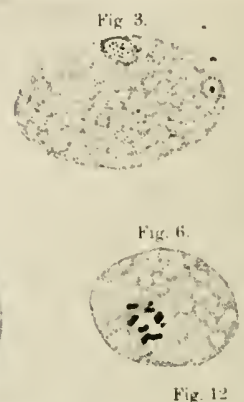

Fig. 10.
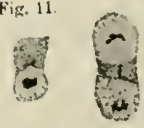

FIg. 108. - Oögenesis and spermatogenesis of Rhabditis aberrans. $1-5$, stages in oögenesis, including incomplete attempt to form one polar body. Eighteen ehromosomes in 1 and again in 4 and 5 . In 3 the entering sperm seen at right. 6 , prophase of first spermatoeyte with 8 double and two single chromosomes (sex chromosomes). At the first division (7) the double chromosomes separate, and the two sex chronosomes divide, giving ten chromosomes to each daughter cell (8). At the next division the two sex chronosomes move to opposite poles, giving two female-producing sperm (9 and 10). Rarely one of them may be left at the division plane and lost, so that a male-producing sperm results that aceounts for the rare occurrence of males. (After E. Krüger.)

shown that if the ovary of the female bird is removed or defieient, she assumes the plumage of the male. Possibly, therefore, some of these cases may fall under this heading, but it is improbable that they can all be explained in this way. In the cases examined by Guyer himself the hybrids were dissected and all four were found to be males. 
Pearl has recently pointed out that the sex ratio in the Argentine Republic varies somewhat according to whether individuals of the same race, or of different races, are the parents. As seen in the following table, the sex ratio of Italian by Italian is 100.77 ;

Comparison of the Sex Ratios of the Offspring of Pure and Cross Matings

\begin{tabular}{|c|c|c|c|}
\hline \multicolumn{2}{|c|}{ Matings } & \multirow{2}{*}{$\begin{array}{c}\text { Sex Ratio } \\
105.72 \pm .46\end{array}$} & \multirow{2}{*}{$\begin{array}{c}\text { Difference } \\
\text { P.E. OF Difference }\end{array}$} \\
\hline Italian $\widehat{\delta}$ & Argentine & & \\
\hline Italian $\hat{\delta}$ & Italian ? & $100.77 \pm .20$ & \\
\hline \multicolumn{2}{|c|}{ Difference } & $4.95 \pm .50$ & 9.9 \\
\hline Italian $\hat{\sigma}$ & Argentine $q$ & $10.5 .72 \pm .46$ & \\
\hline Argentine $\delta$ & Argentine $?$ & $103.26 \pm .34$ & \\
\hline \multicolumn{2}{|c|}{ Difference } & $2.46 \pm .57$ & 4.3 \\
\hline Spanish $\hat{\sigma}$ & Argentine? & $106.69 \pm .74$ & \\
\hline Spanish $\widehat{\sigma}$ & Spanish $q$ & $105.55 \pm .36$ & \\
\hline \multicolumn{2}{|c|}{ Difference } & $1.14 \pm .82$ & 1.4 \\
\hline Spanish $\hat{\sigma}$ & Algentine ? & $106.69 \pm .74$ & \\
\hline Argentine $\widehat{\delta}$ & Argentine $?$ & $103.26 \pm .34$ & \\
\hline \multicolumn{2}{|c|}{ Difference } & $3.43 \pm .81$ & 4.2 \\
\hline
\end{tabular}

Argentine by Argentine, 103.26 ; but Italian by Argentine, 105.72. If, as has so often been found to be the case, a hybrid combination gives a more vigorous progeny, the higher sex ratio of the cross-breed may account for the observed differences, since other data show that the male infant is less viable and the increased vigor of a hybrid combination may increase the chance of survival of the male. 
(6) We come now to the most perplexing case on record. In frogs the normal sex ratio is approximate equality. Professor Richard Hertwig has found that if the deposition of the eggs is prevented for two to three days (after the eggs have reached the uterus) the proportion of males is enormously increased in the extreme case all the offspring may be males. By critical experiments Hertwig has shown that the results are not due to the age of the spermatozoa, although in general he is inclined to attribute certain differences in sex-determination to the sperm as well as to the eggs.

The evidence obtained by his pupil, Kuschakewitsch, goes clearly to show that the high male sex ratio is not due to a differential mortality of one sex.

In the following table four experiments $(a, b, c, d)$ are summarized. The interval between each record
a) $47 \%: 32 \hat{\jmath}$
0 \&: 97 今

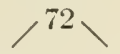

b) $34 q: 47 \delta$<smiles>C[Hg]C</smiles>

65 $: 77 \hat{\circ}$<smiles>C[In]C</smiles>

156 ९ : $194 \hat{\jmath}$

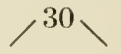

7 ㅇ: 48 ๙

c) 64 $: 61$ के<smiles>C[As]C</smiles><smiles>C[AlH]C</smiles>

$\gamma^{18} \backslash$

d) $55 q: 52 \delta$

148 ᄋ : 87 古

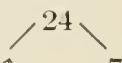

$115 q: 169$ 후

is written above in hours. In all cases an excess of males is found if the eggs have been kept for several hours before fertilization. In the first $(a)$, second $(b)$, and fourth $(d)$ cases the excess of males is very great. Hertwig attempts to bring his results into line with 
his general hypothesis of nucleo-plasm relation. He holds, for instance, that sex may be determined by the relation between the size of the nucleus and the protoplasm of the cell. As the value of the evidence has been seriously called into question in general, and as there is practically no evidence of any weight in its favor in the present case, I shall not dwell further on the question here. But the excessively high male ratio is evident and positive. How to explain it is difficult to say. It is just possible, I think, that delay may have injured the egg to such an extent that the sperm may start the development but fail to fuse with the egg nucleus. Under these circumstances there is the possibility that all the frogs would be males.

Miss King has also carried out extensive sets of experiments with the common toad. She has studied the eggs and the sperm under many different conditions, such as presence of salt solutions, acids, sugar solutions, cold, and heat. Her results are important, but their interpretation is uncertain. In sugar solutions and in dry fertilization the males decreased, in the latter from 114.10 to 29.41 per 100 우. The normal sex ratio for the toad is $90 \delta$ to $100 q$. Whether the solutions have in any sense affected the determination of sex, or acted to favor one class of sperm at the expense of the other remains to be shown, as Miss King herself frankly admits.

In the case of man there are extensive statistics concerning the birth rate. The accompanying tables give some of the results. There are in all parts of the world more males born than females. The excessively high ratios reported from the Balkans (not given here) may be explained on psychological grounds, as failure 


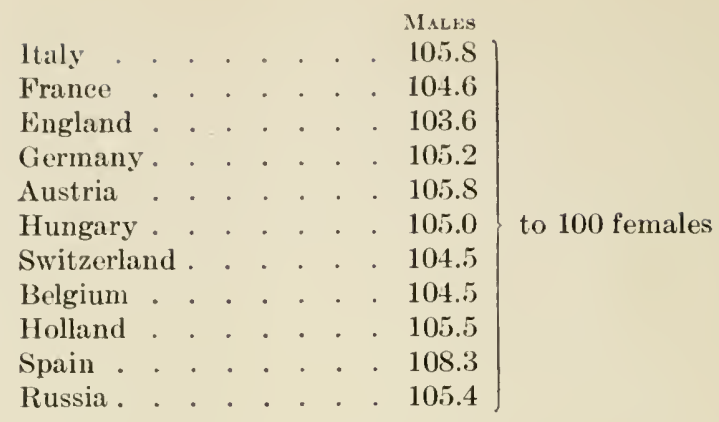

to report the birth of a boy is more likely to lead to the imposition of a fine on account of the conscription.

There can be no doubt, however, that slightly more males than females are born. Moreover, if the stillborn infants alone are recorded, surprisingly large ratios occur, as shown in the next table.

\begin{tabular}{|c|c|c|c|c|}
\hline & & & Males & \\
\hline Italy & . . & & 131.1 & \\
\hline France & . & . & 142.2 & \\
\hline Germany. & . & . & 128.3 & \\
\hline Austria . & . & . & 132.1 & \\
\hline Hungary . & . & . & 130.0 & \\
\hline Switzerland & . & . & 135.0 & to 100 females \\
\hline Belgium . & . & . & 132.1 & \\
\hline Holland . & . & . & 127.7 & \\
\hline Sweden . & . & & 135.0 & \\
\hline Norway . & . & & 124.6 & \\
\hline Denmark & & & 132.2 & \\
\hline
\end{tabular}

And if abortive births are also taken into account, the ratio is still higher. It seems that the male embryo is not so strong as the female, or else less likely, from other causes, to be born alive.

In many of the domesticated animals also, especially 
the mammals, there is an excess of males at birth, as the next table shows.

\begin{tabular}{|c|c|c|c|c|c|c|c|}
\hline & & & & & & MaLes & FEMales \\
\hline Horse & . & & . & . & . & 98.31 & 100 (Düsing) \\
\hline Cattle & . & - & • & . & . & 107.3 & 100 (Wilckens) \\
\hline Sheep & . & . & . & . & . & 97.7 & 100 (Darwin) \\
\hline Pig . & . & - & . & . & . & 111.8 & 100 (Wilckens) \\
\hline Rat. & - & . & . & - & . & 105.0 & 100 (Cuénot) \\
\hline Dove & . & . & . & . & . & 105.0 & 100 (Cuénot) \\
\hline Hen. & . & . & & . & . & 94.7 & 100 (Darwin) \\
\hline
\end{tabular}

A little later I shall bring forward the evidence that makes probable the view that in man the mechanism for sex-determination is like that in other animals, where two classes of sperm are produced, male- and female-producing. How then can we account in the human race for the excess of eggs that are fertilized by male-producing spermatozoa? At present we do not know, but we can at least offer certain suggestions that seem plausible.

In mammals the fertilization occurs in the upper parts of the oviduct. In order to reach these parts the sperm by their own activity must traverse a distance relatively great for such small organisms. If the rate of travel is ever so slightly different for the two classes of sperm, a differential sex ratio will occur.

Again, if from any cause, such as disease or alcoholism, one class of sperm is more affected than the other, a disturbance in the sex ratio would be expected.

At present these are only conjectures, but I see no ground for seizing upon any disturbance of the ratio in order to formulate far-reaching conclusions in regard to sex-determination itself. As I pointed out in the beginning of this chapter, we may go 
wide of the mark if we attempt to draw conclusions concerning the determination of sex itself from deviations such as these in the sex ratio, yet it is the mistake that has been made over and over again. We must look to other methods to give us sufficient evidence as to sex-determination. Fortunately we are now in a position to point to this other evidence with some assurance. With the mechanism itself worked out, we are in a better position to explain slight variations or variables that modify the combinations in this way or in that.

THE ABANDONED VIEW THAT EXTERNAL CONDITIONS DETERMINE SEX

But before taking up the evidence for sex-determination in man I must briefly consider what I have been bold enough to call the abandoned view that external conditions determine sex.

Let us dismiss at once many of the guesses that have been made. Drelincourt recorded 262 such guesses, and Gerldes and Thomson think that this number has since been doubled. Naturally we camnot consider them all, and must confine ourselves to a few that seem to have some basis in fact or experiment.

The supposed influence of food has been utilized in a large number of theories. The early easual evidence of Landois, of Mrs. Treat, and of Gentry has been entirely set aside by the careful observations of Riley, Kellogg and Bell, and Cuénot. In the latter cases the experiments were carried through two or even three generations, and no evidence of any influence of nourishment was found. 
The influence of food in sex-determination in man has often been exploited. It is an ever recurrring episode in the ephemeral literature of every period. The most noted case is that of Schenk. In his first book he said starvation produced more females; in his second book he changed his view and supposed that starvation produces more males.

Perhaps the most fertile source from which this view springs is found in some of the earlier statistical works, especially that of Düsing. Düsing tried to show that more girls are born in the better-fed classes of the community, in the poorer classes more boys. The effective difference between these two classes is supposedly one of food! For instance, he states that the birth-rate for the Swedish nobility is 98 boys to 100 girls, while in the Swedish clergy the birth-rate is 108.6 boys to 100 girls.

Other statistics give exactly opposite results. Punnett found for London (1901) more girls born amongst the poor than the rich. So many elements enter into these data that it is doubtful if they have much value even in pointing out causes that affect the sex ratio, and it is quite certain that they throw no light on the causes that determine sex.

In other mammals where a sex ratio not dissimilar to that in man exists, extensive experiments on feeding have absolutely failed to produce any infiuence on the ratio. We have, for instance, Cuénot's experiments with rats, and Schultze's experiments with mice. The conditions of feeding and starvation were much more extreme in some cases than is likely to occur ordinarily, yet the sex ratio remained the same. Why in the face of this clear evidence do we find 
zoölogists, physicians, and laymen alike perpetually discovering some new relation between food and sex? It is hard to say. Only recently an Italian zoölogist, Russo, put forward the view that by feeding animals on lecithin more females were produced. He claimed that he could actually detect the two kinds of eggs in the ovary - the female- and the male-producing. It has been shown that his data were selected and not complete; that repetition of his experiments gave no confirmative results, and probably that one of the two kinds of eggs that he distinguished were eggs about to degenerate and become absorbed.

But the food theories will go on for many years to come - as long as credulity lasts.

Temperature also has been appealed to as a sex factor in one sense or another. R. Hertwig concluded that a lower temperature at the time of fertilization gave more male frogs, but Miss King's observations failed to confirm this. There is the earlier work of Maupas on hydatina and the more recent work of von Malsen on Dinophilus apatris. I have already pointed out that Maupas' results have not been confirmed by any of his successors. Even if they had been confirmed they would only have shown that temperature might have an effect in bringing parthenogenesis to an end and instituting sexual reproduction in its stead. In hydatina the sexual female and the male producing individual are one and the same. A more striking case could not be found to show that the environment does not determine sex but may at least change one method of reproduction into another.

There remain von Malsen's results for dinophilus, 
where large and small eggs are produced by the same female (Fig. 109). The female lays her eggs in clusters, from three to six eggs, as a rule, in each cluster. The large eggs produce females; the small eggs pro-

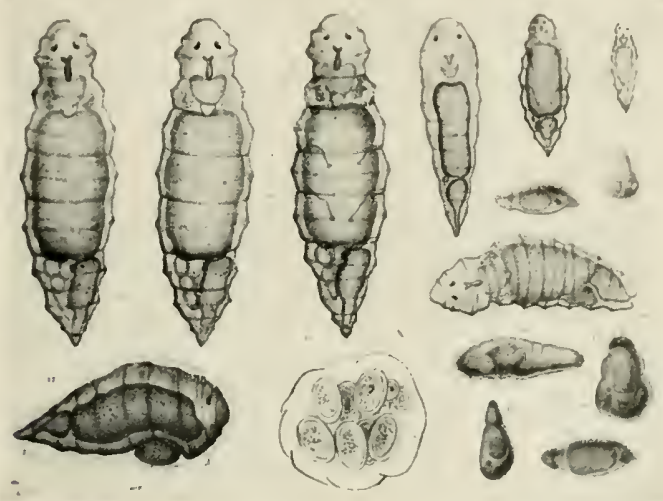

Fig. 109. - Dinophilus gyrociliatus. Females (above and to left) and males (below and to right). Two kinds of eggs shown in middle of lower row. (After Shearer.)

duce rudimentary males that fertilize the young females as soon as they hatch and before they have left the jelly capsule.

Von Malsen kept the mother at different temperatures, with the results shown in the table. The ratio of small eggs to large eggs changes. But the result

\begin{tabular}{|c|c|c|c|c|c|}
\hline Temperature & $\begin{array}{l}\text { No. of } \\
\text { Broods }\end{array}$ & 8 & q & $\begin{array}{c}\text { Sex } \\
\text { Ratio }\end{array}$ & $\begin{array}{c}\text { EGGS PER } \\
\text { BROOD }\end{array}$ \\
\hline Room temp. $19^{\circ} \mathrm{C}$. & 202 & 327 & 813 & $1: 2,4$ & 5,6 \\
\hline Cold, $13^{\circ} \mathrm{C}$. & 925 & 973 & 2975 & $1: 3,5$ & 4,2 \\
\hline Heat, $26^{\circ} \mathrm{C}$. & 383 & 507 & 886 & $1: 1,7$ & 3,6 \\
\hline
\end{tabular}


obviously may only mean that more of the large eggs are likely to be laid at one temperature than at another. In fact, temperature seemed to act so promptly according to Von Malsen's observations that it is very unlikely that it could have had any influence in determining the kind of egg produced, but rather the kind of egg that was more likely to be laid. We may dismiss this case also, I believe, as not showing that sex is determined by temperature.

\section{SEX-DETERMINATION IN MAN}

Let us now proceed to examine the evidence that bears on the determination of sex in man. I shall draw on three sources of evidence:

1. Double embryos and identical twins.

2. Sex-linked inheritance in man.

3. Direct observations on the chromosomes.

The familiar case of the Siamese twins is an example of two individuals organically united. A large series of such dual forms is known to pathologists. There are hundreds of recorded cases. In all of these both individuals are of the same sex, i.e. both are males or both are females. There is good evidence to show that these double types have come from a single fertilized egg. They are united in various degrees (Fig. $110)$; only those that have a small connecting region are capable of living. These cases lead directly to the formation of separate individuals, the so-called identical twins.

Galton was one of the first, if not the first, to recognize that there are two kinds of twins - identical twins and ordinary or fraternal twins. 
Identical twins are, as the name implies, extremely alike. They are always of the same sex. There is every presumption and some collateral evidence to show that they come from one egg after fertilization. On the other hand, amongst ordinary twins a boy and a girl, or two boys and two girls, occur in the ratio expected, i.e. on the basis that their sex is

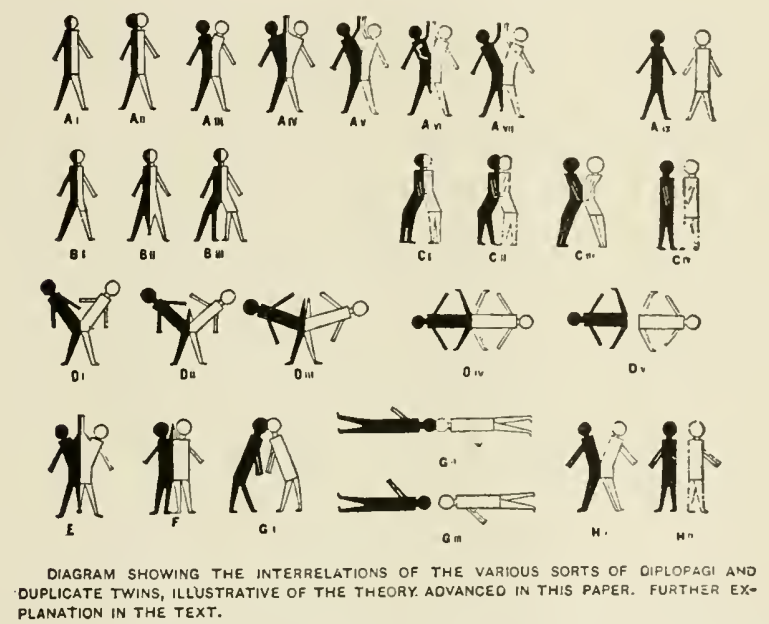

FIG. 110. - Diagram showing different types of union of double monster (After Wilder.)

not determined by a common external or internal cause. Since fraternal twins and identical twins show these relations at birth and from the fact that they have been in both cases subjected to the same conditions, it follows with great probability that sex in such cases is determined before or at the time of fertilization.

This conclusion finds strong support from the condi- 
tions that have been made out in the armadillo. Jehring first reported that all the young of a single litter are of the same sex (Fig. 111). The statement has been verified by Newman and by Patterson on a large scale. In addition they have found, first, that only one egg leaves the ovary at each gestative period; and second, that from the egg four embryos are pro-

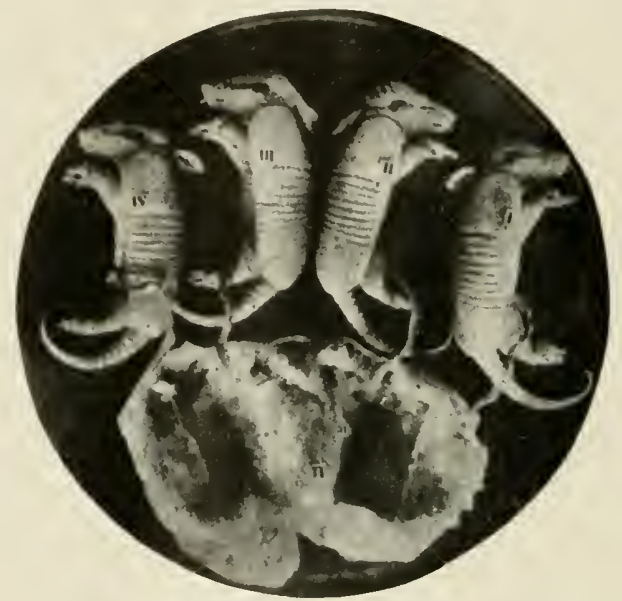

FIG. 111. - Nine-banded Armadillo. Four identical twins with a common placenta. (After Newman and Patterson.)

duced (Fig. 112). The material out of which they develop separates from the rest of the embryonic tissue at a very early stage. The four embryos are identical quadruplets in the sense that they are more like each other than like the embryos of any other litter, or even more like each other than they are to their own mother.

The second source of evidence concerning sex-deter- 
mination in man is found in the heredity of sex-linked characters.

The following cases may well serve to illustrate some of the better ascertained characters. The tables are taken from Davenport's book on "Heredity in Relation to Eugenics." The squares indicate males, affected males are black squares; the heavy circles indicate females, that are supposed to carry the factors, but

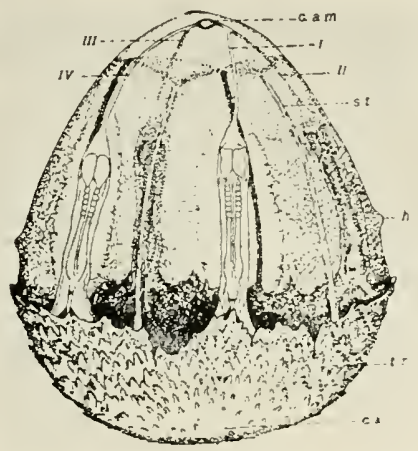

FIG. 112. - Nine banded Armadillo. Embryonic blastocyst that has four embryos on it, two of which are seen in figure. (After Newman and Patterson.)

such females do not exhibit the character themselves. Solid black circles stand for affected females.

Hæmophilia appears in affected stocks almost exclusively in males (Fig. 113). Such males, mating with normal females, give only normal offspring, but the daughters of such unions if they marry normal males will transmit the disease to half of their sons. Affected females can arise only when a hæmophilious male marries a female carrying hæmophilia. If we 


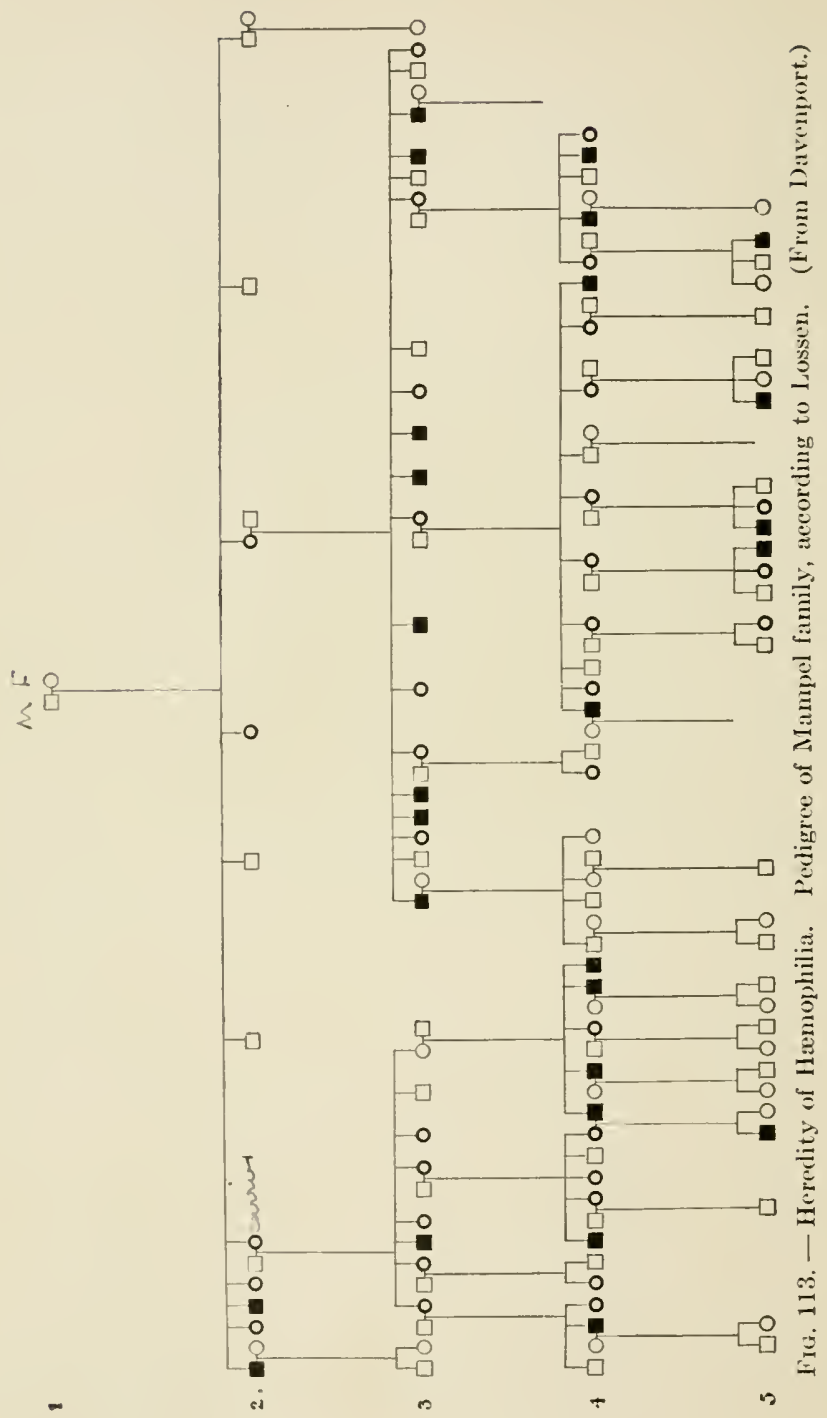



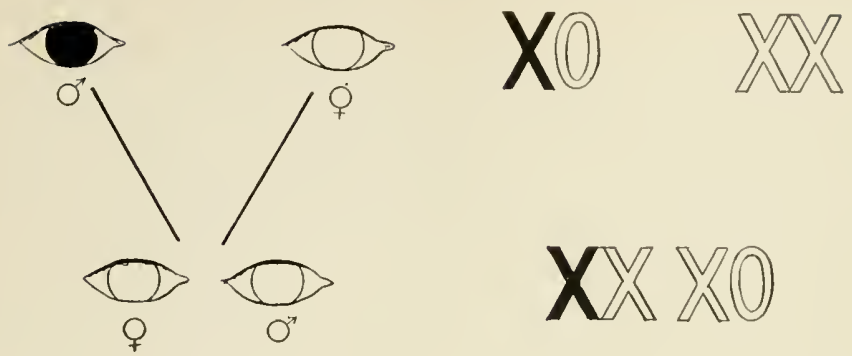

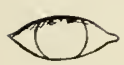

2 ?
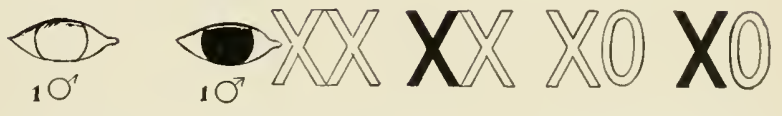

FIG. 114. - Diagram to indicate heredity of color blindness through male. A color-blind male (here black) transmits his defect to his grandsons only.
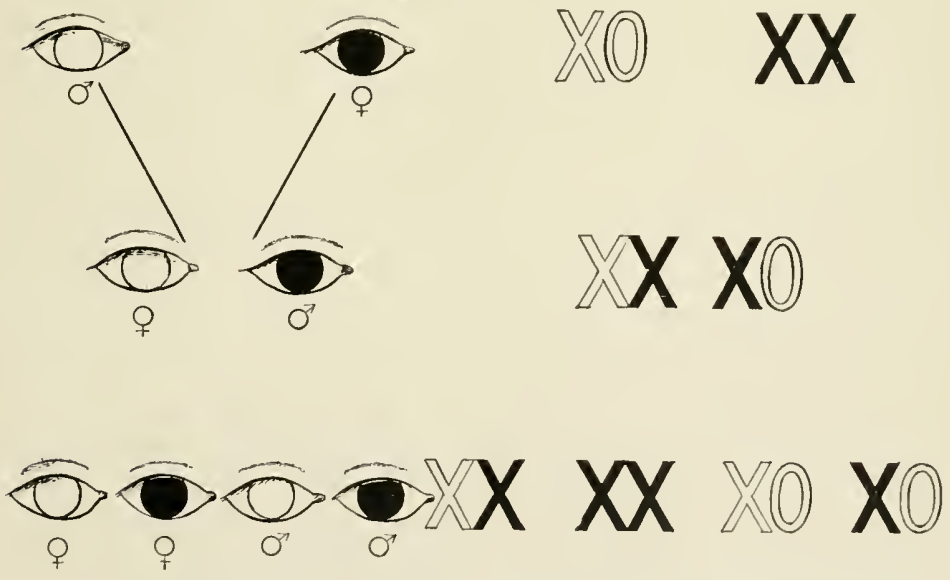

FIG. 115. - Diagram to indicate heredity of color blindness through female. A color-blind female transmits color blindness to all of her sons, to half of her granddaughters and to half of her grandsons. 
substitute white eyes for hæmophilia, the scheme already given for white versus red eyes in flies applies to this case. If, for instance, the mother with normal eyes has two $X$ chromosomes (Fig. 114), and the factor for hæmophilia is carried by the single $X$ in the male (black $X$ of diagram), the daughter will have one affected $X$ (and in consequence will transmit the factor), but also one normal $X$ which gives normal

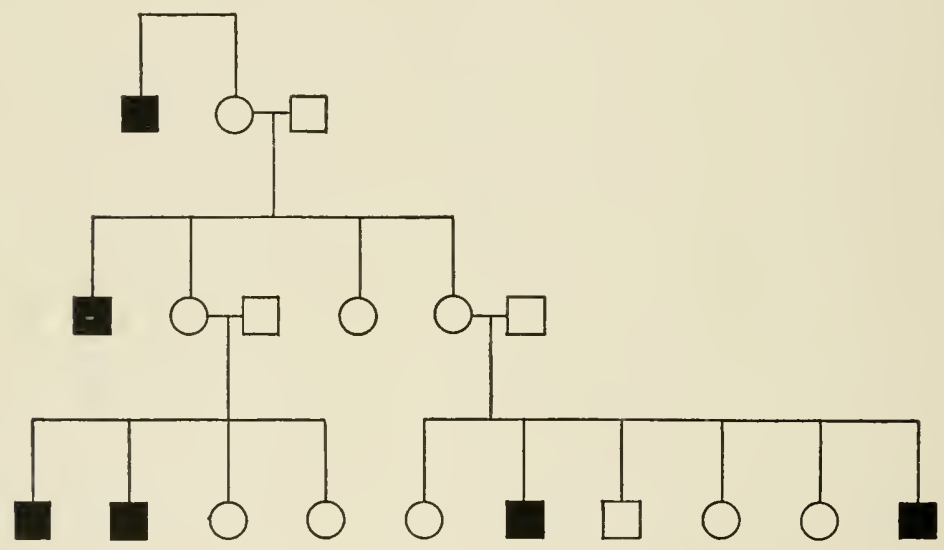

FIG. 116. - Pedigree of Ichthyosis from Bramwell. (After Davenport.)

vision. The sons will all be normal, since they get the $X$ chromosomes from their mother. In the next generation, as shown in the diagram (third line), four classes arise, normal females, hybrid females, normal males, and hæmophilious males. Color blindness follows the same scheme, as the above diagrams illustrate (Figs. 114 and 115). In the first diagram the colorblind male is represented by a black eye; the normal female by an eye without color. The offspring from 
SPECIAL CASES OF SEX-INHERITANCE 243

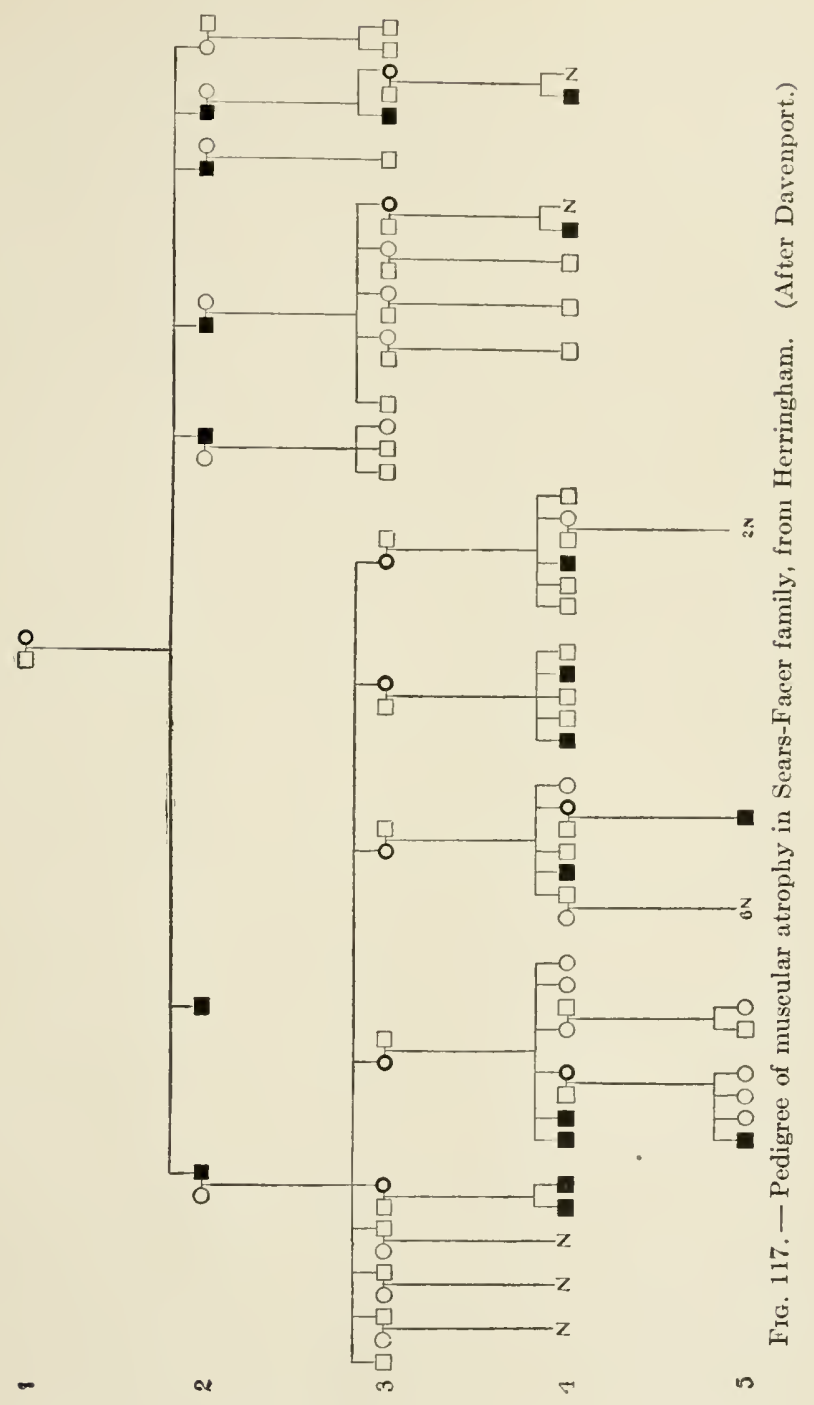


two such individuals are normal, but the color blindness reappears in one-fourth of the grandchildren, and in these only in the males. The reverse mating is shown in the next diagram in which the female is color-blind. She will have color-blind sons and normal daughters (criss-cross inheritance), and all four kinds of grandchildren.

Other cases in man that are said to show sex-linked inheritance are atrophy of the optic nerve, multiple

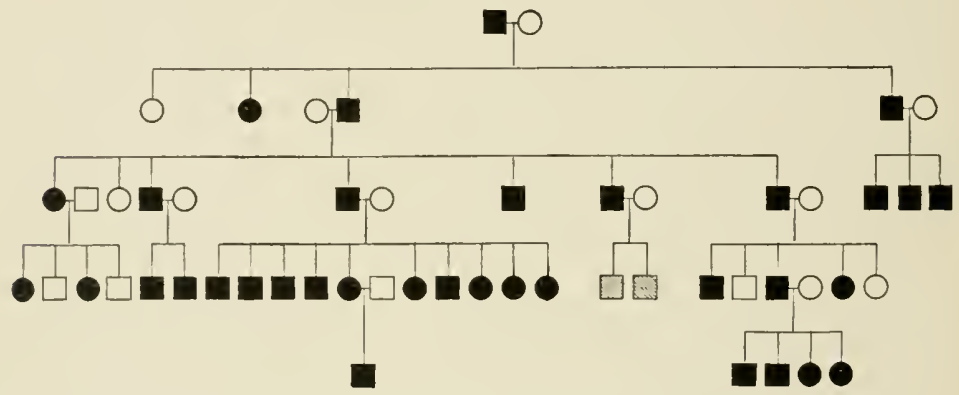

FIG. 118. - Pedigree of night blindness in a negro family, from Bordley. (After Davenport.)

sclerosis, myopia, ichthyosis (Fig. 116), muscular atrophy (Fig. 117). Night blindness is described in certain cases as sex-linked; in other cases, however, a disease by the same name appears to be a simple dominant and not sex-linked (Fig. 118).

All these cases of sex-linked inheritance in man are explained by the assumption that the factor that produces these characters is carried by the sex chromosome, which is duplex $(X X)$ in the female and simplex $(X)$ in the male. A simpler assumption has not yet been found. If one is fastidious and objects to the 
statement of factors being carried by chromosomes, he has only to say, that if the factors for the characters follow the known distribution of the sex chromosome, the results can be accounted for.

The culmination of the evidence of sex-determination in man is found in a study of the cell structure of the human race itself. Strange as it may seem, we have been longer in doubt concerning the number of chromosomes in man than in any other animal as extensively studied. Four conditions are responsible: (1) The large number of chromosomes present in man. (2) The clumping or sticking together of the chromosomes. (3) The difficulty of obtaining fresh material. (4) The possibility that the negro race has half as many chromosomes as the white race.

Two years ago Guyer announced the discovery that in all probability there exist in man two unpaired chromosomes in the male (Fig. 119) that behave in all respects like that in the typical cases of the sort in insects, where, as we have seen, there are two classes of spermatozoa, differing by the addition of one more chromosome in one class. These produce females; the lacking class produces males. But Guyer's evidence was not convincing. He found in all 12 chromosomes in one class of sperm and 10 in the other. Montgomery has also studied the same problem, but his account, while confirming the number, is in disagreement in regard to the accessory.

Jordan has gone over a number of other mammals, in some of which he thinks that he has found indications at least of two classes of sperm.

Still more recently another investigator, von Wini- 
warter, has attacked the problem (Fig. 120). His material and his methods appear to have been superior to those of his predecessors. His results, while stated with caution and reserve, seem to put the whole question on a safer basis.

His main results are illustrated in the diagram

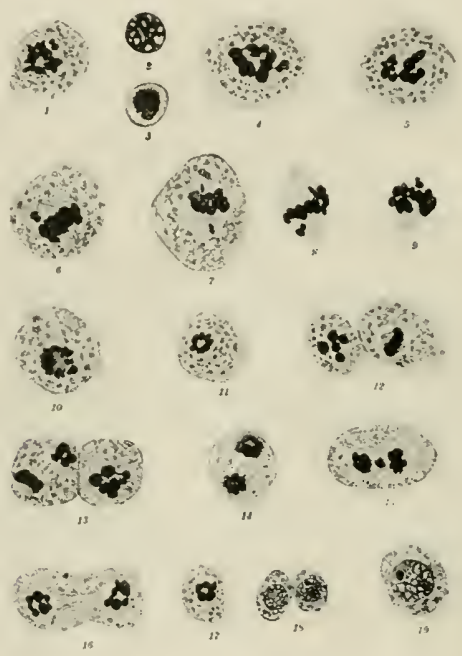

Fig. 119. - Human spermatogenesis according to Guyer. The sex chromosomes are seen in 6-9.

(Fig. 120). In the male he finds 47 chromosomes. Of these 46 unite at reduction to give 23 double chromosomes - one remains without a mate. At the first reduction division the pairs separate, 23 going to each pole, the unpaired chromosome into one cell only. 
At the next division all the chromosomes in the 23 group divide, likewise all in the 24 group divide. There are produced two spermatozoa containing 24

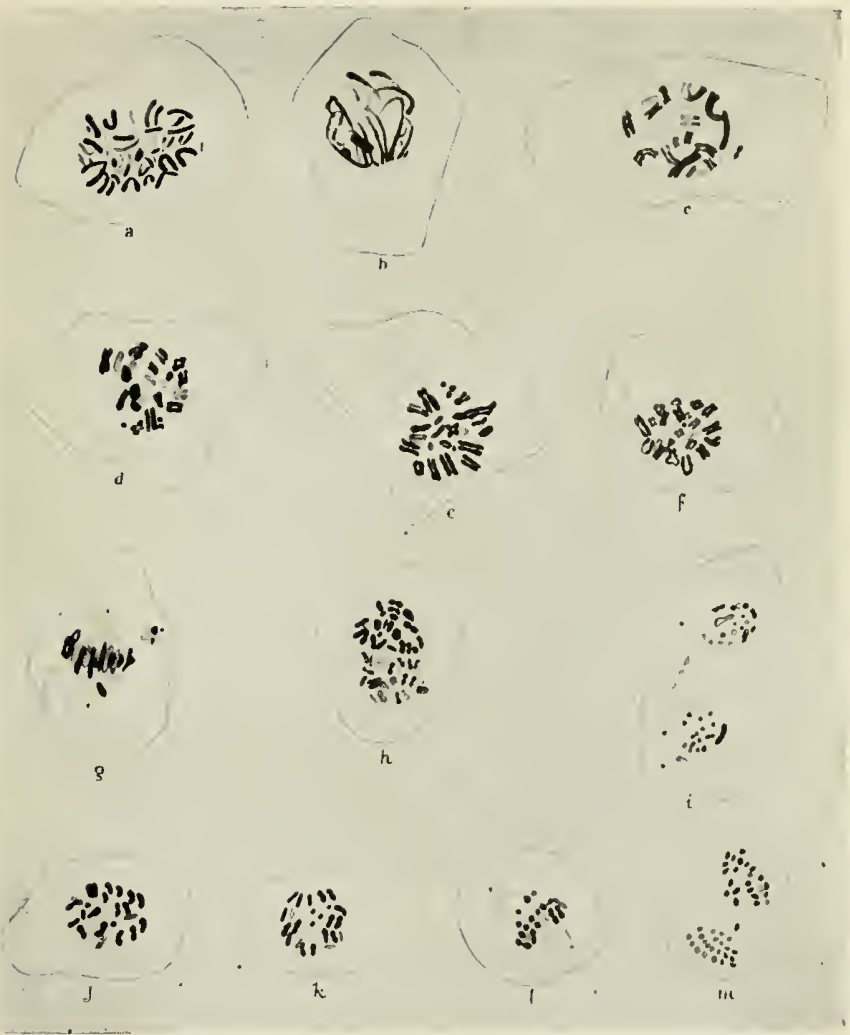

FIG. 120. - Human spermatogenesis according to von Winiwarter. $a$, spermatogonial cell with duplex number; $b$, synapsis ; $c, d, e, f$, first spermatocytes with haploid number of chromosomes; $g$, first spermatocyte division, sex chromosomes (below) in advance of others; $h$, two polar plates of later stage; $i$, first division completed; $j$, second spermatocyte with 23 chromosomes; $k$, second spermatocyte with 24 chromosomes; $l$, second spermatocyte division; $m$, two polar plates of later stage. 
chromosomes, and two containing 23 chromosomes; all four sperms having come from the same spermatogonial cell (Fig. 121).

In the female von Winiwarter had difficulty in determining the number of chromosomes present. His

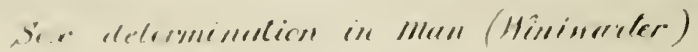

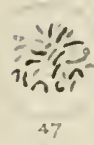

A
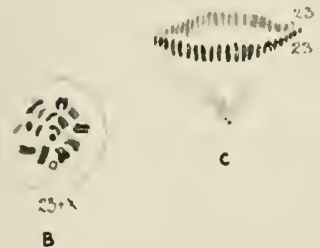

B
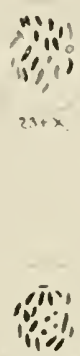

23

0
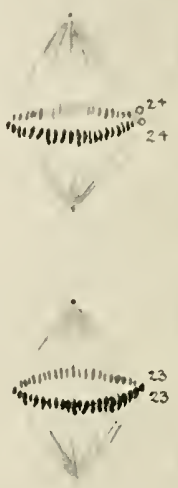

$\varepsilon$

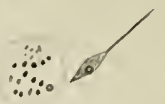

$2+$
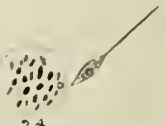

24

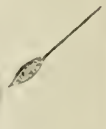

23

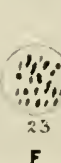

F

FIG. 121. - Diagram of human spermatogenesis. $A$, spermatogonial cell with 47 ehromosomes; $B$, first spermatoryte with redueed haploid number and sex (-hromosome (open eircle) ; $C$, first division; $D$, two resulting cells $=$ second spermatocytes; $E$, division of second spermatocytes; $F$, four resulting spermatozou, two female-producing (above), two male-produeing (below).

best counts gave 48 chromosomes for the full or duplex number. These observations fit in with the results from the male.

If these observations are confirmed, they show that in man, as in so many other animals, an internal mechanism exists by which sex is determined. It is futile then to search for environmental changes that 
might determine sex. At best the environment may slightly disturb the regular working out of the two possible combinations that give male or female. Such disturbances may affect the sex ratio but have nothing to do with sex-determination. 



\section{BIBLIOGRAPHY}

Andrews, E. A., 1895. Conjugation in an American Crayfish. Ain. Nat, XXIX.

Andrews, E. A., 1904. Breeding Habits of Crayfish. Am. Nat., XXXVIII.

Andrews, E. A., 1910. Conjugation in the Crayfish Cambarus affinis. Jour. Exp. Zoöl., IX.

Arkell, T. R., 1912. Some Data on the Inheritance of Horns in Sheep. N. H. Agr. Exp. Sta. Bulletin, 160.

Arkeli, T. R., and C. B. Davenport, 1912. The Nature of the Inheritance of Horns in Sheep. Science, N. S., XXXV.

Arkell, T. R., and C. B. Davenport, 1912. Horns in Sheep as a Typical Sex-limited Character. Science, N. S., XXXV.

von BaEhr, W. B., 1908. Ueber die Bildung der Sexualzellen bei d. Aphididæe. Zool. Anz., XXXIII.

VON BAEHR, W. B., 1909. Die Oogenese bei einigen viviparen Aphiden und die Spermatogenese von Aphis saliceti. Arch. $f$. Zellf., III.

von BaEhr, W. B., 1912. Contribution a l'étude de la caryokinese somatique, de la pseudoréduction et de la réduction. La Cellule, XXVII.

Bartsell, G. A., 1912. Experiments on the Reproduction of the Hypotrichous Infusoria. Jour. Exp. Zoöl., XIII.

Baltzer, F., 1908. Über die Grösse und Form der Chromosomen von Seeigeleiern. Verh. d. deutsch. zool. Ges., 1908.

Baltzer, F., 1909. Die Chromosomen von Strongylocentrotus lividus und Eehinus microtubereulatus. Arch. f. Zellf., II.

BaLtzer, F., 1910. Ueber die Beziehung zwischen dem Chromatin und der Entwicklung und Vererbungsrichtung bei Echinodermenbastarden. Arch. f. Zellf., V.

Baltzer, F., 1911. Zur Kentnis der Mechanik der Kernteilungsfiguren. Arch. Entw.-mech. f. d. Org., XXXIII.

Bateson, W., 1909. Mendel's Principles of Heredity. Cambridge. 
Batesos, IV., 1912. Biological Fact and the Structure of Society. Cambridge.

Bateson, W., 1913. Mendel's Principles of Heredity. 3d impression. Cambridge.

Bateson, W., and R. C. Puxvett, 1905. Rep. Evol. Comtm., II. Batesox, W., and R. C. Puxxett, 1908. The Heredity of Sex.

sicience, XXVII.

Bateson, IV., and R. C. Punnett, 1911. On the Interrelations of

Genetic Factors. Proc. Roy. Soc, LXXXIV.

Batesox, W., and R. C. Punsett, 1911. The Inheritance of the

Peculiar Pigmentation of the Silky Fowl. Jour. Gen., I.

Bateson, W., and R. C. Punnett, 1911. On Gametic Series Involving Reduplication of Certain Terms. Jour. Gen., I.

Baumgartier, IV. J., 1912. Observations on the Gryllidæ-IV. Copulation. Kans. Univ. Sci. Bull., V.

BAur, E., 1911. Ein Fall von Faktorenkoppelung bei Antirrhinum majus. V'erh. naturf. V'er. Brünn, XLIX.

BAUR, E., 1912. Tererbungs- und Bastardierungsversuche mit Antirrhinum - II. Faktorenkoppelung. Zeits. Abst. u. Vercrb., VI.

BAur, F., 1912. Ein Fall von geschlechtsbegrenzter Vererbung bei Melandrium album. Zeits. Abst. u. V'ererb., VIII.

BeArd, J., 1902. The Determination of Sex in Animal Development. Zool. Jahrb. Abt. Anat., XVI.

Beddard, F. E., 1906. Proc. Zoöl. Soc. London, 1906, II, p. 533.

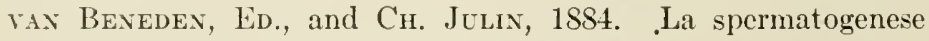
chez l'ascaride megalocéphale. Bull. de l'acad. roy. de Belgique. Année 53, $3^{\text {me }}$ Ser., T. VII.

Berry, E. H., 1906. The "Accessory Chromosome" in Epeira. Biol. Bull., XI.

Blackias, M. W., 1905. The Spermatogenesis of Myriapods. III. Bull. Mus. Comp. Zoöl., Harvard College, XLVIII.

Blakeslee, A. F., 1904. Sexual Reproduction in the Mucorineæ. Proc. Amer. Acad. Arts and Sci., XL.

Blakeslee, A. F., 1904. Zygospore Formation a Sexual Process. Science, XIX.

Blakeslee, A. F., 1906. Differentiation of Sex in Thallus Gametophyte and Sporophyte. Bot. Gaz., XLII. 
Blakeslee, A. F., 1908. Șexual Condition in Fegatella. Bot. Gaz., XLVI.

Boring, A. M., 1909. A Small Chromosome in Ascaris megalocephala. Arch.f. Zellf., IV.

Boveri, Tн., 1907. Zellen Studien. Die Entwicklung dispermer Seeigel-Eier, etc. Jena.

Bover1, Тн., 1908. Ueber die Beziehung des Chromatins zur Geschlechtbestimmung. Sitz. Phys.-Med. Gesell. Würzburg. Dez., 1908.

Boveri, Th., 1909. Die Blastomerenkerne von Ascaris megalocephala und die Theorie der Chromosomen-Individualität. Areh. Zellf., III.

Boverı, Th., 1909. Über "Geschlechtschromosomen" bei Nematoden. Arch. Zellf., IV.

Boverı, Th., 1911. Ueber das Verhalten der Geschechtschromosomen bei Hermaphroditismus. Verh. Phys.-Med. Gesell. Würzburg, XLI.

Brauer, A., 1993. Zur Kenntniss der Spermatogenese von Ascaris megalocephala. Arch. mikr. Anat., XLII.

Bresca, G., 1910. Experimentelle Untersuchungen über die sekundären Sexualcharaktere der Tritonen. Arch. Entw.mech., XXIX.

Rrewster, F. T., 1906. Note on the Determination of Sex in Man. Am. Anthropol., VIII.

Bridges, C. B., 1913. Partial Sex-Linkage in the Pigeon. Science, XXXVII.

Buchner, Paul, 1911. Ueber hermaphrodite Seesterne. Zool. Anz., XXXVIII.

Bugnion, E., 1910. Les Cellules Sexuelles et la Détermination du Sexe. Bull. Soc. Vaudoise Sci. Nat., LXVI.

Burgeff, H., 1913. Ueber Sexualität, Variabilität und Vererbung bei Phycomyces nitens. Ber. deutsch. Bot. Gesell., X.

Calkins, G. N., 1902. Studies on the Life-History of Protozoa. III. Biol. Bull., III.

Calkins, G. N., 1904. Studies on the Life-History of Protozoa. IV. Jour. Exp. Zool., I.

Calkins, G. N., 1911. Protozoön Germ Plasm. Pop. Sci. Monthly. Calkins, G. N., 1913. Further Light on the Conjugation of Paramecium. Proe. Soc. Exp. Biol. Med., X. 
Calkiss, G. N., and C. C. Lieb, 1902. Studies on the Life-History of Protozoa, II. Arch. Protist., 1902.

Carmichael, E. S., and F. H. A. Marshall, 1908. On the Occurrence of Compensatory Hypertrophy in the Ovary. Jour. Physiol. XXXVI.

Castre, W. E., 1903. The Heredity of Sex. Bull. Mus. Comp. Zoöl., Harvard College, XL.

C.sstıe, W. E., 1909. A Mendelian View of Sex Heredity. Science, XXIX.

Castre, II. E., 1910. The Effect of Selection upon Mendelian Characters Manifested in One Sex only. Jour. Exp. Zoöl., VIII.

Castle, W. E., 1911. Double-mating of Silkworm Moths. Science, XXXIII.

Castle, II. E., 1911. Heredity in Relation to Evolution and Animal Breeding. New York.

Castre, W. E., 1912. Are Horns in Sheep a Sex-limited Character?

Science, XXXY.

Castle, W. E., 1913. Simplification of Mendelian Formulæ. Am. Nat., XLVII.

Castle, W. E., F. W. Carpenter, A. H. Clark, S. O. Mast, and

IV. M. BArrows, 1906. The Effects of Inbreeding, Crossbreeding, and Selection upon the Fertility and Variability of

Drosophila. Proc. Am. Acad. Arts and Sci., XLI.

CAstle, W. E., and J. C. Phillips, 1909. A Successful Orarian

Transplantation in the Guinea-pig, etc. Science, XXX.

Chidester, F. E., 1911. The Mating Habits of Four Species of the Brachyura. Biol. Bull., XXI.

Chopard, L., 1912. Note sur un cas de gynandromorphisme chez

Forficula auricularia. Arch. Zool. Exp. et Gen., Ser. 5, T. X.

Cole, L. J., 1912. A Case of Sex-linked Inheritance in the Domestic Pigeon. Science, XXXVI.

Collins, G. N., 1912. Gametic Coupling as a Cause of Correlations. Am. Nat., XLVI.

Colton, H. S., 1912. Lymnæa columella and Self-fertilization. Proc. Acad. Nat. Sci. Phil.

Conklin, E. G., 1906. Sex-differentiation in Dinophilus. Science, XXIV. 
Cook, M. H., 1910. Spermatogenesis in Lepidoptera. Proc. Acad. Nat. Sci. Phil.

Correns, C., 1907. Zur Kenntnis der Geschlechtsformen polygamer Blütempflanzen und ihrer Beeinflussbarkeit. Jahrb. f. Wiss. Bot., XLIV.

Correns, C., 1907. Die Bestimmung und Vererbung des Geschlechts. Berlin.

Correns, C., 1908. Weitere Untersuchungen über die Gesehlechtsformen polygamer Blütenpflanzen und ihre Beeinflussbarkeit. Jahrb. f. wiss. Bot., XLV.

Correns, C., 1908. Die Rolle der Männlichen Keimzellen bei der Geschlechtsbestimmung der gynodioecischen Pflanzen. Ber. deutsch. Bot. Ges., XXVI.

Conrexs, C., 1908. Weitere Untersuchungen ueber die Gesehleehtsformen polygamer Blütenpflanzen und ihre Beeinflussbarkeit. Jahrb.f. wiss. Bot., XLV.

Correns, C., 1912. Selbststerilität und Individualstoffe. Fests. Med. Nat. Gesell. 84. Versam. deut. Natur. Acrzte.

Correns, C., and R. Goldschnidt, 1913. Die Vererbung und Bestimmung des Geschlechts. Gesamtsitz. 'naturw. mediz. Hauptg. St. Vers. deuts. Naturf. u. Aerzte in Münster.

Cúñot, L., 1899. Sur la determination du sexe ehez les animaux. Bull. Scient. France Belg., XXXII.

Cunningham, J. T., 1908. The Heredity of Secondary Sexual Characters in Relation to Hormones. Arch. f. Entw.-mech., XXVI.

Darling, C. A., 1909. Sex in Diœcious Plants. Bull. Tor. Bot. Club, IXXVI.

Darwin, C., 1S86. The Deseent of Man, and Selection in Relation to Sex. New York.

Darwin, C., 1889. Different Forms of Flowers on Plants of the Same Species. New York.

Darwin, C., 1895. Cross and Self-Fertilization in the Vegetable Kingdom. New York.

Davenport, C. B., 1906. Inheritance in Poultry. Carnegie Inst. Wash., pub. 53.

Davenport, C. B., 1909. Inheritance of Charaeteristies in Domestic Fowl. Carnegie Inst. Wash., pub. 121. 
Davenport, C. B., 1911. Heredity in Relation to Eugenies. New York.

Davenport, C. B., 1911. Another Case of Sex-limited Heredity in Poultry. Proc: Soc. Exp. Biol. Med., IX.

Davenport, C. B., 1912. Sex-limited Inheritance in Poultry. Jour. Exp. Zoöl., XIII.

Dederer, P. H., 1907. Spermatogenesis in Philosamia cynthia. Biol. Bull., XIII.

DeLAGE, Y., 190S. Les Idées nouvelles sur la Parthénogénèse expérimentale. La Rerue des Idées, 50.

Delcourt, A., and E. Gurénot, 1911. Génétique et Milieu. Bull. Scient. France Belg., XLT.

Della Valle, P., 1913. Die Morphologie des Zellkerns und die Physik der Kolloide. Zeits. Chem. Industr. Kolloide, XII.

Dexter, J. S., 1912. On Coupling of Certain Sex-linked Characters in Drosophila. Biol. Bull., XXIII.

Dodos, G. S., 1910. Segregation of the Germ-Cells of the Teleost, Lophius. Jour. Worph., XXI.

Doncaster, L., 1907. Inheritance and Sex in Abraxas grossulariata. Nature, LXXVI.

Doxcaster, L., 1907. Gametogenesis and Fertilization in Nematus ribesii. Q.J.M.S., LI.

Doncaster, L., 1905. On Sex-inheritance in the Moth, Abraxas grossulariata and its var. lacticolor. 4th Rep. Evol. Comm., R. Soc. Lond.

Doxcaster, L., 190S. Animal Parthenogenesis. Sci. Progr.

Doycaster, L., 1909. Recent Work on the Determination of Sex. Sei. Progr., XIII.

Doncaster, L., 1910. Gametogenesis of the Gall-fly, Neuroterus lenticularis (Spathegaster baccarum). Part I. Proc. Roy. Soc., B, LXXXII.

Doxcaster, L., 1911. Gametogenesis of the Gall-fly, Neuroterus lenticularis. Part II. Proc. Roy. Soc., IXXXIII.

Doxcaster, L., 1911. Note on the Inheritance of Charaeters in which Dominance appears to be Influenced by Sex. Jour. Genet., I.

Doxcastelr, L., 1911. Some Stages in the Spermatogenesis of Abraxas grossulariata and its var. lacticolor. Jour. Genet., I. 
Doncaster, L., 1912. The Chromosomes in the Oögenesis and Spermatogenesis of Pieris brassicæ, and in the Oögenesis of Abraxas grossulariata. Jour. Genet., II.

Doncaster, L., 1912. Note on the Chromosomes in Oögenesis and Spermatogenesis of the White Butterfly, Pieris brassieæ. Proc. Camb. Phil. Soc., XVI.

Doncaster, L., and G. Gray, 1911. Cytological Observations on Cross-fertilized Echinoderm Eggs. Proc. Camb. Phil. Soc., XVI.

Doncaster, L., and F. H. A. Marshall, 1910. The Effeets of One-sided Ovariotomy on the Sex of the Offspring. Jour. Genet., I.

Doncaster, L., and G. H. Raynor, 1906. Breeding Experiments with Lepidoptera. Proc. Zoöl. Soc. Lond.

Drew, G. A., 1911. Sexual Activities of the Squid, Loligo Pealii (Hes.). I. Copulation, Egg-laying and Fertilization. Jour. Morph., XXII.

Durham, F. M., 1911. Further Experiments on the Inheritance of Coat Colour in Mice. Jour. Genet., I.

Durham, F. M., and D. E. C. Marryat, 1908. Note on the Inheritance of Sex in Canaries. 4th Rep. Evol. Comm., Roy. Soc. Lond.

East, E. M., 1910. Notes on an Experiment concerning the Nature of Unit Characters. Science, XXXII.

EAst, E. M., 1910. The Rôle of Hybridization in Plant Breeding. Pop. Sci. Mon., Oct., 1910.

East, E. M., 1911. The Genotype Hypothesis and Hybridization, Am. Nat., XLV.

East, E. M., 1912. A Study of Hybrids Between Nicotiana bigelovii and N. quadrivalvis. Bot. Gaz., LIII.

EAst, E. M., and H. K. HAYEs, 1911. Inheritance in Maize. Comn. Exp. Sta. Bull., 167.

East, E. M., and H. K. HAYes, 1912. Heterozygosis in Evolution and in Plant Breeding. U. S. Dept. Agric., Bureau Plant Ind. Bull. 243.

Edwards, C. L., 1910. The Sex-determining Chromosomes in Ascaris. Science, XXXI.

Emerson, R. A., 1909. Inheritance of Color in the Seeds of the 
Common Bean, Phaseolus vulgaris. Ann. Rep. Nebr. Agr. Exp. Sta., XXII.

Euersov, R. A., 1911. Morgan on Coupling $v s$. Random Segregation. Science, XXXIV.

Esersox, R. A., 1911. Genetic Correlation and Spurious Allelomorphism in Maize. Ann. Rep. Nebr. Agr. Exp. Sta., XXIV.

Feverlex, H., 1911. Vererbungsstudien an der LepidopterenGattung Pygæra. Arch. Rass. Gesell., III.

FERÉ, C., 1S9S. Experiences relatives aux rapports homosexuels chez les hammetons. C.R. Soc. Biol., V.

FerÉ, C., 1S98. Experiences relatives a l'instinct sexuel chez le bombyx du murier. C. R. Soc. Biol., V.

Fick, R., 1907. Über die Vererbungssubstanz. Arch. Anat. $u$. Phys., Anat. Abt.

Foot, K., and E. C. Strobell, 1913. Preliminary Note on the Results of Crossing Two Hemipterous Species, ete. Biol. Bull., XXIV.

Fowler, G. H., 1894. Notes on some Specimens of Antlers of the Fallow Deer, etc. Proc. Zoöl. Soc. Lond., 1894.

Frolowa, S., 1912. Idiochromosomen bei Ascaris megalocephala. Areh. Zellf., IX.

Geddes, P., and J. A. Thomson, 1889. The Evolution of Sex. London.

Gerould, J. H., 1911. The Inheritance of Polymorphism and Sex in Colias philodice. Am. Nat., XIV.

Goldschmid, R., 1911. Einführung in die Vererbungswissenschaft. Leipzig.

Goldschmid, R., 1912. Erblichkeitsstudien an Schmetterlingen. I, 1. Zeits. Abst. Vererb., VII.

Goldschmid, R., 1912. Bemerkungen zur Vererbung des Geschlechtspolymorphismus. Zeits. Abst. Vererb, VIII.

Goldschuid, R., 1913. Zuchtversuche mit Enten. I. Zeits. Abst. Tererb., III.

Goodale, H. D., 1909. Sex and its Relation to the Barring Factor in Poultry. Science, XXIX.

Goodale, H. D., 1910. Breeding Experiments in Poultry. Proc. Soc. Exp. Biol. Med., VII. 
Goodale, H. D., 1910. Some Results of Castration in Ducks. Biol. Bull., XX.

Goodale, H. D., 1911. Studies on Hybrid Ducks. Jour. Exp. Zoöl., X.

Goodale, H. D., 1911. Sex-limited Inheritance and Sexual Dimorphism in Poultry. Science, XXXIII.

Goodale, H. D., 1913. Castration in Relation to the Secondary Sexual Characters of Brown Leghorns. Am. Nat., XLVII.

Gregory, R. P., 1911. Experinents with Primula sinensis. Jour. Genet., I.

Gregory, R. P., 1911. On Gametic Coupling and Repulsion in Primula sinensis. Proc. Roy. Soc., LXXXIV.

Gross, J., 1912. Heterochromosomen und Geschlechtsbestimmung bei Insekten. Zoöl. Jahrb., XXXII.

Gruenberg, B. C., 1912. Physiological Sex-determination. Science, N. S., XXXV.

Gudernatsch, J. F., 1911. Hermaphroditismus verus in Man. Am. Jour. Anat., XI.

Gudernatsch, J. F., 1912. Feeding Experiments on Tadpoles. I. Arch. Entw.-mech., XXXV.

Gudernatsch, J. F., 1912. Fütterungsversuche an Amphibienlarven. Zentrbl. f. Physiol., XXVI.

Gulick, A., 1911. Ueber die Geschlechtschromosomen bei einigen Nematoden. Arch.f. Zellf., VI.

Guyer, M. F., 1902. Hybridism and the Germ Cell. Univ. of Cincinnati Bull., No. 21.

Guyer, M. F., 1903. The Germ Cell and the Results of Mendel. Cincinnati Lancet-Clinic.

Guyer, M. F., 1905. Guinea-Chicken Hybrids. Science, N. S., XXI.

Guyer, M. F., 1905. Notes on Cross-bred Chickens. Science, N. S., XXI.

Guyer, M. F., 1907. Do Offspring Inherit Equally from Each Parent? Science, N. S., XXT.

Guyer, M. F., 1909. Atavism in Guinea-Chicken Hybrids. Jour. Exp. Zoöl., VII.

Guyer, M. F., 1909. La Livrée du Plumage chez les Hybrides de Pintade et de Poule. Bull. Mus. d'hist. nat. 
GuYer, M. IF, 1909. The Spermatogenesis of the Domestic ('hicken. Anat. Anz., XXXIV.

GuYkr, M. F., 1909. The Spermatogenesis of the Domestic Guinea. Anat. Anz., XXXIV.

Ciuren, M. F., 1909. Deficieneies of the Chromosome Theory of

Ileredity. University Stulies (Cincinnati), Series II, Vol. V.

Guver, M. F., 1909. On the Sex of Hybrid Birds. Biol. Bull., XTI.

Guyer, M. F., 1910. Accessory Chromosomes in Man. Biol. Bull., XIX.

Guyer, M. F., 1911. Nucleus and Cytoplasm in Heredity. Am. Nat., XLV.

Haduey, P. B., 1910. Sex-limited Inheritance. Science, XXXII. Hagedoorn, A. L., 1909. Mendelian Inheritance of Sex. Arch.f. Entw.-mech., XXVIII.

Hagedoors, A. L., 1912. The Genetic Factors in the Development of the House Mouse, etc. Zeits. Abst. Vererb., VI.

Hartley, C. P., E. B., Brown, C. H., Kyle, and L. L. Zook, 1912. Cross-breeding Corn. U.S. Dept. Agr. Bull., 218.

Hartman, F. A., 1913. Variations in the Size of Chromosomes. Biol. Bull., XXIV.

Hasper, M., 1911. Zur Entwicklung der Geschlechtsorgane von Chironomus. Zool. Jahrb., Abt. Anat., XXXI.

Heape, W., 1897. Further Note on the Transplantation and Growth of Mammalian Ova within a Uterine Foster-mother. Proc. Roy. Soc., LXII.

Heape, W., 1899. Note on the Fertility of Different Breeds of Sheep. Proc. Roy. Soc., LXV.

Heape, W., 1905. Ovulation and Degeneration of Ova in the Rabbit. Proc. Roy. Soc., B, IXXVI.

Heape, W., 1907. Notes on the Proportion of the Sexes in Dogs. Proc. Camb. Phil. Soc., XIV.

Heape, IV., 1907. Note on the Influence of Extraneous Forces upon the Proportion of the Sexes produced by Canaries. Proc. Camb. Phil. Soc., XIV.

Heape, II., 1908. Note on Russo's Attrempt to show Differentiation of Sex in the Ovarian Ova of the Rabbit. Proc. Camb. Phil. Soc., XIV. 
Heape, IV., 1908. The Proportions of the Sexes produced by Whites and Colored Peoples in Culat. Phil. Trans. Roy. Soc. Lond., Series B, Vol. 200.

Heider, K., 1906. Vererbung und Chromosomen. Jena.

Henking, H., 1891. Untersuehungen ueber die ersten Entwieklungsvorgänge in den Eiern der Insekten. Zeits.f. wiss. Zool., LI. Herbst, C., 1909. Vererbungstudien VI. Arch. Entw.-mech., XXVII.

Hertwig, O., 1S90. Vergleich der Ei und Samenbildung bei Nematoden. Arch. mikr. Anat, XXXVI.

Hertwig, R., 1906. Ueber Knospung und Geschlechtsentwickelung von Hydra fusea. Festschr. f. J. Rosenthal. Leipzig. Hertwig, R., 1907. Über den Chromidialapparat und den Dualismus der Kernsubstanzen. Sitz. ber. Gesell. Morph. und Phys, in München. 1907.

Hertwig, R., 1907. Untersuchungen über das Sexualitätsproblem. III. Teil. Verh. Deutsch. Zool. Gesell.

Hertwig, R., 1912. Über den derzeitigen Stand des Sexualitätsproblems nebst eigenen Untersuchungen. Biol. Centr., XXXII.

Holding, R. E., 1905. Exhibition of, and Remarks upon, a Series of the First Year Antlers of Certain Deer. Proc. Zoöl. Soc. Lond., II.

Holmes, S. J., 1903. Sex Recognition among Amphipods. Biol. Bull., V.

JANDA, V., 1912. Die Regeneration der Gesehlechtsorgane bei Criodrilus lacuum. Arch, Entw.-mech., XXXIV.

Jannsens, F. A., 1901. La spermatogénèse chez les tritons. La Cellule, XIX.

Jannsens, F. A., 1905. Evolution des Auxocytes mâles du Batracoseps attenuatus. La Cellule, XXII.

Jannsens, F. A., 1909. La théorie de la ehiasmatypie. Nouvelle interprétation des cinèses de maturation. La Cellule, XXV.

Jannsens, F. A., and R. Dumez, 1903. L'élément nucléinien pendant les cinèses de maturation des spermatocytes chez Batraeoseps attenuatus et Plethedon einereus. La Cellule, XX. 
Jexviscs, H. S., 1908. Heredity, Variation and Evolution in Protozoa, II. Proc. Am. Phil. Soc., XLVII.

Jevnusgs, H. S., 1909. Heredity and Variation in the Simplest Organisms. Amer. Nat., XliII.

Jexnisgs, H. S., 1910. Experimental Evidence of the Effectiveness of Selection. Amer. Nat., XLIV.

Jennixgs, H. S., 1911. Assortative Mating, Variability and Inheritance of Size in the Conjugation of Paramceium. Jour. E.xp. Zoöl., XI.

Jenvings, H. S., 1911. Pure Lines in the Study of Geneties in Lower Organisms. Amer. Nat., XLV.

Jennings, H. S., 1913. The Effeet of Conjugation in Paramecium. Jour. Exp. Zoöl., XIV.

Jennings, H. S., and G. T. Hargitt, 1910. Characteristics of the Diverse Races of Paramecium. Jour. Morph., XXI.

Jennings, H. S., and K. S. LAshley, 1913. Biparental Inheritance and the Question of Sexuality in Parameeium. Jour. Exp. Zoöl., XIV.

Johannsex, W., 1909. Elemente der exakten Erblichkeitslehre. Jena.

Jolinnnsen, W., 1911. The Genotype Conception of Heredity. Am. Nat., XLV.

Joves, WV. N., 1912. Species Hybrids of Digitalis. Jour. Genet., II.

Kahle, W., 190S. Die Pædogenesis der Cecidomyiden. Stuttgart. Keeble, F., and C. Pellew, 1910. The Mode of Inheritance of Stature and of Time of Flowering in Peas (Pisum sativum). Jour. Genet., I.

Kellogg, V. L., 1907. Some Silkworm Moth Reflexes. Biol. Bull., XII.

Kelloga, V. L., 1907. Artificial Parthenogenesis in the Silkworm. Biol. Bull., XIV.

Kellogg, V. L., 1911. An Experiment in Double Mating. Science, XXXIII.

King, H. D., 1907. Food as a Factor in the Determination of Sex in Amphibians. Biol. Bull., XIII.

King, H. D., 1909. Studies on Sex-Determination in Amphibians. II. Biol. Bull., XVI. 
Kinc, H. D., 1910. Temperature as a Factor in the Determination of Sex in Amphibians. Biol. Bull., XVIII.

King, H. D., 1910. Some Anomalies in the Genital Organs of Bufo lentiginosus and their Probable Significance. $1 \mathrm{~m}$. Jour. Anat., X.

Ǩng, H. D., 1911. Studies on Sex-Determination in Amphibians. IV. Biol. Bull., XX.

King, H. D., 1911. The Sex Ratio in Hybricl Rats. Biol. Bull., XXI.

King, H. D., 1912. Dimorphism in the Spermatozoa of Necturus maculosus. Anat. Rec., VI.

King, H. D., 1912. Studies on Sex-Determination in Amphibians. V. Jour. Exp. Zool., XII.

Kopec, S., 1911. Untersuchungen über Kastration und Transplantation bei Schmetterlingen. Arch. Entw.-mech., XXXIII. KrüGer, Eva, 1912. Die phylogenetische Entwicklung der Keimzellenbildung einer freilebenden Rhabditis. Zool. Anz., XL.

Kuschaкеwitsch, S., 1910. Die Entwickelungsgeschichte der Keimdrüsen von Rana esculenta. Festschr. f. R. Hertwig, Bd. II, 1910. Jena.

Kuschakewitsch, S., 1911. Ein Fall von Hermaphroditismus kateralis verus bei Rana esculenta. Anat. Anz., XXXVIII.

Kuschakewitsch. S., 1911. Erklärung zur Notiz von T. Н. Morgan: "Is the female frog heterozygous in regard to sexdetermination?" Anat, Anz., XXXIX.

Lang, A., 1912. Vererbungswissensehaftliche Miszellen. Zeits. Abst. Vererb., VIII.

von Lenhossék, 1903. Das Problem der geschlechtsbestimmenden Ursachen. Jena, 1903.

Little, C. C., 1912. Preliminary Note on the Occurrence of a Sexlimited Character in Cats. Science, XXXV.

Loeb, J., 190S. Hervorrufung der Membranbildung, etc. Arch. Gesell. Phys., CXXII.

Lовв, J., 1908. Entwieklungserregung unbefruchtete Annelideneier, ete. Arch. Gescll. Phys., CXXII.

Loes, J., 1909. Die Chemische Entwicklungserregung des tierischen Fies. Berlin. 
Loes, J., 1911. The Rôle of Salts in the Prescrvation of Life. Science, XXXIV.

LozB, J., 1912. Heredity in Heterogeneous Hybrids. Jour. Morph., XXIII.

Loeb, J., and F. W. BAxcroft, 1911. Some Experiments on the Production of Mutants in Drosophila. Science, XXXIII.

Loeb, J., and F. W. BAncroft, 1913. The Sex of a Parthenogenetic Tadpole and Frog. Jour. Exp. Zoöl., XIV.

Loeb, J., und H., Wasteneys, 1911. Die Beeinflüssung der Entwicklung, etc. Bioch. Zeits., XXXVII.

Loeb, J., und H. Wasteners, 1911. Weitere Bemerkungen über den Zusammenhang zwischen Oxydationsgrösse und Cytolyse der Seeigeleier. Bioch. Zeits., XXXI.

Lutz, A. MI., 1912. Triploid Mutants in Oenothera. Biol. Centr., XXXII.

Lutz, F. E., 1911. Experiments with Drosophila ampelophila concerning Evolution. Carnegie Inst. Wash., pub. 143.

Lutz, F. E., 1913. Experiments concerning the Sexual Difference in the Wing Length of Drosophila ampelophila. Jour. Exp. Zoöl., XIV.

McClendon, J. F., 1910. On the Effect of External Conditions on the Reproduction of Daphnia. Am. Nat., XLIV.

McCluxg, C. E., 1902. The Accessory Chromosome-Sex Determinant? Biol. Bull., III.

McClung, C. E., 1902. Notes on the Accessory Chromosome. Anat. Anz., XX.

McCluxg, C. E., 1905. The Chromosome Complex of Orthopteran Spermatocytes. Biol. Bull., IX.

МсCоok, H. C., 1893. American Spiders and their Spinning Work. 3 vols. Philadelphia.

MCCracken, I., 1909. Heredity of the Race-characters. Univoltinism, etc., in the Silkworm. Jour. Exp. Zoöl., VII.

Mark, E. L., and U. Copeland, 1907. Maturation Stages in the Spermatogenesis of Vespa maculata. Proc. Am. Acad. Arts and Sci., XLIII.

Marshall, F. H. A., 1908. The Effects of Environment and Nutrition upon Fertility. Sci. Progr., VII. 
Marshali, F. H. A., 1912. On the Effects of Castration and Ovariotomy on Sheep. Proc. Roy. Soc., LXXXY.

Marshall, F. H. A., and W. R. Pell, 1910. "Fatness" as a Cause of Sterility. Jour. Agri. Sci., III.

Mast, S. O., 1912. Behaviour of Fire-flies (Photinus pyralis?) with Special Reference to the Problem of Orientation. Jour. An. Behar., II.

Mayer, A. G., 1900. On the Mating Instinct in Moths. Ann. Mag. Nat. Hist., V.

Mayer, A. G., and C. G. Soule, 1906. Some Reactions of Caterpillars and Moths. Jour. Exp. Zoöl., III.

de MeiJere, J. C. H., 1910. Ueber Jacobsons Züchtungsversuche bezüglich des Polymorphismus von Papilio Memnon. Zeits. Abst. Vererb., III.

de MeiJere, J. C. H., 1910. Ueber getrennte Vererbung der Geschlechter. Biol. Centr., XXX.

de Meijere, J. C. H., 1911. Über getrennte Vererbung der Geschlechter. Arch. Rass. Gesell., VIII.

Meisenhemier, J., 1908. Über den Zusammenhang von Geschlechtsdrüsen und sekundären Geschlechtsmerkmalen bei den Arthropoden. Verh. d. deutsch. Zool. Gesell., 190 S.

Meisexheiner, J., 1909. Experimentelle Studien zur Soma- und Geschlechtsdifferenzierung, I. Jena, 1909.

Meisenheiner, J., 1912. Experimentelle Studien zur Soma und Geschlechtsdifferenzierung. Fests. zum 60 Geburtstage von Dr.J.W. Spengel. III.

Mendel, G., 1865. Versuche über Pflanzen-Hybriden. Terh. d. Naturf. Vereins in Brünn, IV.

Meves, Fr., 1903. Richtungskörperbildung in der Spermatogenese. Mittheil. f. d. Terein Schles.-Holst. Aerzte, XI.

Meves, F., 1907. Die Spermatocytenteilungen bei der Honigbiene, ete. Arch. mikr. Anat., LXX.

Meves, Fr., and J. Duesierg, 1908. Die Spermatocytenteilung bei der Hornisse. Arch, mikr. Anat., LXXI.

Meyns, R., 1912. Transplantation embryonaler und jugendlicher Keimdrüsen u. s. w. Arch. mikr. Anat., LXXIX.

Moenkhaus, W. J., 1910. Cross Fertilization among Fishes. Proc. Ind. Acad. Sci. 
Monnkhaus, Wr. J., 1911. Effects of Inbreeding, ete, in Drosophila ampelophila. Jour. Morph., XXII.

Mostgomery, T. H., 1903. Studies on the Habits of Spiders, Particularly those of the Mating Period. Proc. Acad. Nat. Sci. Phila.

Montgonelix, T. H., JR., 1905. The Spermatogenesis of Syrbula and Lycosa, with General Considerations upon Chromosome Reduction, cte. Proc. Acad. Nat. Sci. Phil., 1905.

Montgonery, T. H., Jr., 1906. Chromosomes in the Spermatogenesis of Hemiptera and Iteteroptera. Trans. Am. Phil. Soc., XXI.

MIontgomery, T. H., JR., 1906. The Terminology of Aberrant Chromosomes and their Behavior in ecrtain Hemiptera. Scicnce, IXIII.

Montgonery, T. H., Jr., 1906. On Reproduetion, Animal Life Cyeles, and the Biological Unit. Trans. Tex. Acad. Sci., IX.

Montgonery, T. H., JR., 1907. On Parthenogenesis in Spiders. Biol. Bull., XIII.

Montgonery, T. H., Jr., 1908. The Sex-ratio and Cocooning Habits of an Aranead and the Genesis of Sex-ratios. Jour. Exp. Zoöl., V.

Mostgonery, T. H., JR., 1910. The Cellular Basis of the Determination of Sex. International Clinics, Vol. I.

Montgomery, T. H., 1910. The Significance of the Courtship and Secondary sexual Characters of Araneads. Am. Nat., XXXIT. Montgomery, T. H., 1910. Further Studies on the Activities of Araneads. II. Proc. Acad. Nat. Sci. Phila., 1909.

Montgomery, T. H., 1912. Human Spermatogenesis. Jour. Acad. Nat. Sci. Phila., XV.

Morgan, T. H., 1903. Recent Theories in Regard to the Determination of Sex. Pop. Sci. Mon., 1903.

Morran, T. H., 1905. Ziegler's Theory of Sex-determination and an Alternative Point of View. Science, XXII.

Morgan, T. H., 1905. An Alternative Interpretation of the Origin of Gynandromorphous Inseets. Science, XXI.

Morgan, T. H., 1906. The Male and Female Eggs of Phylloxerans of the Hickories. Biol. Bull., X. 
Morgan, T. H., 1907. Experimental Zoölogy. New York.

Morgan, T. Il., 1907. The Cause of Gynandromorphism in Insects. Am. Nat., XLI.

Morgan, T. H., 1907. The Biological Significance and Control of Sex. Science, XXV.

Morgan, T. H., 190S. The Production of two kinds of Spermatozoa in Phylloxerans. Proc. Soc. Exp. Biol. and Med., V.

Morgan, T. II., 1909. Sex-Determination and Parthenogenesis in Phylloxerans and Aphids. Science, XXIX.

Morgan, T. H., 1909. Are the Drone Eggs of the Honey Bee Fertilized? Am. Nat., XiIII.

Morgan, T. H., 1909. Hybridology and Gynandromorphism. Am. Nat., XLIII.

Morgan, T. H., 1909. A Biological and Cytological Study of Sex-Determination in Phylloxerans and Aphids. Jour. Exp. Zoöl., VII.

Morgan, T. H., 1910. Sex-limited Inheritance in Drosophila. Science, XXXII.

Morgan, T. H., 1910. Hybridization in a Mutating Period in Drosophila. Proc. Soc. Exp. Biol. and Med., VII.

Morgan, T. H., 1910. The Chromosomes in the Parthenogenetic and Sexual Eggs of Phylloxerans and Aphids. Proc. Soc. Exp. Biol. and Med., VII.

Morgan, T. H., 1910. Chromosomes and Heredity. Am. Nat., XLIV.

Morgan, T. H., 1910. The Method of Inheritance of two Sexlimited Characters in the Same Animal. Proc. Soc. Exp. Biol. Med., VIII.

Morgan, T. H., 1911. An Attempt to analyze the Constitution of the Chromosomes on the Basis of Sex-limited Inheritance in Drosophila. Jour. Exp. Zoöl., XI.

Morgan, T. H., 1911. The Application of the Conception of Pure Lines to Sex-limited Inheritance and to Sexual Dimorphism. Am. Nat., XIV.

Morgan, T. H., 1911. A Dominant Sex-limited Character. Proc. Soc. Exp. Biol. Hed., IX.

Morgan, T. H., 1911. An Alteration of the Sex-ratio induced by Hybridization. Proc. Soc. Exp. Biol. and Med., VIII. 
Morgax, T. H., 1911. Is the Female Frog Heterozygous in regard to sex-determination? Am. Nat., XLV.

Morcix, T. H., 1911. Random Segregation vs. Coupling in Mendelian Inheritance. Science, XXXIV.

Morgax, T. H., 1911. Chromosomes and Associative Inheritance. Science, XXXIV.

Molegax. T. H., 1911. The Origin of Nine Wing-mutations in Drosophila. science, XXXIII.

Morgan, T. H., 1911. The Origin of Five Mutations in Eye-color in Drosophila. Science, XXXIII.

Morgan, T. H., 1912. The Elimination of the Sex-chromosomes from the Male-producing Eggs of Phylloxerans. Jour. Exp. Zö̈l., XII.

Morgan, T. H., 1912. Heredity of Body Color in Drosophila. Jour. Exp. Zoöl., XIII.

Morgan, T. H., 1912. A Modification of the Sex-ratio, and of other Ratios in Drosophila through Linkage. Zeits. Abst. Vererb., VII.

Mlorgan, T. H., 1912. Is the change in Sex-ratio of the Frog that is affected by External Agents, due to Partial Fertilization? Am. Nat., NLVI.

Morgax, T. H., 1912. The Explanation of a New Sex Ratio in Drosophila. Science, XXXVI.

Morgax, T. H., 1912. Complete Linkage in the Second Chromosome of the Male. Science, XXVI.

Morgan, T. H., 1912. Further Experiments with Mutations in Eye-color in Drosophila. Jour. Acad. Nat. Sci. Phil., XV.

Morgax, T. H., 1912. Eight Factors that show Sex-linked Inheritance in Drosophila. Science, XXXV.

Morgax, T. H., 1912. The Masking of a Mendelian Result by the Influenee of the Environment. Proc. Soc. Exp. Biol. Med., IX. Mongax, T. H., 1913. Factors and Unit Characters in Mendelian IIeredity. Am. Nat, XLVII.

Morgax, T. II., and E. Cattell, 1912. Data for the Study of Sexlinked Inheritance in Drosophila. Jour. Exp. Zoöl., XIII.

Morgax, T. H., and L. Cattell, 1913. Additional Data for the Study of Sex-linked Inheritanee in Drosophila. Jour. Exp. Zoöl., XIV. 
Morgan, T. H., and H. D. Goodale, 1912. Sex-linked Inheritance in Poultry. Ann. N. Y, Acad. Sci., XXIl.

Morgan, T. H., and C. J. Lynch, 1912. The Linkage of Two Factors in Drosophila that are not Sex-linked. Biol. Bull., XXIII.

Morgan, T. H., F. Payne, and E. N. Browne, 1910. A Method to test the Hypothesis of Selective Fertilization. Biol. Bull., XVIII.

Morrill, C. V., 1909. Preliminary note on the Chromosomes in the Oögenesis, Fertilization and Cleavage of certain Hemipteri. Science, XXX.

Morrill, C. V., 1910. The Chromosomes in the Oögenesis, Fertilization and Cleavage of Coreid Hemiptera. Biol. Bull., XIX. Morse, M., 1910, Sterility. Am. Nat., XLIV.

Mulsow, K., 1912. Der Chromosomeneyclus bei Aneyraeanthus cystidicola Rud. Arch.f. Zellf., IX. 1.

Nachtshein, H., 1912. Parthenogenese, Lireifung und Gesehleehtsbestimmung bei der Honigbiene. Sitzungsber. Gesell. Morph. u. Phys. München.

Newman, H. H., 1907. Spawning Behavior and Sexual Dimorphism in Fundulus heteroclitus and Allied Fish. Biol. Bull., XII.

Newman, H. H., 1908. A Signifieant Case of Hermaphroditism in Fish. Biol. Bull., XV.

Newman, H. H., and J. T. Patterson, 1909. A Case of Normal Identical Quadruplets in the Nine-banded Armadillo. Biol. Bull., XVII.

Newman, H. H., and J. T. Patterson, 1910. The Development of the Nine-banded Armadillo, etc. Jour. Morph., XXI.

Newman, H. H., and J. T. Patterson, 1911. The Limits of Heredity Control in Armadillo Quadruplets. Jour. Morph., XXII.

Nussbaum, M., 1909. Üher Geschleehtsbildung bei Polypen. Arch. Gesell. Physiol., CXXX.

Nuttall, G. H., and G. Merrian, 1911. The Process of Copulation in Ornithodorus moubata. Parasitology, IV.

Payne, F., 1912. A Further Study of the Chromosomes of the Reduviida, etc. Jour. Morph., XXXIII.

Payne, F., 1912. The Chromosomes of Gryllotalpa borealis. Arch. f. Zellf., IX. 
Pearl, M. and R., 1908. On the Relation of Race Crosing to the Sex Ratio. Biol. Bull., XV.

PEARL, R., 1911. Inheritance of Fecundity in the Domestic Fowl. Am. Tat., XLV.

Pearl, R., 1911. Breeding Poultry for Egg Production. Ann. Rep. Uc. Agr. Exp. St., 1911.

PEARL, R., 1912. The Mode of Inheritance of Fecundity in the Domestic Fowl. Jour. Exp. Zoöl., XIII.

Pearl, R., 1912. Notes on the History of Barred Breeds of Poultry. Biol. Bull., XXII.

Pearl, R., 1912. The Mendelian Inheritance of Fecundity in the Domestic Fowl. Am. Nat., XLVI.

Pearl, R., and M. R. Curtis, 1912. Studies on the Physiology of Reproduction in the Domestic Fowl. I. Jour. Exp. Zoöl., XIII.

Pearl, R., and H. MI. Parshlex, 1913. Data on Sex Determination in Cattle. Biol. Bull, XXIT.

Pearl, R., and F. M. Surface, 1910. On the Inheritance of the Barred Color Pattern in Poultry. Arch. Entw.-mech., XXX. Pearl, R., and F. M. Surface, 1910. Studies on Hybrid Poultry. Papers Biol. Lab. Me. Agr. Exp. Sta., 21.

Pearl, R., and F. M. Surface, 1910. Experiments in Breeding sweet Corn. Papers Biol. Lab. Me. Agr. Exp. Sta., 18.

Pearl, R., and F. M. Surface, 1910. Further Data Regarding the Sex-limited Inheritance of the Barred Color Pattern in Poultry. Science, XXYII.

Pearl, R., and F. M. Surface, 1911. A Biometrical Study of Egg Production in the Domestic Fowl. $U$. S. Dept. Agric., Bur. Anim. Ind., Bull. 110.

Petrse, A. S., 1909. Observations on Copulation among Crawfishes with Special Reference to Sex Recognition. Am. Nat., XLIII.

Peckнam, G. II. and F. G., 1889. Observations on Sexual Selection in Spiders of the family Attida. Nat. Hist. Soc. Wis. Occasional Papers, I.

Pескнам, G. W. and E. G., 1890. Additional Observations, with some Remarks on Mr. Wallace's Theory of Sexual Ornamentation. Nat. Hist. Soc. Wis. Occasional Papers, I. 
Pergande, T., 1904. North American Phylloxerine affecting Hicoria and other Trees. Proc. Dav. Acad. sci., 1X.

Petrunkewitsch, A., 1902. Das Schicksal der Richtungskörper im Drohnenei. Jena, 1902.

Petrunkewitsch, A., 1910. Courtship in Dysdera crocata. Biol. Bull., XIX.

Phillips, E. F., 1903. A Review of Parthenogenesis. Proc. Am. Phil. Soc., XLII.

Plate, L., 1910. Die Erbformeln der Aglia tau-Rassen im Anschluss an die Standfussehen Züehtungen. Arch. Rass. Gesell., VII.

Plate, L., 1913. Vererbungslehre. Leipzig.

Pocock, R. I., 1905. The Effects of Castration on the Horns of a Prong Buck. Proc. Zoöl. Soc. Lond., I.

Porter, J. P., 1906. The Iabits, Instincts, and Mental Powers of Spiders, Genera Argiope and Epeira. Am. Jour. Psych., XVII. Potts, F. A., 1910. Notes on Free-Living Nematodes. I. Q. J. M. S., LV.

Punnett, R. C., 1903. On Nutrition and Sex-determination in Man. Proc. Cambr. Phil. Soc., XII.

Punnett, R. C., 1906. Sex-determination in Hydatina, with some Remarks on Parthenogenesis. Proc. Roy. Soc., LXXVIII. Punnett, R. C., 1909. On the Alleged Influence of Lecithin upon the Determination of Sex in Rabbits. Proc. Camb. Phil. Soc., XV.

Punnett, R. C., 1910. "Mimicry" in Ceylon Butterflies, etc. Spol. Zeyl., VII.

Punnett, R. C., 1911. Mendelism.

Punnett, R. C., 1912. Inheritance of Coat Color in Rabbits. Jour. Genet., II.

Rawls, E., 1913. Sex-ratios in Drosophila ampelophila. Biol. Bull., XXIV.

Regen, J., 1909. Kastration und ihre Folgeerscheinungen bei Gryllus eampestris. I. Zool. Anz., XXXIV.

Regen, J., 1910. Kastration und ihre Folgeerscheinungen bei Gryllus eampestris. II. Zool. Anz., XXXY.

Riddes, O., 1909. Our Knowledge of Melanin Color Formation and its Bearing on the Mendelian Deseription of Heredity. Biol. Bull., XVI. 
Riddef, O., 1912. Prelininary Chemical Studies on Male and Female Producing Eggs of Pigeons. Science, XXXV.

Ripde, O., and A. A. Spohx, 1912. On a Relation found to exist between Changes in the Chemical Composition of a Membrane and Changes in its Permeability. Science, XIXV.

SAlxdels, E. R., 1911. Further Experiments on the Inheritance of "Doubleness" and Other Characters in Stocks. Jour. Genet., I. SAtrders, E. R., 1911. Studies in the Inheritance of Doubleness in Flowers. I. Petunia. Jour. Genet., I.

Schle1P, IV., 1911. Variation, Heredität, Bastardierung, Descendenzlehre. Jahrb. u. d. For. d. Anat. u. Entutschr. Gesch., XVI.

Schleip, W., 1912. Geschlechtsbestimmende Ursachen im Tierreich. Ergeb. und Fortschr. der Zool., III.

Schultze, O., 1902. Was lehren uns Beobachtung und Experiment über die Ursachen männlichen und weiblicher Geschlechtsbildung, etc.? Sitz.-ber. der Phys.-med. Gesell. Würzburg.

Schultze, O., 1903. Zur Frage ron den geschlechtsbildenden Ursachen. Arch. mikr. Anat., LXIII.

Seiler, J., 1913. Das Terhaltung der Geschlechtschromosomen bei Lepidopteren. Zool. Anz., XLI.

Seliguaxx, C. G., 1906. Proc. Zool. Soc. Lond., II., p. 903.

Shearer, C., 1911. The Problem of Sex-Determination in Dinophilus grrociliatus. Jour. Marine Biol. Ass., IX.

Shearer, C., 1912. The Problem of sex-Determination in Dinophilus grrociliatus. Q.J.M. S., LVII.

Shearer, C., and D. J. Lloyd, 1913. On Methods of Producing Artificial Parthenogenesis in Echinus esculentus, etc. Q. J. M. S., IVIII.

Shearer, C., W. de Morgan, and H. MI. Fuchs, 1911. Preliminary Notice on the Experimental Hybridization of Echinoids. Jour. Marine Biol. Ass., IX.

Shearer, C., IV. de Morgay, and H. M. Fuchs, 1912. On Paternal Characters in Echinoid Hybrids. Q.J. M.S., LVIII. Shull, A. F., 1910. Studies in the Life Cycle of Hydatina senta. Jour. Exp. Zoöl., VIII.

Shulı, A. F., 1910. The Artificial Production of the Partheno- 
genetic and Sexual Phases of the Life Cyele of Hydatina senta. Am. Nat., XLIV.

Shuld, A. F., 1911. Studies in the Life Cyele of Hydatina senta. II. Jour. Exp. Zoöl., X.

Shull, A. F., 1912. Studies in the Life Cycle of Hydatina senta. III. Jour. Exp. Zoöl., XII.

Shull, A. F., 1912. The Influence of Inbreeding on Vigor in IIydatina senta. Biol. Bull., XXIV.

Shull, G. H., 1908. The Composition of a Field of Maize. Am. Breeders' Assoc., IV.

Shull, G. H., 1909. The "Presence and Absence" Hypothesis. Am. Nat., XLIII.

Shuld, G. H., 1909. A Pure Line Method in Corn Breeding. Am. Breed. Ass., V.

Shull, G. H., 1910. Hybridization Methods in Corn Breeding. Am. Breeders' Mag., I.

Shull, G. H., 1910. Inheritance of Sex in Lychnis. Bot. Gaz., XLIX.

Shull, G. H., 1911. Reversible Sex-mutants in Lychnis dioica. Bot. Gaz., LII.

Shuld, G. H., 1912. "Genotypes," "Biotypes," "Pure Lines," and "Clones." Science, XXXY.

Shuld, G. H., 1912. Hermaphrodite Females in Lychnis dioica. Science, XXXVI.

Surth, G., 1910. Studies in the Experimental Analysis of Sex. Parts 1 and 2. Q. J. M. S., LIV.

Siıtн, G., 1910. Studies in the Experimental Analysis of Sex. Parts 3 and 4. Q.J.M. S., LV.

Surth, G., 1911. Studies in the Experimental Analysis of Sex. Part 5. Q.J.M.S., LVI.

Suith, G., 1911. Studies in the Experimental Analysis of Sex. Part 6. Q.J. M. S., LVII.

Surth, G., 1911. Studies in the Experimental Analysis of Sex. Part 7. Q.J.M.S., LVII.

Spemans, H., 1895. Zur Entwicklung des Strongylus paradoxus. Zool. Jahrb. Anat. Abt., VIII.

Spillanan, W. J., 1908. Spurious Allelomorphism. Results of Recent Investigations. Am. Nat., XLII. 
Splluman, W. J., 1909. Barring in Barred Plymouth Rocks. Poultivy, $\mathrm{V}$.

Standfuss, M1., 1896. Handbuch der paläarktischen Grosschmetterlinge. Jena.

Standerss, M., 1910. Chacrocampa elpenor und einige Mitteilungen über Aglia tau. Iris, XXIV.

Staples-Browne, R., 1912. Second Report on the Inheritance of Colour in Pigeons, with special Reference to Sex-limiter Inheritance. Jour. Genet., II.

Steñach, E., 1912. Williürliche Umwandlung von Säugetiermänmehen, ete. Arch. Cresell. Physiol., CXLIV.

Sterens, N. M., 1905. Studies in Spermatogenesis with Especial Reference to the "Aceessory Chromosome." Carnegie Inst. Wash., pub. 36.

Sterexs, N. M., 1906. Stuchies in Spermatogenesis. II. Carnegie Inst. Wash., pub. 36.

Stevens, N. M., 1907. Color Inheritance and Sex Inheritance in Certain Aphicts. Science, XXVI.

S'teress, N. M., 1908. The Chromosomes in Diabrotica, etc. Jour. Exp. Zoöl., V.

Stevens, N. M., 190S. A Study of the Germ-cells of Certain Diptera. Jour. Exp. Zoöl., V.

Sterens, N. M., 1909. Further Studies on the Chromosomes of the Coleoptera. Jour. Exp. Zoöl., VI.

Stevens, N. M., 1909. An Unpaired Chromosome in the Aphids. Jour. Exp. Zoöl., VT.

Stevexs, N. M., 1910. A Note on Reduction in the Maturation of Male Eggs in Aphis. Biol. Bull., XVIII.

Stevers, N. M., 1910. The Chromosomes in the Germ-cells of Culex. Jour. Exp. Zoöl., VIII.

Stevess, N. M., 1910. An Unequal Pair of Heterochromosomes in Forficula. Jour. Exp. Zoöl., VIII.

Stevens, N. M., 1911. Further Studies on Heterochromosomes in Mosquitoes. Biol. Bull., XX.

Stevens, N. M., 1911. Preliminary Note on Heterochromosomes in the (ininea Pig. Biol. Bull., XX.

Stevens, N. M., 1911. Heterochromosomes in the Guinea Pig. Biol. Bull., XXI. 
Stockard, C. R., 1908. Habits, Reactions and Mating Instincts of the "Walking Stick," Aplopus maycri. Papers Tortugas Lab., II.

Strasburger, E., 1910. Ueber geschlechthestimmende Ursachen. Jahrb. wiss. Bot., XLVIII.

Strong, R. M., 1912. Another View of Sex-limited Inheritance. Science, XXXVI.

Strong, R. M., 1912. Results of Hybridizing Ring-Doves, Including Sex-Linked Inheritance. Biol. Bull., XXIII.

Sturtevant, A. H., 1911. Another Sex-limited Character in Fowls. Science, XXXIII.

Sturtevant, A. H., 1912. An Experiment Dealing with Sexlinkage in Fowls. Jour. Exp. Zoöl., XII.

Sturtevant, A. H., 1912. Is there Association between the Yellow and Agouti Factors in Mice? Am. Nat., XINI.

Sturtevant, A. H., 1912. Federley's Breeding Experiments with the Moth Pygara. Am. Nat., XLVI.

Sturtevant, A. H., 1913. The Linear Arrangement of Six Sexlinked Factors in Drosophila, as shown by their Mode of Association. Jour. Exp. Zoöl., XIV.

Surface, F. M., 1912. The Diagnosis of Infectious Abortion in Cattle. Ann. Rep. Kent. Agr. Exp. Sta.

Sutron, IV. S., 1902. On the Morphology of the Chromosome Group in Brachystola magna. Biol. Bull., IV.

Sutton, IV. S., 1903. The Chromosomes in Heredity. Biol. Bull., IV.

Tannreurher, W. S., 1907. History of the Germ-cells and Early Embryology of Certain Aphids. Zool. Jahb. Anat. Abt., XXIV. Tennent, D. H., 1911. A Heterochromosome of Male Origin in Echinoids. Biol. Bull., XXI.

Tennent, D. H., 1912. Studies in Cytology, I and II. Jour. Exp. Zoöl., XII.

Thonsen, E., 1911. Die Differenzierung des Geschlechts und das Verhältnis der Geschlechter beim Hühmchen. Arch. Entw.mech. der Org., XXXI.

Tower, IV. L., 1906. An Investigation of Evolution in Chrysomelid Beetles of the Genus Leptinotarsa. Carnegie Inst. Wash., pub. $4 \mathrm{~S}$. 
Torası, K., 1907. Studies on Hybridology of Inseets. I. Bull. Col. Agr. Tokiyo Imp. U'mi., VII.

Torans, K., 1912. On Certain Characteristics of the Silkworm apparently Non-mendelian. Biol. Cent., XXXII.

'TıетлакоFғ, D., 1905. Die Spermatogenese bei Ascaris megalocephala. Arch. mikr. Anat., LXV.

Trow, A. II., 1913. On the Inheritance of Certain Characters in the Common Groundsel - Senecio vulgaris - and its Segregates. Jour. Genet., II.

Trow, A. H., 1913. Forms of Reduplication-Primary and Secondary. Jour. Genet., II.

v. Tschermak, A., 1912. Ueber Veränderung der Form, Farbe und Zeichnung von Kanarieneiern durch Bastardierung. Arch. f. Gesell. Phys., CXLVIII.

v. Tschermak, E., 1908. Der moderne Stand des Vererbungsproblems. Arch. Rass. und Gesell., V.

de Vilmorin, P., and IV. Bateson, 1911. A Case of Gametic Coupling in Pisum. Proc. Roy. Soc., B, LXXXIV.

DE VRIEs, H., 1901. Die Mutationstheorie. Leipzig.

DE VRIEs, H., 1908. Über die Zwillingsbastarde von Enothera nanella. Ber. deutsch. Bot. Gesell., XXVI a.

DE Vries, H., 1908. Bastarde von Enothera gigas. Ber. deutsch. Bot. Gesell., XXVI $a$.

de Tries, Hugo, 1909. On Triple Hybrids. Bot. Gaz., XLIX.

DE VRIes, H., 1911. Über doppeltreziproke Bastarde von Enothera biennis und O. murieata. Biol. Centr., XXXI.

WALKER, C. E., 1908. The Influence of the Testis upon the Secondary Sexual Characters of Fowls. Proc. Roy. Soc. Med., 1908.

Wexke, K., 1906. Anatomie eines Argynnis paphia-Zwitters. Zeits. f. wiss. Zool., LXXXIV.

Wheeler, W. M., 1903. The Origin of Female and Worker Ants from the Eggs of Parthenogenetic Workers. Science, XVIII.

Wheeler, W. MI., 1910. The Effects of Parasitic and other Kinds of Castration in Insects. Jour. Exp. Zool., VIII.

Wheeler, W. M., 1910. A Gynandromorphous Mutillid. Psyche, XVII. 
Whitney, D. D., 1912. Reinvigoration produed by Cross Fortilization in Hydatina senta. Jour. Exp. Zoöl., XII.

Wilder, H. H., 1904. Duplieate Twins and Double Momsters. Am. Jour. Anat., III.

Willians, L. W., 1907. The Signifieance of the Grasping Antenne of the Harpactecoid Copepods. Science, XXV.

Wilson, E. B., 1899. The Cell in Development and Inheritance. New York.

Wilson, E. B., 1905. Studies on Chromosomes, I and II. Jour. Exp. Zoöl., II.

Wilson, E. B., 1906. Studies on Chromosomes, III. Jour. Exp. Zoöl., III.

Wruson, E. B., 1909. Studies on Chromosomes, IV and V. Jour. Exp. Zoöl., VI.

Wilson, E. B., 1909. Recent Researehes on the Determination and Inheritance of Sex. Science, XXIX.

Wilson, E. B., 1909. Secondary Chromosome Couplings and the Sexual Relations in Abraxas. Science, XXIX.

Wilson, E. B., 1910. Note on the Chromosomes of Nezara. Science, XXXI.

Wilson, E. B., 1910. The Chromosomes in Relation to the Determination of Sex. Sci. Progr., XVI.

Wilson, E. B., 1910. Studies on Chromosomes, VI. Jour. Exp. Zoöl., IX.

Wilson, E. B., 1911. Studies on Chromosomes, VII. Jour. Morph., XXII.

Wilson, E. B., 1911. The Sex Chromosomes. Arch. Mikr. Anat., LXXVII.

Wilson, E. B., 1912. Studies on Chromosomes, VIII. Jour. Exp. Zoöl., XIII.

Wilson, E. B., 1912. Some Aspects of Cytology in Relation to the Study of Geneties. Am. Nat., XLVI.

Woltereck, R., 1911. Über Veränderung der Sexualität bei Daphniden. Leipzig, 1911.

Wood, J. G., 1874. Insects Abroad. New York.

Woodrufr, L. L., 1905. An Experimental Study of the Life-History of Hypotrichous Infusoria. Jour. Exp. Zoöl., II. 
Woodrurf, L. L., 190s. The Life Cycle of Parameciun Proc. soc. Exp. Biol. and Med., 1908.

IVoodiufr, L. L., 1908. The Life Cyele of Paramecium when subjected to a Varied Enviromment. Amer. Nat., XLII.

IToodruff, L. L., 190S. Effects of Alcohol on the Life Cycle of Infusoria. Biol. Bull., XV.

Woodruff, L. L., 1912. A Summary of the Results of Certain Phyrsiological Studies on a Pedigreed Race of Paramecium. Bioch. Bull., I.

Woodruff, L. I., 1912. Observations on the Origin and Sequence of the Protozoan Fauna of Hay Infusions. Jour. Exp. Zoöl., XII.

Woodruff, J. L., and G. A. Baitsell, 1911. Rhythms in the Reproductive Activity of Infusoria. Jour. Exp. Zoöl., II.

Zacharias, O., 1912. Zur Cytologie des Eies von Asearis megalocephala. Anat. Anz., XLII.

Ziegler, H. E., 1911. Die Chromosomen als Vererbungsträger. Jahresb. d. Vereins. vaterl. Naturk. Würzburg, LXVII.

\section{ADDENDA}

Agar, W. E., 1913. Transmission of Environmental Effects trom Parent to Offspring in Simocephalus vetulus. Proc. Trans. Roy. Soc., London. Series B, 203.

Agar, IV. E., 1914. Parthenogenetic and Sexual Reproduction in Simocephalus vetulus and Other Cladocera. Jour. Gen., III.

BAltzer, F., 1914. Die Bestimmung des Geschlechts nebst eine Analyse des Geschlechtsdinorphismus bei Bonellia. Mittheil. Zoöl. Stat. Neapel, XXII.

Brrdges, C. B., 1913. Non-disjunction of the Sex Chromosomes of Drosophila. Jour. Exp. Zoöl., XV.

Bos, Ritzema, 1891. Zur Frage der Vererbung von Traumatisinen. Biol. Centralbl., II.

DFlage, Yves, 1909. Le sexe chez les oursins issus de parthénogenèse expérimentale. C. R., Puris, 148, 1909.

Erdiand, Rif., And Woodruff, L. L., 1914. Vollständige period- 
ische Emeurung des Kernapparates ohne Zollverschmelzung bei reinlinigen Paramzeiên. Biol. Centrulbl., XXX11.

Foot and Strobeli, 1914. The Chromosomes of Euchistus variolarius, Euchistus servus, and the Iyylorids of the $F_{1}$ and the $F_{2}$ Generations. Archiv f. Zellf., XII.

Grosvenor, G. H., And Geoffrey Sumt, 1913. The life Cycle of Moina rectirostris. Q.J.M.S., LVIII.

Hyde, R. R., 1914. Fertility and Sterility in Drosophila atmpelophila. Jour. Exp. Zoöl., XVII.

Issakowitsch, A., 1908. Es besteht eine zyklische Fortpflanzung bei den Clacloceren, aber nicht im sinne Weismanns. Biol. Centralbl., XXVIII.

Marchal, E. and E., 1907. Aposporie et sexualité chez les mousses. Bull. Ac. R. Belgique, Classe sciences, 1907.

Meтz, C. W., 1914. Chromosone studies in the Diptera. Jour. Exp. Zoöl., XVII.

Mitchell, C. W., 1913. Sex-cletermination in Asplanchna amphora. Jour. Exp. Koöl., XV.

Morgan, T. H., 1914. Two Sex-linked Lethal Faetors in Drosophita and their Influence on the Sex-ratio. Jour. Exp. Zoöl., XVII.

Morgan, T. H., 1914. Mosaics and Gynandromorphs in Dro sophila. Proc. Srre. Exp. Biol. and Med., 1914.

Oudemans, J. Th., 1S99. Falter aus kastrierten Raupen. Zoöl. Jahrb. Abt. Syst., XII.

Papanicolad, G., 1910. Experimentelle L'ntersuchungen über die Fortpflanzungsverhältnisse der Daphniden. Biol. Zentralbl., XXX.

Ротть, F. A., 1906. The Modification of the Sexual Characters of the Hermit Crab caused by the Parasite Peltogaster. Q.J. II. S., L.

RöriG, A., 1899. Welehe Beziehungen bestehen zwischen den Reproduktionsorganen der Cerviden und der Geweihbildung derselben? Arch.f. Entw.-mech., VIII.

Russo, A., 1909. Studien über die Bestimmung des weiblichen Greschlechtes, Jena, 1909.

Schenk, L., 1900. Lehrbuch der Gesehlechtshestimmung. Halle, 1900. 
Schlenp, W., 1911. Z̈ber lie Chromatinverhältnisse bei Angiostomum nigrovenosum. Ber. d. naturf. Ges. Freiburg, XIX.

Weismann, A., 1892. Das Kémplasma. Jena, 1892.

Whitsey, D. D., 1914. The Production of Males and Females Controlled by Food Conditions in Hydatina senta. Science, XXXIX, June 5, 1914.

Winiwarter, H. von, 1912. Études sur la Spermatogenese humaine. Arch. de Biol, XXVII.

Wood, T. B., 1906. Note on the Inheritanee of Horns and Face Colour in Sheep. Jour. Agricultural Seience, 1906.

Woodruff, I. I.. 1914. so-called Conjugating and Non-Conjugating Races of Paramæeium. Jour. Exp. Zoöl., XVI.

Woodruff, L. L., and Erduann, Rh., 1914. Complete Periodic

Nuelear Reorganization without Cell Fusion in a Pedigreed Race of Paramæcium. Proc. Soe. Exp. Biol. and Med., XI. Woodruff, L. L., and Erdmann, Rh., 1914. A Normal Periodic Nuclear Reorganization without C'ell Fusion in Paramæcium. Jour. Exp. Zoöl., XVII. 


\section{INDEX}

Abraxas, 128

Achates, 151

Achia, 106

Addison's disease, 147

Adkins, 217-21s

Adrenal, 147

Agenor, 151

Allen, 113

Amphibia, 145

Amphipoda, 117

Andrews, 117

Angiostomum, 170

Antlers, 1 10, 133

Ants, 117

Argentine, 227

Argonauta, 26

Aristotle, 35

Armadillo, 238

Ascaris, 20, 21, 49

Ascidian, 217

Baltzer, 55, 5s, 61

Bancroft, 194

Barnacle, 155

Bateson, 72, 75, 99, 100, 125

Baur, E., 99

Beans, 123

Bee, $174,175,176,220$

Bees, 32

Beetles, 106

Bell, 232

Belt, 102

Bird of paradise, king, 109 six-shafted, 109

superb, 109

Black, 96-97

Blakeslee, 171

Bobolink, 27

Boring, 51

Boveri, 51, 55, 58, 162, 165, 170, 171

Bresca, 145

Bridges, 223, 224
Bruce, 212

Bryonia, 171-172

Bütschli, 8

Calkins, 8, 198, 206, 209, 210

Callosamia, 116

Capons, 142, 143

Cardamine, 215-216

Castle, 195

Ceylon, 125, 127

Checker diagram, 78

Chenotaxis, 117

Chidester, 117

Cicada, 106

Ciona, 217-218

Clipped wings, 119

Colias, 129-130, 150

Collins, 202

Color-blind, 241

Color blindness, 242

Conger eel, 2

Corpus luteum, 147

Correns, 74, 79, 99, 171, 172, 215, 216

Crab, 155

Cretinism, 146

Cricket, 150

Criodrilus, 168

Cuénot, 232, 233

Cunningham, 121

Daphnians, 182-185, 189

Darwin, C., 73-74, 101, 103, 104, 107, $112-114,120,125,142,194,197$, $200-202$

Davenport, C., 72, 143, 239

Deer, $110,133,134$

Delage, 193

Dinophilus, 234

Diplogaster, 225

Doncaster, 176

Dorsets, 134, 135, 136, 137, 138

Drelincourt, 232

Drone, 175 
Drosophila, 63-68, 96, 117, 130

Düsing, 233

East, 99, 202, 204, 211

Edw:urds, 51

Egret, 111

Eland, 136

Elaphomyia, 106

Elephant, 110

Emerson, 99

Eosin eye, 130, 154, 155

Eupaguras, 158

Eusehistus, 151

Fabre, 220, 221

Fielde, 117

Firefly, 28, 30, 31

Fishes, 32

Florisiga, 102

Foot, 151

Forel, 117

Frog, 145, 147, 228

Frolowa, 51

Fruit fly, 117, 195, 196, 221

Fundulus, 32

Gall, 179

Galton, 236

Game, 144, 212

Geddes, 232

Gentry, 232

Germ-cells, 23

Gerould, 130, 150, 151

Giard. 155

Gigautism, 146

Goldsehmidt, 124

Goodale, 72, 142

Gosse, 103

Growtlı, 3

Gudernatseh, 147

Guinea hen, 225

Gulick, 51

Guyer, 2.25-226, 245

Gynandromorphism, 161

Gypsy moths, 117

Habrocestum, 107

Hæmophilia, $239,240,242$

Hectoeotvlized arm, 26

Henking, 50

Herbst, 55, 61, 62

Herdwicks, 134-135
Hermaphroditism, 161

Hertwig, R., 9, 228, 234

Holmes, 117

Hormones, 146

Horns, 133-138

Hudson, 114, 115

Humming-birds, 103, 108

Hydatina, 2, 185

Hyde, 196, 199, 215

Ichthyosis, 242

Identieal twins, 236-239

Inaehus, 155

Ipomoea, 197

Italian, 227

Jacobson, 151

Janda, 168

Janssens, 94

Jehring, 238

Jennings, 9, 12, 206-208

Johannsen, 122-125

Jordan, H. E., 245

Keeble, 212

Kellogg, 117, 232

King, 229, 234

Kopec, 149

Kruger, 225

Kuschakewitsch, 228

Lamarekian school, 17

Landois, 232

Langshan, 69-71

Laomedon, 151

Lethal factor, 2:1-2:3

Linkage, 93

Lion, 27

Lister, 34

Loeb, J., 62, 190, 191, 192, 193

Lutz, $11 \mathrm{~S}$

Lyehnis, 172-173 •

Lygæus, 44

Lymantria, 148

McClung, 50

Mævia, 108

Mallard, 2S, 142

Malseu, von, 234, 235, 236

Mammals, 159

Mammary glands, 140

Man, 34, 229, 236-249 
Marchals, 171

Mast, 30

Maupas, 5, 8, 187, 198, 234

Mayer, 116

de Meijere, 151

Meisenheimer, 145, 148-149

Mendel, 84, 73-75, 80, 84

Menge, 34

Merino, 134, 135

Miastor, 21, 174

Mice, 233

Mimicry, 127-130

Miniature wings, 66-67

Mirabilis, 79-80

Moenkhaus, 196

Montgomery, 34, 50, 115, 117, 245

Mosquito, 51

Mosses, 171

Mulsow, 51

Myopia, 242

Nematode, 224-226

Nereis, 36

Neuroterus, 176-177

Newmann, 238

Night blindness, 242

Non-disjunction, 223-224

Nussbaum, 16, 145

Ocneria, 148

Octopus, 25

Oncopeltus, 46,84

Optic nerve atrophy, 244

Oudemans, 148

Ovariotomy, 135

Owl, 111

Papanicolau, 183-185

Papilio, 125-129, 151

Paramcecium, 5, 6, 12, 206-211

Parathyroid, 146

Parthenogenesis, 161

Patterson, 239

Paulmier, 50

Pea, edible, 75-78, 85-88

Pearl, R., 72, 212-213, 227

Pearse, 117

Peckham, 115-116, 120

Pellew, 212

Peltogaster, 158

Petrunkewitsch, 117

Phalarope, 112
Pheasants, 225

Phidippus, 34

Photinus, 2s

Phylloxerans, 52, 54, 178, 179, 180 , 181,189

Pigeons, 32

Pituitary body, 146

Plutei, 60

Plymoutl rock, 69-71, 212

Polar bodies, 37

Polytmus, 103

Porter, 117

Porthetria, 117, 148

Primula, 201, 202

Promethea, 116

Protenor, 40

Punnett, 127, 128, 138, 233

Rawls, 221

Rat, 140, 233

Reduplication, 100

Reindeer, 136

Rhabditis, $169,224,226$

Riley, 232

Ritzema-Bos, 195

Rotifers, 185-189

Rudimentary wing, 214, 215

Russo, 234

Sacculina, 155

Sagitta, 21, 22

Schenk, 233

Schleip, 170, 171

Schultze, 233

Sclerosis, 242

Seabright, 143-144

Sea cow, 27

Sea-lion, Steller's, 110

Sea-urchin, 56-62

Segregation, 81,100

Sex, 83,84

Sex chromosome, 50, 80, 83, 84

Sex determination, 81

Sex-linited, 83

Sex-linked, $81,83,84,132$

Sheep, 134-138

Shull, A. F., 187, 197, 205

Shull, G. H., 173, 202, 204, 211

Shuster, 145

Siamese twins, 236

Silkworm, 117, 165

Sinéty, 50 
Skcleton, rat, 140

Sinith, (i., 145, 155

Anoule, 110

Sparrow, 22

spermatophores, 25

Spherechinus, 59-60

Spiders, $34,107,115,117$

Squuid, 24

Stag, 133

Steinach, 140

stephanosphæra, 5

Sitrens, 51

Strobell, 151

Sitrongyloeentrotus, 59, 60, 62

Sturtevant, $72,98,117,11 \mathrm{~s}$

Stylonichia, 2

Suffolks, 136-138

synapsis, 93

Tadpoles, 147

Tanager, srarlet, 27

Thomson, 232

Thymus, 146-147

Thyroid, 146-147

Toad, 229

Tower, 117

Toyama, 165

Treat, 232
Triton, 145

Trow, 99

T'sehermak, 74

Vermilion eye, 119

Vestigial wing, 96-97 $\checkmark$

Vigor, 120

Vincent, 146

de Vries, 74,125

Wallace, $102,113-114,120,125,127$

IV asp, 220

Weismann, 16, 17, 40, 194, 195

Wheeler, 117

White eye, 62-65, $81,82,88-92,118$, $119,221-223$

Whitney, 1\$5, 187, 197, 205

Wilder, 237

Wilson, 51

Winiwarter, 245-248

Wood, 136

Woodruff, 8, 198

X-chromosome, 51, 82, 84, 242

Y-chromosome, 51, 84

Yellow body color, 67, 88-92, 119 


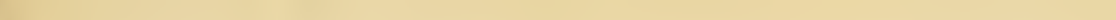







\title{
RINDING LIET JUL 1 1S29
}

QH llorgan, Thomas Hunt

431 Heredity and sex

$\because 757$

$191 / 4$

BioMed

\author{
PLEASE DO NOT REMOVE \\ CARDS OR SLIPS FROM THIS POCKET
}

UNIVERSITY OF TORONTO LIBRARY 


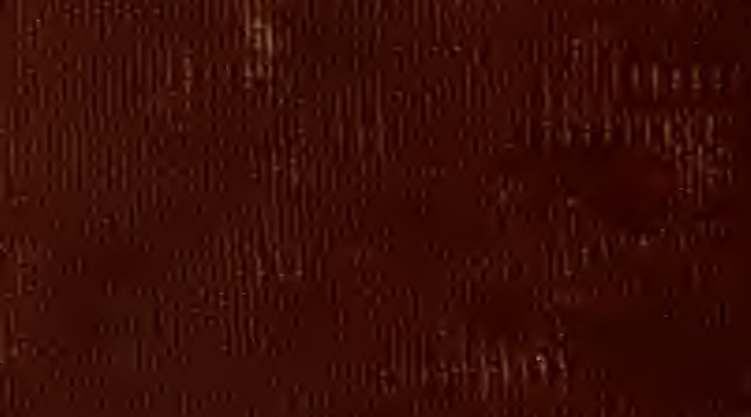

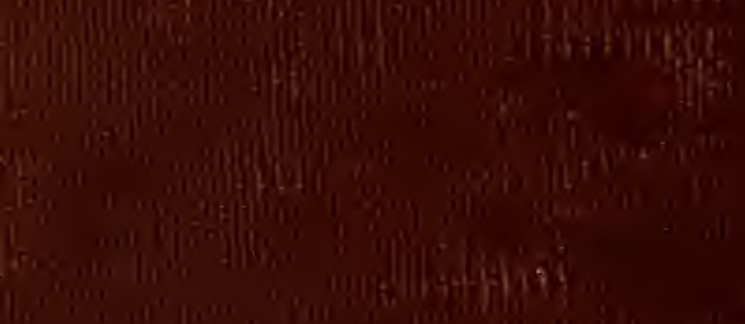

